\title{
TO EVINCE ATMOSPHERES
}

\author{
Pritish J. Pathak
}




\title{
TO EVINCE ATMOSPHERES
}

\author{
by Pritish J. Pathak
}

Bachelor of Architectural Science, Ryerson University,

2015

\author{
A thesis \\ presented to Ryerson University \\ in partial fulfillment of the \\ requirements for the degree of \\ Master of Architecture \\ in the Program of \\ Architecture
}

Toronto, Ontario, Canada, 2017

(c) Pritish J. Pathak, 2017 



\section{AUTHOR'S DECLARATION}

I hereby declare that I am the sole author of this thesis. This is a true copy of the thesis, including any required final revisions, as accepted by my examiners.

I authorize Ryerson University to lend this thesis to other institutions or individuals for the purpose of scholarly research.

I further authorize Ryerson University to reproduce this thesis by photocopying or by other means, in total or in part, at the request of other institutions or individuals for the purpose of scholarly research.

I understand that my thesis may be made electronically available to the public. 



\section{TO EVINCE ATMOSPHERES}

Pritish J. Pathak

Master of Architecture 2017

Architecture Program, Ryerson University

\section{ABSTRACT}

Though architecture is rooted in the physicality of built form. it transcends into the realms of the intangible, ephemeral and perceptive. In architecture, these immaterial characteristics imbued within a place are more accurately described as its 'atmosphere.' Despite the wealth of literature regarding the relevance of atmosphere as an architectural concept, in practice it has been deliberately reduced to a condition of constant neutrality. Atmosphere has here been defined as the character of place, encompassing a set of variables, distinguishing it from that of any other location. The atmosphere of a place emerges as the totality of these variables. This definition further suggests the presence of an atmosphere preceding the existence of builtform. Therefore, this thesis proposes that the spatial atmosphere of architecture should be defined by its engagement with these contextual variables, rather than through the fabrication of an artificial atmosphere, by redefining the boundary as a gradient threshold. 


\section{ACKNOWLEDGMENTS}

Kendra Schank Smith.

your contagious positivity has been an invaluable source of motivation.

Thank you for your unwavering support and encouragement. Our

frequent conversations have truly been the highlight of this endeavour.

John Cirka,

whose critical questions and in-depth knowledge of the subject matter undoubtedly helped refine this thesis.

Vera Straka,

whose insightful remarks helped guide this thesis forward.

My M.Arch cohort,

this experience has been punishing at times and I could not have asked for a better group to be punished with. 
to my parents, Jayant and Savita 

iii//

AUTHOR'S

DECLARATION

$\mathrm{vi} / /$

ACKNOWLEDGMENTS

xviii//

PREFACE

$41 / /$

2.0

ATMOSPHERE

EXPANDED

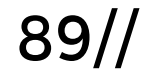

4.0

SIX MILE LAKE

RETREAT

$163 / /$

APPENDIX $\mathrm{v} / /$

ABSTRACT

$x / /$

LIST OF FIGURES

$1 / /$

1.0

ATMOSPHERE

TODAY

$81 / /$

3.0

ON BOUNDARIES

$159 / /$

5.0

SPECULATION

$223 / /$

BIBLIOGRAPHY 


\section{LIST OF FIGURES}

Figure 1: Toronto Dominion Centre under construction

Source: Spremo, Boris. Toronto Dominion Centre under construction. 1966. Baldwin Collection, Toronto Reference Library, Toronto Star Photo Archive.

Figure 2: Dubai Creek Tower

Source: Dubai Creek Tower. Digital Image. Dubai Real Estate Centre. Accessed March 12, 2017. http://www.dubairealestatecentre.com/listings/creektower/creek-tower.php

Figure 3: Mumbai Shreepati Arcade

Source: Mumbai Shreepati Arcade. Digital Image. Wikipedia. May 18, 2006. https://en.wikipedia.org/wiki/Shreepati_Arcade\#/media/File:Bombay 12. jpg

Figure 4: Shanghai Maxdo Centre

Source: Shanghai Maxdo Centre. Digital Image. Wikipedia. July 19, 2009. https:// en.wikipedia.org/wiki/Maxdo_Centre\#/media/File:Maxdo_building_ shanghai.jpg

Figure 5: Walt Disney Concert Hall

Source: Gehry Partners, LLP. Walt Disney Concert Hall, Frank Gehry. Digital Image. Archdaily. Accessed January 4. 2017. http://www. archdaily.com/441358/ad-classics-walt-disney-concert-hall-frankgehry/5264acf3e8e44ef4c200021 b-ad-classics-walt-disney-concert-hallfrank-gehry-photo

Figure 6: Museo Guggenheim

Source: Museo Guggenheim. Digital Image. Worldpass Magazine. Accessed January 4, 2017. http://magazine.world-pass.com/en/bilbaosguggenheim-museum-in-spain/ 
Figure 7: Frontispiece of Marc-Antoine Laugier: Essai sur l'architecture

Source: Eisen. Charles. Frontispiece of Marc-Antoine Laugier: Essai sur l'architecture. December 31, 1754. Wikipedia Commons. https://en.wikipedia.org/wiki/The_ Primitive_Hut\#/media/File:Essai_sur_1\%27Architecture___Frontispiece.jpg

Figure 8: Cité de Refuge de Le Corbusier

Source: Cité de Refuge de Le Corbusier. Digital Image. François Chantillon Architecte. Accessed December 26, 2016. http://architecte-chatillon.com/projets/cite-de-refuge/

Figure 9; Dome over Manhattan, Buckminster Fuller

Source: Dome over Manhattan. Digital Image. Treehugger. Accessed November 4, 2016. https:/www.treehugger.com/urban-design/look-bucky-fullers-dome-over-new-yorkcity.html

Figure 10: Rain, Steam and Speed - The Great Western Railway, JMW Turner

Source: Turner, JMW. Rain, Steam and Speed. 1844. Oil on canvas. London, National Gallery. http://www.nationalgallery.org.uk/paintings/joseph-mallord-william-turner-rainsteam-and-speed-the-great-western-railway

Figure 11: The Water Lilies - The Clouds, Claude Monet

Source: Monet, Claude. The Water Lilies - The Clouds, Claude Monet. 1915 - 1926. Oil on canvas. Paris, Musée de l'Orangerie. http://www.musee-orangerie.fr/en/artwork/waterlilies-clouds

Figure 12: Charred Wood Tower - Exterior

Source: Pritish J. Pathak

Figure 13: Charred Wood Tower - Interior

Source: Pritish J. Pathak

Figure 14: Twine Cave - Exterior

Source: Pritish J. Pathak 
Figure 15: Twine Cave - Interior

Source: Pritish J. Pathak

Figure 16: OSB Tunnel - Exterior

Source: Pritish J. Pathak

Figure 17: OSB Tunnel - Interior

Source: Pritish J. Pathak

Figure 18: The Weather Project, Olafur Eliasson

Source: Holmes, Bill. The Weather Project. Olafur Eliasson. Novermber 27, 2003. Flickr. https://www.flickr.com/photos/flaneur/22033173

Figure 19: HtwoOexpo Interactive Museum, NOX/Lars Spuybroek

Source: HtwoOexpo Interactive Museum, NOX/Lars Spuybroek. Digital Image. Archdaily. Accessed February 14, 2017. http://www.archdaily.com/795388/when-dropletscreate-space-a-look-at-liquid-architecture

Figure 20: $\quad$ Still from The Powers of Ten depicting the $10^{1}$ scale

Source: Eames, Charles, and Ray Eames. The Powers of Ten. Directed by Charles and Ray Eames. Chicago, IBM, 1977

Figure 21: MAXXI, Rome 2009 - Soft Opening, Main Entrance

Source: Baan, Iwan. MAXXI, Rome 2009 - Soft Opening. Main Entrance. Digital Image. Patrik Schumacher. 2010. http://www.patrikschumacher.com/Texts/The\%20Meaning\%20 of\%2OMAXXI.htm

Figure 22: Place - Space

Source: Pritish J. Pathak

Figure 23: Place - Space - Atmosphere

Source: Pritish J. Pathak

Figure 24: Atmosphere Expanded

Source: Pritish J. Pathak

Figure 25: Intersection of Church Street and Cerrard Street East

Source: Pritish J. Pathak

Figure 26: Shore of Fogo Island, Newfoundland and Labrador 
Source: Shore of Fogo Island, Newfoundland and Labrador. Digital Image. Newfoundland Labrador. Accessed March 31, 2017. http://www.newfoundlandlabrador.com/ TheLatest/NewsArticle/217

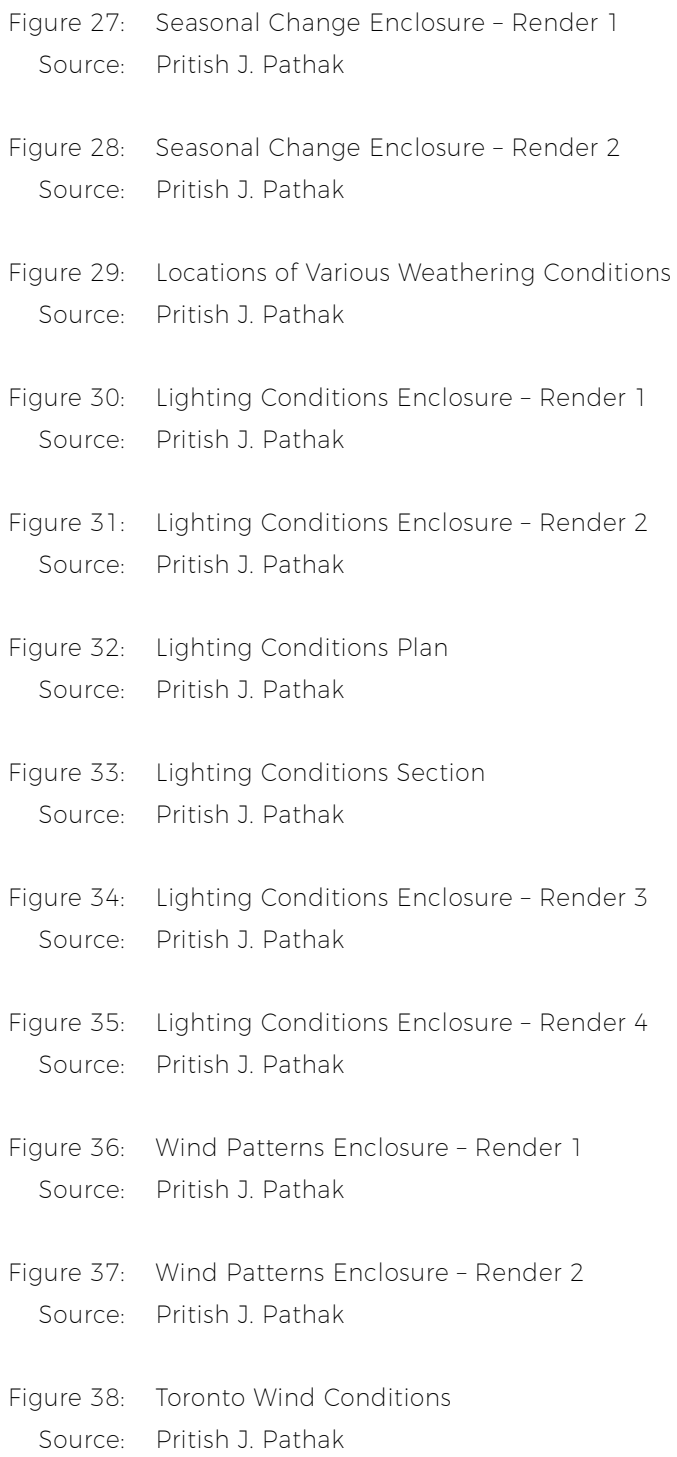


Figure 39: Topography Enclosure - Render 1

Source: Pritish J. Pathak

Figure 40: Topography Enclosure - Render 2

Source: Pritish J. Pathak

Figure 47: Brick Laying Pattern

Source: Pritish J. Pathak

Figure 42: Topography Enclosure Unfolded Section

Source: Pritish J. Pathak

Figure 43: Material Composition Enclosure - Render 1

Source: Pritish J. Pathak

Figure 44: Material Composition Enclosure - Render 2

Source: Pritish J. Pathak

Figure 45: Brick Usage

Source: Pritish J. Pathak

Figure 46: Temporal Material

Source: Pritish J. Pathak

Figure 47: Atmospheric Variables

Source: Pritish J. Pathak

Figure 48: Ranges of the Senses

Source: Malnar. Joy, and Frank Vodvarka. 2004. Sensory Design. Minneapolis: University of Minnesota Press

Figure 49: Sensorial Envelope

Source: Lally, Sean. 2014. The Air from Other Planets: A Brief History of Architecture to Come. Zürich: Lars Müller Publishers.

Figure 50: Comparison between architectural depiction of an environmental boundary (top) and that of the physicist (bottom)

Source: Addington, Michelle, and Daniel Schodek. 2005. "Energy: behaviour, phenomena and environments." In Smart Materials and New Technologies for Architecture and Design Professions, by Michelle Addington and Daniel Schodek, 46-78. Burlington: 
Architectural Press

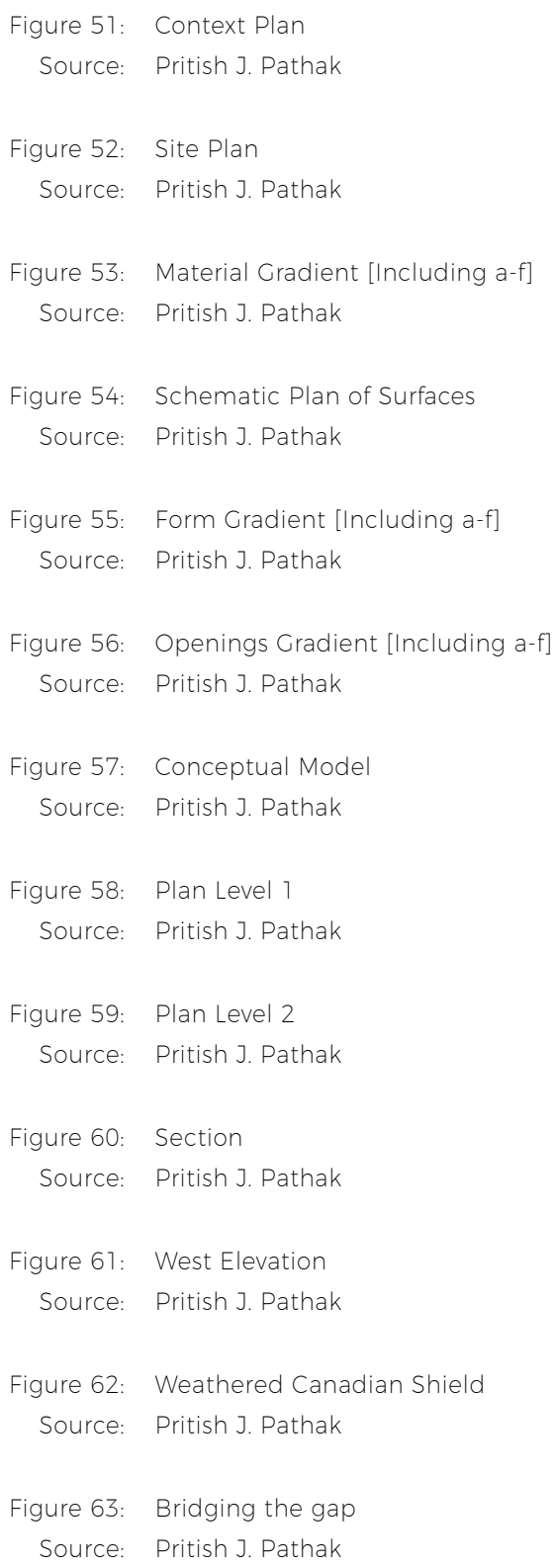




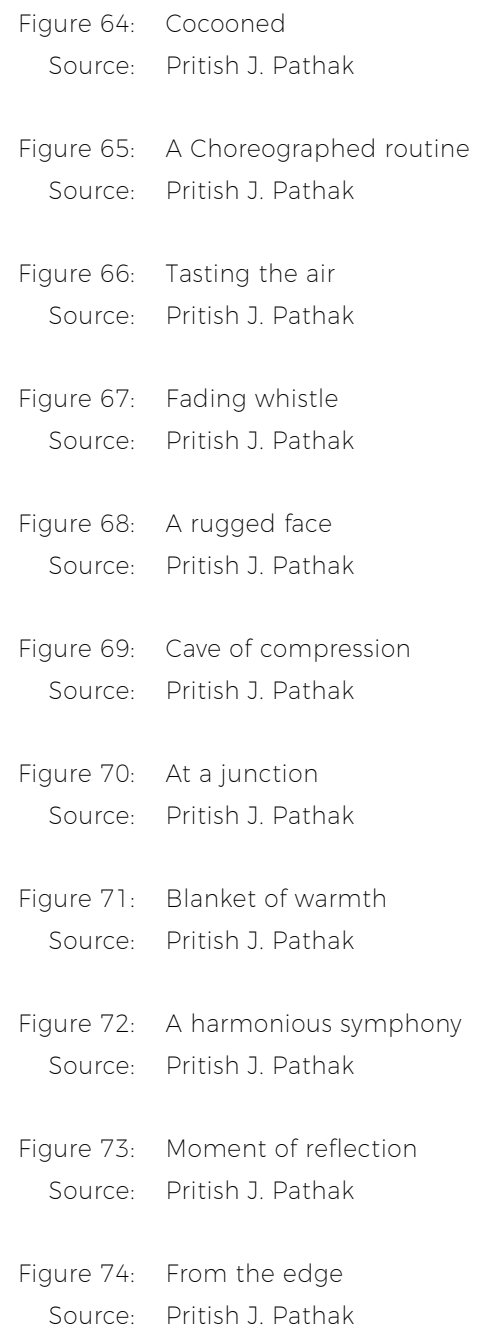





\section{PREFACE}

The research contained herein began in September 2015 with an initial interest in the experience of architecture, more specifically the neutrality of it today. Over the course of the subsequent year. the concept of atmosphere was explored as something that can be strategically, yet artificially, produced by the objects buildings - architects design to challenge this neutrality. Such was the course of this thesis until October 2016. That is when the understanding of atmosphere transformed from something that can be artificially fabricated to something that is an inherent quality of a particular place. Over the course of the upcoming months, in addition to atmosphere, several threads were researched, the previous one leading to the next, to acquire a profound understanding of the current state of affairs.

The introductory chapter. Atmosphere Today, traces the origins of the paradigm within which the discourse operates today, identifying specific forces, both from within and beyond the discourse, that have relegated the consideration of atmosphere in architecture to an "ideal" neutral environment. This is followed by a brief literature review that elucidates the positions of authoritative figures regarding the subject matter. Unfortunately, except for 
a very selective few practicing architects, atmosphere as an architectural concept has almost exclusively remained the subject of interest for theorists. The chapter concludes by shedding light on a relatively recent perversion of the term atmosphere that essentially equates it with mere theatrics.

Chapter two, Atmosphere Expanded, articulates the thesis' specific stance on atmosphere. It expands the discussion to include peripheral subjects of interest while still identifying specific, more tangible variables of an otherwise elusive concept. Documented within the chapter are a series of design-research investigations that were conducted as an exercise in not producing an artificial atmosphere, but rather capturing specific atmospheric phenomena that contribute to the overall character of a place.

Chapter three. On Boundaries, introduces the architectural focus of this design-research, the threshold, within the context of the established position on atmosphere; while the following chapter. Six Mile Lake Retreat. presents the culmination of the foregoing research in the form of a design project, a rural retreat for a landscape artist where the architecture doesn't impose an artificial atmosphere, but rather serves as a device to evince the atmosphere of its context. 

evince [verb]: revealing the presence of (a quality or feeling) 


\section{0}

\section{ATMOSPHERE TODAY}

Christian Borch declares that "every encounter with architecture contains the possibility that we are being seized by its atmosphere, even if some atmospheres are felt more intensely than others." This position is echoed by Mark Wigley when he argues "to construct a building is to construct [such] an atmosphere."2 The crucial point being made by these two authors is that the inevitability of atmosphere in the built environment remains despite the omission of its consideration in the design of architecture. However when disregarded by design, the resultant atmosphere is one of banality.

The critical position of this thesis is not that the concept of atmosphere is necessarily neglected in architectural practice today, but rather that it is not realized to its fullest potential, resulting in a highly superficial spatial experience. This thesis instead suggests that the desire today is to intentionally design architecture with a constant, homogeneous, neutral atmosphere as opposed to architecture charged with atmospheric intensity. Therefore, to posit that as a result buildings don't have an atmosphere would be inaccurate. Even a dull, mundane atmosphere, is exactly that, a building's atmosphere. The gradual suppression of atmospheric 
considerations within contemporary architectural practice can be traced back to three major forces.

\subsection{STANDARDIZATION OF ARCHITECTURE}

Architecture today is practiced in a culture that favours standardization. Generic skins draped around vertically stacked repetitive floorplans, coupled with highly controlled mechanical systems legitimize the existence of acontextual architecture which neither responds to nor is shaped by the environment within which it is located. Architecture that arises from such malpractice leads to placelessness. Edward Relph suggests placelessness is "the casual eradication of distinctive places and the making of standardized landscapes that results from an insensitivity to the significance of place." ${ }^{3}$ Placelessness is the result of the lack of consideration attributed to the peculiarities of a site - a place - that distinguishes it from any other location.

The historic development of a culture of "making standardized landscapes" coincided closely with the rise of globalization. Globalization is an external force that although doesn't have its roots in architecture, continues to affect the discourse on a startling scale. Globalization is an umbrella term coined to define the cumulative process of an international expansion of trade and products, commodity and financial markets, migration and culture, 
media, news, ideology, fashion and computer programs. ${ }^{4}$ Clobalization is a world order that began very much as a phenomenon of Western ideals of Enlightenment. The devastation of the Second World War had the dominant Western powers convinced of the need to create a new world order that protected the world economy from such catastrophic destruction. The formation of institutions like the International Monetary Fund and the World Bank established the framework for a global economy and a global political philosophy. This was the foundation of globalization. ${ }^{5}$

Clobalization is dominated by the unhindered and ongoing expansion of Western culture as evidenced by the spread of north-Atlantic products and corporations to less industrialized parts of the world. Advances in communication technology are bringing Western consumer conformity to the most remote corners of the planet through films, products and ideals. All provide astounding images of Western beauty, luxury and sophistication, epitomized by the architecture of the West, as something to be desired.

The emergence of globalization corresponded intimately with the rise of Modernism as an architectural movement. Modernism itself was a Western cultural phenomenon anchored in the same ideals of Enlightenment that informed the ascent of globalization: rationality, scientific innovation, progress and the end of tradition. The arrival of the 20th century marked a period when several prominent American and European architects rebelled against the principles of classicism and neoclassicism, united by the belief that this modern age demanded a new architecture capable of responding to the rapidly emerging industries, technologies, mobility and social and political orders. By the time the foundations of globalization were laid in 
1948, modernism had so obliterated vernacular architecture that it came to be described plainly as "modern." ${ }^{6}$

The ideals of founding modernists, such as Walter Gropius and Mies van der Rohe, were always global in ambition. Foreshadowing the reality of the impending future, in 1919 Walter Gropius was quoted as saying "one day there will be a worldview, and then there will also be its sign, its crystal architecture."7 This crystal architecture came to be known and the International Style that homogenized cities around the world. American architect John Gaw Meem noted in 1934 that "it [the International Style] reflects contemporary Western civilization, especially our devotion to the ideal of the scientific truth." ${ }^{8}$ Its rise was driven by principles of systemization and standardization, mass production, economies of scale, functional logic and aesthetic composition and the absolute elimination of unnecessary ornamentation and sentiment. The spread of the International Style around the globe revealed four critical common design strategies that became characteristic of buildings designed under this style: rectilinear forms, light planar surfaces that have been stripped of the slightest evidence of ornamentation and decoration, open floor plans that provide vast interior spaces, and a visually weightless quality induced by the use of post-beam construction and cantilevers [Fig. 1]. The use of concrete and masonry was minimized as construction materials, as the discipline shifted towards the now ubiquitous glass and steel combination. Given a similar functional program, under the guiding design principles of the International Style, a building in South America could have looked remarkably similar to one in Southeast Asia, without anyone questioning the legitimacy of either one despite the distinct contexts. This was essentially the problem with 


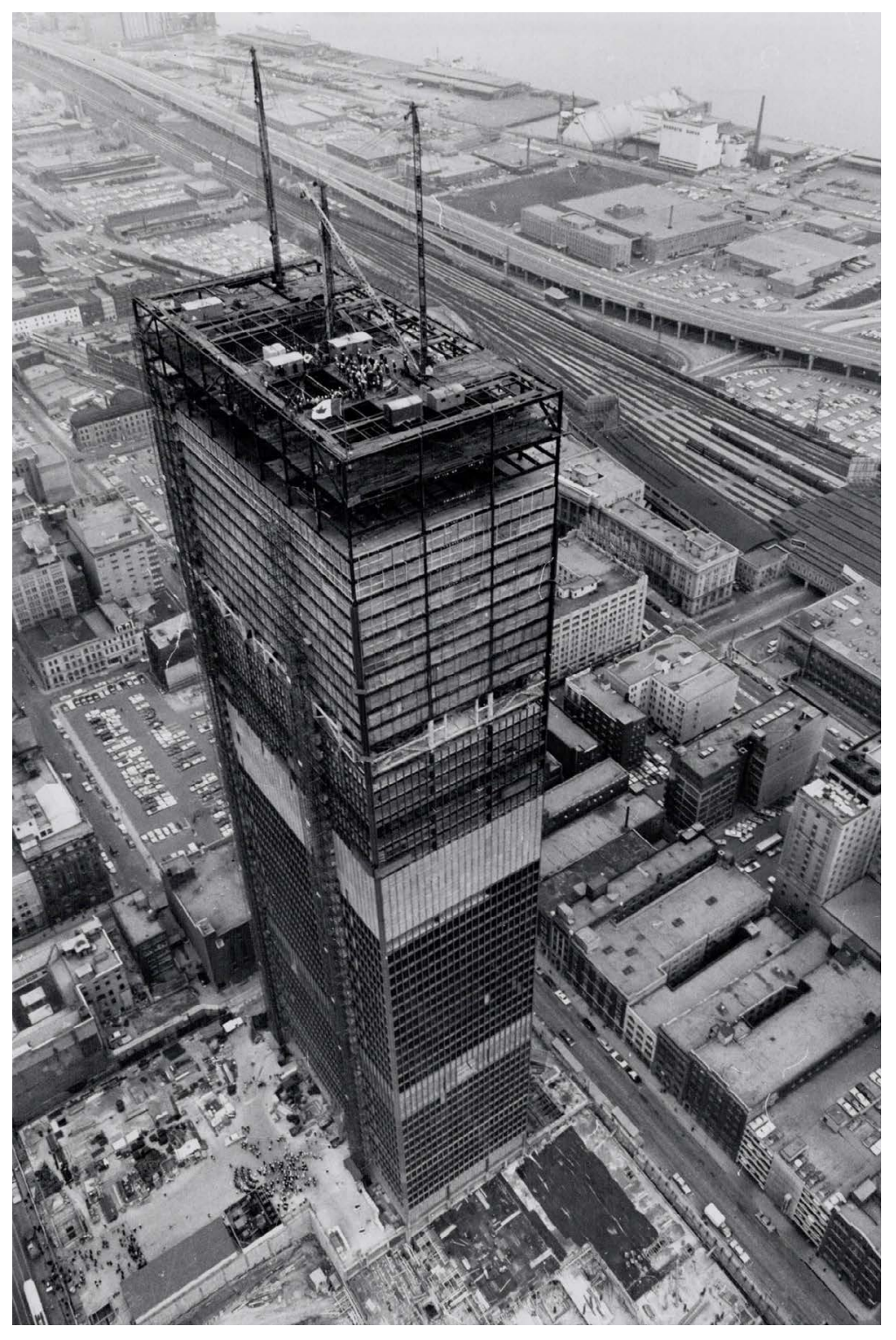


Modernism, it always thought in ideals that could be universally applied to all contexts. ${ }^{9}$

For several decades after its inception, International Style thinking had a profound influence on building typologies such as office towers, schools, hospitals, laboratories and multifamily housing. With the exponential growth of cities in the first half for the 20th century, particularly after World War II, the International Style promised an easily available stylistic option for large scale urban development projects. The deployment of the International Style was seen as a tool to maximize floor space on any particular site, with the attempt to convince local planners, politicians and the general public that such a development would bring global economic capital to the city.

Regardless of its criticisms, for developing countries that are now beginning to be engulfed by the wave of the global economy, the link between Modernism and the rationality, success and dominance of Western economies is irrefutable. This is the benchmark developing countries hope to achieve both economically and architecturally. Additionally, the modernist association between key building typologies and globalization is now adopted by these emerging economies. The thriving shopping mall, the vast new airport, the international hotel and the mile-high corporate office tower are seen to demonstrate a clear symbolic link with drivers of global economic expansion. The homogenized global economy now finds its parallel in the homogenized urban centres of the planet. The new glasswalled office towers that have come to epitomize every central business district throughout the world have been christened the "Coca-Cola of architecture."10 Now, without the subtle hints of local signage or vehicle 


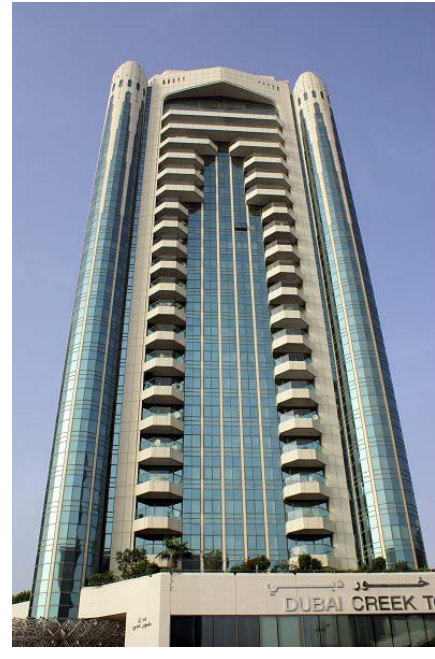

2

2 Dubai Creek Tower

3 Mumbai Shreepati Arcade

4 Shanghai Maxdo Centre

5 Walt Disney Concert Hall

6 Museo Guggenheim

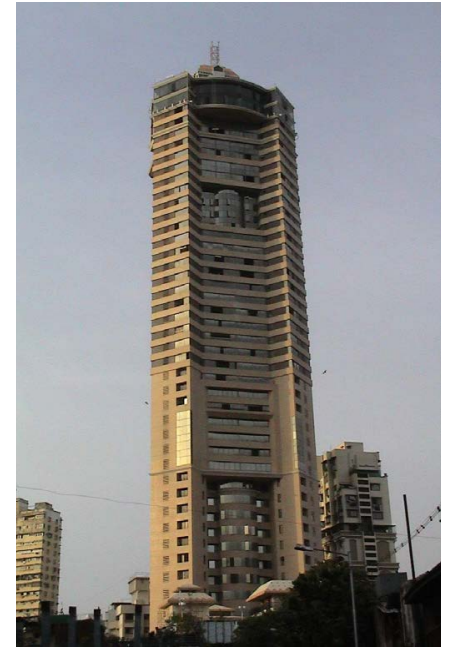

3

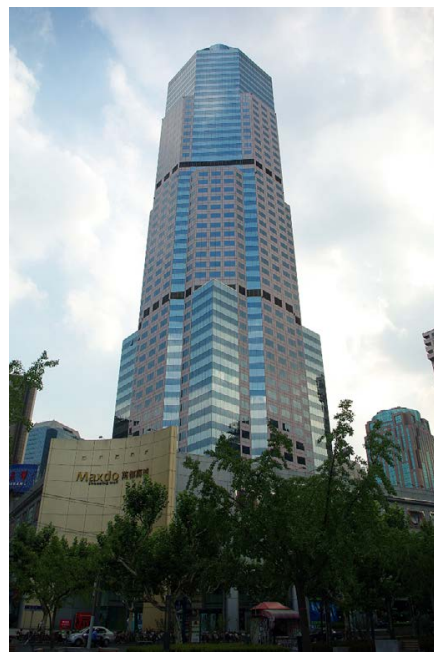

4

5

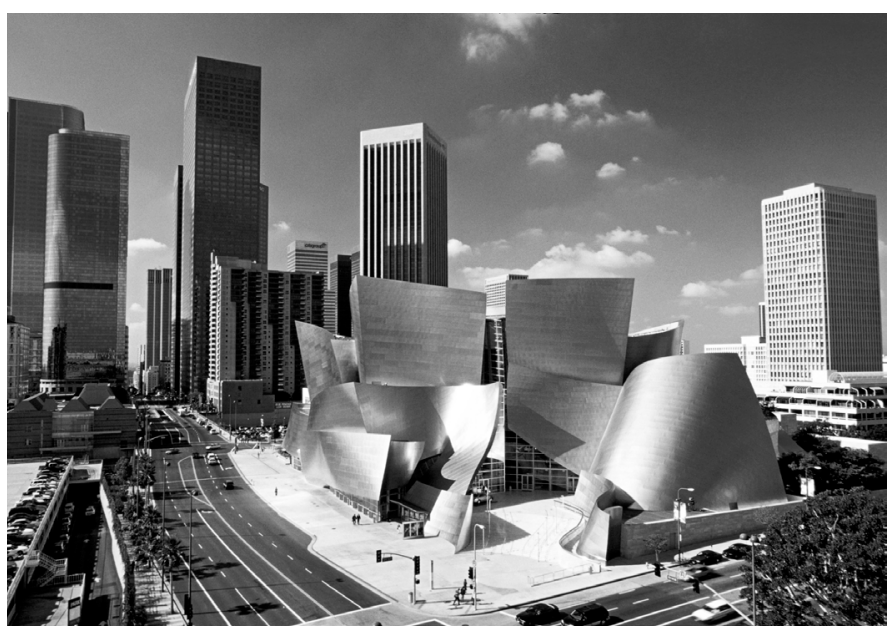


license plates, it is nearly impossible to determine whether a building is located in Dubai, Mumbai or Shanghai [Fig. 2, 3, 4]

As cities, more than countries, now bid to attract global investment and global tourism, they pursue brand differentiation and symbolic modernity. This demand for brand differentiation has nurtured a symbiotic relationship with an infamous breed of starchitects. The commissioning of public buildings by a list of starchitects is now viewed as a branding tool. This list includes familiar names like Daniel Libeskind, Jean Nouvel, Santiago Calatrava, Rem Koolhaus and Frank Gehry, perhaps the archetype of the starchitect [Fig. 5, 6]. The personal stature of these architects is so valuable and the demand for their presence so great, that their work is almost strictly conceptual and cannot be relied on for any level of detailed analysis of cultural locality. It is the intention of these buildings to be a global icon, with no reference to local cultural distinctiveness. ${ }^{11}$

6

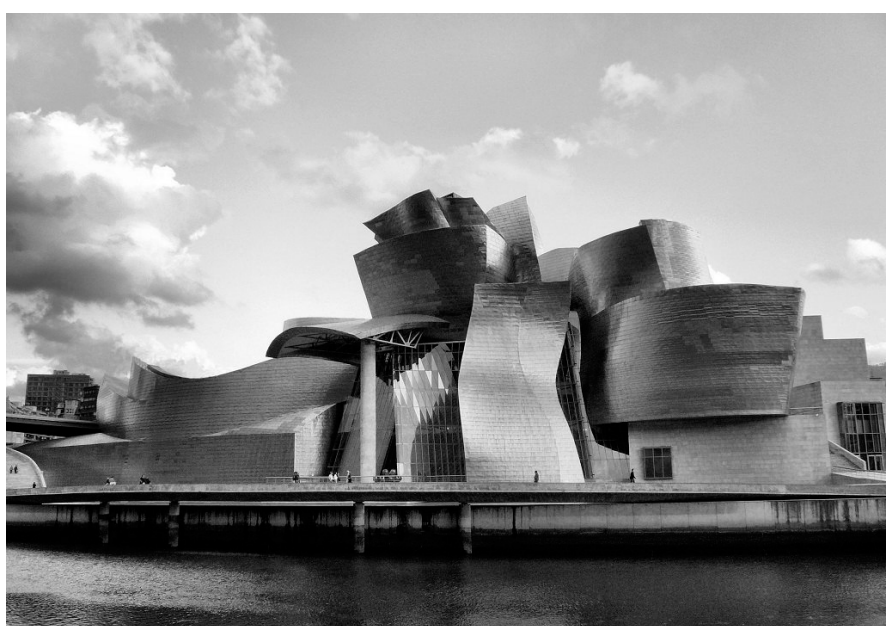




\subsection{STANDARDIZATION OF INTERIOR ENVIRONMENTS}

In his seminal book American Building: The Environmental Forces that Shape It, theoretician James Marston Fitch suggested that the "ultimate task of architecture is to act in favour of man: to interpose itself between man and the natural environment in which he finds himself, in such a way as to remove the gross environmental load from his shoulders." This suggestion has been accepted quite literally, without any challenge by contemporary practice.

The standardization of landscapes on a planetary scale has been accompanied by the standardization of interior environments. Even though the forces that architecture must respond to have by and large remained unchanged, the reaction to those forces, the techniques employed for the construction and maintenance of buildings have become progressively advanced and consequently more universal. Architecture was conceived to address the practical need for human shelter. This concept of shelter has been explored by a number of theorists in the form of the primitive hut as a means to mediate the hostile environment for the occupant [Fig. 7]. In its primitive days, architecture was never concerned with comfort, it served to ameliorate environmental conditions that were too extreme for human adaptation.

Technology and advancements in construction methods have allowed for interior environments to be strictly controlled and maintained in a way that is almost completely independent from the varying conditions beyond their walls. The arrival of mechanical climate systems in the 20th century, brought forth the transformation of the role of building envelope from 


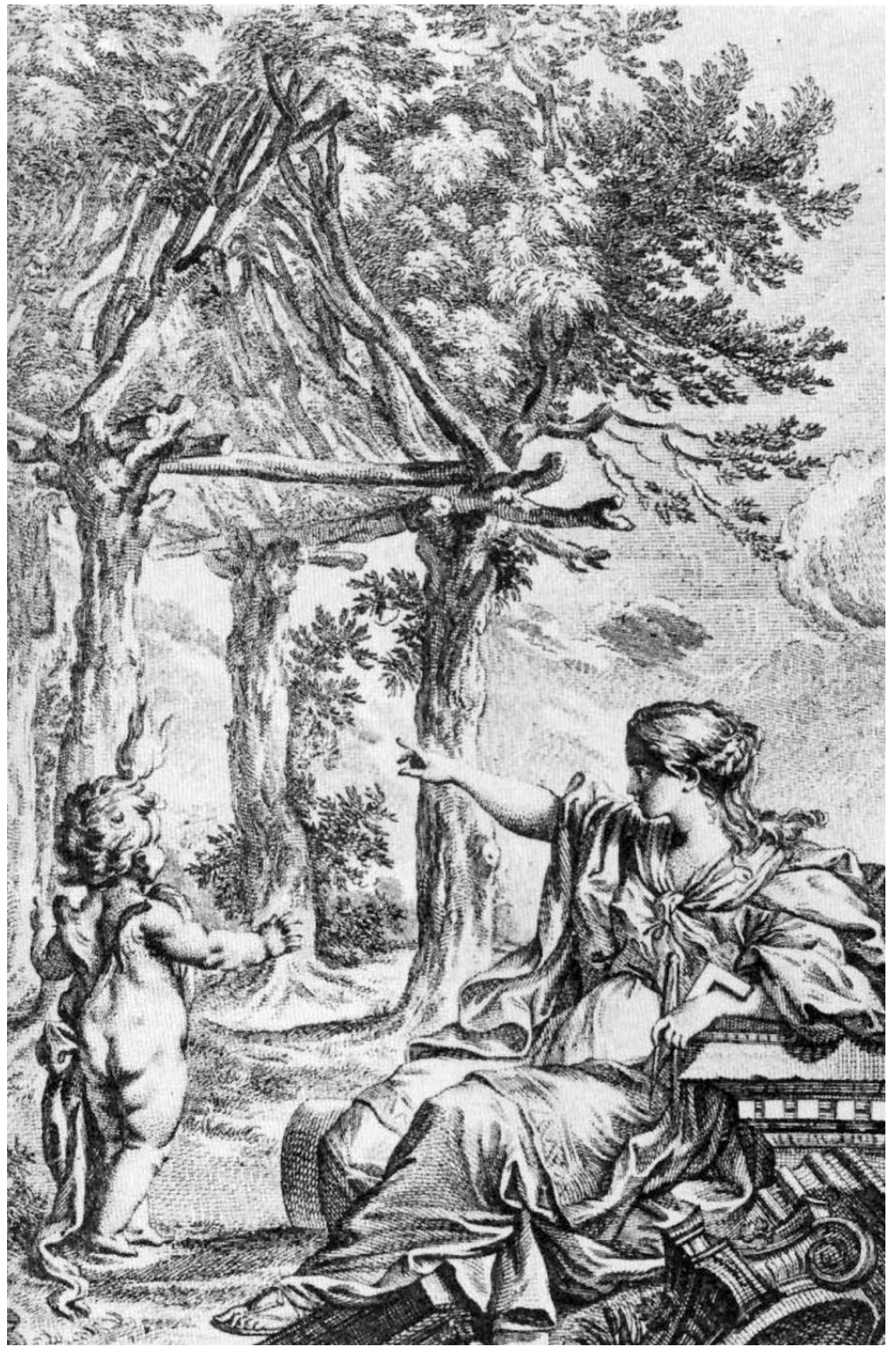

7 Frontispiece of Marc-Antoine Laugier: Essai sur l'architecture 
mediator to an impervious separator of two distinct conditions, interior and exterior. ${ }^{12}$ The building envelope continues to function as a "barrier to the exterior, a container of the interior and determinant of all extant physical phenomena." ${ }^{33}$ The interior is characterized as a singular and stable environment that can be optimized by maintaining ideal conditions. The exterior environment is considered fully hostile, and only the creation of a separate and highly controlled interior environment can complete this ideal container for the occupants.

The neutrality of the "ideal," homogeneous interior environments of buildings make them apathetic to the inconstant and dynamic character of the city and the outdoor environment in general. Consequently, one's experience of moving through buildings is often banal and uneventful. As a result, when an individual moves through a building they rarely reflect on the effect that the spatial configurations, materials and the overall construction have on their experience. It is only during moments of extreme intensity. or even discomfort, that an occupant begins to develop an experiential understanding of the place they inhabit. This room is very cold, the floor is rough, the lighting in here is too bright; it is due to the severity of the conditions of a place, as described by these phrases, that the occupant becomes acutely aware of their surroundings.

This is not to say that these technological advancements are without their benefits, but the intensity of the exterior environment that one experiences is lost the moment they cross the threshold into a building. The body's connection to varying conditions, moments of intensity and calm have been lost to a neutral and constant condition. While outside, one is aware of one's 
body and its comfort in an intense way.

Le Corbusier was arguably one of the most ardent proponents of explicitly segregating the exterior environment from the interior. He reserves an extensive portion of his book Ville Radieuse, the publication that followed his totalitarian master plan of the same name, to elaborate on the notion of the house as "a machine for living." Le Corbusier intended a single building type for all nations and climactic conditions. Le Corbusier's belief in the need for such a building was driven by his characterization of the air of the urban environment as the "devil's air," adversarial to human health. The ideal, well-tempered interior environment in all locations was to be achieved by maintaining an annual interior temperature of $18^{\circ} \mathrm{Celsius}^{14}$ The consequence of "the building for all nations" was the clear distinction between inside and outside, achievable only by treating the inside as a hermetically sealed, impenetrable chamber. Flatness is the term used by Mohsen Mostafavi and David Leatherborrow to describe the result of Le Corbusier's desire to produce a highly controlled interior environment as witnessed by the failure of his Cité de Refuge [Fig. 8].15

The work of Buckminster Fuller can be used to further draw parallels with the desire to create such a deprived environment. His utopian idea for a dome over Manhattan dramatically highlights the modern ambition to strictly control the built environment and separate it from the reality of changing environmental conditions. The advent of mechanical climate systems certainly facilitated this separation; and continues to foster a high level of detachment between the two types of environments humans occupy [Fig. 9]. 

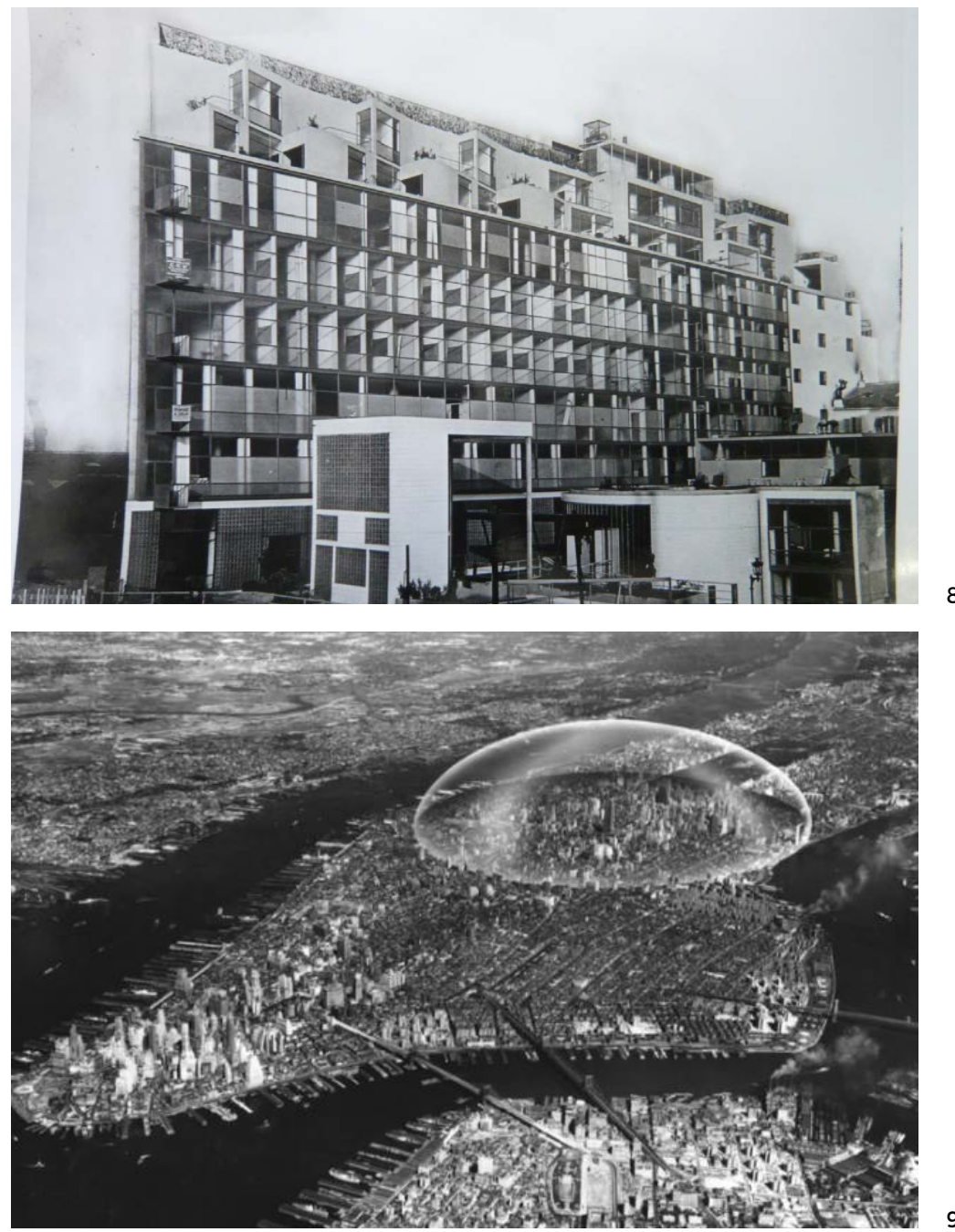
The issues described here are not intended to be interpreted in the nostalgic sense that current practices should be abandoned in order to move back into vernacular building types. This thesis is instead suggesting that through a careful consideration of atmosphere in architecture, the superficiality of experience today may be challenged.

\subsection{DIGITAL PARADIGM}

Given the technological advances of the current digital paradigm, people are preoccupied with processing the fast-moving, visual information they are confronted by daily in today's built environment. This coupled with the individual's obsession with personal technology has fostered a population that is detached from the built environment that surrounds them. The dominance of vision has invariably reduced the human experience to a matter of visually registering a deluge of images.

The discourse of architecture has not remained immune to this paradigm shift. With the continued development of mobile technology, architecture too, has become more invested in the visual representation of ideas and the speed of its delivery. This intentional focus on the image of an architectural concept appears to have caused a decrease in the consideration of the environment of architecture, that is, its atmospheric quality. In addition to the culture of standardization, a more recent ocularcentric culture has emerged that has hijacked the discourse of architecture. Buildings are ontological, not representational in character; to borrow Heidegger's terminology, a building is a "thing" not a "sign." 16 Yet the current digital paradigm has caused the commodification of architecture by reducing it to scenographic representation. 
Digital methods of production have been lauded for their ability to liberate human creativity. They present themselves as innovative forms of design development and production. Practitioners, educators and students alike have been captivated by the ability to produce striking and memorable visual imagery through the use of computers that present their work as pristine objects in space. Such rhetoric focuses on architecture as simply image by inevitably altering the design process into "one of passive visual manipulation, a retinal journey." ${ }^{17}$ Vision becomes the sole mode of communication between built form and the occupant. This reality often shifts focus away from a more precise and experiential consideration of atmosphere in architecture. With the focus of architectural design purely on the visual aesthetics of the project, any opportunity to provide a heightened atmospheric experience is never capitalized upon.

The disproportionate importance placed on the visual aspects of architecture has resulted from a desire to engage in form-making over place-making. While occupying oneself in the practice of form-making may result in buildings that are visually appealing, the experience they provide is reduced to one of superficiality. Digital technologies however are providing architects with powerful new tools for experimentation with form-making on an unprecedented scale. The world of computational design permits architects to pursue new frontiers where a novel kind of architecture may surface through the application of algorithms and software. There is a growing generation of architects motivated by the ambition of creating a new world order of "digitally materialized architecture." ${ }^{8}$ Consider the example of robotics in production. It is an undeniable fact that robotics have streamlined the manufacturing industry. It is the hope of this group of 
architects that the implementation of robotics in the construction process will achieve those same results of efficiency, precision and speed. That being said, architects need to ensure that robotics aren't imbued with more value than they merit. Observing robotics in motion might suggest self-direction, independent from another source, but it is still the architect on the other end, inputting large amounts of data into virtual space that the computer is able to manipulate into commands for the robot to output in physical reality. Without human intervention, the whole operation ceases to exist. On a fundamental level, robotics are simply another tool in the architect's arsenal to execute their designs, albeit with greater ease. The dematerialization of architecture can be understood as a direct consequence of the current digital paradigm. ${ }^{19}$ To reference Heidegger once again, buildings lose their very thing-ness.

On a fundamental basis, by engaging in the act of manipulating material to form places for human activity, architects craft the human experience. Materials therefore are the architect's work palette. If digital technology, such as robotics, is to be privileged for more than what it really is, the architect's work palette loses its plasticity.

\subsection{WHAT IS ATMOSPHERE}

The use of the word 'atmosphere' has become commonplace in contemporary language as people use it in their descriptions of a whole host of events such as the weather, a place or even a particular situation. However, the concept of atmosphere as an ambient description was still relatively young when JMW Turner boldly proclaimed: "atmosphere is my style," during a conversation with John Ruskin in 1844.20 Turner, as a painter. 

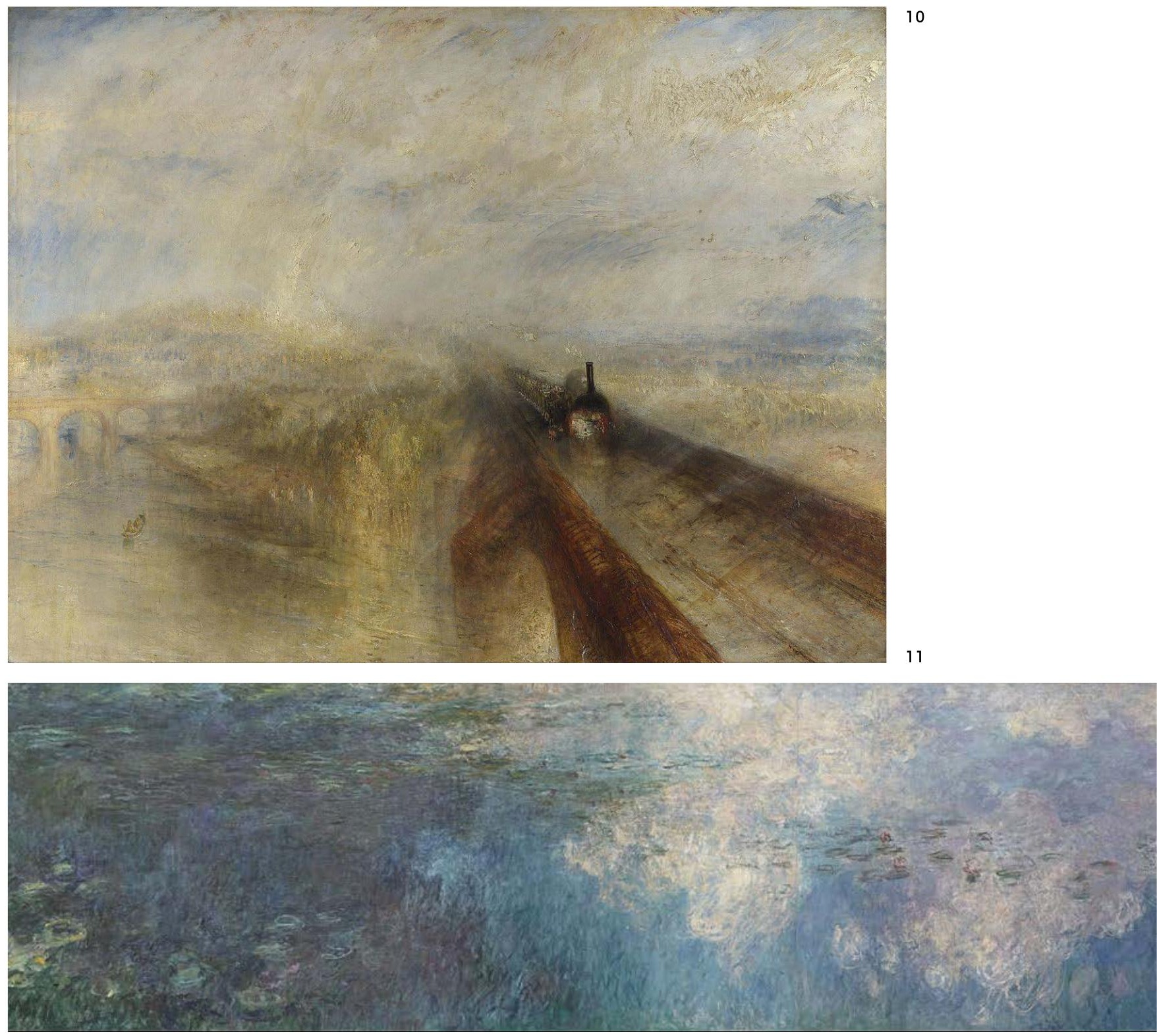
10 Rain, Steam and Speed - The Great Western Railway, JMW Turner

11 The Water Lilies - The Clouds, Claude Monet

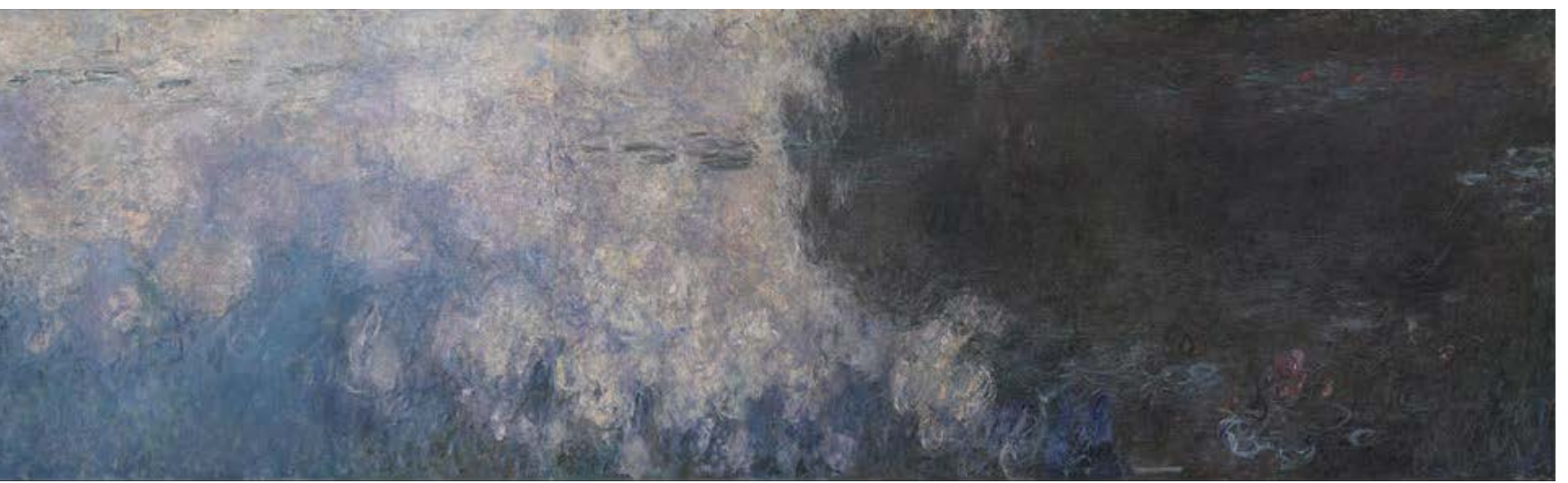


did not concern himself with depicting physical objects through his work, rather he focused keenly on the way an observer may consider the ambient condition of the situation captured. Through his mastery of integrating light with the ambiguous 'blur' between subjects, Turner expressed space as a consideration of the whole environment rather than focusing attention on specific individual elements [Fig. 10]. ${ }^{21}$ The observer thus perceives the painting as a singular totality, allowing for multiple understandings of the work. Renowned German art historian Michael Bockemühl proposes that to suggest the impression of an in-depth spatial, atmospheric expanse. Turner was required to concentrate and shorten the countless particulars of the scene, bringing out their characteristic features. These characteristic features of the environment are what in fact produce an atmospheric quality in his work. ${ }^{22}$ His paintings suggest an instantaneous response to the environment portrayed, where details are only revealed through further investigation.

The work of Turner was furthered years later by Claude Monet, a French Impressionist painter, who explored painting as the 'art of observation'.23 Monet focused on natural light and its ability to manipulate space in order to express the experiential quality of a scene; specifically how changes in the condition of light might affect the observer's perception of the relationship between themselves and the subject. Most notably in his Water Lilies series, Monet crops the scene to eliminate the river bank in an attempt to refocus the observer's attention on the water's surface and the light's interaction and reflection upon it [Fig. 11]. ${ }^{24}$ By removing perspective Monet was able to abstract moments which often would be unseen had he not drawn the observers' attention to them. Both these esteemed artists were dealing with atmosphere as the subject matter of their work, although one more 
explicitly than the other. Whereas Turner focused on the wider ambient condition of the environment, Monet concentrated his efforts on a specific detail which aided in developing an ambient condition.

Although the consideration of atmosphere in the work of a painter is confined strictly to their canvas, it is not too dissimilar to how atmosphere in architecture might be approached as well. Given its fleeting, ephemeral nature and the subjectivity of an individual's perception of it, atmosphere in architecture can be challenging to describe. Thus the following authoritative figures were consulted to obtain a deeper understanding of this subject matter.

"Quality architecture to me is when a building manages to move me. What on earth is it that moves me?... One word for it is atmosphere... I enter a building, see a room, and in a fraction of a section I have this feeling about it."

-Atmospheres: Architectural Environments - Surrounding Objects

Peter Zumthor

For Zumthor, encounters with atmosphere are intrinsically linked with embodied experience. He asserts that "we perceive atmosphere through our emotional sensibility - a form of perception that works incredibly quickly."25 Essentially, this a spontaneous emotional response to an environment that has impacted the body in a subconscious manner. In experiencing a space, individuals feel its material-haptic qualities, see its lights, hear its sounds, smell its scents and feel its temperature. Unlike some of his contemporaries, Zumthor's concept of atmosphere isn't restricted to building interiors. 
Atmosphere also relates to how a building situates itself within its surrounding. Consequently, if a building isn't contextually appropriate, its atmospheric qualities suffer. Landscape, along with materiality, light and craftsmanship are elemental in generating a particular atmosphere in Zumthor's work.

"How is atmosphere constructed? Atmosphere seems to start precisely where construction stops. It surrounds a building, clinging to the material object. Indeed it seems to emanate from the object."

- The Architecture of Atmosphere Mark Wigley

Wigley argues that the atmosphere of a building is produced by the physical form. Atmosphere is a "sensuous emission of sound, light, heat, smell and moisture; a swirling climate of intangible effects generated by a stationary object."26 While this sensuous climate that surrounds the individual is ephemeral, it is still tangibly felt. Upon entering a building, the individual enters its atmosphere. So when one speaks of a spatial experience, what is truly experienced is its atmosphere.

The architectural implication of Wigley's position is that atmosphere in architecture is the by-product of the buildings architects design. It is the physical manipulation of the object that produces a particular atmosphere, whether that is the architect's intention or not.

"An atmospheric perception also involves judgements beyond the five Aristotelian senses, such as sensations of orientation, gravity, balance, stability, 
motion, duration, continuity, scale and illumination. Indeed, the immediate judgement of the character of space calls for our entire embodied and existential sense, and it is perceived in a diffuse, peripheral and unconscious manner rather than through precise, focused and conscious observation."

-Space, Place and Atmosphere: Emotion and Peripheral Perception in Architectural Experience Juhani Pallasmaa

Pallasmaa defines atmosphere as the "judgement of environmental character. a complex multisensory fusion of countless factors which are immediately and synthetically grasped as an overall feeling, mood or ambiance."27 What is significant about this definition is that it suggests an understanding of atmospheres from an experiential and existential point of view.

Pallasmaa makes two critical statements on how atmospheres are experienced. Firstly, atmospheres are perceived emotionally before they are understood intellectually. An individual grasps the totality of a spatial atmosphere before identifying the constituent details it is comprised of. ${ }^{28}$ Pallasmaa's observations here regarding the relationship between the details and the overall atmosphere in architecture help draw parallels with the consideration of atmosphere in the works of the painters referenced above. Turner chose to emphasize the overall ambient quality of the scene depicted in his work but Monet chose to do the inverse, giving precedence to the individual details that capture an atmosphere in his work.

Secondly, preceding this intellectual response, an individual's encounter with architecture is multisensorial. A space can be heard, smelt, felt instead 
of just seen. Pallasmaa is highly critical of the current ocularcentric paradigm arguing that focused vision makes people mere observers of space by establishing distance between the individual and the object. He argues for primacy of peripheral vision and haptic-touch, believing the former embeds an individual within their environment as participants and the latter to be the sense of nearness, intimacy and affection, both crucial in establishing a comprehensive spatial experience. ${ }^{29}$

"But seeing itself is not a sense that defines being-in-something but rather a sense that establishes difference and creates distance. There is another sense specifically for being-in-something; it is the sense that might be called 'mood.' A mood contributes to where we are. By feeling our own presence we feel the space in which we are present."

-Atmosphere as the Subject Matter of Architecture

Cernot Böhme

Whereas the authors discussed above have tried to define atmosphere as a distinct entity. Böhme makes no such attempt. Although he agrees with Pallasmaa's position that the registration of atmosphere is a multisensory phenomenon and Wigley's position that atmospheres can be produced by strategically shaping objects, Böhme only speaks of atmosphere in terms of the body's experience of space. ${ }^{30}$ His understanding of atmosphere perhaps most closely resembles that of laypeople. If an ordinary person was asked to describe the atmosphere of a particular space, they might respond with "I feel tranquil in this space" or "this space makes me feel claustrophobic." What is being described by the individual in this case is their sensitivity to the atmosphere created by a particular environment. This cognitive awareness of 
how a particular space is affecting the inhabitant is what Böhme describes as "mindful physical presence." ${ }^{31}$

If each of the positions described above were boiled down to its essence, the concept that emerges is one that defines a relationship between the object and the subject. Within the architectural context, the term object can be read as building and subject as the occupant. Architects themselves do not produce atmospheres, what they produce instead are objects. These produced objects are what create an atmosphere. Therefore objects can be manipulated by architects to bring forth a desired atmosphere.

The following concrete model series, titled "Producing Atmospheres," were designed as tectonic experiments, informed by this initial literature review [Fig. 12-17].

By relying exclusively on one material, concrete, to define the formal boundaries of the spaces created, the internal atmosphere emerges simply as the result of the various texture treatments applied to the surfaces of the formwork used to carve out each volume; specifically twine, charred pine and oriented strand board.

While these models are no longer representative of this thesis' understanding of atmosphere, they were an important evolutionary step in the progress of this research and have thus been documented here.

This is where this thesis disagrees with the position of the figures outlined above. While they argue that atmosphere is something that can be 


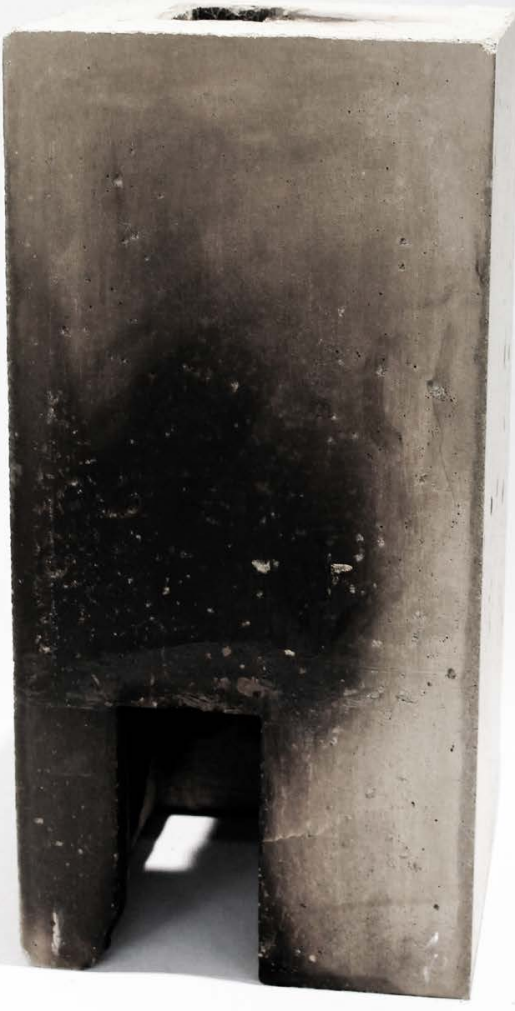

12 Charred Wood Tower - Exterior 


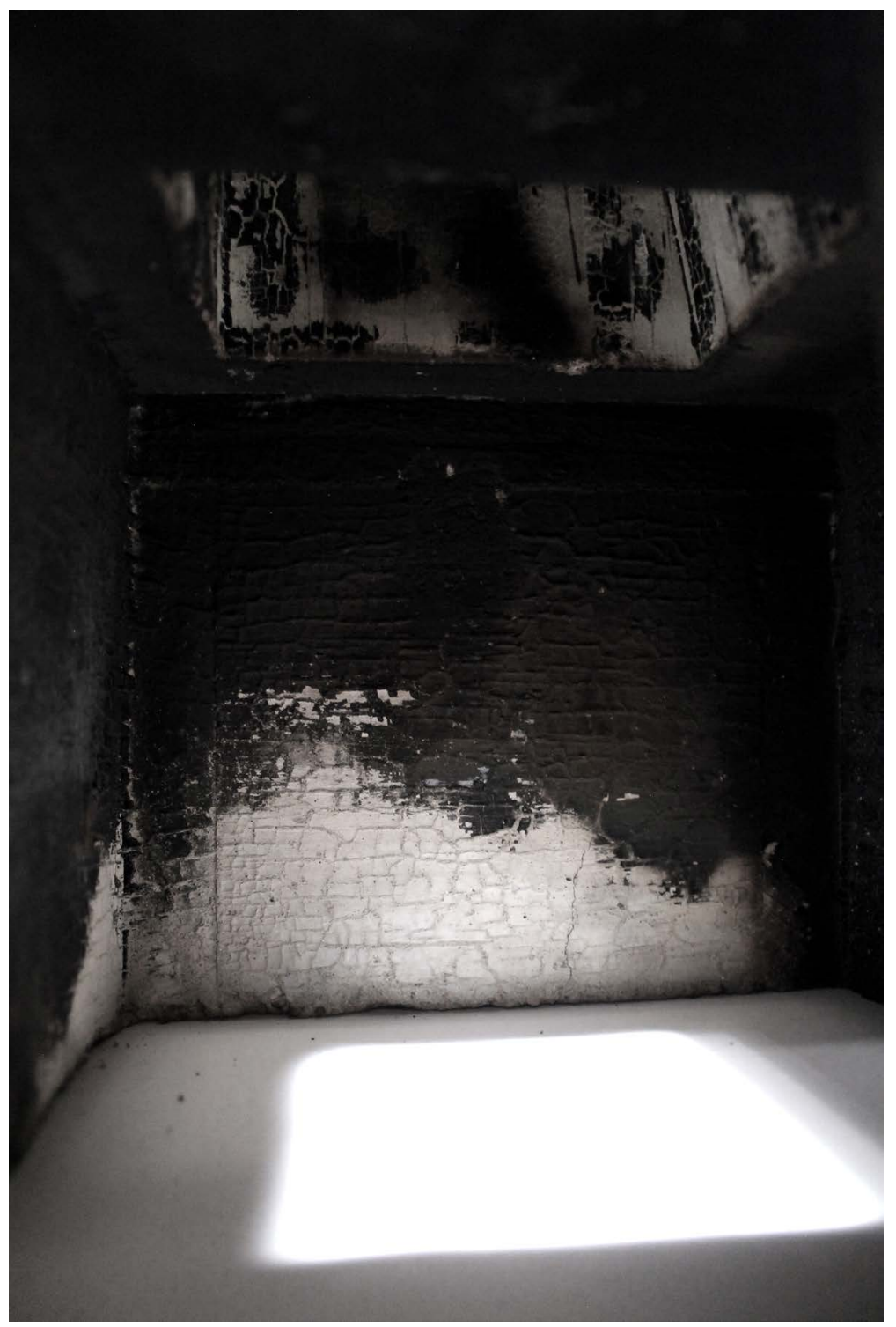

13 Charred Wood Tower - Interior 


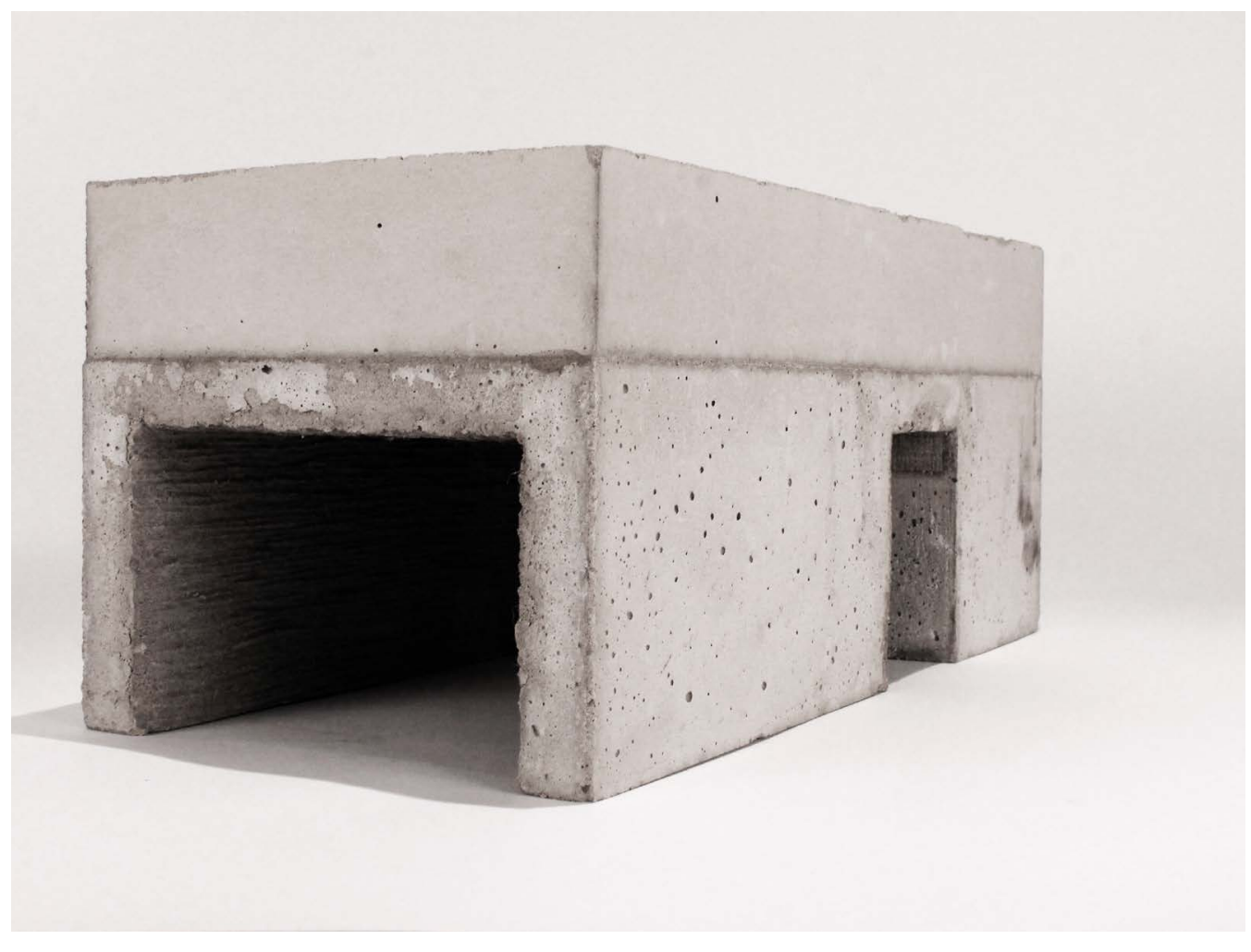




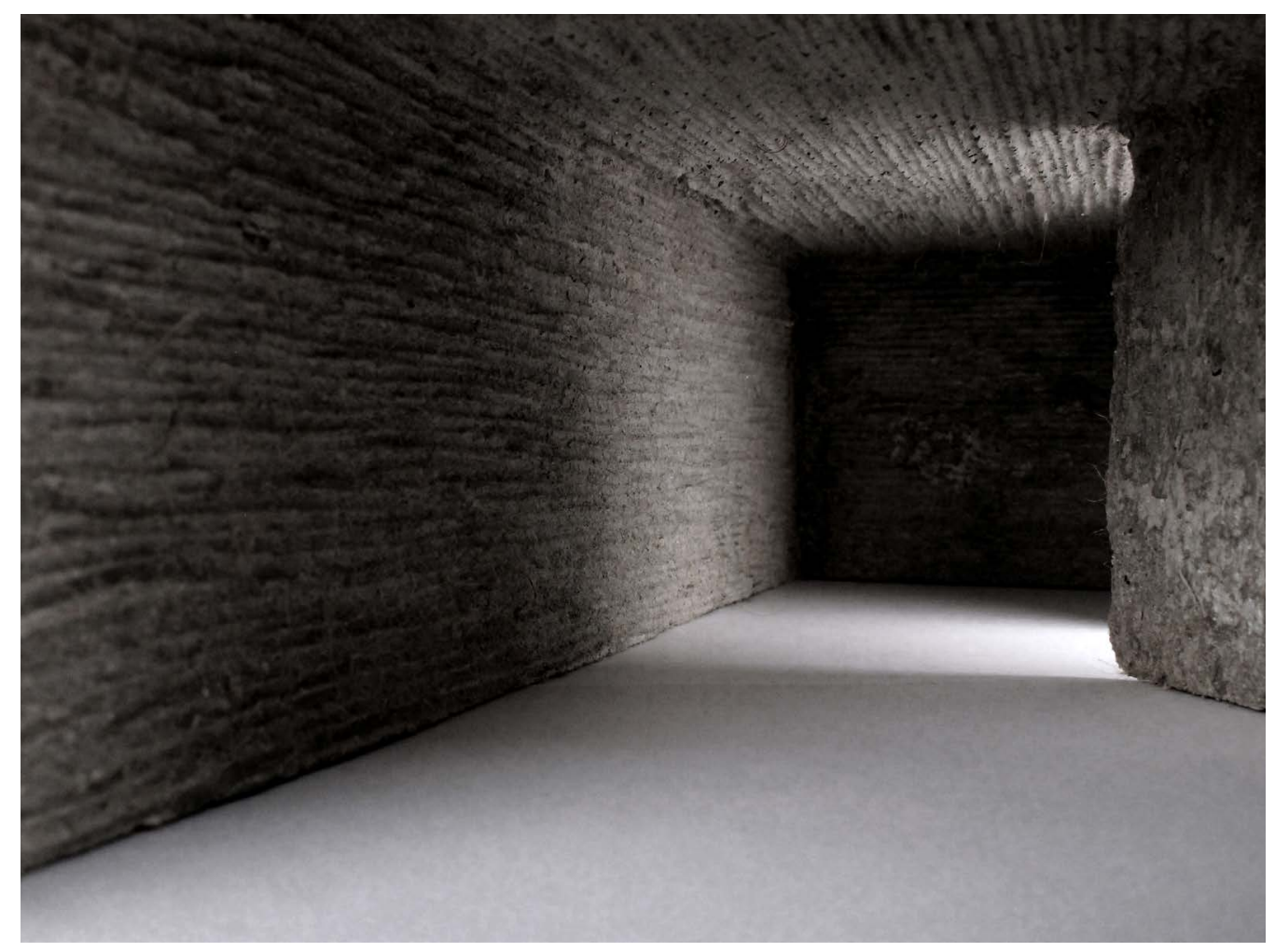




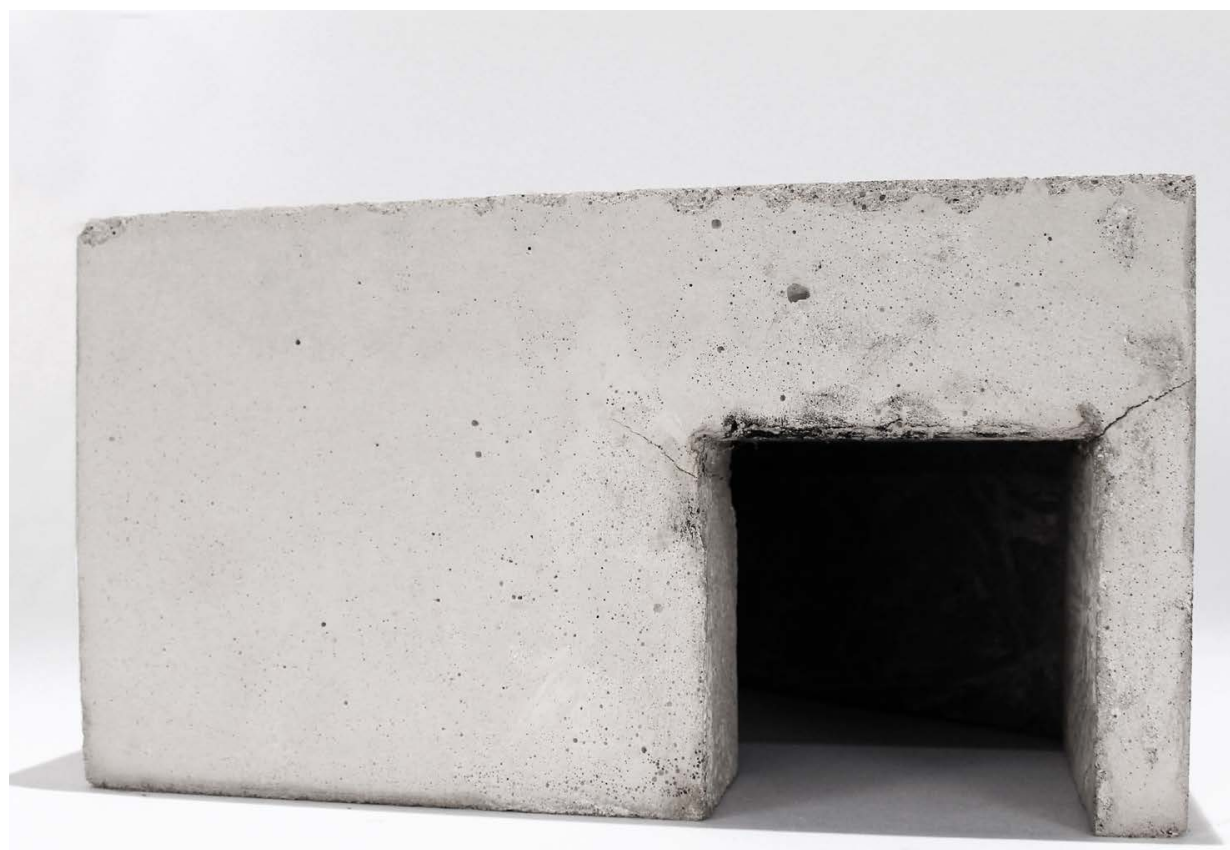




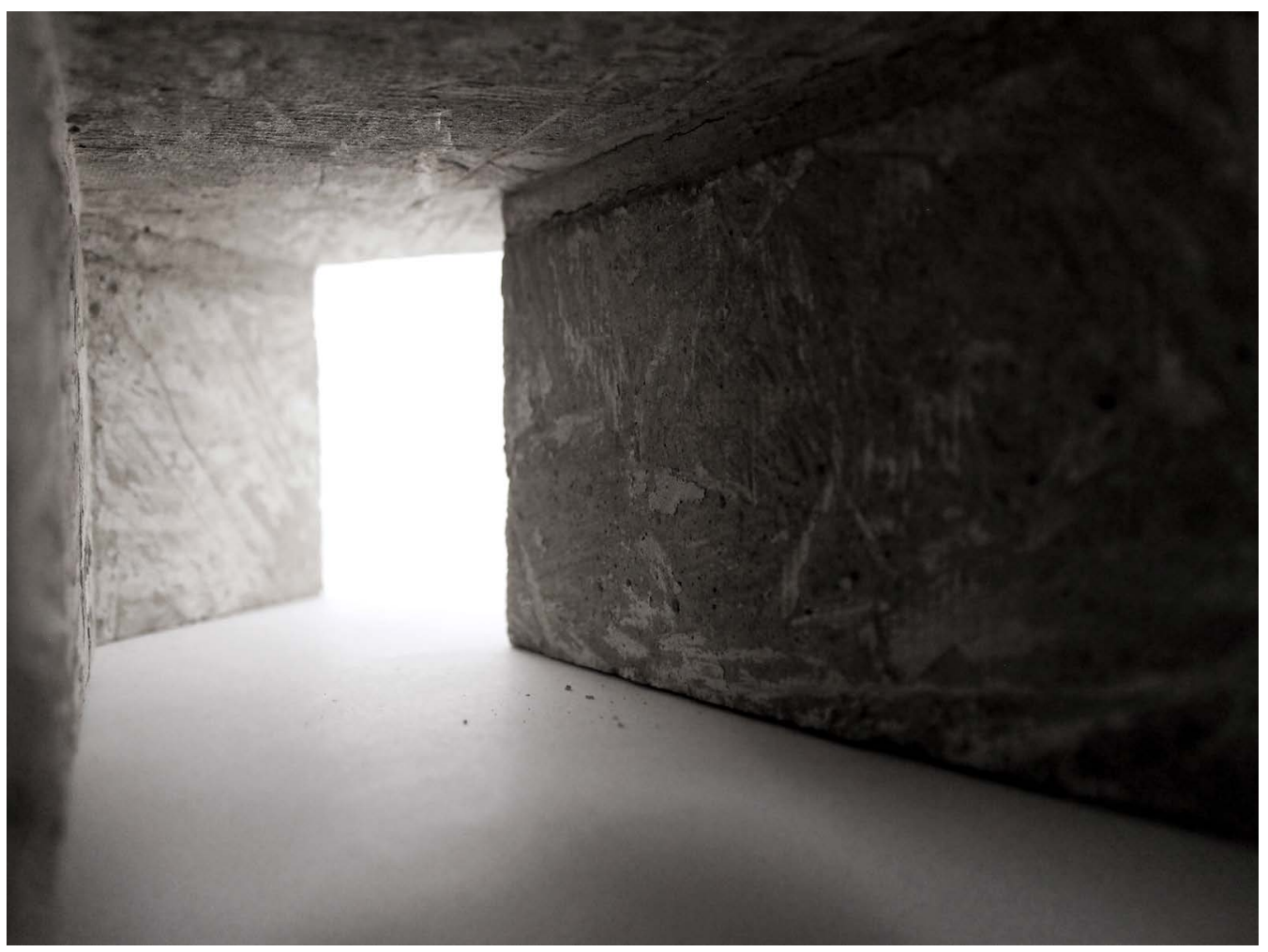


strategically, albeit artificially, fabricated, it is the position of this thesis that atmosphere is an inherent quality of any particular place. It proposes that a building's spatial atmosphere should be authentic, and therefore defined by its engagement with the contextual conditions which are often beyond the control of the architect. It is further suggested that architecture and specifically its interior atmosphere, become a manipulation of uncontrollable external parameters. Therefore the argument presented here is that architects need not manufacture a false atmosphere but rather give presence to the atmospheric variables that are an intrinsic component of the environment within which the built form exists.

\subsection{EFFECTS $\neq$ ATMOSPHERE}

Though the first section of this chapter traces the historical reduction of atmospheric considerations within contemporary practice to an "ideal," bland, stale ambiance, it would be remiss however to not mention that there has been a recent revival in interest regarding the subject of atmosphere in architecture. Unfortunately, this is no call for celebration as this interest is predicated strictly on superficiality. David Leatherbarrow sternly, yet appropriately, warns atmosphere is not merely the "orchestration of effects." 32 Regrettably, this is precisely how atmosphere is approached today. By suggesting that atmosphere can be produced, as the literature on this matter overwhelmingly does, a perversion of the term's definition has emerged that essentially equates atmosphere with "effect." It further subjugates atmosphere to a subordinate relationship with the object. It reduces atmosphere to a cursory effect, the result of a calculated manipulation of the object it is supposed to radiate from. 
Sean Lally succinctly articulates this point during his discussion on the role of the "surface" in architecture when he states:

"Under such a regime, luminosity from reflections or glows emitted from lit surfaces, temperature gradients emanating from facades, and scent and moisture traces rising from material weathering all rely on a surface... These auras may at times appear interactive (manifesting cause and effect) or immersive (surrounding the body like a cloud of water droplets or a dizzying light display), but they are predominantly theatrics. As theatrics, they maybe layered on top of one another as a means of demonstration, but they always link back to the surface and geometry...remove the surface and the effect is gone. 133

In the argument that Lally presents, the surface is the instigator of the effect. It is a cosmetic treatment that may be applied to any space, one that may just as easily be replaced by another; akin to the act of stage-setting. As proof of this assertion, one only needs to look to what is considered "atmospheric design" now. Since the profession at large, with the exception of a very selective minority of architects, have distanced themselves from the subject of atmosphere in architecture, the cause for atmosphere has been taken up by largely by contemporary artists; chief amongst them is Danish-Icelandic artist Olafur Eliasson.

Known for his sculptures and large scale installation art employing elemental materials such as light, water and air temperature, Eliasson's most successful exhibition is perhaps The Weather Project in which he experimented with atmospheric density, installed at the Tate Modern [Fig 18]. Eliasson used 


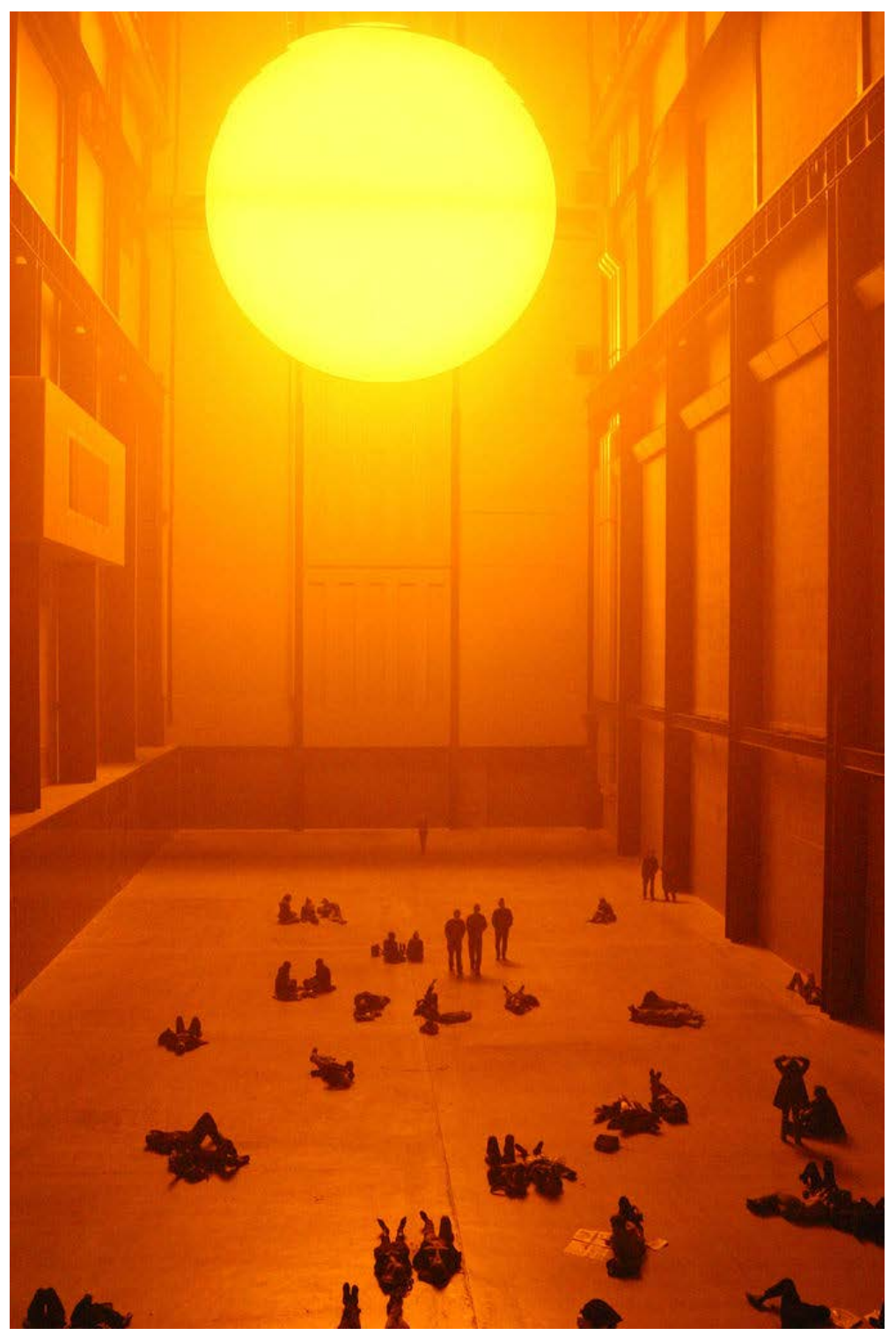


humidifiers to create a fine mist in the air via a mixture of sugar and water. as well as a circular disc made up of hundreds of monochromatic lamps which radiated yellow light. Consider the following excerpt which was taken from the museum's website that describes the project:

"A fine mist permeates the space. Throughout the day, the mist accumulates into faint, cloud-like formations, before dissipating across the space. A glance overhead, to see where the mist might escape, reveals that the ceiling of the Turbine Hall has disappeared, replaced by a reflection of the space below. At the far end of the hall is a giant semi-circular form made up of hundreds of mono-frequency lamps. The arc repeated in the mirror overhead produces a sphere of dazzling radiance linking the real space with the reflection. Generally used in street lighting, mono-frequency lamps emit light at such a narrow frequency that colours other than yellow and black are invisible, thus transforming the visual field around the sun into a vast duotone landscape. 134

This description is essentially outlining the critique levelled against this type of work. It is mislabelled as "atmospheric" when it is simply the orchestration of a series of effects.

This desire to engage in effect generation, disguised as "atmospheric," has begun to creep into the work of architects as well, buttressed today by digital media. A notable example of which is the HtwoOexpo Pavilion by NOX/Lars Spuybroek, hailed as an "interactive museum" that houses a permanent water exhibit [Fig 19]. This pavilion is meant to generate sensory stimuli that correspond to the movement and position of the "recipient" as 
they interact with the sensors and "interfaces" of the interior. The sensory stimuli of this permanent exhibition are based on water technologies like the freezing of a wall, the spraying of mist, artificial rainfall and jumping jets of water. This constant and artificial modification of the interior is supposedly meant to reveal something regarding the essence of water. Again, the firm's description itself provides the evidence of this project's miscategorization as atmosphere when it is just a series of generative effects:

"The building contains a wide range of sensors through which visitors can change the sound. light and projections that completely alter the atmosphere of the interior. 35

The implication of this criticism isn't that pursuit of such works must be abandoned. The deliberate intent of engaging such projects as devices to create artificial effects is not being challenged here. There arises an issue when they are camouflaged as a consideration of atmosphere in architecture. As a counter, this thesis proposes a far less pessimistic view of atmosphere in architecture. Atmosphere is productive, its variables are active agents that continue to define the character of place. By proposing that the atmosphere of a building should be defined by its engagement with contextual conditions, the atmosphere of the context is made explicit within the design of the built form, avoiding the simplistic cliché of inducing effects. 


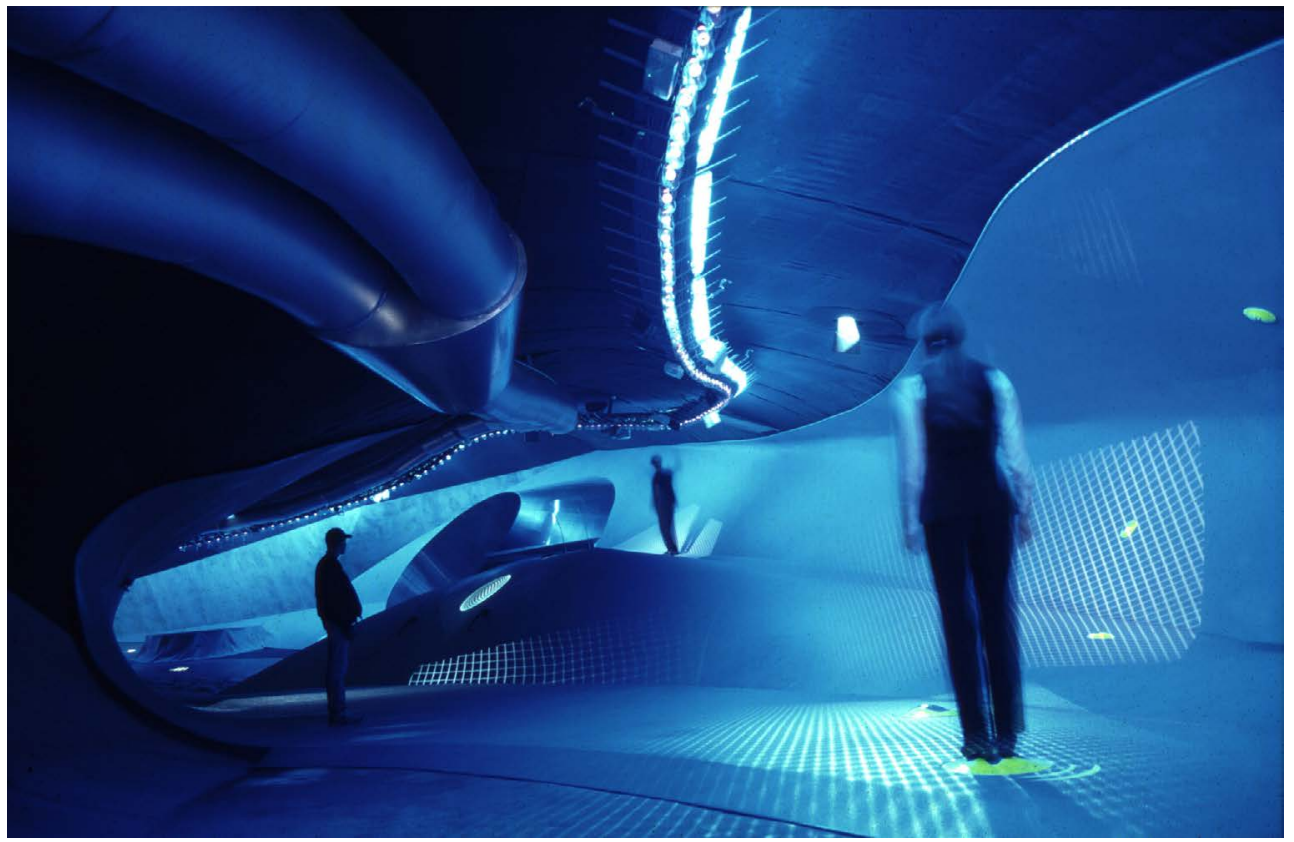

19 HtwoOexpo Interactive Museum, NOX/Lars Spuybroek 


\section{ENDNOTES}

1. Christian Borch, et al., Architectural Atmospheres: On the Experience and Politics of Architecture (Basel: Birkhauser, 2014), 80.

2. Mark Wigley, "The Architecture of Atmosphere," Daidalos, (1996): 18.

3. David Seamon and Jacob Sowers, "Places and Placelessness, Edward Relph." In Key Texts in Human Geography, by P Hubbard, R Kitchen, \& C Vallentine (London: Sage Publishers, 2008), 43.

4. Robert Adam. The Clobalisation of Modern Architecture: The Impact of Politics, Economics and Social Change on Architecture and Urban Design Since 1990 (Newcastle Upon Tyne: Cambridge Scholars Publishing, 2013), 83.

5. Ibid, 109.

6. Ibid, 124.

7. Kenneth Frampton, "The International Style: Theme and Variation 1925-65." In Modern Architecture: A Critical History, by Kenneth Frampton (New York: Oxford University Press, 1980), 224.

8. Ibid, 228.

9. Adam, The Clobalisation of Modern Architecture: The Impact of Politics, Economics and Social Change on Architecture and Urban Design Since 1990, 97.

10. Ibid, 87

11. Ibid, 179.

12. Michelle Addington, "Contingent Behaviours" Architectural Design: Energies (2009): 13.

13. Ibid, 16.

14. Mohsen Mostafavi and David Leatherbarrow. On Weathering: The Life of Buildings in Time (Cambridge: The MIT Press, 1997), 30. 
15. Ibid, 31

16. Martin Heidegger, "Building. Dwelling. Thinking." In Basic Writings, by Martin Heidegger (New York: Harper Collins, 1977), 3.

17. Juhani Pallasmaa, The Eyes of the Skin: Architecture and the Senses (Chichester: Wiley, 2005), 33.

18. Fabio Gramazio, et al., "Reality Matters." In The Robotic Touch: How Robots Change Architecture, by Fabio Gramazio, Matthias Kohler, \& Jan Willmann (Zurich: Park Books, 2014), 382

19. Pallasmaa. The Eyes of the Skin: Architecture and the Senses, 32.

20. Peter Zumthor, Atmospheres: Architectural Environments and Surrounding Objects (Basel: Birkhauser, 2006), 5.

21. Michael Bockemühl, J.M.W. Turner, 1775-7857: The World of Light and Colour. Translated by Michael Claridge (Cologne: Taschen, 1991), 61.

22. Ibid, 18 .

23. George Shackelford, Monet and the Impressionists (Sydney: Art Gallery of New South Wales, 2008), 55.

24. Ibid, 125

25. Zumthor, Atmospheres: Architectural Environments and Surrounding Objects, 17.

26. Wigley. "The Architecture of Atmosphere," 18.

27. Klaske Havik and Gus Tielens, "Atmosphere, Compassion and Embodied Experience: A Conversation about Atmosphere with Juhani Pallasmaa," OASE (2013): 33.

28. Ibid, 37. 
29. Juhani Pallasmaa, "Hapticity and Time: Notes on Fragile Architecture," The Architectural Review (2000): 83.

30. (Böhme, Atmosphere as the Subject Matter of Architecture 2005), 27.

31. Ibid, 29.

32. Alberto Pérez-Gómez, Attunement: Architectural Meaning after the Crisis of Modern Science (Cambridge: MIT Press, 2016), 23.

33. Sean Lally. The Air from Other Planets: A Brief History of Architecture to Come (Zurich: Lars Müller Publishers, 2014), 100.

34. "Olafur Eliasson the Weather Project: about the installation." Tate. Accessed March 07, 2017. http://www.tate.org.uk/whats-on/exhibition/unilever-series-olafureliasson-weather-project/olafur-eliasson-weather-project.

35. "H2O Expo Pavilion." NOX Art Architecture. Accessed February 13, 2017. http:// www.nox-art-architecture.com/projects/Netherlands/Nrouwenpolder/H2O\%20

Expo\%20Water\%20Pavilion/ 


\section{0}

\section{ATMOSPHERE EXPANDED}

This thesis defines atmosphere as "the particular character of a place." However, the term place itself begs further clarification. The definition of place that this thesis subscribes to is that of Christian Norberg- Schulz who defines place as "a concrete term for environment...a total phenomenon made up of concrete things having material substance, shape, texture and colour." The implication of this definition is that place as a concept, is a bearer of certain properties. Within the context of this thesis, space and atmosphere - the most comprehensive property of any place have been identified as the two properties.

\subsection{PLACE, SPACE, ATMOSPHERE}

Although the concept of place is an ubiquitous topic today, it is certainly not new. As Norberg-Schulz argues, ancient "man saw it as being very important to deal with the genius of the locality where his life takes place."2 Places may be described as natural or man-made and are designated by nouns: Boreal Forest, Baffin Island, Yonge-Dundas Square, Gerrard Street. Certain places imply certain meanings. A valley for example implies direction and depth where as a plane manifests unbound extension. Additionally, places can classified through a series of levels. Nouns 
like Canada, Ontario, Toronto, 325 Church Street, studio form a series of gradually diminishing environmental scales, each carrying with it a certain set of meanings that are associated with those places. At the "top" of the series exist the comprehensive natural places that contain the more manmade places on the "lower" end of the series.

This concept of scale was explored in such a manner by the 1977 Charles and Ray Eames film titled The Powers of Ten [Fig 20]. The film begins with a $1 \mathrm{~m}^{2}$ shot of a couple enjoying a picnic in a Chicago park. This is the first level called $10^{\circ}$. Over the next ten seconds, the camera zooms out to frame an area of $10 \mathrm{~m}^{2}$ called the $10^{1}$ level, followed by the $100 \mathrm{~m}^{2}\left(10^{2}\right.$ level) ten seconds later that frames the park and so on. The entire globe appears in the frame at the $10^{7}$ level. The crisis, as outlined in the first chapter, is that attention is paid to issues much more on the $10^{7}$ level, given the global framework which is the backdrop for all operations today. Architecture, Bjarne Mastenbroek argues, operates on roughly the $10^{3} / 10^{2}$ levels. Due to the increasing intensification of global relations, people are pre-occupied with issues on the $10^{7}$ level in such manner that they often neglect the impact of their immediate environment on their daily experiences.

This thesis argues that a crucial task of architecture is to transform a given 

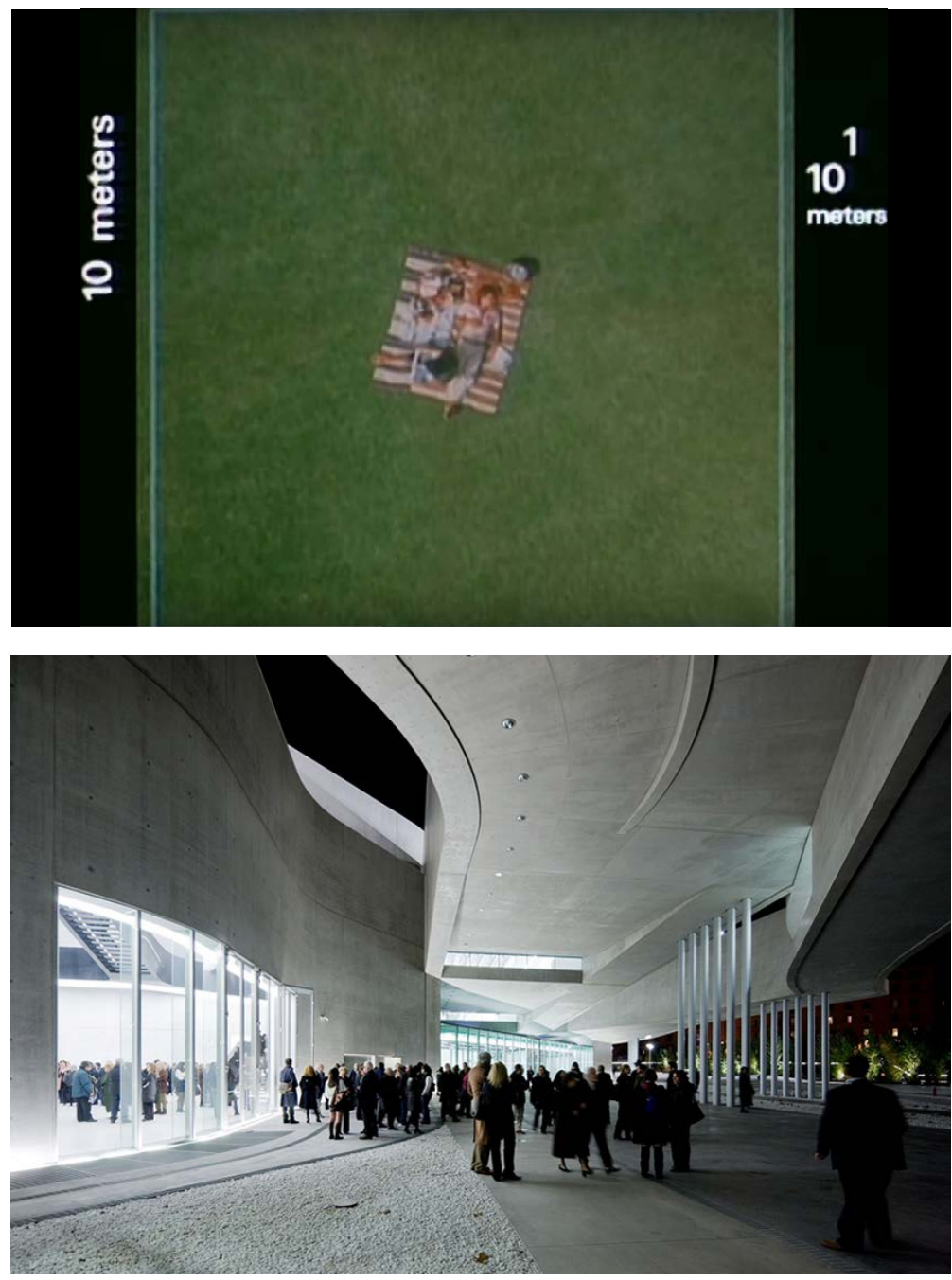

20 Still from The Powers of Ten depicting the $10^{1}$ scale

21 MAXXI, Rome 2009 - Soft Opening. Main Entrance 
site into a place, bringing into presence the meanings potentially present in the given environment. This is a position also shared by Patrik Schumacher of Zaha Hadid Architects. In an interview with Karen Forbes, published in her book Site Specific, Schumacher provides some insight into the design of the MAXXI Museum [Fig 21]. He states:

"It [MAXXI] can't be comprehended as an object because it is not a hermetically sealed volume: The boundaries are ambiguous, dynamic relationship between interior and exterior. We are not so much designers of ideal objects or figures, we like the experiential theatre of engaging in the space and spatial sequences and so on. That's the difference between what we're doing today and with Modernism. which was willing to think in the ideal types or in prototypes or optimised solutions. Modernism didn't have the means we have now of responding to site conditions. Our ambition is always to craft a unique solution. which establishes connections with the surroundings and affiliations." 3

Perhaps the most general attribute of architecture is the way in which it synthesizes the forces present in a particular place through the built form. It synthesizes them with a concrete presence. The particular way in which a location gathers its surroundings - the circumstantial condition of locality and building task - gives it identity, its "placeness."

At this moment it is important to introduce a discussion on "space;" since it is through an analysis of the property of space that one can determine how architects in fact make places [Fig. 22]. Space is defined, by this thesis, as the three dimensional extension of a place. Aristotle spoke of space as 


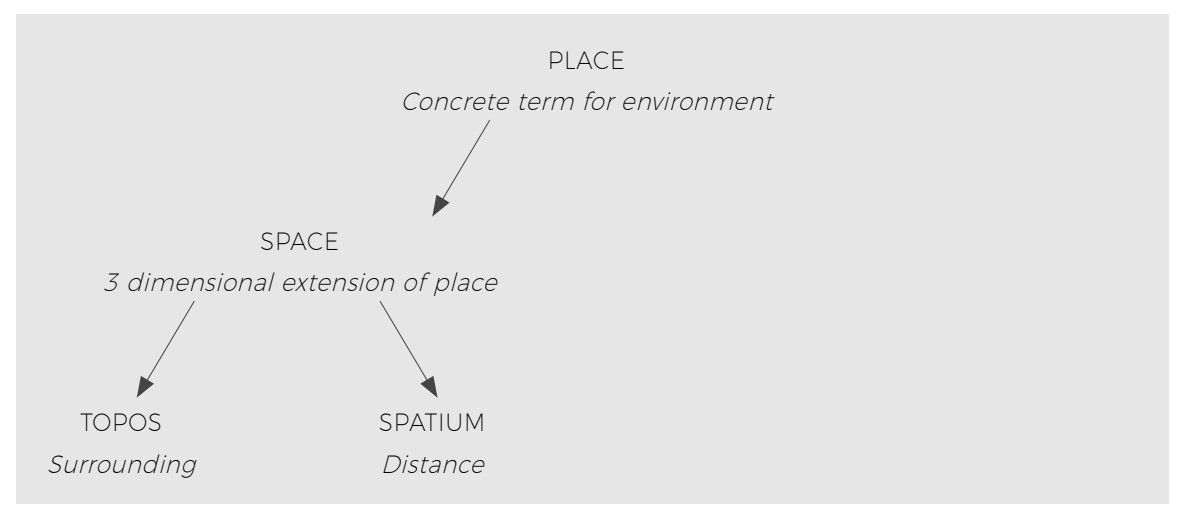

topos, meaning the space of surrounding, and spatium, meaning the space of distance. Space, in respect to topos, refers to the way in which a place is organized-central, linear, clustered etc. Of chief concern to architects is topos, it is space as perceptual field resulting in "concrete space."

The distinctive quality of any man-made place, the realm of the architect, is enclosure. It can be argued that the very character and spatial properties of a place are determined by the degree of enclosure. The term enclosure implies both boundary and threshold. The boundaries of man-made places include architectural elements like the floor, the wall and the ceiling. The boundaries of natural places are also similar in structure, consisting of the ground, horizon and sky. Architects make places through the establishment of boundaries that capture a certain amount of space. How a particular boundary encloses space depends on its formal articulation, the way in which it is built. This process occurs within the space of the place that is the site. A return to the discussion of scales may prove beneficial to further articulate this concept. Consider for a moment the period before 
the building occupied by the Department of Architectural Science of Ryerson University at the south-east corner of Church Street and Gerrard Street existed. Preceding the construction of the building, there existed an open site - a place - with a particular character. When the property lines were determined, the boundaries of the site were established and space within these confines was enclosed that extended vertically. One could argue that the permissible building height of zoning bylaws determines the vertical boundary of the site/place, further enclosing its space. This scenario describes the act of making places by capturing space on a relatively macro scale. With the commissioning of Ron Thom for the design of the building began the same process on a more micro scale. As Thom drew the exterior walls in plan, he established the boundaries that enclosed space to make the "architecture building," a place. On an even more specific scale, as he began drawing the interior walls, he began further enclosing space to create places like the studios, offices, the resource centre, etc.

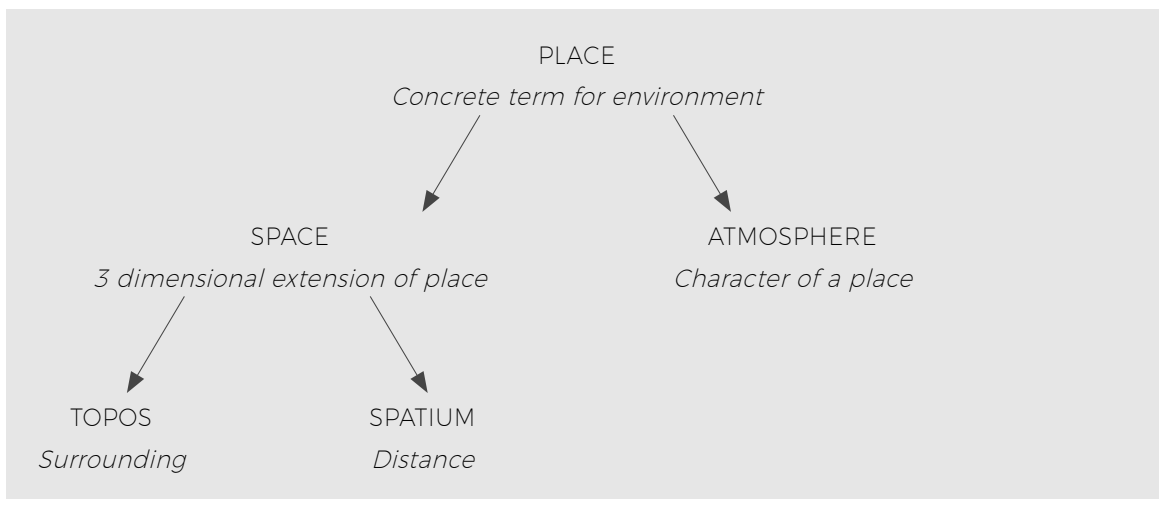

23

22 Place - Space

23 Place-Space-Atmosphere 
People exist within space and are exposed to a particular atmosphere, the second property of place [Fig. 23]. Though space is an abstract concept, the concept of atmosphere more significantly contributes to the identity of a place; as it is the atmospheric peculiarities of a place that generate a unique identity. Every place can be said to have a particular atmosphere before the existence of a building within that place. But architecture has the innate ability to either diminish or enhance this aura of a place and the experience of being in it. When people speak of certain cities having a particular atmosphere, they often reminisce of European or Asian cities that were established and flourished before the Enlightenment period. Cities like Prague, Rome, St. Petersburg, Istanbul, Varanasi are often mentioned. The reason these cities are the ones often mentioned is because the buildings - man-made places - within them gather and condense the attendant atmosphere which is saturated with locally rooted meaning. People are drawn to these places because of the traditional architecture that is locally distinct. Historic buildings, neighbourhoods and communities that are shaped by site, history, native culture and locally available materials and construction technology are cherished. In speaking specifically of Prague, Norberg-Schulz argues that the buildings of the city are grounded on Earth and reach towards the sky in a manner that gives presence to the particular atmosphere of Prague. By contrast, post-Enlightenment cities, notably North American cities, lack a local, individual identity because the buildings they are comprised of buildings that completely ignore the locally present atmosphere. Considering the principles of rationalism, scientific innovation and progress were thought of universal ideals and were the only determining criteria in the establishment of these cities, any opportunity to articulate local character were disregarded. One could in fact argue that 
the only individual character these cities possess are their prosaic zoning by-laws.

The atmosphere of a place is both a function of time and something more concrete. This presents two categories that exist within the concept of atmosphere. These two categories have been defined as the character of the sky, which speaks to the temporal aspects of atmosphere, and the character of the earth, which are the more physically tangible aspects of atmosphere. In addition to these two categories, five phenomena of atmosphere have been determined that can be listed within these two categories. The concept/property of atmosphere is the totality of these five phenomena that contribute to the character of a place. The five phenomena are seasonal changes, lighting conditions and wind patterns which comprise the character of the sky while the phenomena of topography and material composition can be listed under the character of the earth [Fig. 24].

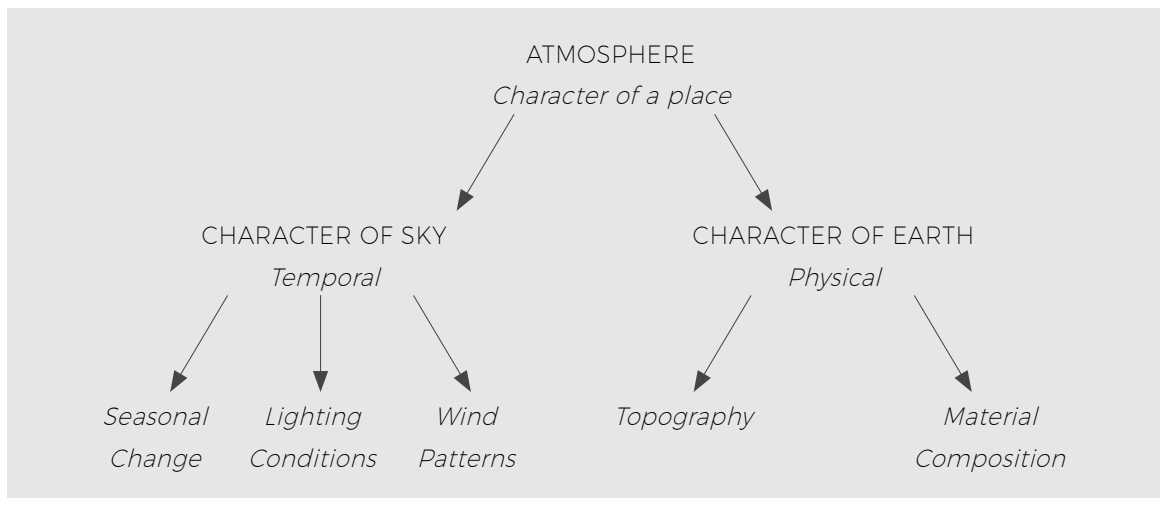

24

24 Atmosphere Expanded 
It is important to note that it is not being suggested that these phenomena are particular to one specific place; the five atmospheric phenomena outlined are an inherent part of every place but the manner in which they operate and exist, varies based on the context. Consider for a moment how the phenomena of material composition may vary between a heavily urbanized setting and a more rural, landscape setting. While the material composition of the place depicted in Figure 25 is comprised of the brick of the surrounding buildings, the asphalt of the road, the vegetation and even the cars gathered at the intersection. Figure 26 depicts a part of Fogo Island that is comprised of only the rocky terrain and the water of the Atlantic Ocean at the edge. The atmosphere presented in the top image is quite drastically different than the one on the bottom.

Therefore, if it posits that by establishing boundaries architects enclose space, in theory it could also be argued that they may enclose the atmosphere of that particular place. This statement however presents an idealized situation that is highly unreflective of current practice. Given not just the bias towards the property of space but also the utter negligence of atmosphere, while architects still engage in the creation of places through the establishment of boundaries that enclose a space, the places that are made have a rather neutral atmosphere that results in a highly banal experience of place.

Through the creation of places that give expression to the peculiarities of a place, architecture can begin to challenge the neutrality of experience today. How these five phenomena are concretized is contingent on how these boundaries are made. To further this line of design-research, five enclosures were designed in the Kerr Hall Quad of Ryerson University as 

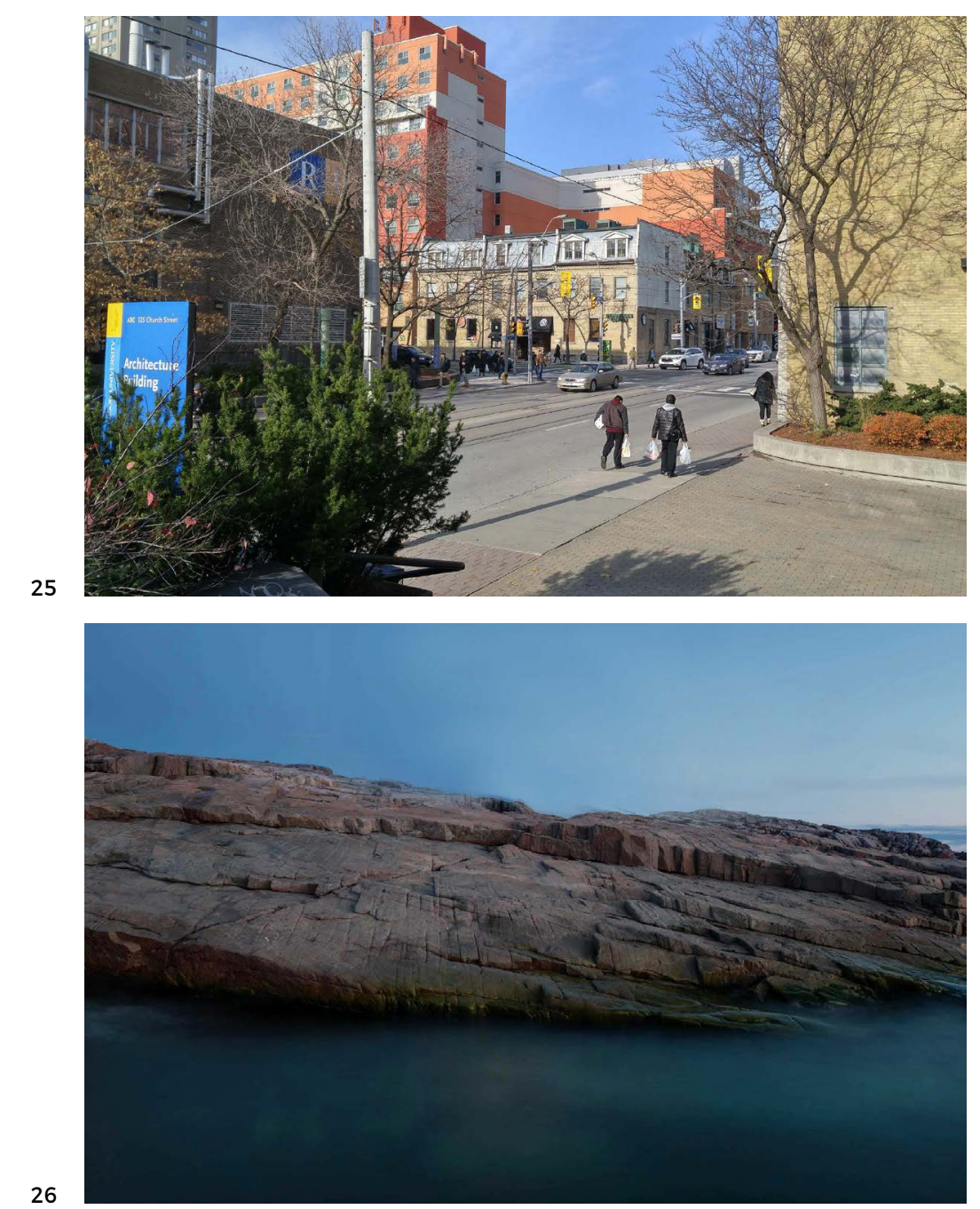

25 Intersection of Church Street and Gerrard Street East 26 Shore of Fogo Island, Newfoundland and Labrador 
a vehicle to explore each of the five phenomena. The goal of this form of design-research is to express phenomena; to frame something that is taking place, to display it and to allow it in some way to become a part of the architecture. The site and the dimensions of the enclosures, 4 metres $\times 4$ metres, were treated as the constants, while each individual phenomena was the variable that dictated how its respective enclosure may be designed to best articulate the phenomena.

\subsection{SEASONAL CHANGE}

There is a fundamental flaw with the architectural mode of thought that conceptualizes buildings as pristine objects of permanence. Buildings do not exist in their original state for the entirety of their lives. Over the course of time, they are subject to the cyclical phenomena of seasonal change, specific to their context, which acts upon the exterior surfaces of the building. The concept of weathering was engaged as a device to articulate this phenomena. Mohsen Mostafavi and David Leatherbarrow describe weathering as "the power of subtraction" that gradually erodes qualities of a surface over the course of seasons. However, weathering can also add by enhancing experience. Weathering adds the "finish" of the environment as it steadily subtracts that of the construction.

Weathering steel was selected for its unique aging qualities as part of the design. The steel walls will mark, in a visible and tangible manner, the passage of time. This notable transformation in both material colour and texture will alter the user's experience of the enclosure as it ages, becoming a permanent yet experientially ephemeral part of the landscape. The process of weathering presents the enclosure in a condition of reality through its 


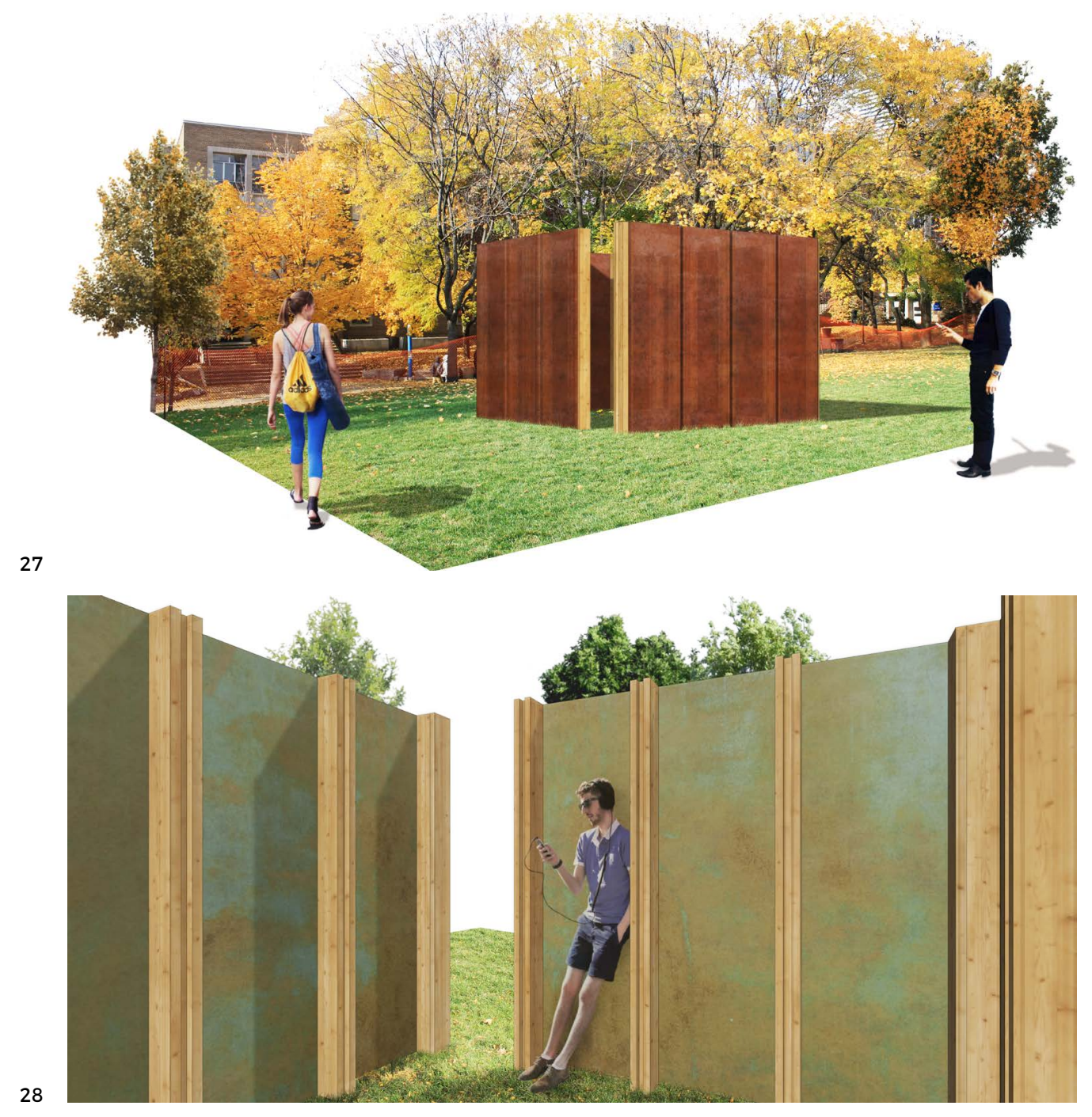

27 Seasonal Change Enclosure - Render 1 28 Seasonal Change Enclosure - Render 2 
transformation over time.

Additionally, timber frames are used to anchor the weathering steel. Timber, another material that weathers when exposed to the elements, does so in a much more reserved manner than the weathering steel. The connection detail was designed in a way to give presence to a third type of weathering at the interface of the two materials as an exploration of how the rust of the weathering steel, coupled with seasonal change may alter the appearance of the timber.

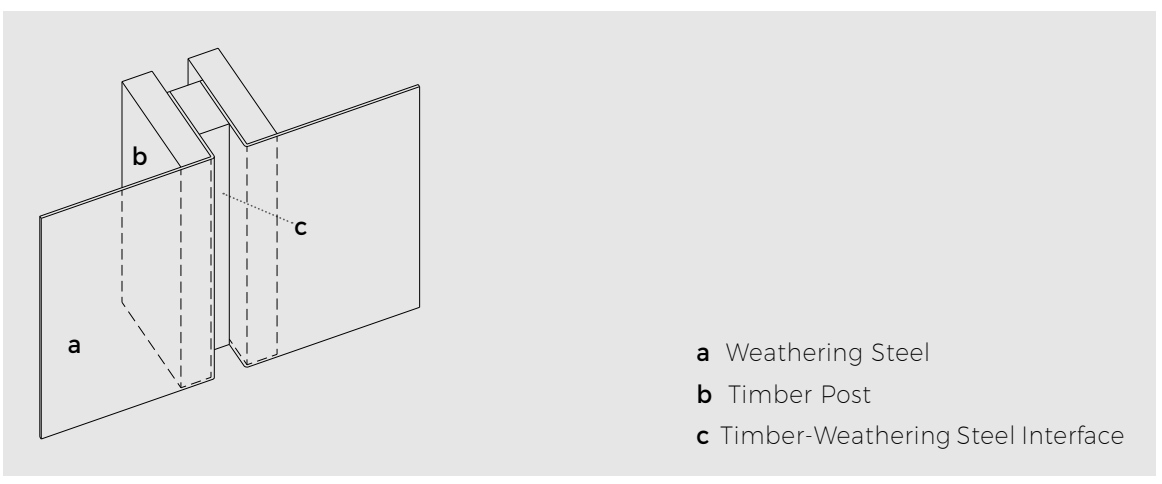

\subsection{LIGHTING CONDITIONS}

Architects work with physically tangible matter, referred to as materials, in the design of their buildings. Architecture also employs a more ephemeral material which is fundamental in the creation of place - light. Unlike the architect's tangible material palette, natural light is not subject to the force of gravity, it is never the same, it is free and unlike the weathering steel, it never ages. 


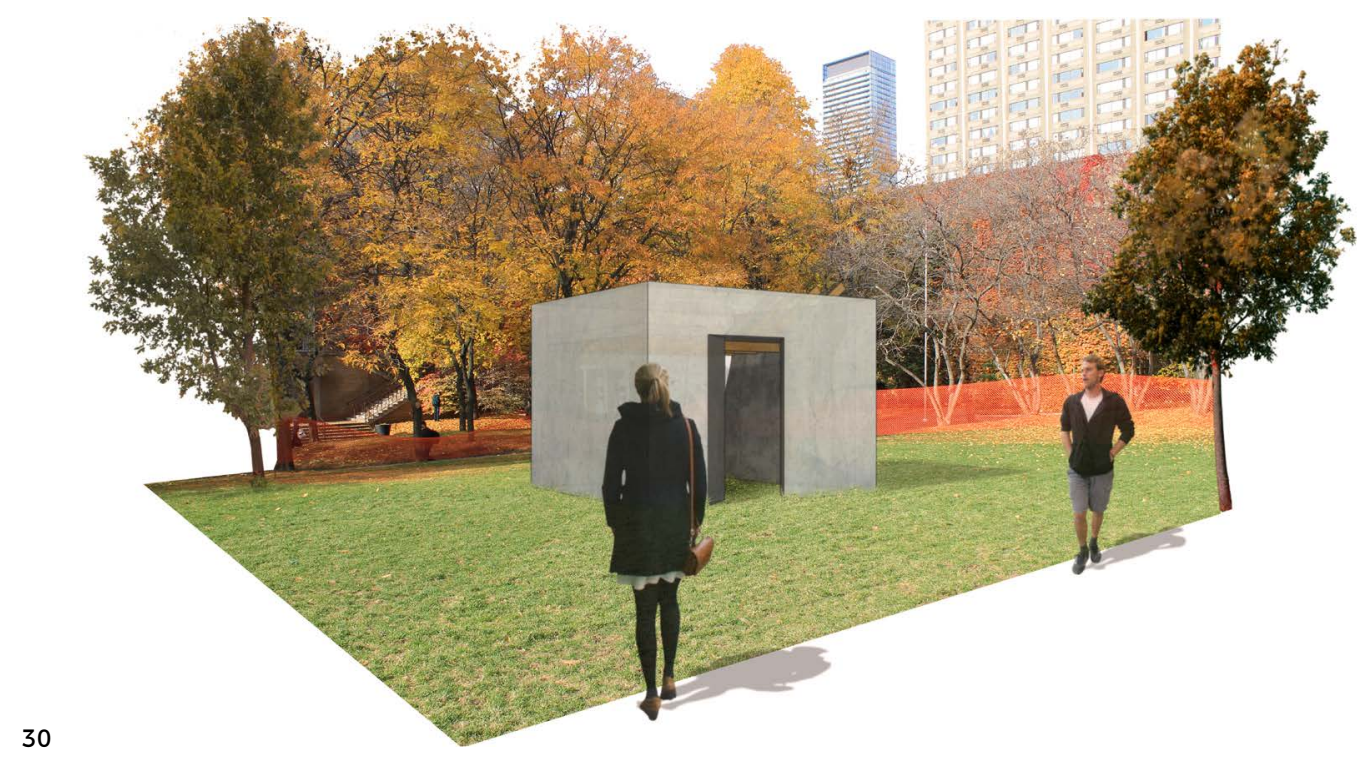

30

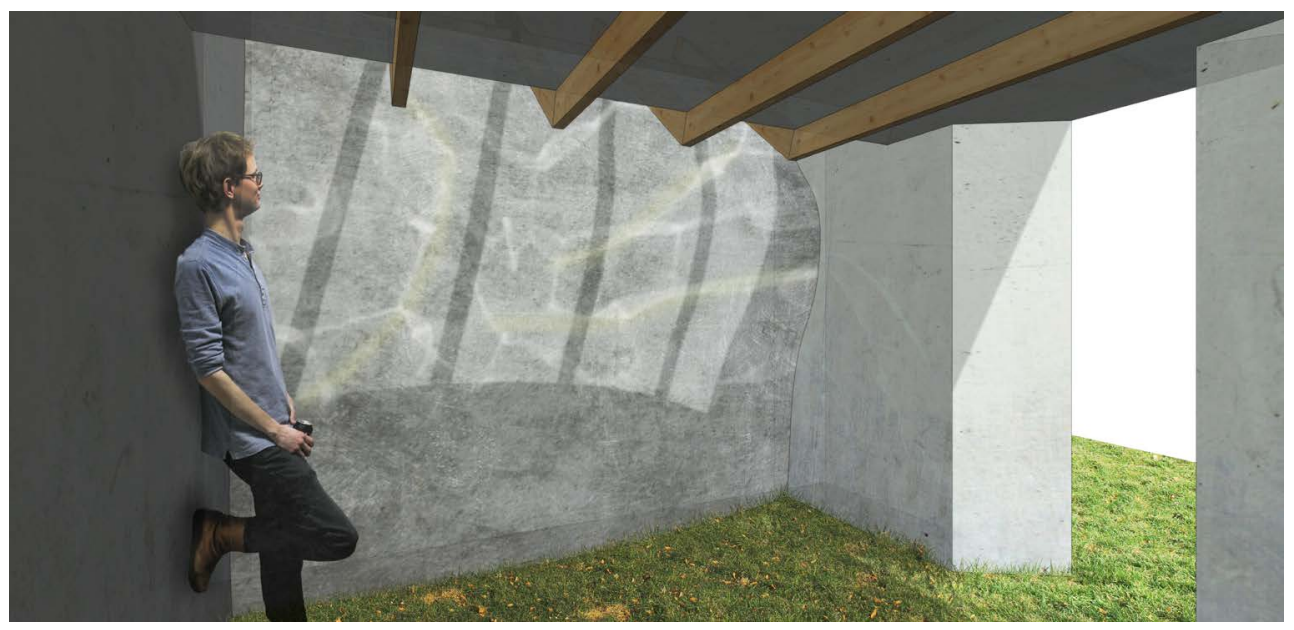

31

29 Locations of Various Weathering Conditions 30 Lighting Conditions Enclosure - Render 1 31 Lighting Conditions Enclosure - Render 2 


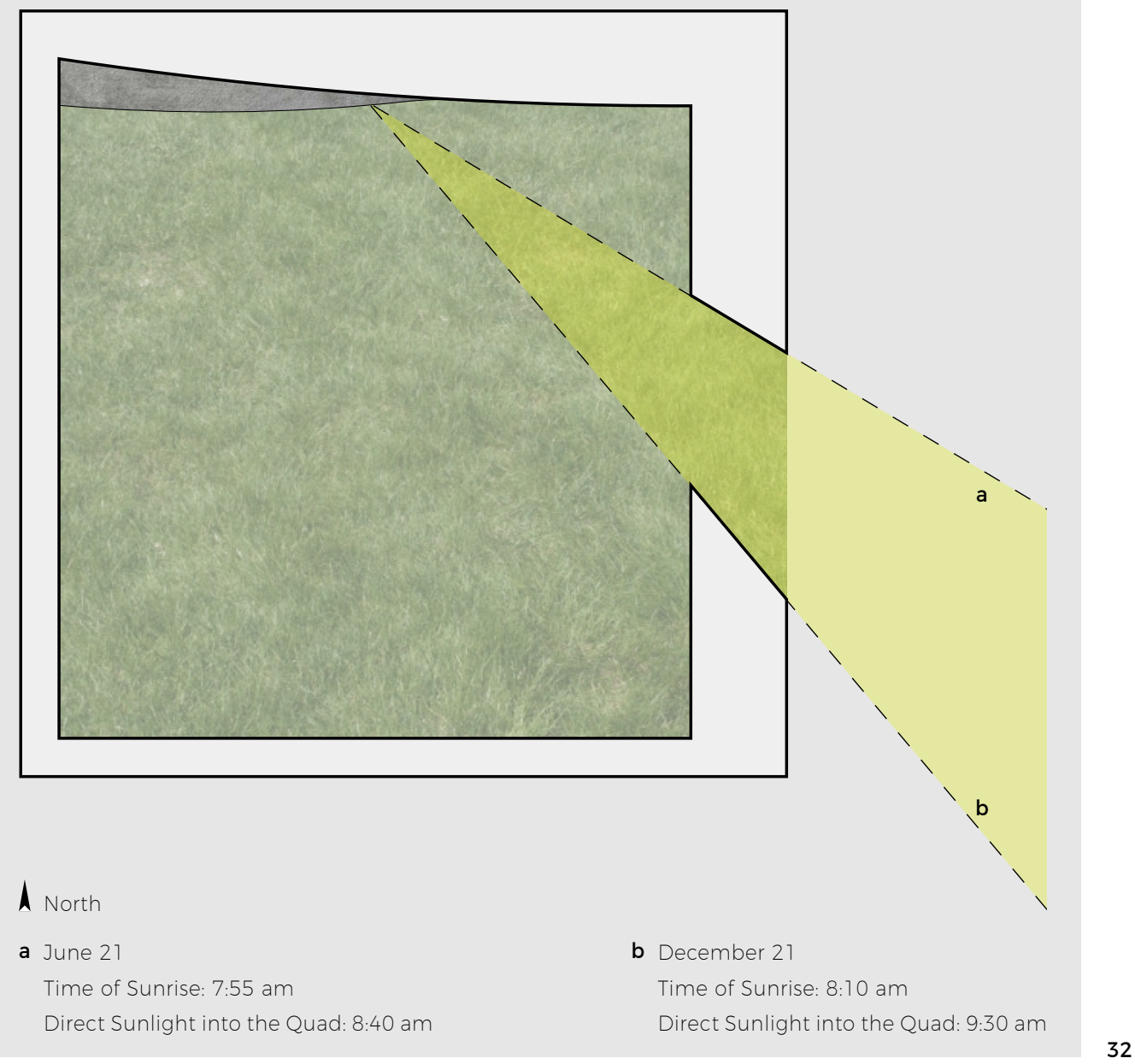

32 Lighting Enclosure Plan

33 Lighting Enclosure Section 


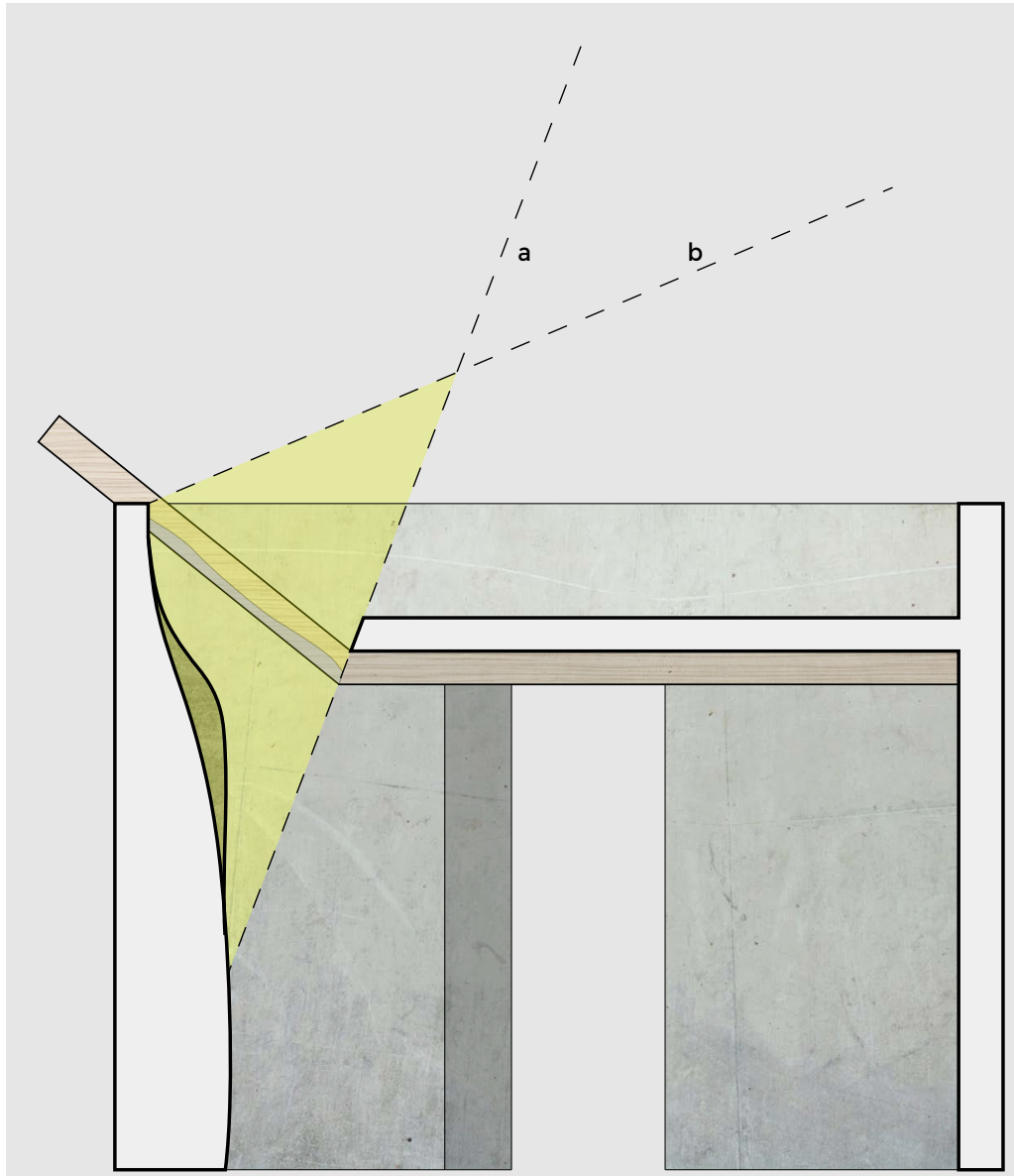

a June 21

b December 21

Sun Angle: $66^{\circ}$

Sun Angle: $22^{\circ}$ 
Natural light is a function of time. The temporality of light is experienced not only on a daily basis but also over the course of a year with the fluctuation of the seasons. Furthermore, this temporal aspect of light is a function of place. With its annual orbit around the sun, the Earth tilts on its axis. This tilt has a profound impact on the quality of light in the high Arctic regions of Canada, Russia and the Nordic countries. In the summer months, the sun never sets while in the winter months, it never rises above the horizon. Adaptability of the built form to these drastic conditions is crucial for the well-being of the local population. This presents a very different condition from regions closer to the equator like the Middle East where the sun is more or less perpendicular to the Earth's surface.

The design of this enclosure required an understanding of the nature of the sun's movement on two levels. Firstly, the movement of the sun over the city of Toronto had to be determined. On a more specific scale, the operation of natural light within the confines of Kerr Hall Quad also had to be established. Times of sun rise was used to demarcate the entrance of the enclosure while its position at midday determined the opening of the skylight. The angles of the sun at particular times were obtained through computer simulation programs.

\subsection{WIND PATTERNS}

Of the five phenomena outlined, wind is perhaps the one that is least considered. Since it cannot be controlled, it is regarded as a nuisance that must never be permitted to penetrate the envelope of a building. This wasn't always the case however. Throughout history, human lives and the built environment have been shaped by both the sun and the forces of wind. 

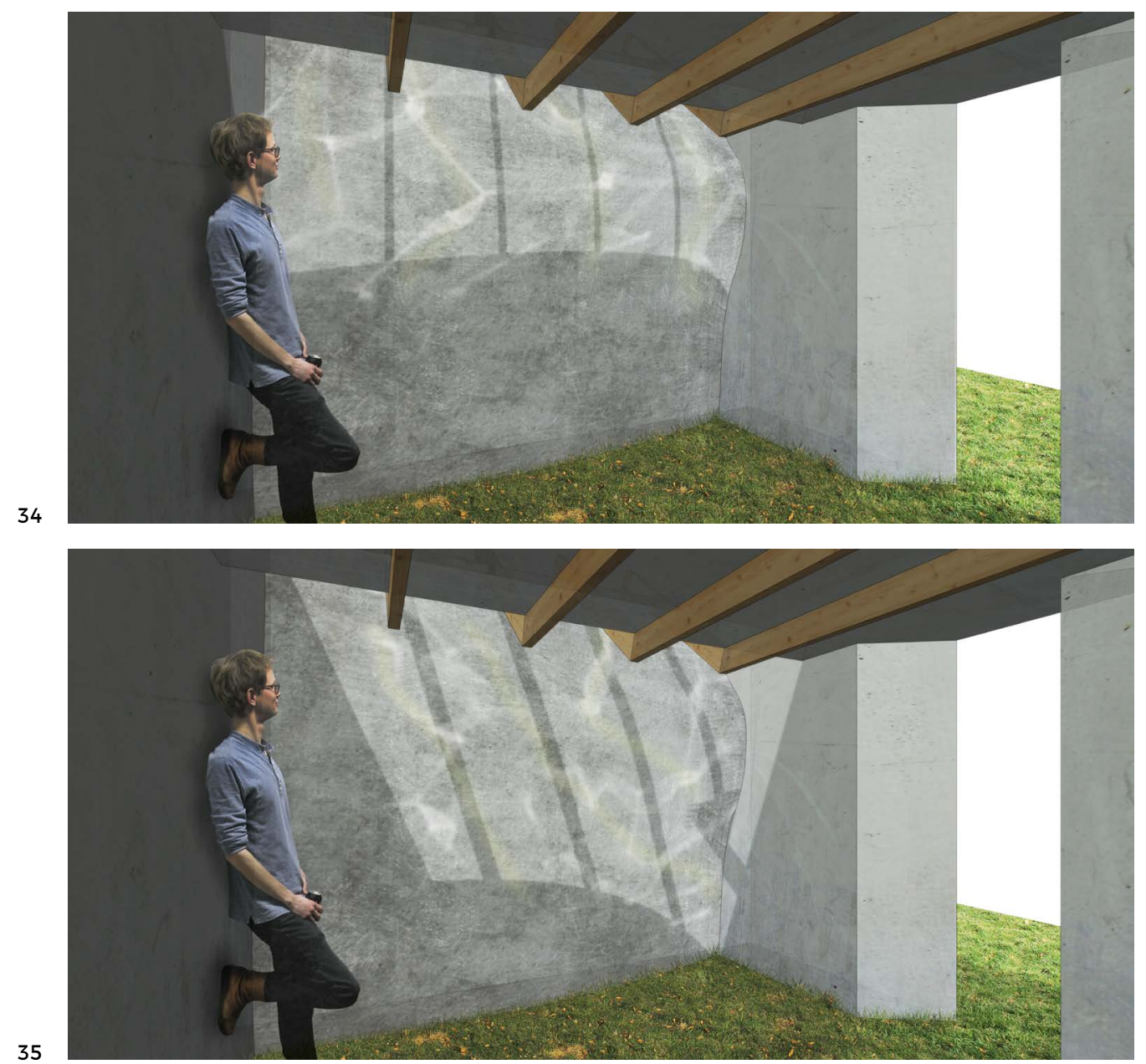

34 Lighting Conditions Enclosure - Render 3

35 Lighting Conditions Enclosure - Render 4 

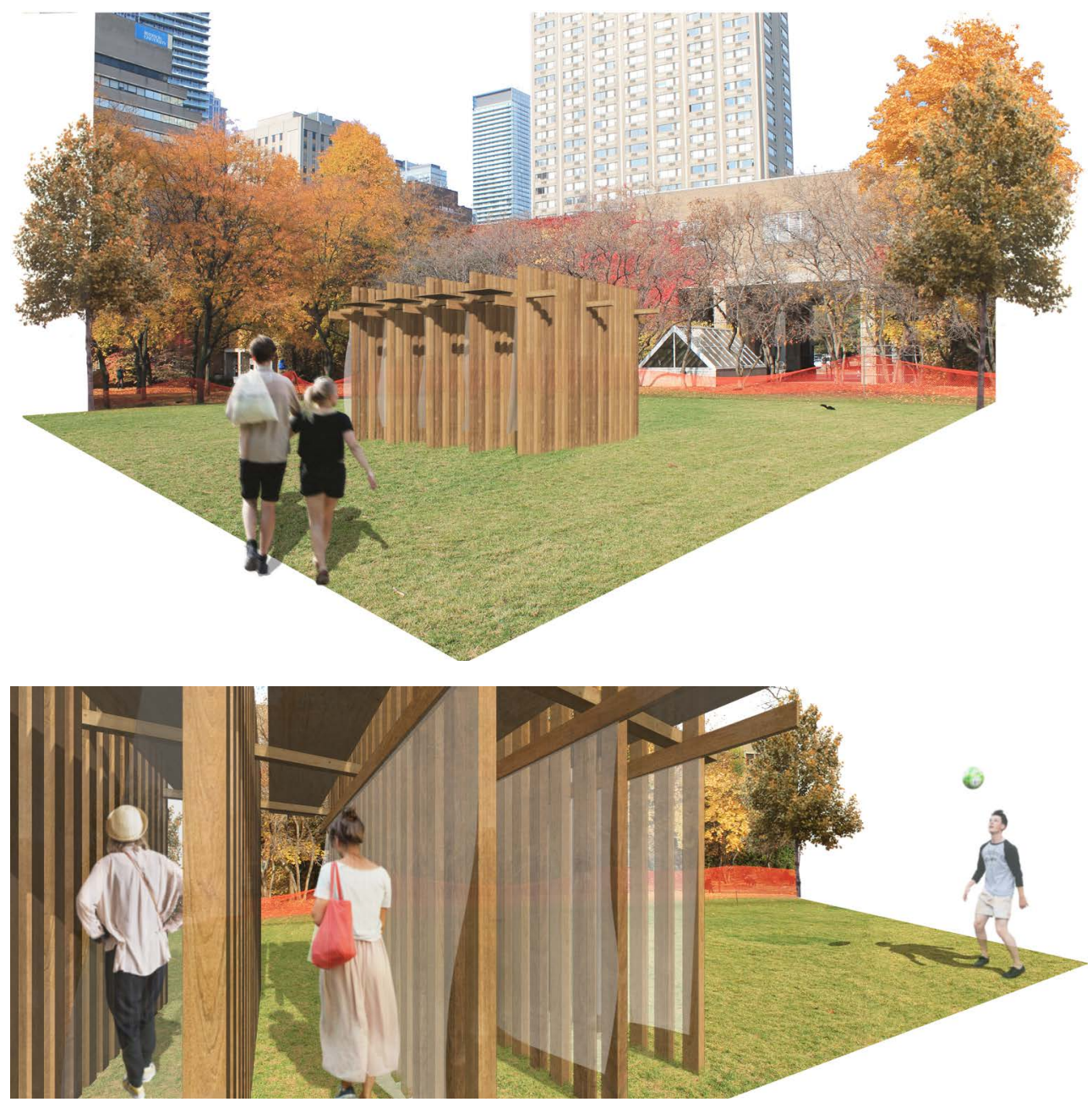

36 Wind Patterns Enclosure - Render 1

37 Wind Patterns Enclosure - Render 2

38 Toronto Wind Conditions 
Wind Direction:

East North East

Months:

March

April

May

June

September

October

November

Wind Direction:

West South West

South South West

Months:

January

July

August

December

Wind Direction:

North West

Months:

February
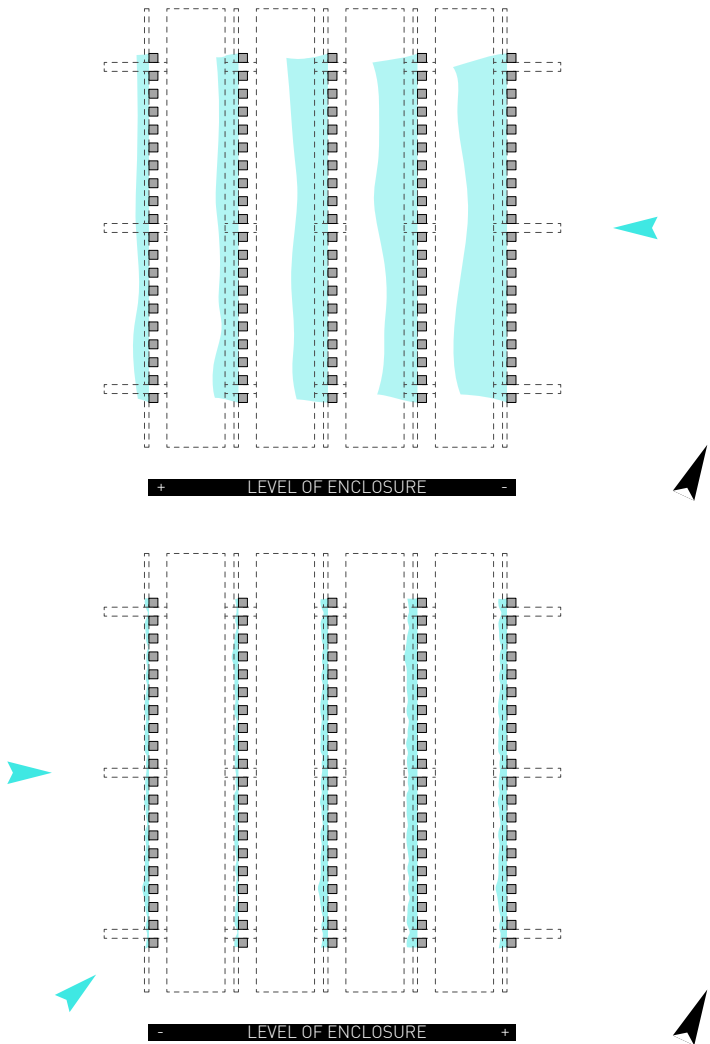

1

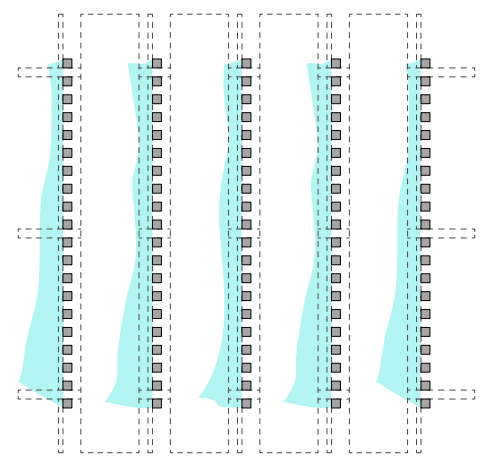


Not until the mid-20th century advent of mechanically controlled buildings did architects reject, almost over-night, wind as a source of temperature control - cooling - and air exchange. ${ }^{4}$ Today, complex HVAC systems are required to complete tasks that may easily be fulfilled by something as simple as opening a window. This enclosure is not meant to be understood as a technical exploration of wind, it is more a device to give presence to a phenomena largely ignored within contemporary practice.

Wind patterns, like light are also a function of time and place. However, like light, its natural presence cannot be visualized, it can only be sensed. An individual experiences wind through their tactile sensibility. The skin acts as the receptor organ that registers variations in wind flow.

The enclosure is essentially a series of rows, comprised of 4 " $\times 4$ " timber posts, placed on top of the mound, the highest point in Kerr Hall Quad. Fabric was incorporated as an element of the enclosure to visually express the presence of wind. The enclosure was designed to address the varying conditions of wind pattern flows that Toronto witnesses.

\subsection{TOPOGRAPHY}

Sites rarely exist as perfect rectangles, they often face multiple direction, have asymmetries, they might even be confronted by drastically different conditions along each edge of its boundary. This is especially true for sites within landscapes and historic centres. Variations in the topography of a site are regarded as an unnecessary inconvenience by contemporary practice. The tabula rasa tendency is realized by the bulldozing of irregular sites to create a perfectly flat datum as the most economic and rational condition 


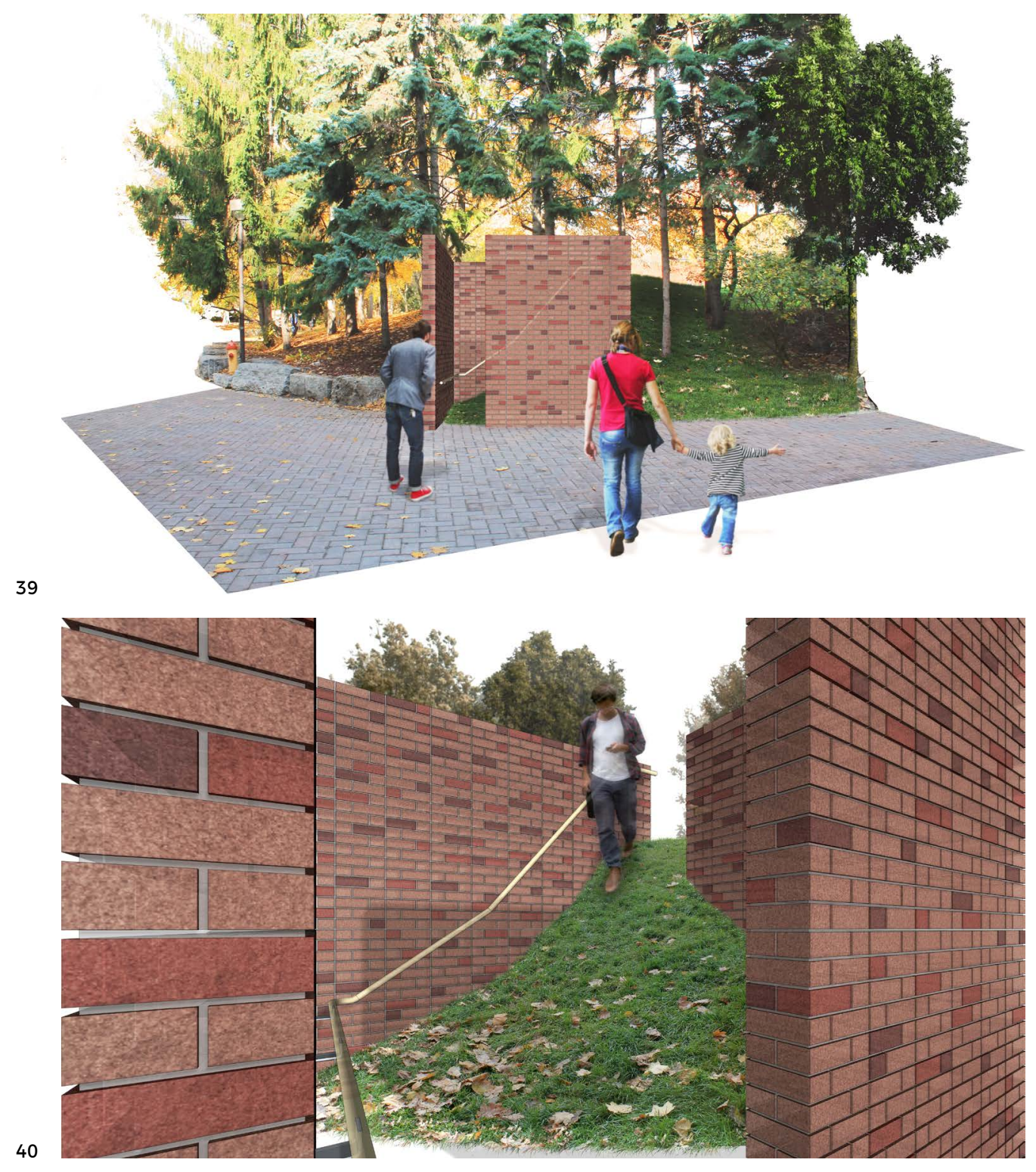

39 Topography Enclosure - Render 1 40 Topography Enclosure - Render 2 

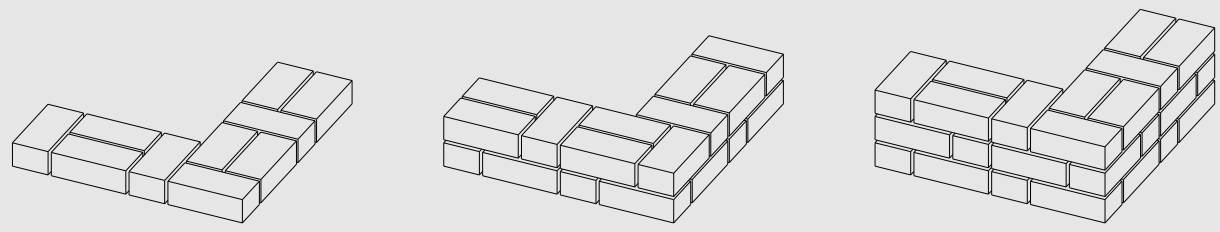

41

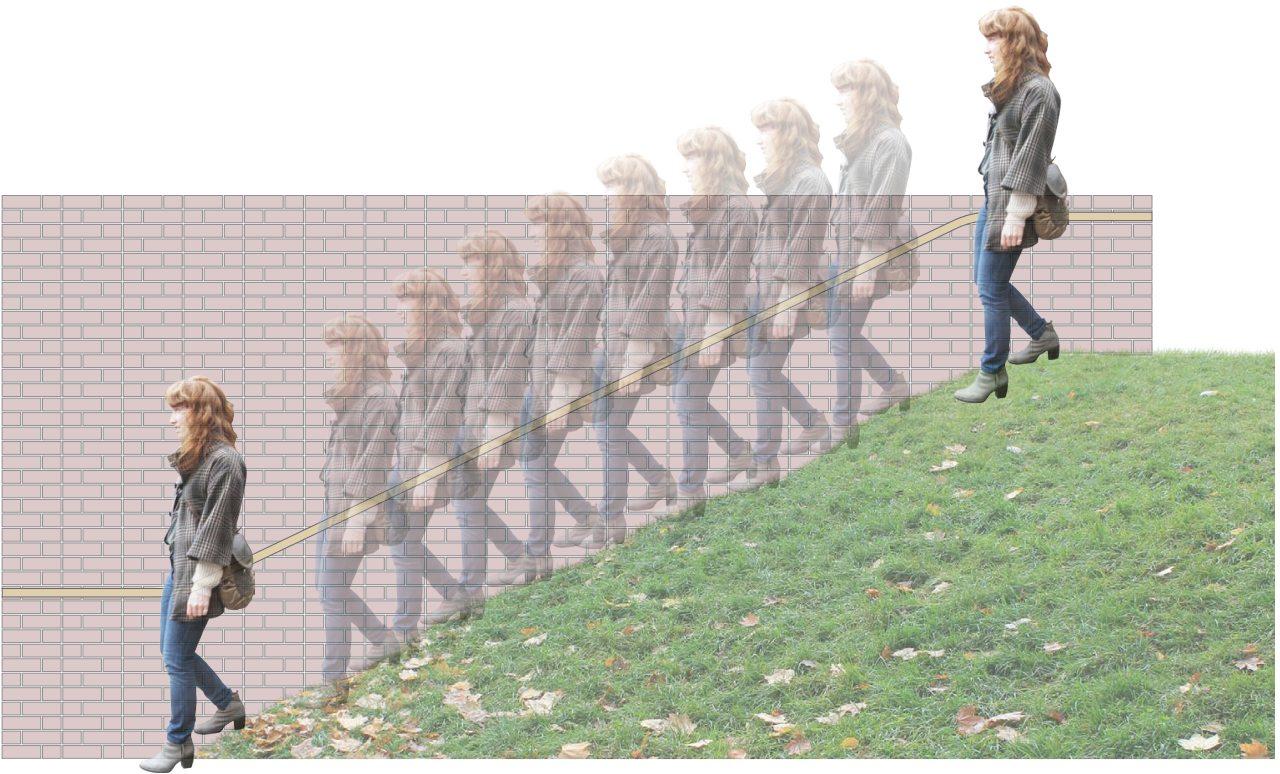

41 Brick Laying Pattern

42 Topography Enclosure Unfolded Section 
to build upon. Consequently, buildings are no longer designed to respond to the physicality of the sites they will occupy, rather the site is artificially manipulated to ease the work of all parties involved. The flattening of a site presents another attempt at eroding the identity of a place. Frampton cites the work of Swiss architect Mario Botta who suggests the concept of "building the site" as a counter to this culture of flattening. By "in-laying" a building into its site, should it have a variation in topography, the "idiosyncrasies of place find their expression without falling into sentimentality."

The phenomenon of topography is categorized under the character of the earth. Therefore, the expression of this phenomenon is very much predicated on how the built form addresses its grade condition. This enclosure was designed to articulate the phenomenon of topography by framing the change in elevation with as minimal as an intervention as possible. The term topography doesn't necessarily imply a variation in elevation. The topography of a site may very well be flat due to natural means.

The site of this enclosure was chosen because it presented the most appropriate opportunity to give presence to this phenomena within Kerr Hall Quad. It does so by presenting two different conditions for the user's experience. The height of the enclosure is constant. However, as one moves through the enclosure, its walls imply different meanings. At one point, the enclosure appears as a ledge while at another a complete wall due to the change in topography. The moment when the enclosure does this is left ambiguous, dependent upon the height of each individual user.

\subsection{MATERIAL COMPOSITION}



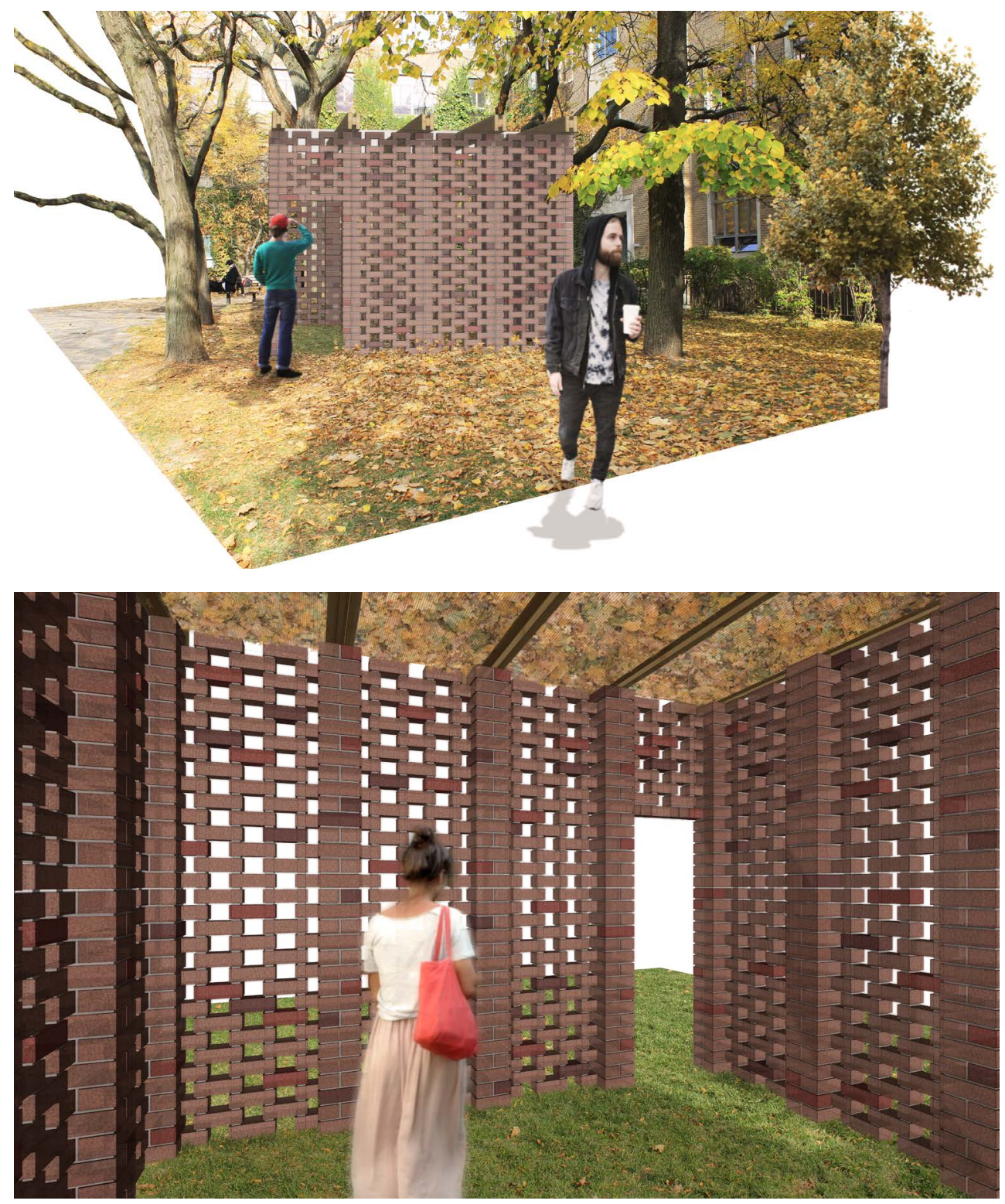

43 Brick Laying Pattern

44 Topography Enclosure Unfolded Section

45 Brick Usage 
The last phenomenon to be explored is that of material composition, which has already been discussed earlier in brief. This phenomenon speaks to the actual, physical make up of a place. Each physical element that a place is comprised of contributes to this phenomenon and its overall atmosphere.

A significant portion of Kerr Hall's façade is clad with brick that is organized as a common bond. The goal of this exploration is not the duplication of the existing conditions, but rather an exercise in determining how the existing conditions may inform the new enclosure. This enclosure is also composed of brick, albeit in a non-replicative manner. Unlike the case of Kerr Hall where the brick was used plainly as a cladding material, this enclosure relies on brick for both its structural, load-bearing properties, to carry the "roofing" element, in addition to serving as a cladding material. Furthermore, Kerr Hall employs the brick as a solid element with the glazing adding the necessary transparency. On the contrary, the enclosure treats the cladding element as a penetrable screen by permitting opening between individual bricks.

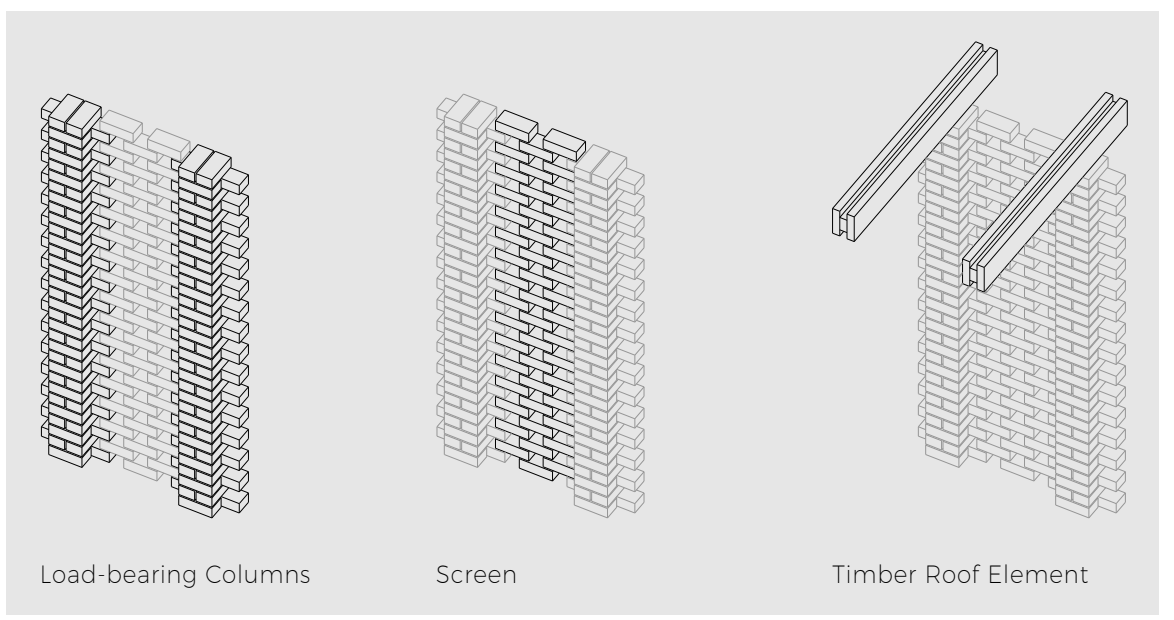


To compliment the use of brick, a site within Kerr Hall Quad was chosen to give presence to a more "temporal material." The enclosure is nestled in the north-east corner of the Quad amongst several mature trees. Hung between the horizontal timber elements of the enclosure is a metal mesh. Over the course of the seasons, as the trees lose their leaves, the mesh gathers them to define the roofing element that can be experienced from within the enclosure due to the transparency of the mesh.

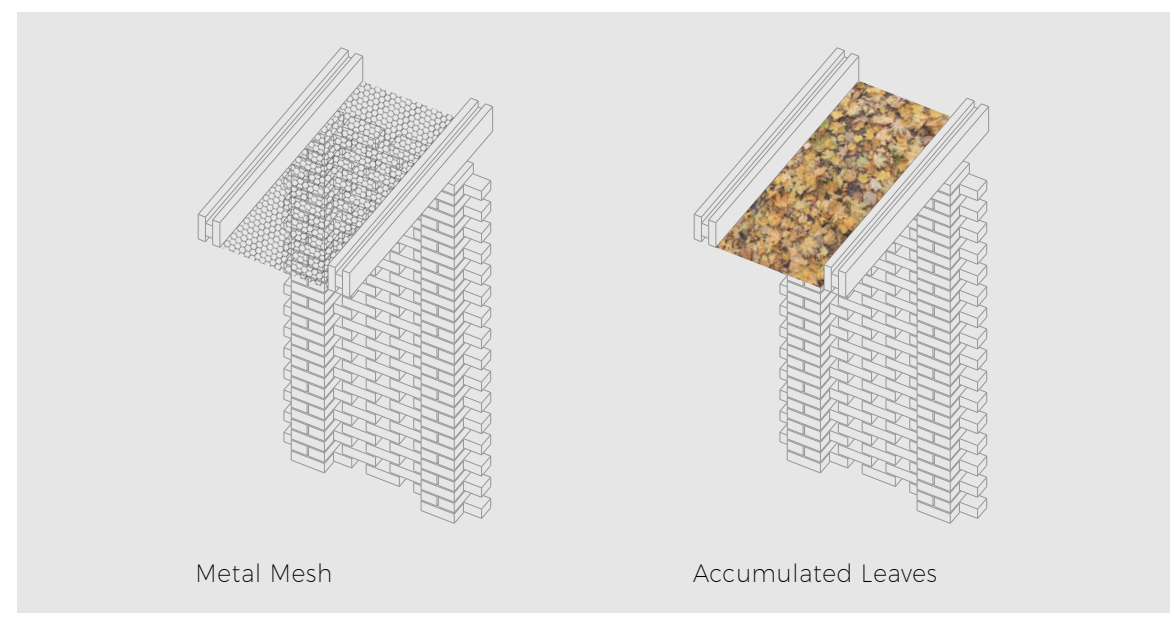

\subsection{ATMOSPHERE AS ENERGY}

The concept of atmosphere is one that is intangible, ephemeral and perhaps difficult to grasp, which is why the previous section was dedicated to identifying certain tangible elements of this concept. However, to gain an even deeper understanding of atmosphere, a slight detour into the branch of physics is required. The intention here is not to digress into an extensive discussion on theoretical physics, but rather to help further define this

46 Temporal Material 
concept of atmosphere, to give it more clarity.

Atmosphere is here defined as the character of a place. This "place" and indeed the entire physical world is defined by some form of energy. The topic of energy can be challenging to discuss since it isn't a material object in the conventional sense, though there is a caveat to this, but is still the elemental determinant of all processes between all entities; whether that entity is something as small as an atom to something as large as an entire ecosystem. For the moment, suffice it to say that energy is not itself an object. An atom by comparison is an object. Energy is something which objects can have, and groups of objects can have, it is a property of objects that characterizes their behaviour and their relationships to one another. The law of conservation states that though energy can exist in various forms, it cannot be created or destroyed. The names given to different types of energy are associated with where it is stored and what form it takes on. For example, thermal energy, acoustic energy, light energy, etc. At the end of the day, it is all the same energy, simply performing different tasks. On a fundamental level, energy in all its forms can be classified as potential, stored energy that can flow, or kinetic, energy that is flowing. ${ }^{6}$

For the purposes of this thesis, the best place to elaborate on this discussion as it pertains to atmosphere would be energy in the form of matter. This is the caveat that was mentioned above. There is a false dichotomy set up between matter and energy as if they are two polar ends of the same spectrum. While it may seem poetic to speak of everything as either strictly matter or energy, from a theoretical physics perspective, such rhetoric is misleading. It simply isn't that black and white. As Kiel Moe suggests, "matter 
is but energy captured."7 On a molecular level, energy in various forms exists within the mass of the object in question. Any physical object, a building, a tree, a human body, is matter that at its core, is defined by a set of vibrating molecules that eventuate in a form for a certain duration. These vibrations are fundamentally energetic. Any event that may occur, that is if anything happens that alters the matter at all, it is the result of energy exchanges from one form to another. All matter is continuously sending and receiving various forms of energy; while some maybe captured and embedded, the remainder is exchanged back into the milieu. ${ }^{8}$

While easily discernible is matter which maybe visibly identified, harder still yet equally vital in contributing to a place's atmosphere is matter on a molecular level. A pertinent example of which is scent. As an individual breathes in, odor molecules are inhaled that were released from objects in that environment due to an internal chemical change. Olfactory receptor cells in the nose detect these odor molecules and transmit that information to the brain which then discerns between different scents. The scent of a place is contingent upon its material composition which is why particular smells are associated with particular places. As renowned poet Mahmoud Darwish so eloquently articulated "cities are smells. Cairo is the smell of mango and ginger. Beirut is the smell of the sun, sea, smoke, and lemons. Paris is the smell of fresh bread, cheese, and derivations of enchantment. Damascus is the smell of jasmine and dried fruit. Tunis is the smell of night musk and salt. Rabat is the smell of henna, incense, and honey. A city that cannot be known by its smell is unreliable."

Another vital non-visual contributor to a place's atmosphere is humidity, 
which is the amount of water vapour in the air. As water molecules gain enough energy through their collisions with one another in the liquid state, they escape their bonds and manifest themselves as vapour in the air. Therefore the humidity of a place also depends on its proximity to a substantial body of water. Though water, when it exists in a collective liquid state as a large body like a sea or lake, is perceived visually, water vapour is perceived primarily through the body's tactile sensibilities. Furthermore, due to a change in the environment, humidity begins to manifest itself as dew, fog and eventually as precipitation when the air is saturated with water molecules. The reason humidity has been identified is because it is a crucial element of a place's atmosphere. Consider for example the difference between the Sahara Desert and the Amazon rainforest. While the former is a region defined by its aridity and dryness, the latter is its polar opposite, a very moist and humid biome.

Energy not captured in time as matter can be understandably more challenging to define considering it is transient, immaterial and fluid. Whether noticeable or not, the forces of potential and kinetic energy effect conditions that contribute to shaping the atmosphere of a place. Two of these condition have already been outlined. The lighting conditions and wind patterns of any given region, of whatever scale, are the result of an alteration in kinetic energy. Light is a form of radiant/electromagnetic energy that travels in waves whereas wind patterns emerge from a change in the air pressure that causes molecules in the air to travel with either increased or decreased kinetic energy. For the scope of this research, two additional forms of energy need to be identified, thermal and sound, both of which are once again forms of kinetic energy. Thermal energy is that 
which comes from the movement of atoms and molecules in the air. The greater the kinetic energy of the molecules, the more energy they give off in the form of thermal energy as they collide. This form of energy is perceived by the body as a change in the temperature of the surrounding. The last form of energy to be discussed is sound energy which is produced by the vibration of objects. These vibrations, caused either by other object, such as the chirping of birds or by events like thunder, create waves of pressure that travel through different medium such as air, water, wood or metal and are perceived by the individuals present in the form of a noise. ${ }^{10}$

The conclusion to be drawn from this slight deviation is that whether noticeable or not, the forces of potential and kinetic energy affect the conditions described above that are elemental in shaping the atmosphere of a place. The goal of this endeavour into the branch of theoretical physics was to identify additional variables to add depth to the five phenomena previously outlined. Therefore the chart presented in Figure 24 may now be altered to include these variables. While the chart thus far served as an appropriate tool to organize the phenomena, given their transient, ephemeral nature, it proves an ineffective method to list the atmospheric variables outlined above and thus required some reconfiguration [Fig. 47].

Consider the variable of precipitation as an example. Precipitation, in any form, is matter and thus can appropriately be classified under the phenomena of material composition. However, it is also temporal in nature because it isn't a permanent fixture of any particular place and its form changes dependent upon the cycles of seasonal change. Instead of relying on the previous technique of vertically categorizing these variables under 
specific phenomena, they have been listed horizontally along a gradient of physicality. Reading the chart from left to right, the physical nature of each successive variable increases, while not necessarily implying a decrease in their temporality. Their proximity to the aforementioned phenomena nonetheless suggests a relationship but stops short of drawing a direct, rigid link between the two.

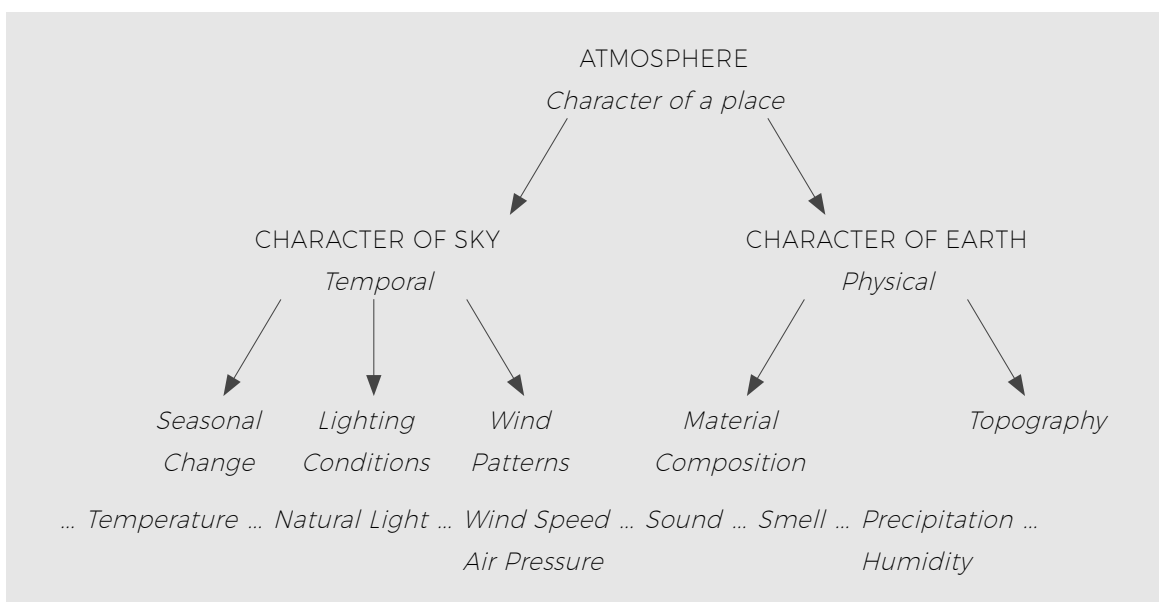

47

\subsection{PERCEPTION OF ATMOSPHERE}

Thus far, this thesis has gone into significant depth defining atmosphere; more specifically articulating its position on the subject and identifying its constituent variables. However, what remains to be determined is how the atmosphere of a particular place is experienced by individuals occupying it. This seemingly simple question invites into consideration a far more complex set of factors if one is to articulate an appropriate response to it. To do so, a departure, once again, from the discourse of architecture and

47 Atmospheric Variables 


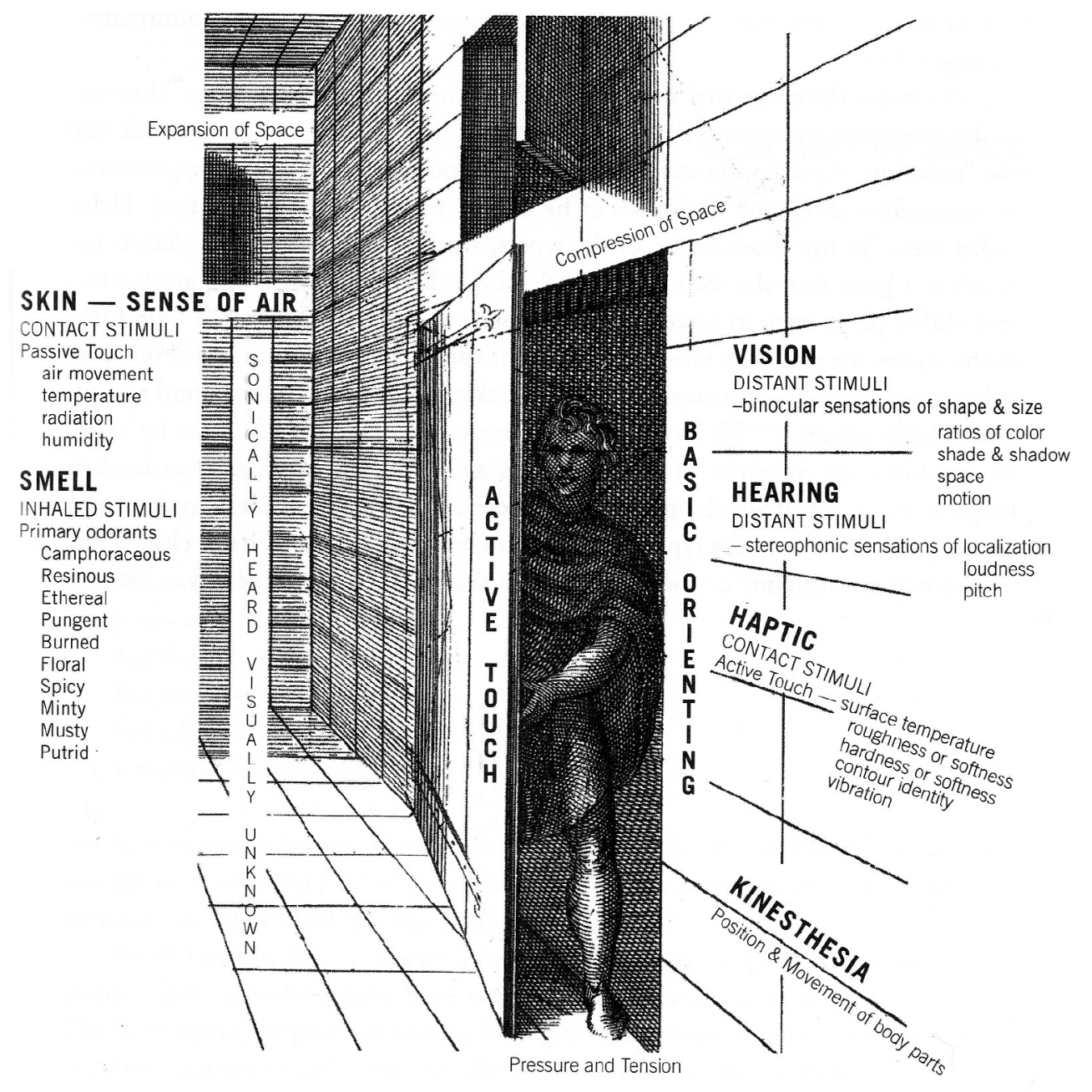


a venture this time into the field of psychology is in order. Limits need to be placed on the scope of this research to avoid getting embroiled in the complexities of human psychology thus ensuring that the subject matter in question remains relevant to the topic of atmosphere in architecture. This limit manifests itself in the form of the goal to identify the human body's apparatus for perception. More on the reasoning of this limit to follow.

In many ways, the most influential authors on this topic are in agreement on the way that humans experience the built environment. The body's senses are tasked with gathering information regarding its surrounding which are used by the individual to construct their understanding of a place through cultural modifiers, prior experience, personal preference and contextual issues. The senses work together to form this understanding; as many of the things an individual sees are reinforced by also hearing them, touching them and so on.

It is commonly assumed that the body has five individual senses, sight, smell, sound, taste and touch. However, this represents a very rudimentary understanding of the full range of human senses. Extensive research published by neurologists and psychologists suggests that humans may have up to twenty one senses. ${ }^{11}$ There are two definitions of the verb to sense. The first, to actively detect something, and the second, to passively have a sensation. When the senses are considered as "perceptual systems," as psychologist James J. Gibson proposes, the definition that is implied is the first one.

The registration of spatial atmosphere is the responsibility of the body's 
various perceptual systems. The body's perceptual systems are as follows. The basic orienting system, the auditory system, the haptic system, the taste-smell system and the visual system. The two primary perceptual systems, the visual and haptic, are inherently linked and work together to "yield a doubly guaranteed input of information." 12 This assertion is furthered by Pallasmaa when he declares "seeing is, as it were, touch at a distance; our understanding of form originates in our hands as we literally or imaginatively hold objects and feel their shapes." ${ }^{13}$ Consider the example of a wall. From a distance, one can perceive its colour, its texture.

An individual's ability to gain a thorough understanding of the space surrounding them is subject to the perceptual systems providing them information about that environment. The body's perceptual systems actively seek out this information, operating beyond its outermost layer, the skin, in the form of stimulus energy. The stimulus energy that is being sought, is the atmosphere of that particular place. By remaining active in the environment beyond their immediate confines, the body's perceptual systems extend the threshold for registering stimulus energy outward in all directions in the form of a gradient. Sean Lally's concept of the "sensorial envelope" serves as an appropriate method to diagram this [Fig. 49]. The diagram depicts the body's senses - Lally refers to them as senses but outlines more than the cursory five - reaching into the environment, gathering information regarding the environment surrounding it. What's vital about Lally's observations is that the level to which this envelope extends is subjective to each individual.

These perceptual systems however have quantifiable thresholds below which this stimulus energy cannot be registered. Additionally, these 

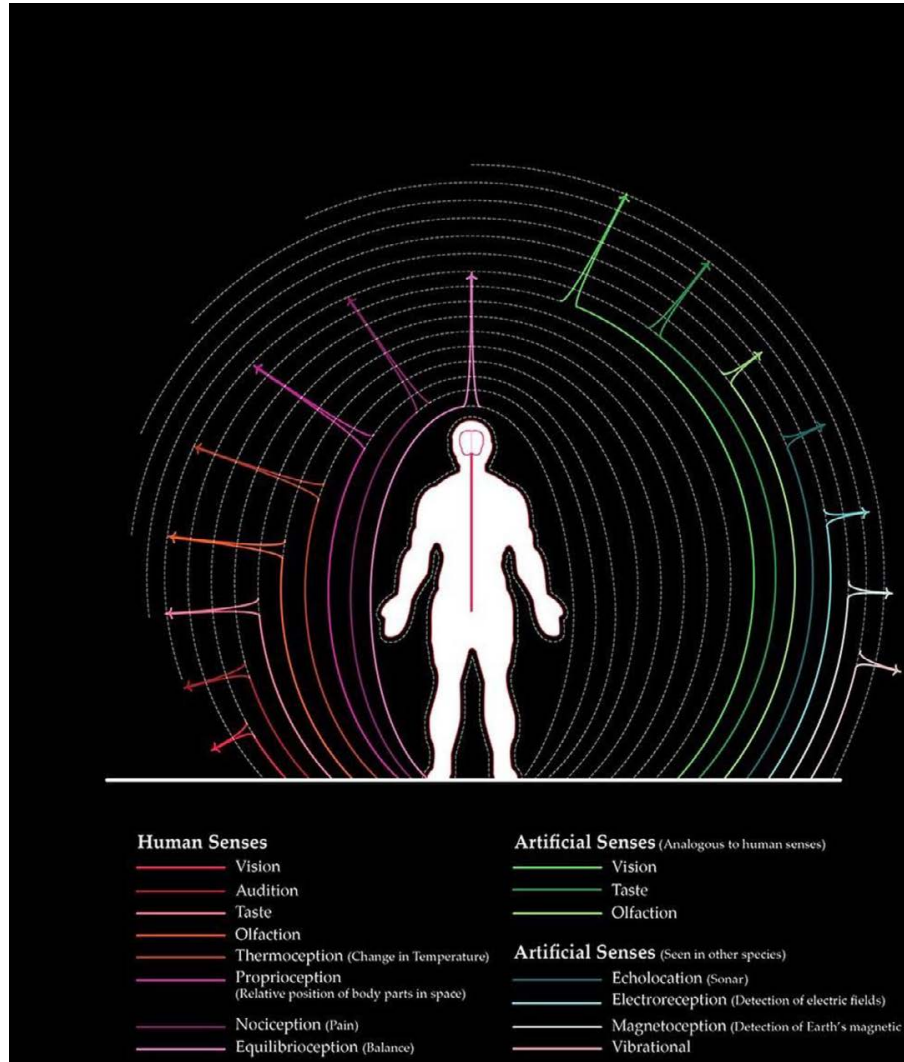

Artificial Senses (Analogous to human senses)

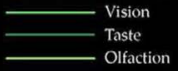

Artificial Senses (Seen in other species)

Artificial Secation (Sonar)

—_ Electroreception (Detection of electric fields)

Magnetoception (Detection of Earth's magnetic ficld)

Equilibrioception (Balance)

Central Nervous System

Interoception
(senses found within the body)

Pharmaceutical

Ex. The chemoreceptor trigger rone is
area of the medulla in the brain that

receives inputs from blood-borne drug

or hormones, and communicates with the

Pharmaceutical 
thresholds of perception are individualized, they differ from one person to another. Consider for a moment the auditory system and the reliance of the elderly on devices such as hearing aids. A young woman's ability to decipher a softly spoken word or detect a loud bang from a distance is far greater than that of an elderly gentleman. The reasons for such differences in perceptual thresholds may not always be due to a difference in age; one might be aware of someone, anecdotally though it maybe, who can detect odours more intensely than someone else. Such analogies are endless. It is beyond the scope of this thesis to determine why these distinctions in perceptual thresholds exist, but suffice it to say that it is crucial that buildings provide a heightened atmospheric experience to its occupants because the status quo of a homogeneous, neutral atmosphere makes for a very banal experience of place. Furthermore, it is critical to ensure that this heightened atmospheric experience is not one of a constant intensity as the perceptual systems will simply grow numb to it over time. The challenge for architecture is to provide an atmospheric experience that is dynamic. In this case the term dynamic is not meant to imply the cliché of "kinetic architecture," but more accurately atmosphere that is changing and fluid, atmosphere that exists as varying degrees of intensities.

Any discussion on atmosphere, from an architectural perspective, has an inherent limit. To go beyond this limit, one would be operating deep in the territory of human psychology. The reason for placing a limit on the scope of this research was alluded to above, the subjectivity of human experience. The perception of any atmosphere is subjective. People experience places with different sensory strengths. Given this lack of objectivity, architects always operate on a certain level of ambiguity considering no two people 
will experience a place in the same manner. To counter this ambiguity, tangible variables were identified in the previous section as tools architects can employ as they consider atmosphere in their work.

A final point to be made on this matter is the distinction between mood and atmosphere; though the two are very closely linked, they are not necessarily the same thing as is often mistaken. Mood, as described by Alberto PerezComes is a person's emotive response to a particular place or event. ${ }^{14}$ Though a building's atmosphere, regardless of what it may be, can invite a mood, it cannot demand it. One can cry and be unenthused in a place one day, while cheerful and excited the next. Moods are both subjective and contextual. The term contextual here is not limited to a person's built environment. A person's mood, their emotive response to any place, would be conditioned by their pre-existing cultural, political, religious, social - the list can go on - disposition. Even when a building does bring about an emotive response from an individual or a group of individuals, it is often due to a shared historical or cultural context. Churches for example can invite a mood of serenity and self-reflection from their visitors, but the experience of a group of practicing Catholics on a tour of Italy's Renaissance cathedrals would be quite different than the experience of an atheist on the same tour. there to simply enjoy their great architecture. 


\section{ENDNOTES}

1. Christian Norberg-Schulz, Cenius Loci: Towards a Phenomenology of Architecture (New York: Rizzoli International Publications, 1980), 6.

2. Ibid, 36

3. Karen Forbes, Site Specific (Novato: ORO Editions, 2015), 103.

4. Mary Guzowski, "The New Architecture of Sun and Wind," AlA Cote Whitepaper. (2012): 3

5. Kenneth Frampton, "Towards a Critical Regionalism: Six Points for an Architecture of Resistance," In Labour. Work and Architecture, by Kenneth Frampton (New York: Phaidon Press, 2002), 26.

6. Michelle Addington and Daniel Schodek, "Energy: behaviour, phenomena and environments," In Smart Materials and New Technologies for Architecture and Design Professions, by Michelle Addington, \& Daniel Schodek (Burlington: Architectural Press, 2005), 46

7. Kiel Moe, "Matter is but Captured Energy." In Matter: Material Processes in Architectural Production, by Gail Borden, \& Michael Meredith (New York: Routledge, 2013), 313

8. Ibid.

9. Barbara Erwine, "Olfactory Space," In Creating Sensory Spaces, by Barbara Erwine (New York: Routledge, 2017), 191.

10. Addington and Schodek, "Energy: behaviour, phenomena and environments," 47.

11. Juhani Pallasmaa. The Eyes of the Skin: Architecture and the Senses (Chichester: Wiley, 2005), 15.

12. James J. Gibson, The Senses Considered as Perceptual Systems (Boston: Houghton Mifflin Company, 1966), 54

13. Pallasmaa. The Eyes of the Skin: Architecture and the Senses, 12. 
14. Alberto Pérez-Gómez, Attunement: Architectural Meaning after the Crisis of Modern Science (Cambridge: MIT Press, 2016), 27. 


\section{0}

\section{ON BOUNDARIES}

In his 1954 essay “Building. Dwelling. Thinking” Heidegger defines a boundary as "not at which something stops, but as the Greeks recognized, the boundary is that from which something begins its presencing." This definition of a boundary in practice never caught on however. Today, boundaries are the embodiment of difference. It necessitates reiterating the position of this thesis to frame the following discussion on the role of the boundary condition when it comes to the consideration of atmosphere in architecture. It is argued here that atmosphere of a building should be defined by the engagement of the atmospheric variables present within the surrounding context in lieu of producing an artificial one as some manner of theatrics. Regrettably, contemporary architectural design practice does not permit this.

Architectural design practice today consistently relies on hard material thresholds in the form of boundaries to define spatial arrangements and areas for predetermined use by the inhabitants. The term boundary in architecture traditionally connotes a limit - the boundary as a property line, a building envelope or the walls of a room. This is partially due to its two dimensional representation as a line that demarcates a discontinuity between 
adjacent entities. Producing representations of walls and surfaces is now assumed to be the defining act of architectural design. Interior and exterior exist on opposite sides of a line in plan, as do ground floor and second floor in section. Extruded as a surface, the line not only becomes the limit of an environment, but also its container. This boundary is static, defined and unambiguous.

This historical conceptualization of a boundary as a limit stands in direct opposition to this thesis' position on atmosphere therefore demands a fundamental shift in its understanding to be completely realized. After all, it is the primary function of these boundaries to keep atmospheric variables at bay.

As previously stated, through the establishment of boundaries that capture space, architects create places for inhabitants. In drawing these boundaries what the architect in fact does is prescribe the building's form. Realizing line sketches and block models in solid masses of concrete, steel, stone and wood is the architect's fundamental mode of operation. This is what gives rise to the false equivalence between form and architecture. Even architects too often fail to make this distinction; though the two are closely linked, they are not synonymous. While it is not the intention of this thesis 
to delve into a philosophical discussion on what architecture is and isn't, for this discussion on boundaries, it is important to note that the form of the boundary does not necessarily equate architecture. In a 2015 interview with Forbes Magazine. Bernard Tschumi provided insight into this debate when he suggested, "architecture must originate from ideas and concepts before becoming form. Architecture is not only what it looks like, but also the events that happen in it."

In light of the fact that the boundary is associated with the form of a building. determined to be static objects of permanence by contemporary practice, it posits that their boundaries would share the same characteristics; definitive, solid and permanent. The use of a surface to mediate between existing environmental conditions and the activities, people or objects on the other side can firmly be identified as the longest-running strategy for defining space in architecture. What is being contested here is the conceptualization of the boundary as the hard edge between the interior and exterior. In setting up this dichotomy of two polar conditions, the interior is reduced to a cordoned off chamber of a sterile, homogeneous, neutral condition that humans occupy while the exterior remains an environment charged with atmospheric character. By questioning the role of the boundary as a strict separator and rather treating it as a gradient threshold, one can begin to consider atmosphere in architecture as defined by thesis. Since section 1.2 of chapter 1 identifies why the boundary is treated as a hard edge in practice today, the following few paragraphs are dedicated to outlining the case for the boundary as a gradient threshold.

Though the idea of a gradient threshold was explored as a concept through 
the design of the enclosure for wind, documented in section 2.13, if the spatial atmosphere of a building is to be determined by its engagement with contextual variables, pertinent questions on a larger scale that probe how spaces may be bound and contained in non-traditional ways need to be considered. Though this may prove a challenge for architects, a return to the discussion on energies proves the most appropriate place to do so. Unlike architecture, the field of theoretical physics does not define the boundary as a static edge, but rather an action. The boundary as action is a zone of thermodynamic energy exchange between two different energy fields. Thermodynamic boundaries are not legible, tangible objects but are instead non-visual, ambiguous and transient [Fig. 50]. Energy, in the present sense, defines spatial boundaries not through distinct and defined edges like matter, but through transitional zones of energy fields and flows in the form of a gradient. ${ }^{2}$

There is an emerging body of research aligned with the subject matter of this thesis that focuses explicitly on the manipulation of energies itself that has been labelled as "material energies." This area of research examines how environmental energies themselves might be amplified to define spatial boundaries and create places for human occupation. Sean Lally, the man leading the charge on this research, suggests that it "looks to ways of releasing these material energies from their dependence on surfaces and services to deploy them as building materials in and of themselves: redefining the physical boundaries and edges that architects use as organization strategies opens the potential for design innovation and the creation of new spatial and social constructs." ${ }^{3}$ Consider the analogy of a campfire as elaborated upon by Danish architect Steen Eiler Rasmussen: “a campfire on a dark 


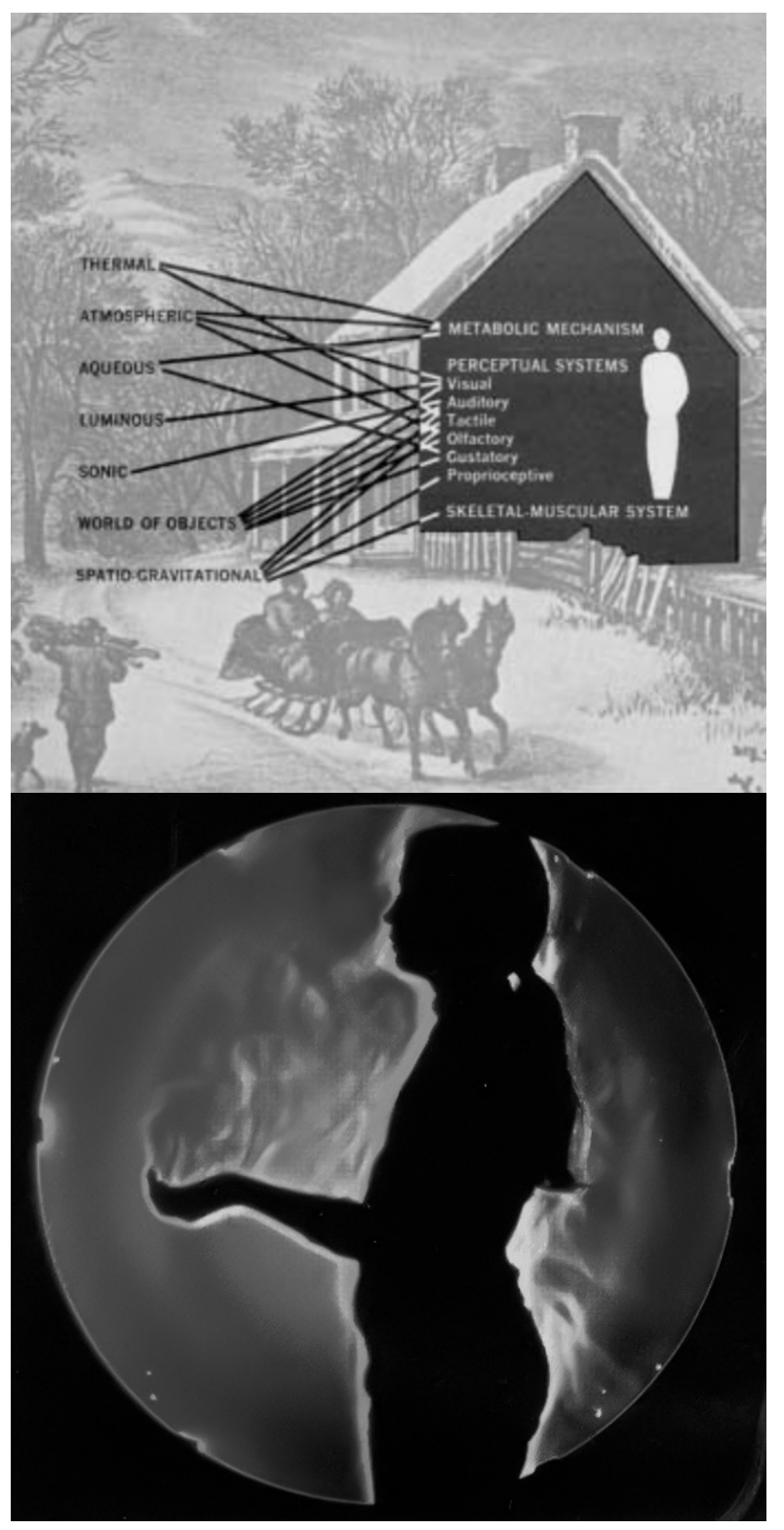

50 Comparison between architectural depiction of an environmental boundary (top) and that of the physicist (bottom) 
night forms a cave of light, circumscribed by a wall of darkness. Those who are within the circle of light have the secure feeling of being in the same room." "Though Rasmussen's poetic description wasn't explicitly referring to energies, the light and heat energy radiating from that campfire alone generate the "walls" of his "room." These walls however are not definitive, they appear in the form of a gradient. The closer one is to this campfire, the more intensely the light and heat energies are perceived.

What this research and this thesis share in common is their quest to examine the blurred boundary as a means to mediate the interior environment, and eliminate the standard of the hermetically sealed box that architecture currently adheres to. This thesis borrows from the research of Lally and his contemporaries but proposes an alternative to how this blurred boundary may be achieved. Instead of simply designing a series of micro-climates by manipulating the atmospheric variables outlined in Figure 47, the proposal presented here is one that employs idea of layering a number of porous surfaces in the form of a gradient that permit the penetration of atmospheric variables of the surrounding context into the space with varying degrees of intensity. By treating the boundary as a gradient threshold, instead of a hard edge, the project takes into consideration the subjectivity of an individual's perception of atmosphere, enabling them to occupy different zones of the project that provide them engagement with the atmospheric variables of their environment at a level of their choosing. 


\section{ENDNOTES}

1. Y-Jean Mun-Delsalle, "Bernard Tschumi's Architecture Is Not Just About Space And Form But Also The Events Happening Inside," Forbes.com, September 7, 2015. https:/www.forbes.com/sites/yjeanmundelsalle/2015/09/07/bernard-tschumisarchitecture-is-not-just-about-space-and-form-but-also-the-events-happeninginside/\#44cc55ef7605 (accessed January 13, 2017).

2. Michelle Addington, "The Phenomena of the Non-Visual," In Softspace: From a Representation of Form to a Simulation of Space, by Sean Lally, \& Jessica Young (New York: Routledge, 2007), 40

3. Sean Lally. The Air from Other Planets: A Brief History of Architecture to Come (Zurich: Lars Müller Publishers, 2014), 122.

4. Elisa Valero Ramos, Light in Architecture: The Intangible Material (Newcastle Upon Tyne: RIBA Publishing, 2015), 25. 


\section{0}

\section{SIX MILE LAKE RETREAT}

The program selected to articulate the concepts described by this thesis is that of a retreat for a landscape artist. The choice of a simple program was guided by the intent of developing architecture that can effectively manifest the atmosphere of its context without being bogged down by logistical requirements. The retreat is not being treated as a primary residence, but rather a workshop that may serve as a secondary dwelling for the landscape artist.

Considering this thesis' intent of harmonizing a place's atmosphere through built form, a site with a level of complexity. yet devoid of extraneous distractions, would serve as the most appropriate place to house the retreat. The context within which the retreat will be located is a rural one to eliminate the commotion of contemporary urban life [Fig. 51]. The choice of program reinforces this decision. Landscape artists have an affinity for their surrounding and that grants them the ability to possess a greater appreciation for the peculiarities of a place as it may serve as inspiration for their work.

The site chosen as the location for the retreat lies just east of 
51

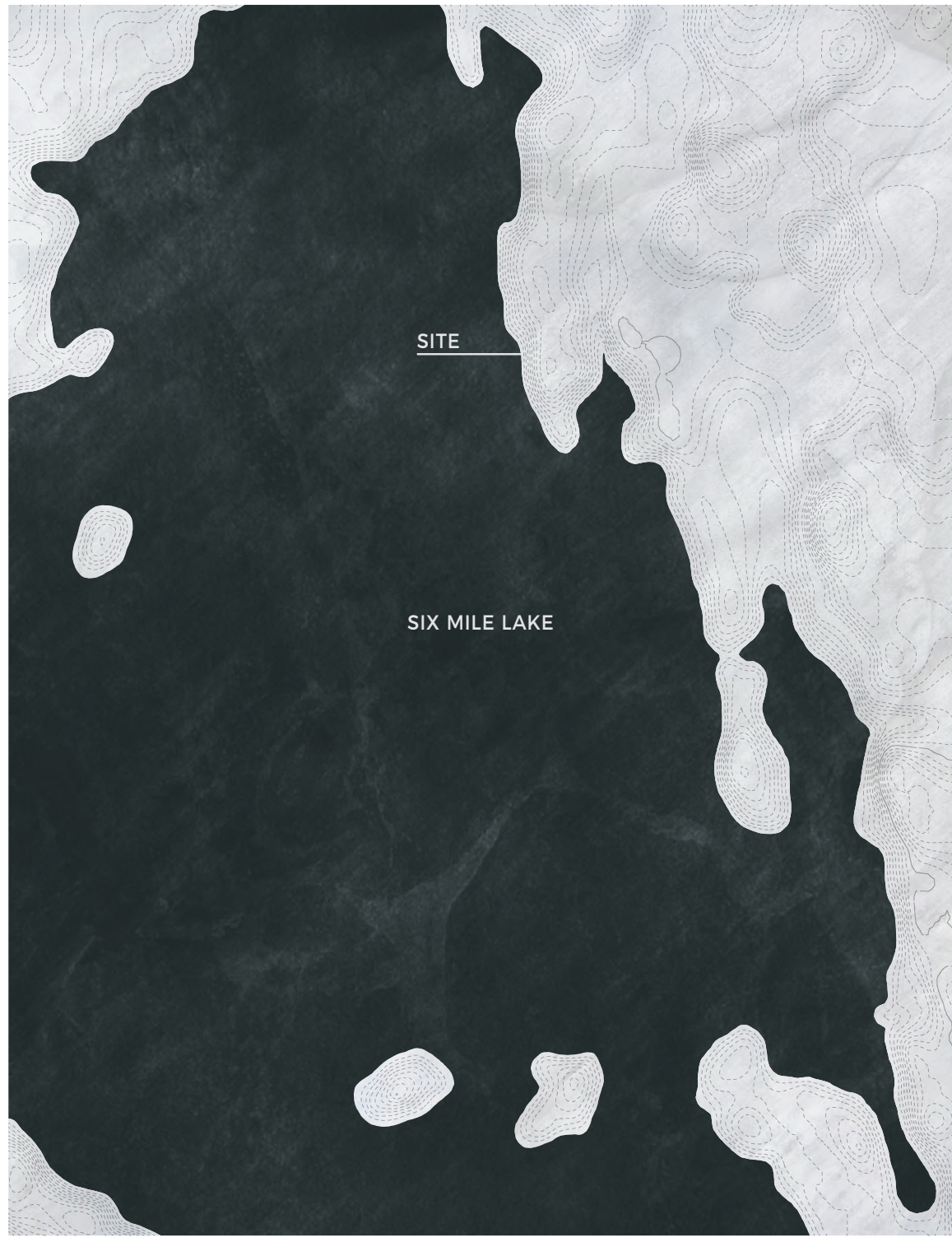

51 Context Plan 


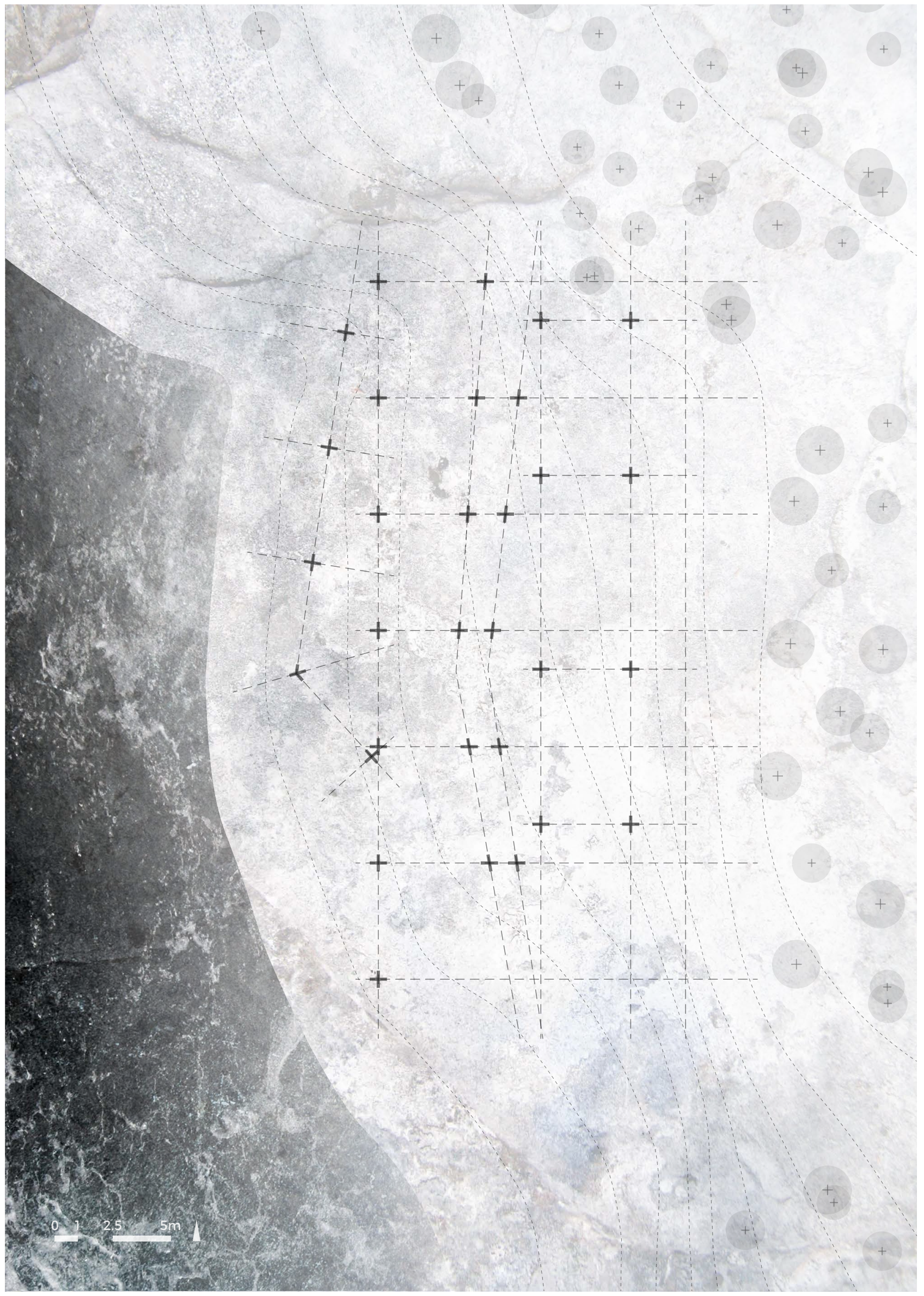


Georgian Bay's southeastern shore, half way between the quaint towns of Potters Landing and Wood Landing. It is situated along the western face of a peninsula that dips into Six Mile Lake, one of the many lakes peppered across the landscape of this region. The site experiences a change in elevation of approximately 14 metres towards the water. The site is further characterized by the rugged rock formations and eastern white pine trees that are distinctive to this region [Fig. 52]

The conceptual foundation of the retreat is the layering of a series of porous surfaces, organized along a gradient, that structure a sequence of inhabitable volumes of different atmospheric character. The concept of a gradient manifests itself within three different facets of the project, the first of which is a material gradient [Fig. 53]. The primary materials chosen as the palette for the retreat are perforated metal, fabric and eastern white pine that is local to this region. These materials are organized along a gradient, increasing in solidity as the artist moves into the project perpendicular to the face of the site. Along this gradient, to take advantage of the natural slope of the site, the exposed igneous rock is treated as the most solid material of the project. Moving north, parallel to the exposed rock, the materials once again increase in solidity.

The decision of draping the external most surfaces of the retreat with simply perforated metal was in response to the harshest conditions experienced by the site in the winter months. As mist in the winter months rolls off the lake, it freezes over time as it comes into contact with the perforated metal, forming a thin sheet of ice. Additionally, snow accumulates over the surface area of the perforated metal that can be distinguished from 

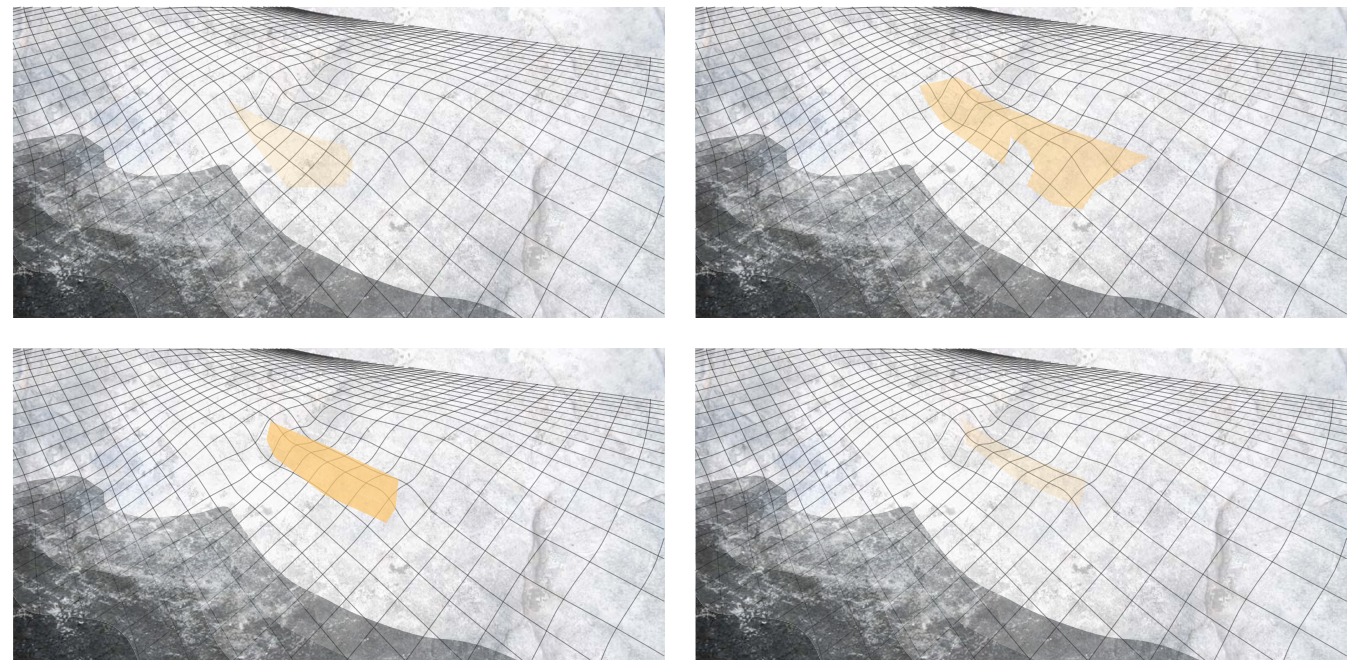

b

c
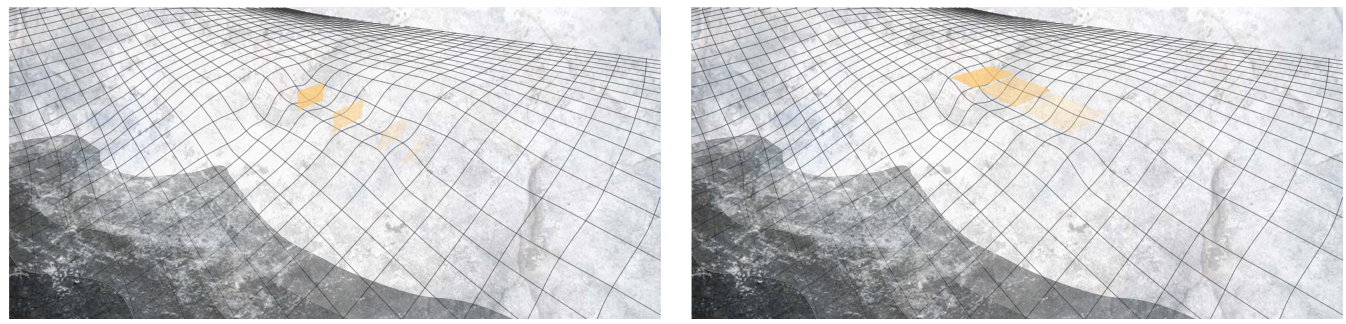

\section{e}

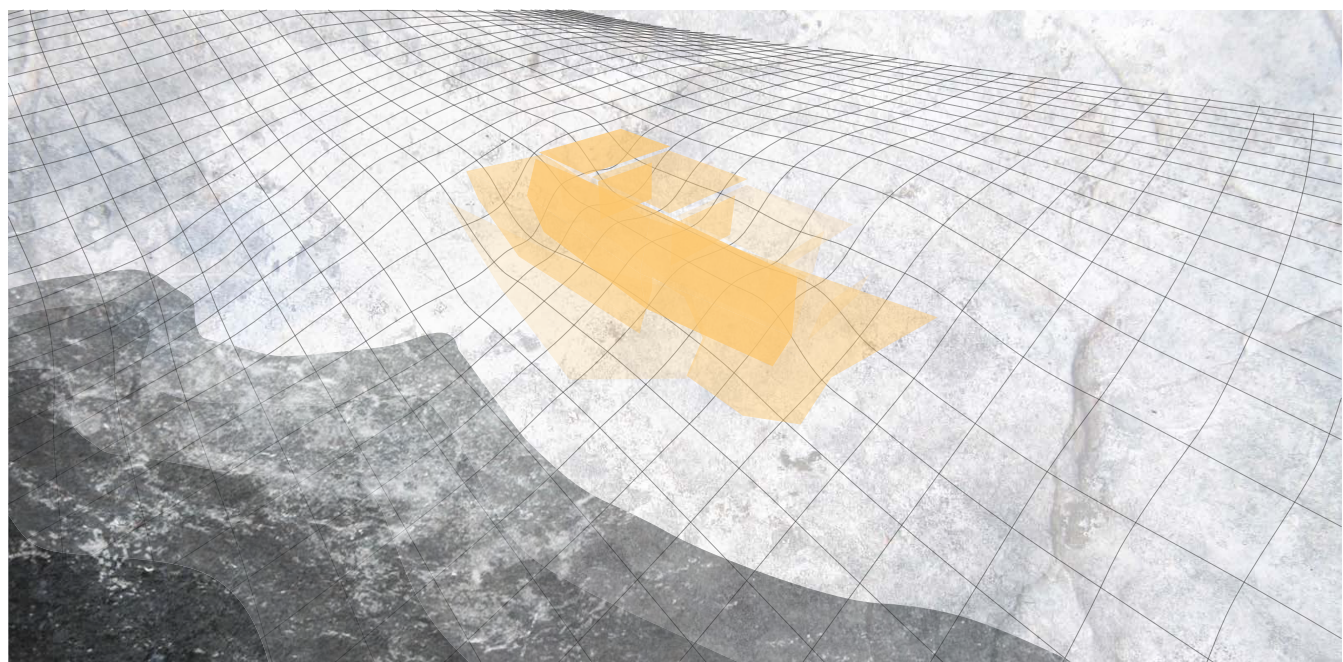

53 Material Gradient

a Surface $A$

b Surface B

c Surface $C$

d Surface $D$

e Surfaces $E$

f Surfaces $F$ 
54

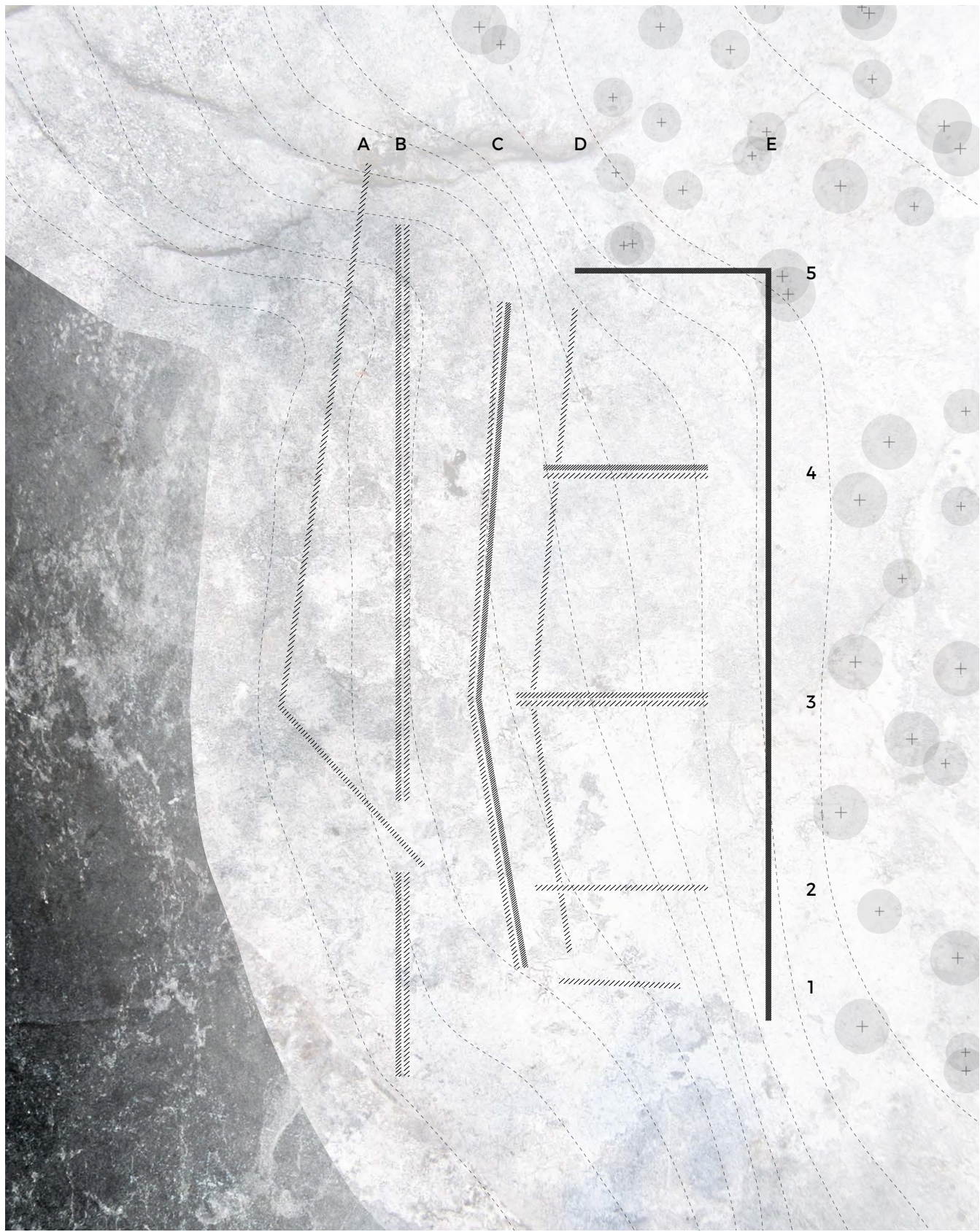

54 Schematic Plan of Surfaces
A- Perforated Metal
B- Perforated Metal + Fabric
C-Perforated Metal + Timber
D- Perforated Metal
E-Igneous Rock

1- Perforated Metal

2- Perforated Metal

3- Perforated Metal + Fabric

4- Perforated Metal + Timber

5- Igneous Rock 
within the retreat. In this temporal manner, the most bitter environmental condition add to the level of enclosure, in the process altering the internal atmosphere of the retreat from what it maybe in the summer.

The solidity of the material is reflected in the rigidity of the form of each surface. The western most surfaces of the retreat begin as a collection of radical, angular panels that gradually transform to more subdued, rectilinear and rational towards the east [Fig. 55].

Lastly, the openings along the surfaces are also organized along a gradient, responding particularly to the wind patterns of the site [Fig. 56]. These openings were not treated as cut outs from the façade, but rather achieved through the folding of the perforated metal panels at various angles. Given that the wind in the summer months blows predominantly from the west and north west directions, the angle of the fold is the highest along those portions of the surfaces, while gradually decreasing towards the south, the direction of wind for the winter months.

In addition to multiple points of access across the retreat, the artist is afforded a multiplicity of pathways to navigate the retreat. Therefore, by overlaying these gradients within the retreat, they are experienced differently each time the artist meanders throughout the retreat. Encompassing these surfaces, the retreat becomes the gradient boundary itself - and not a space first that is contained by a supplementary boundary - that blurs the distinction between interior and exterior. It is important to note that the gradient is not conceived of as a prolonged transition between two polar conditions, interior and exterior, but rather is focused on the in-between. 
a
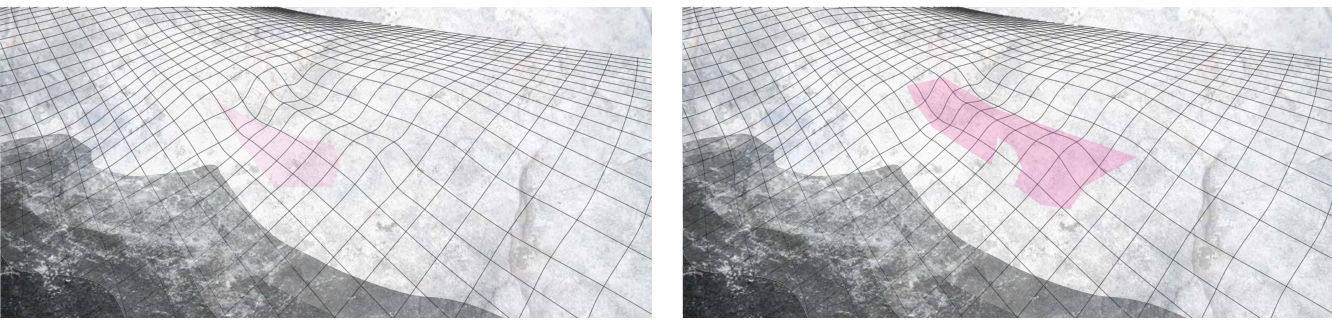

c
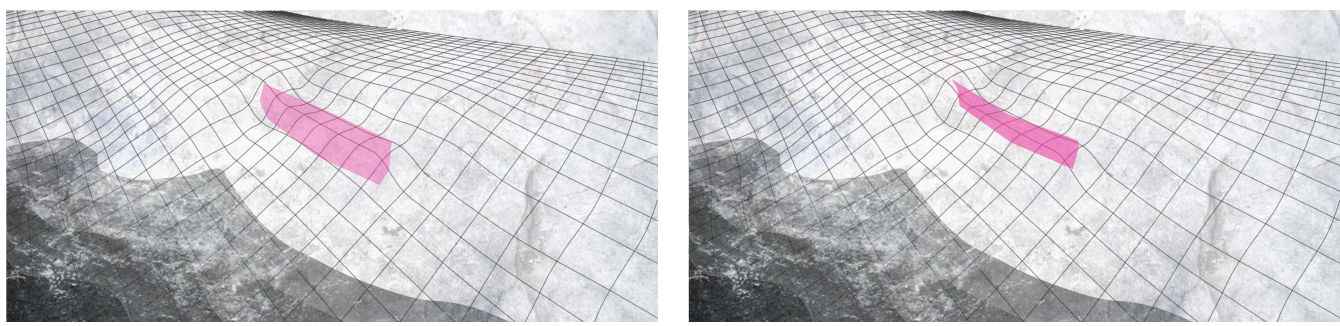

e
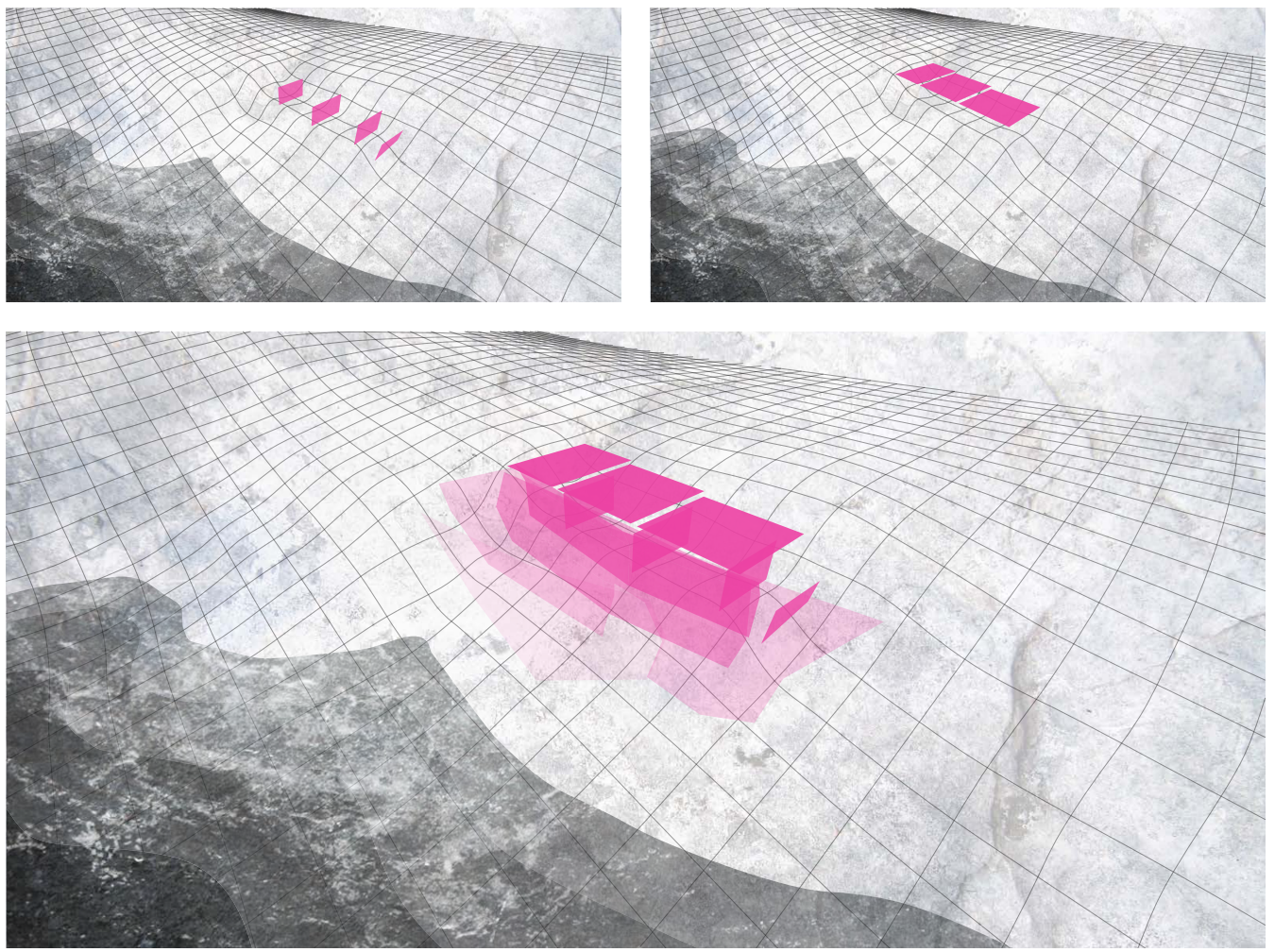

55 Form Gradient

a Surface A

b Surface B

c Surface C

d Surface D

e Surfaces $E$

f Surfaces $F$ 

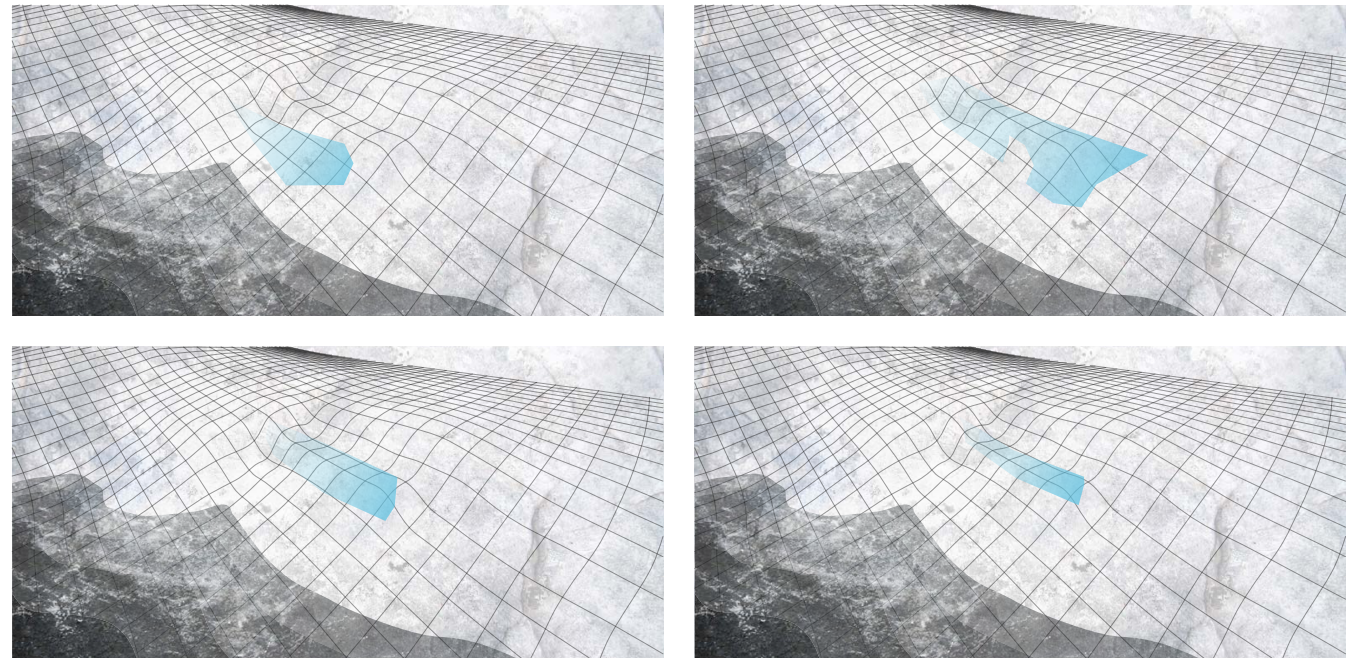

b

c
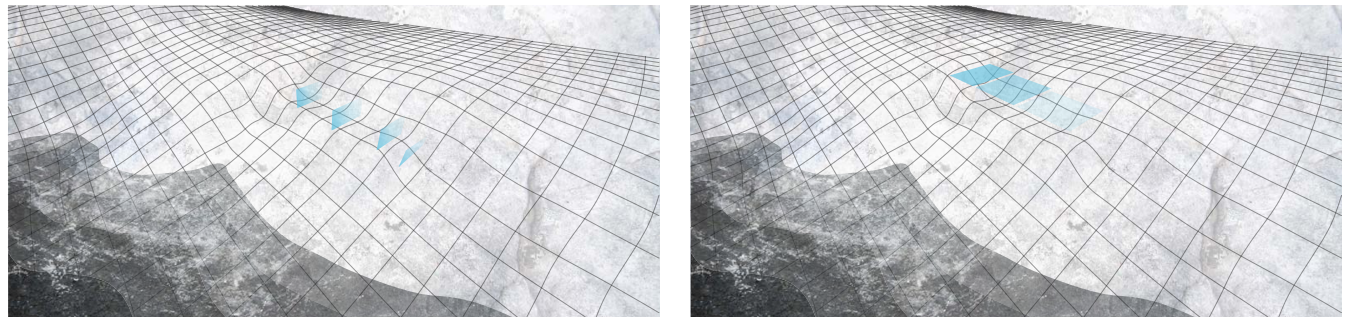

\section{e}

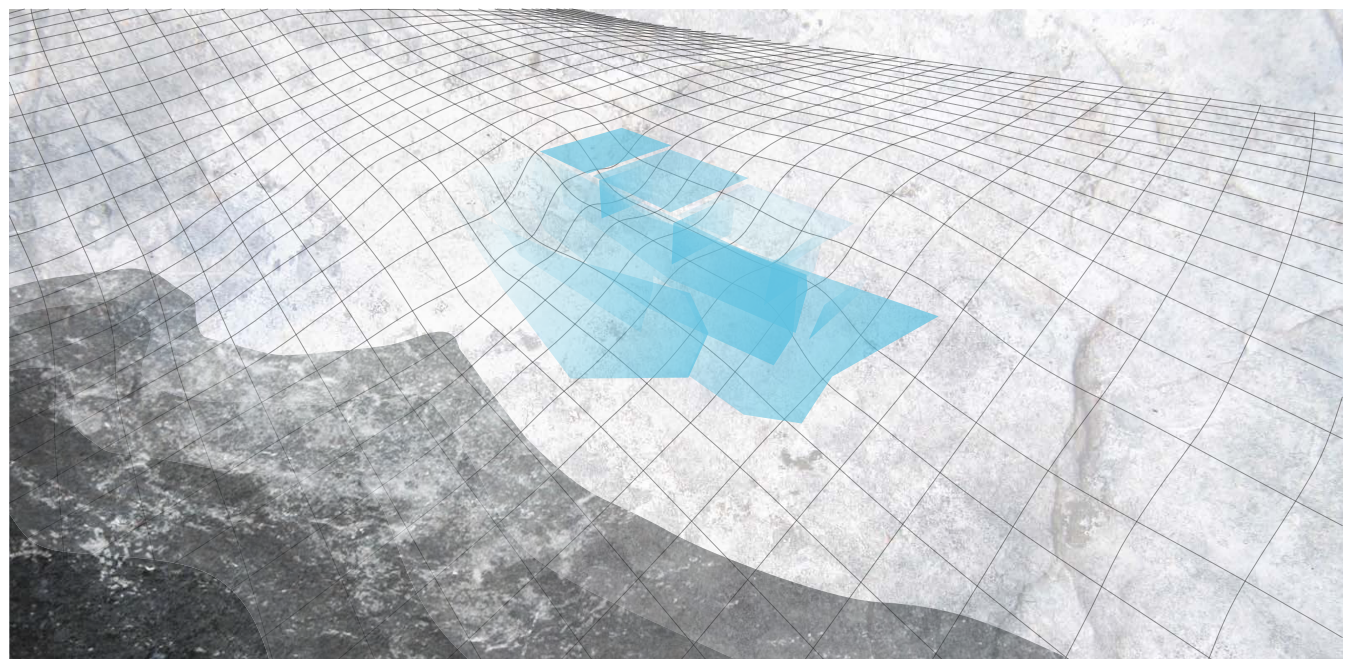


57

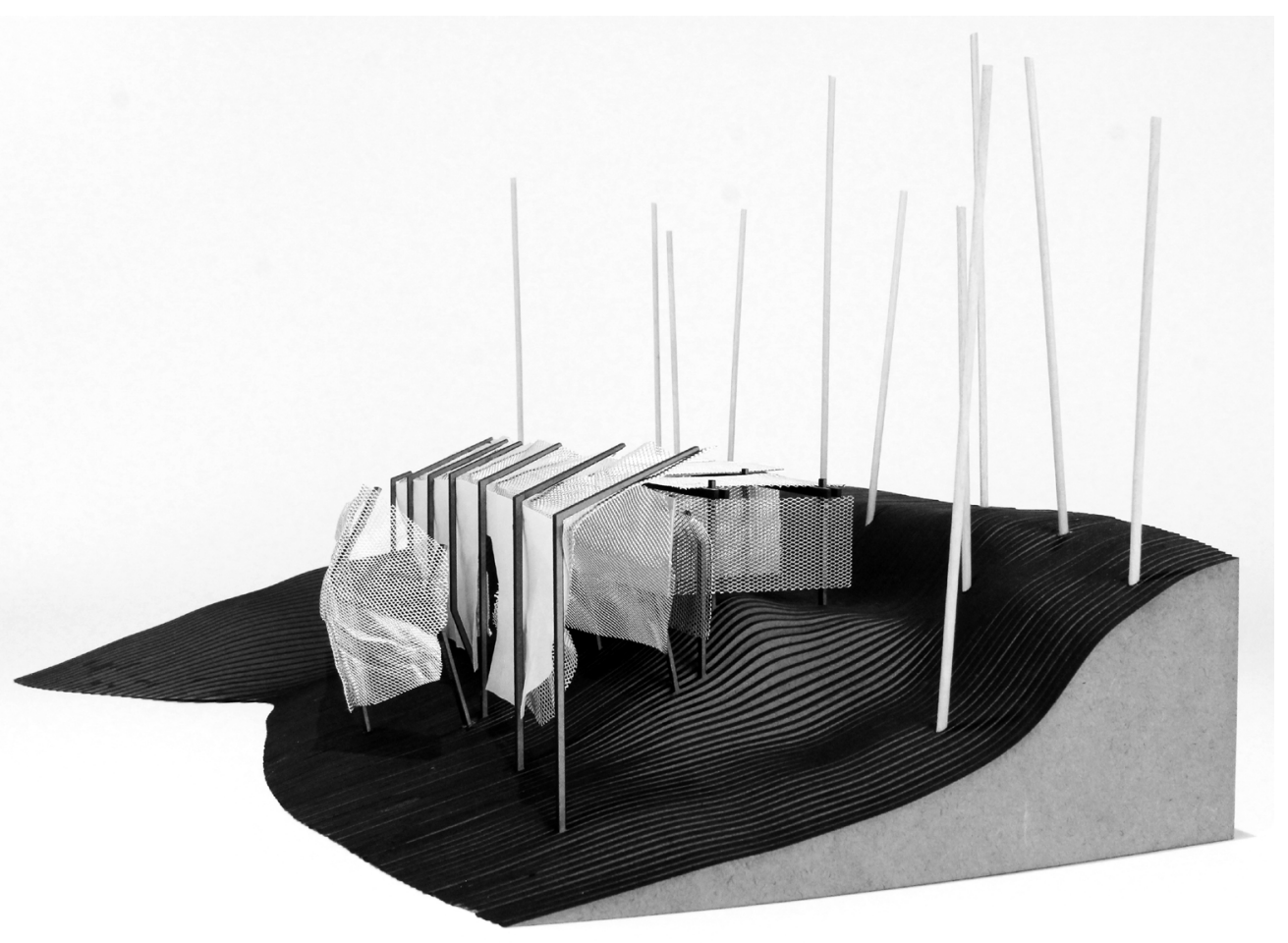

56 Openings Gradient a Surface $A$

b Surface $B$

c Surface $C$

d Surface $D$

e Surfaces $E$

f Surfaces F

57 Conceptual Model 
> 58 Plan Level 1 


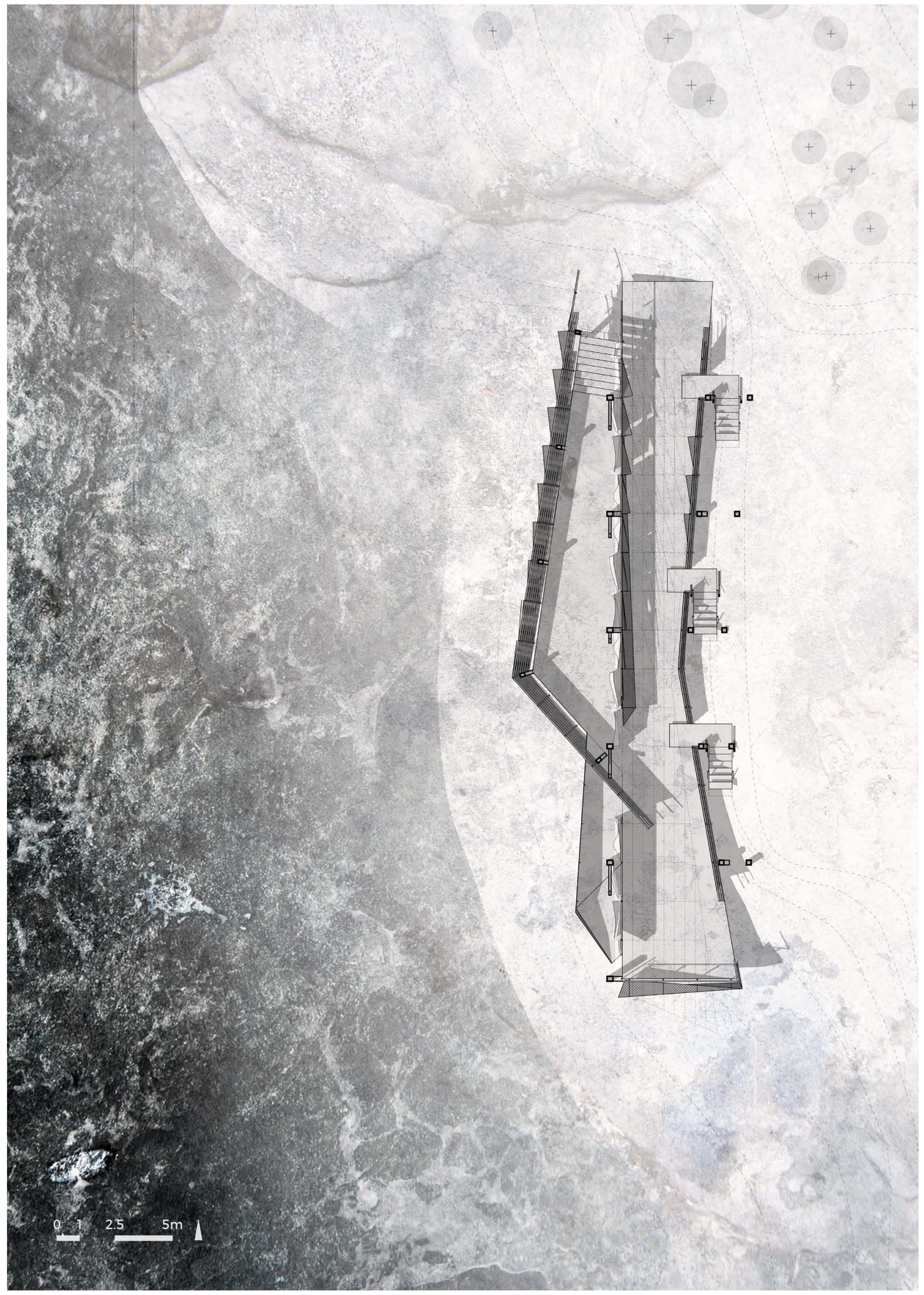


> 59 Plan Level 2 


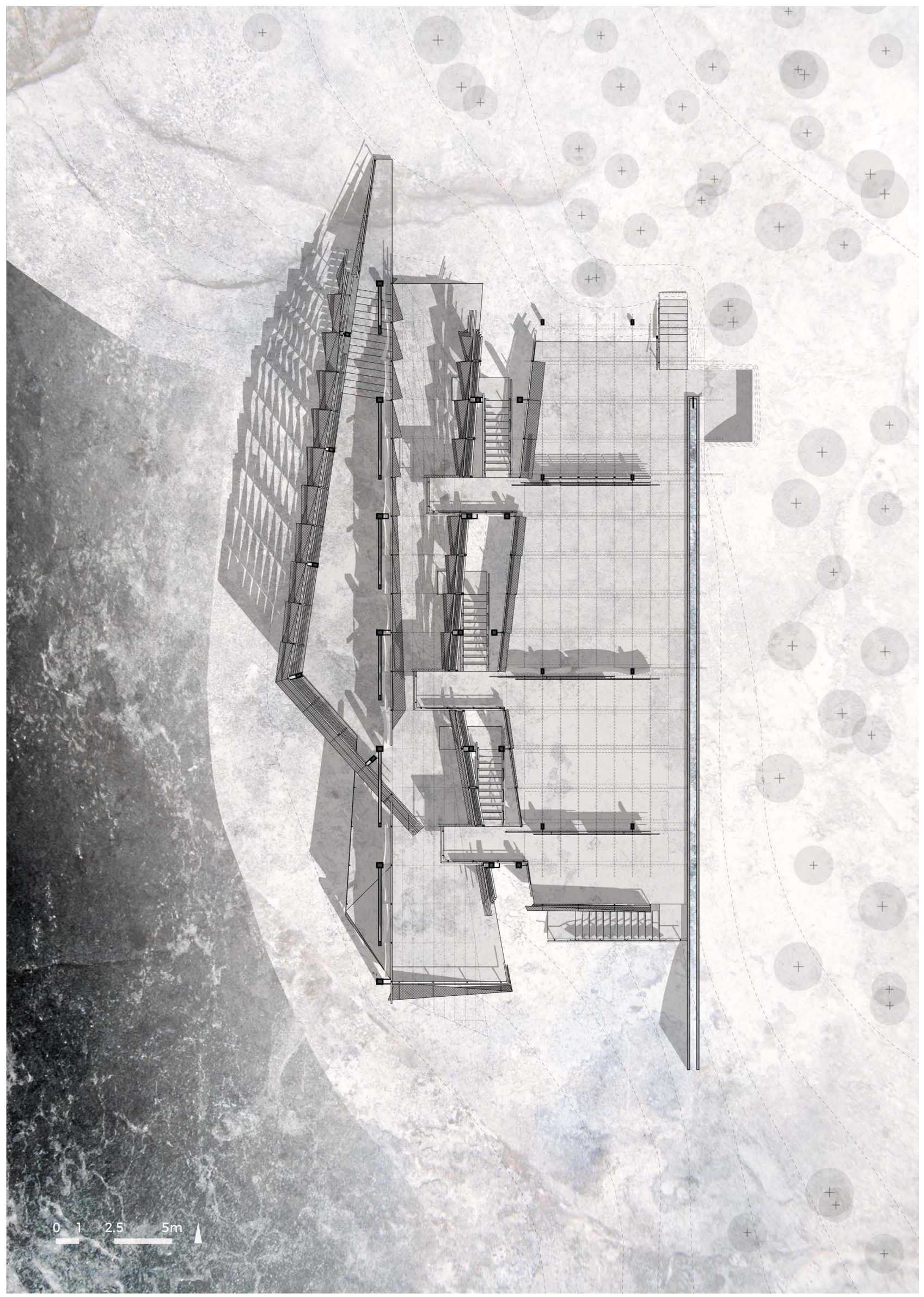




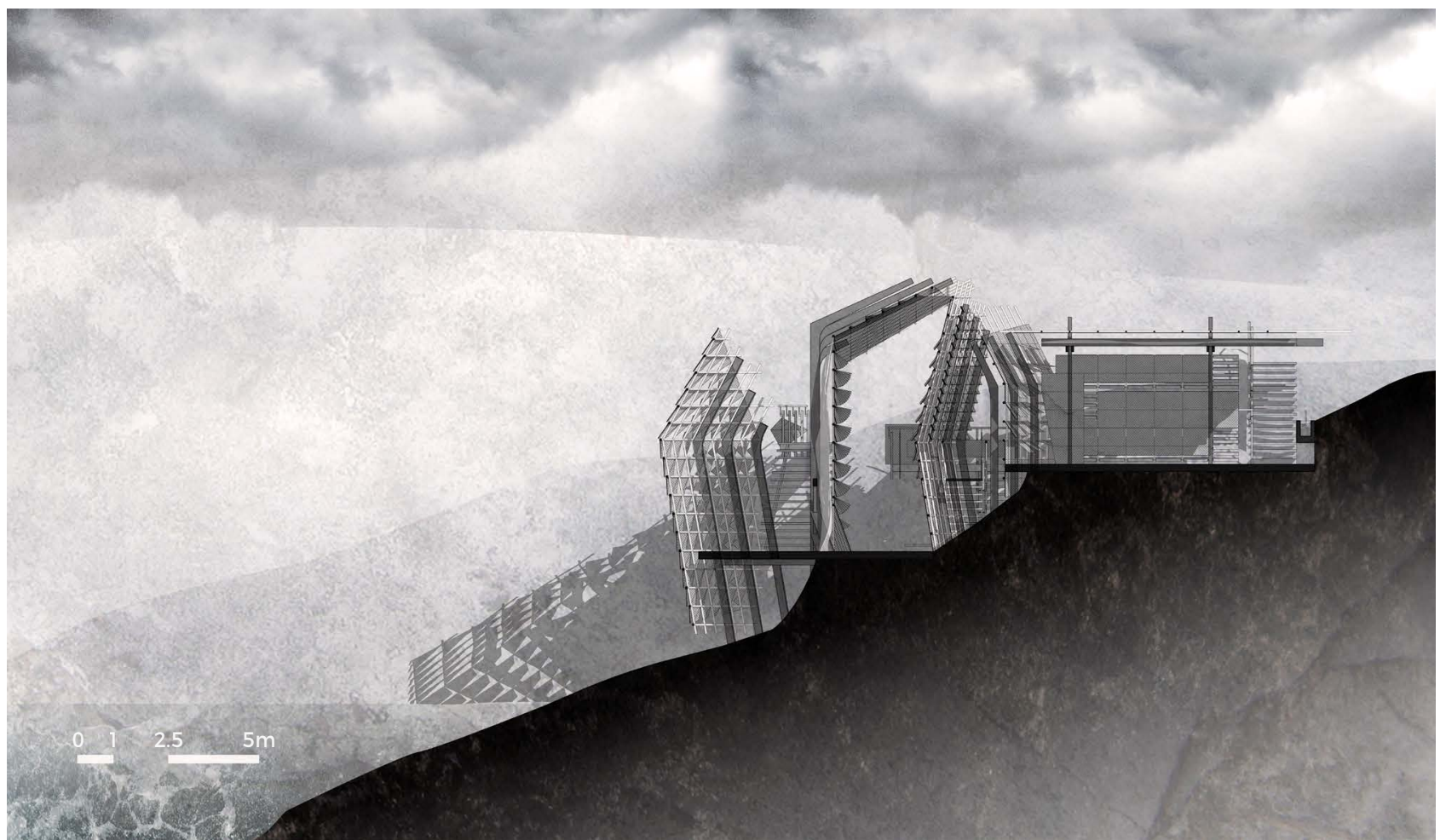

60 Section 
Within the retreat, the artist exists in a liminal space, experiencing varying degrees of enclosure as they transverse the length and width of the project. Because the retreat is designed as a threshold itself, there is no definitive moment within the project when the artist has entered, therefore by extension exited, the project. Moving within the space of the retreat, the artist is in a perpetual state of entering or exiting.

The retreat is not designed as a permanent residence and as such does not conform to the normative definition of a home comprised of hard boundaries and permanent rooms with a pre-determined function. The design is instead predicated upon creating a collection of places with ambiguous edges and a different spatial character that allow for a high degree of flexibility in use. It is up to the artist to determine what activity may occur where. The location of service spaces such as a kitchen or washroom is none the less suggested by the volume carved out of the site and its proximity to the source of water. The retreat relies on a thin linear scupper that runs parallel to the eastern edge of the project as its water source. As water trickles down the face of the rock over cycles of precipitation, it is collected, filtered and poured out from a spout at the north end of the scupper, running its length and eventually cascading off the south end.

The decision to layer different materials and spatial configurations was driven by the intent of creating multiple places of different atmospheric character. As the atmospheric variables filter past each surface, they manifest a different quality, altering the atmosphere of that particular volume. The following speculative narrative describes the experience the artist might have whilst at the retreat. 


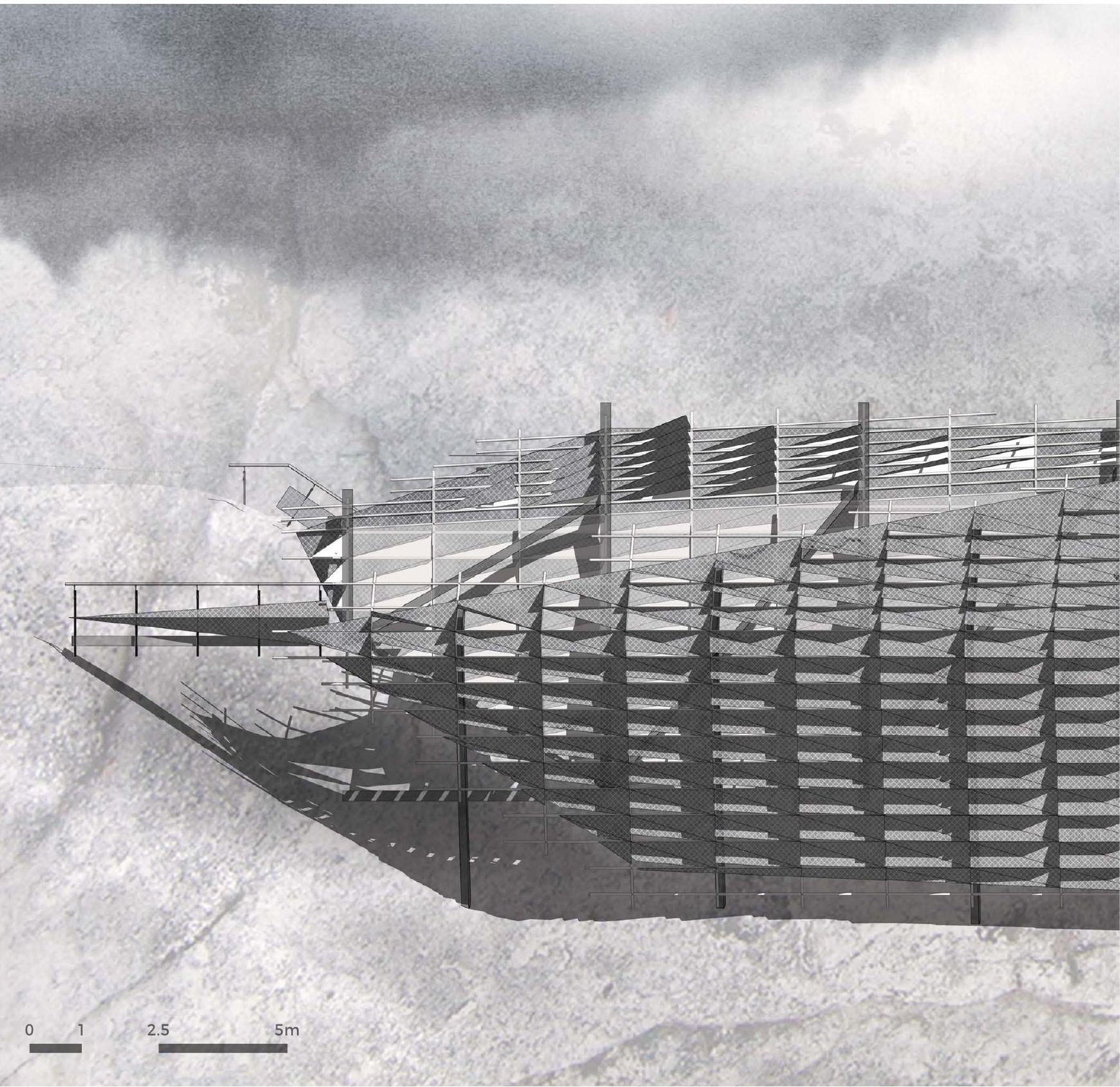




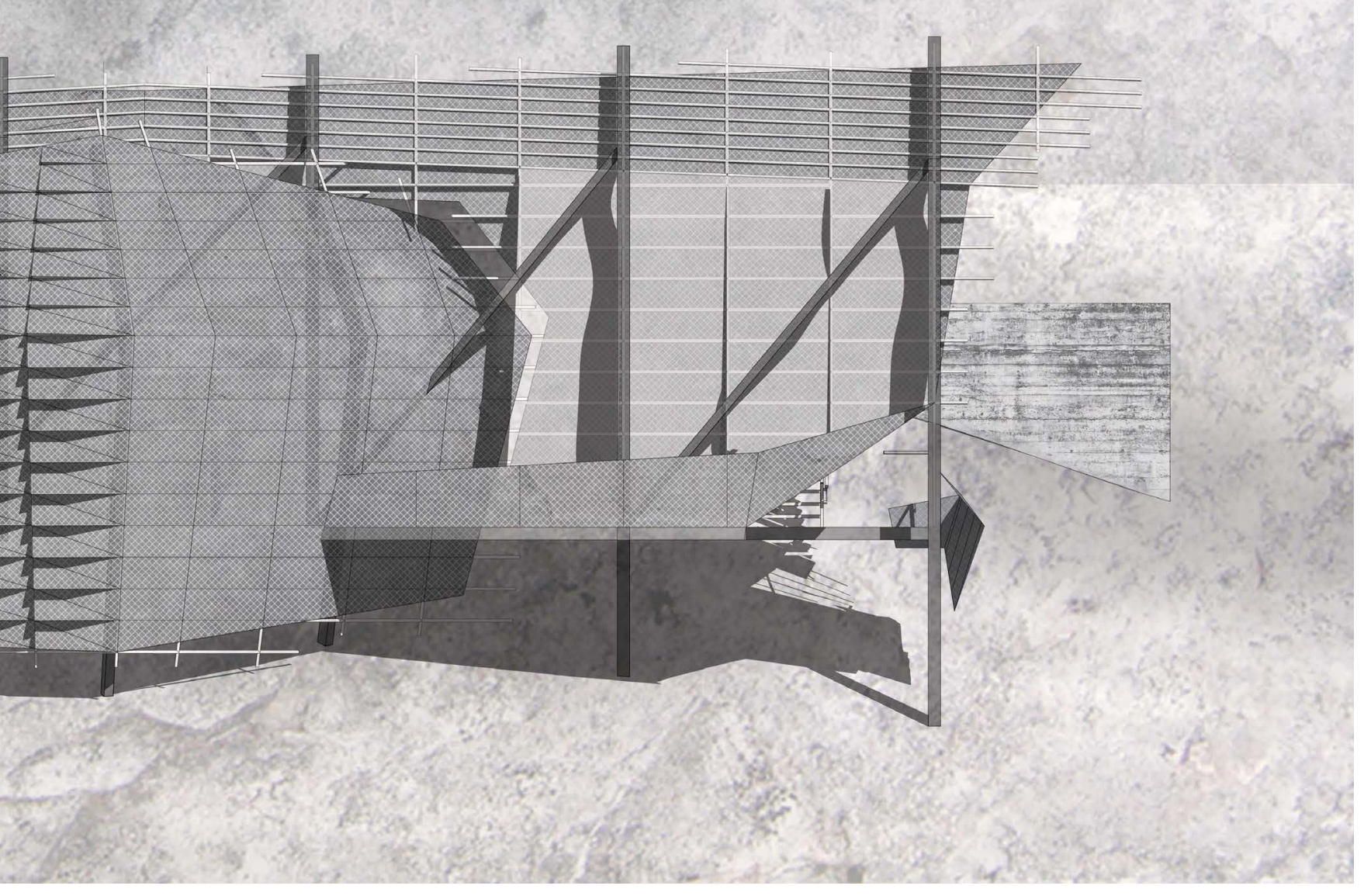

61 West Elevation 
Clearing the thick cluster of windswept white pine trees, the artist pauses on the weathered, metamorphic rock of the exposed Canadian Shield, watching as the deep blue waters of Six Mile Lake stretch out before their eyes. The air is thick with moisture. The potent fragrance of the trees fuses with the earthy scent of a recent downpour into a remarkable aroma. There's a light breeze that caresses the warmth of the artist's skin, carrying with it the sound of the ruffled foliage as it shuffles past. Turning their gaze, the artist spots the alien shell of the retreat peeking out from behind a considerable depression in the profile of the site. 


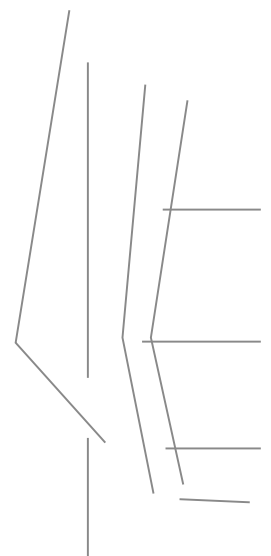




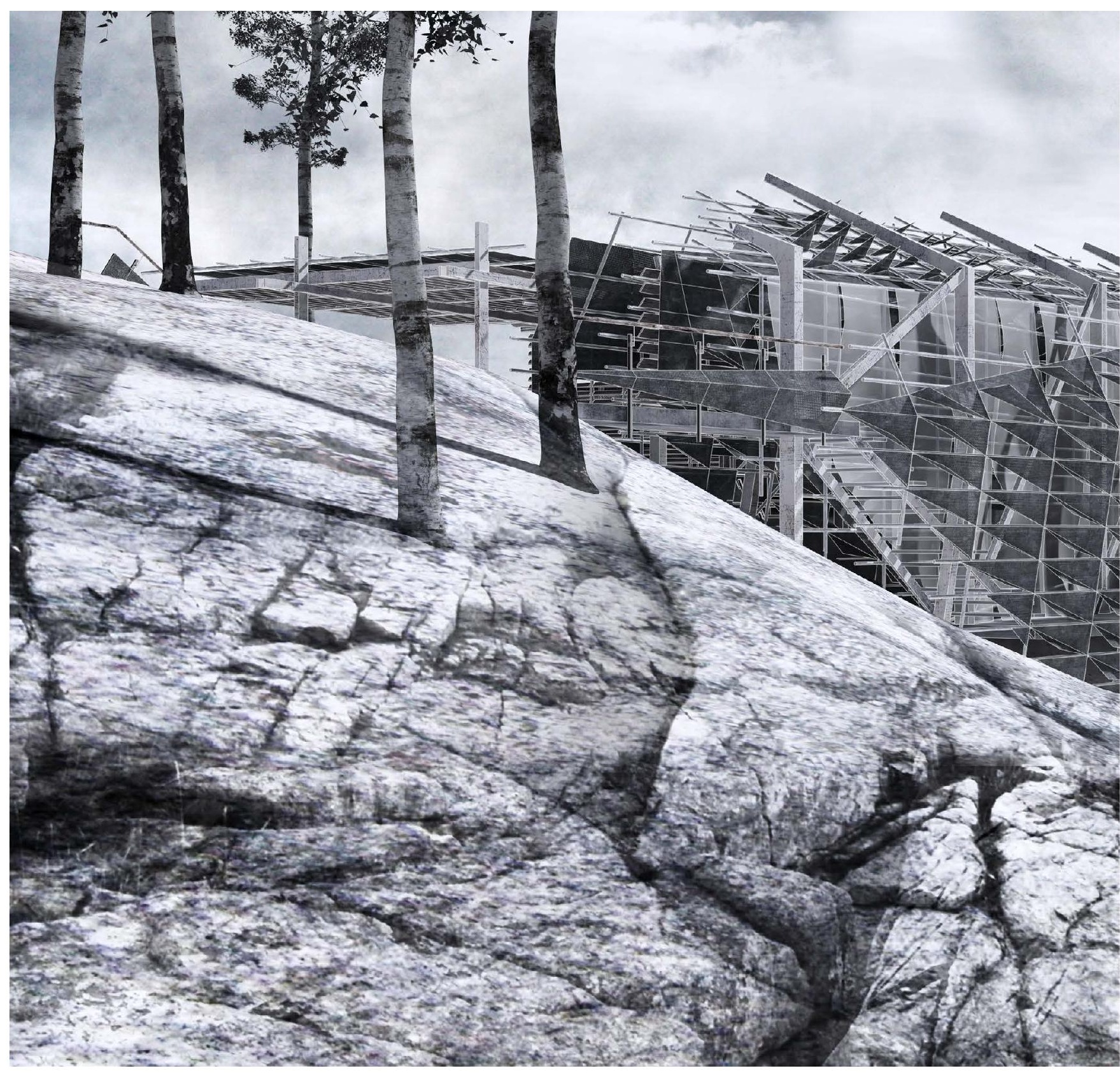




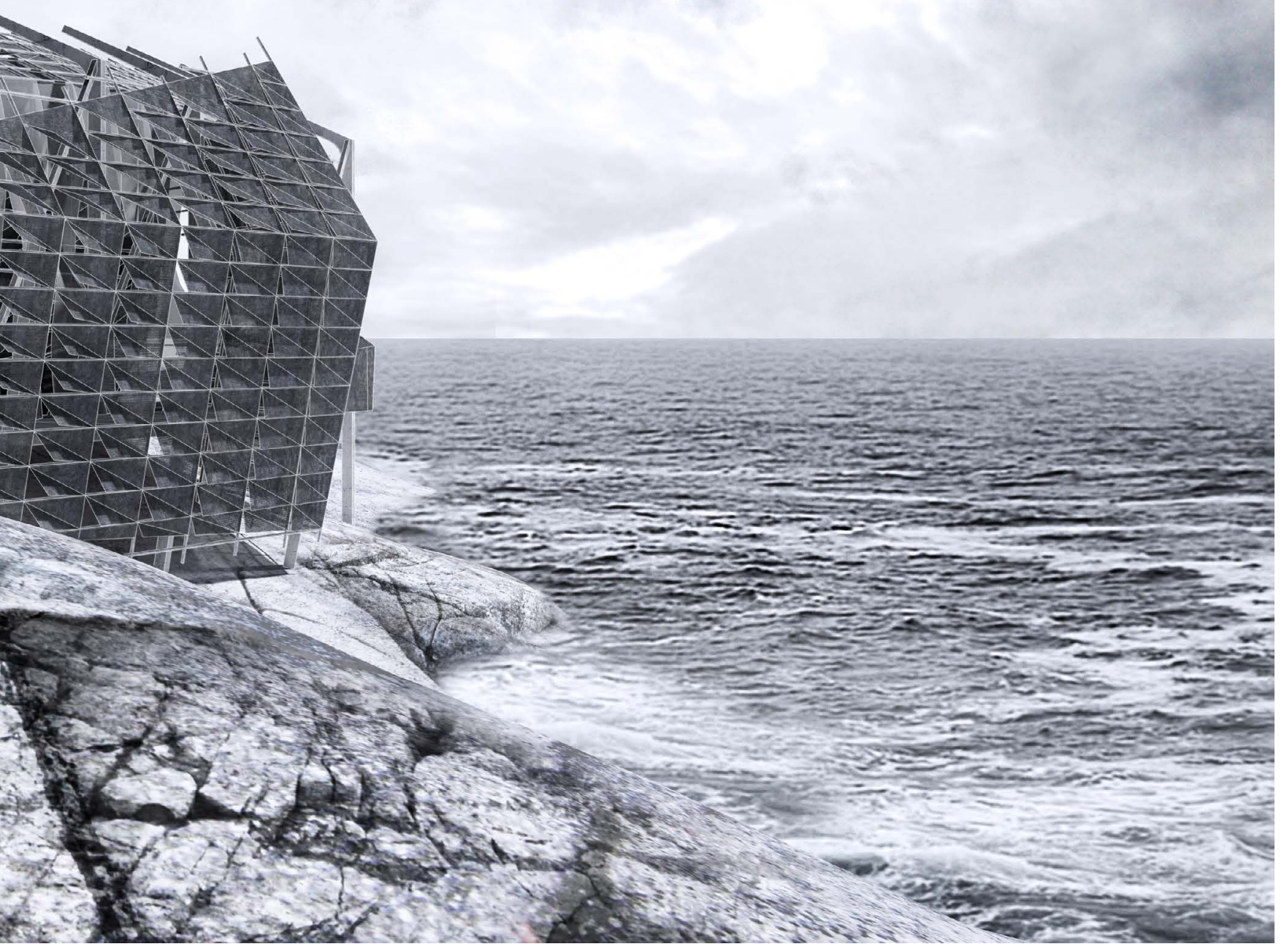

62 Weathered Canadian Shield 
From here, the first point of physical contact with the retreat is a narrow platform which suspends the artist for a brief moment as it bridges the gap left by the same topographic depression. 


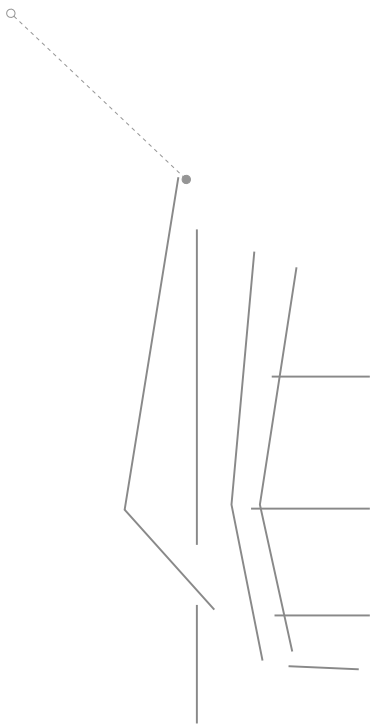




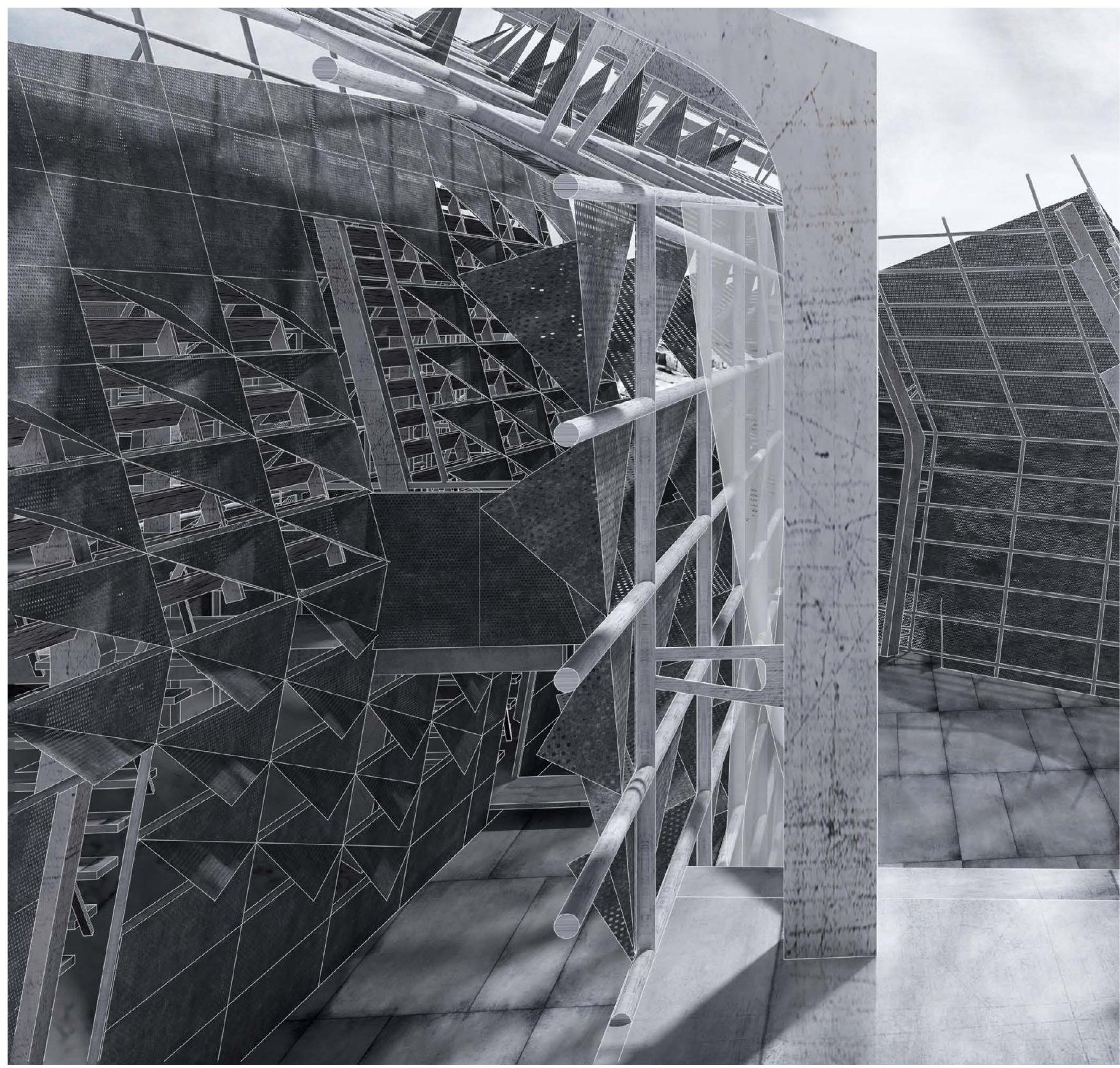



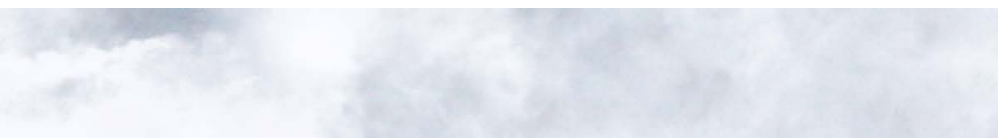

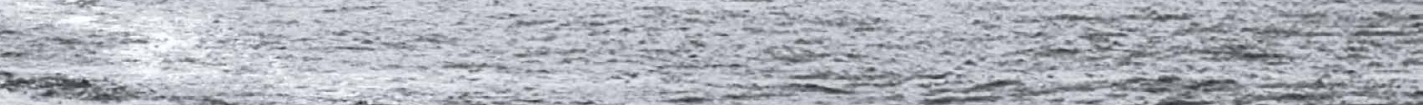

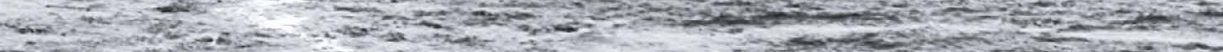

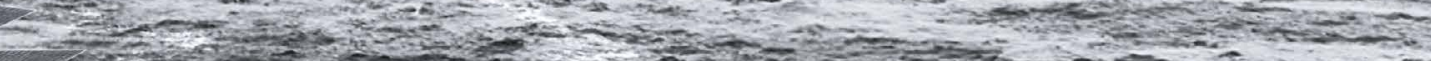

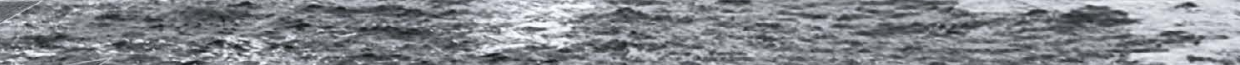

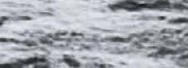

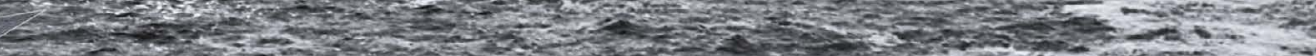

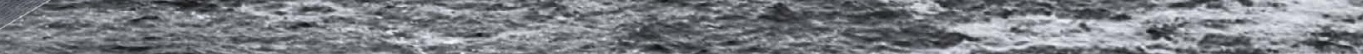
2.

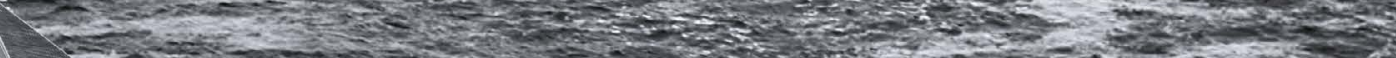

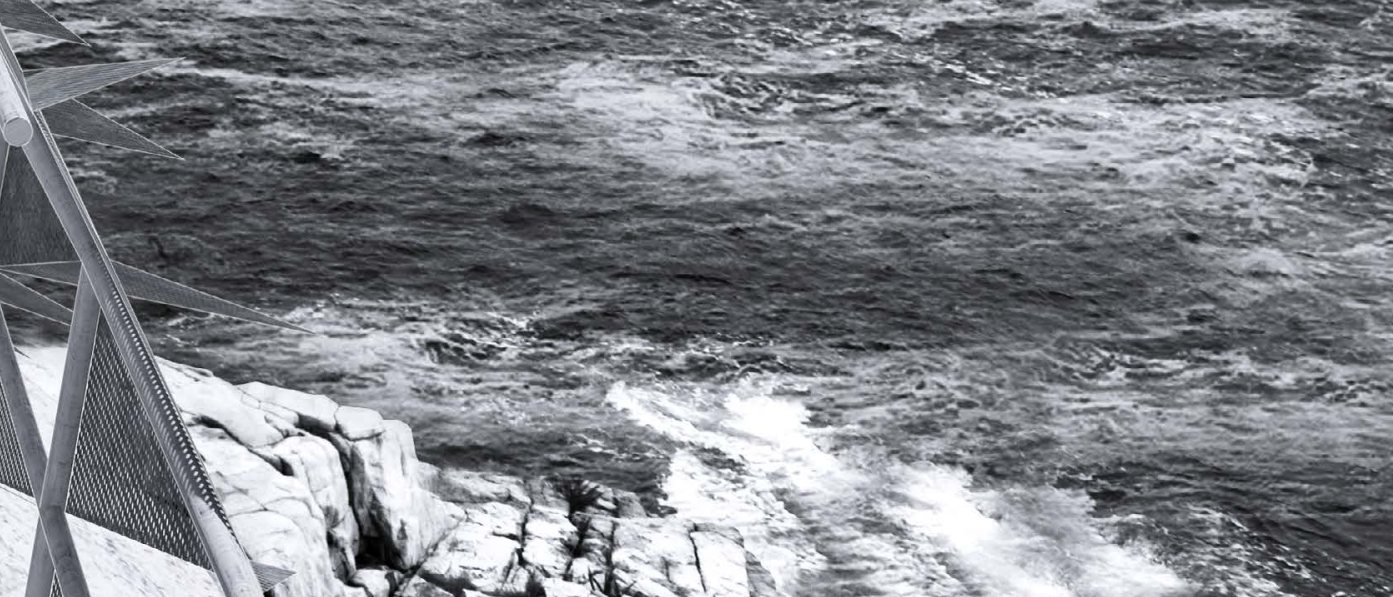

63 Bridging the gap 
Descending into the outer volume, with each consecutive step what was just a railing takes on the form of a wall, or a perhaps a roof; it's indistinguishable. Here the artist finds themselves cocooned by two distinct surfaces. On the right, in a moment of tension, droplets of water tightly grip the pores of the perforated metal panels as they fervently fight the force of gravity seeking to dislodge them from their comfort. The wet floor serves as yet another witness to the earlier rainfall. Though, closer to the right edge it remains dry, printing the outline of the wall / the roof on the deck of the floor. Occasionally the perforated metal panels rattle, adding to the choir of the frondescence and in the process giving victory to gravity in its fight against the water droplets. 


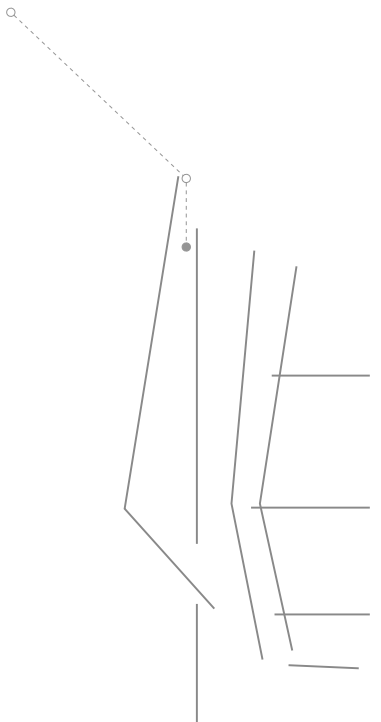




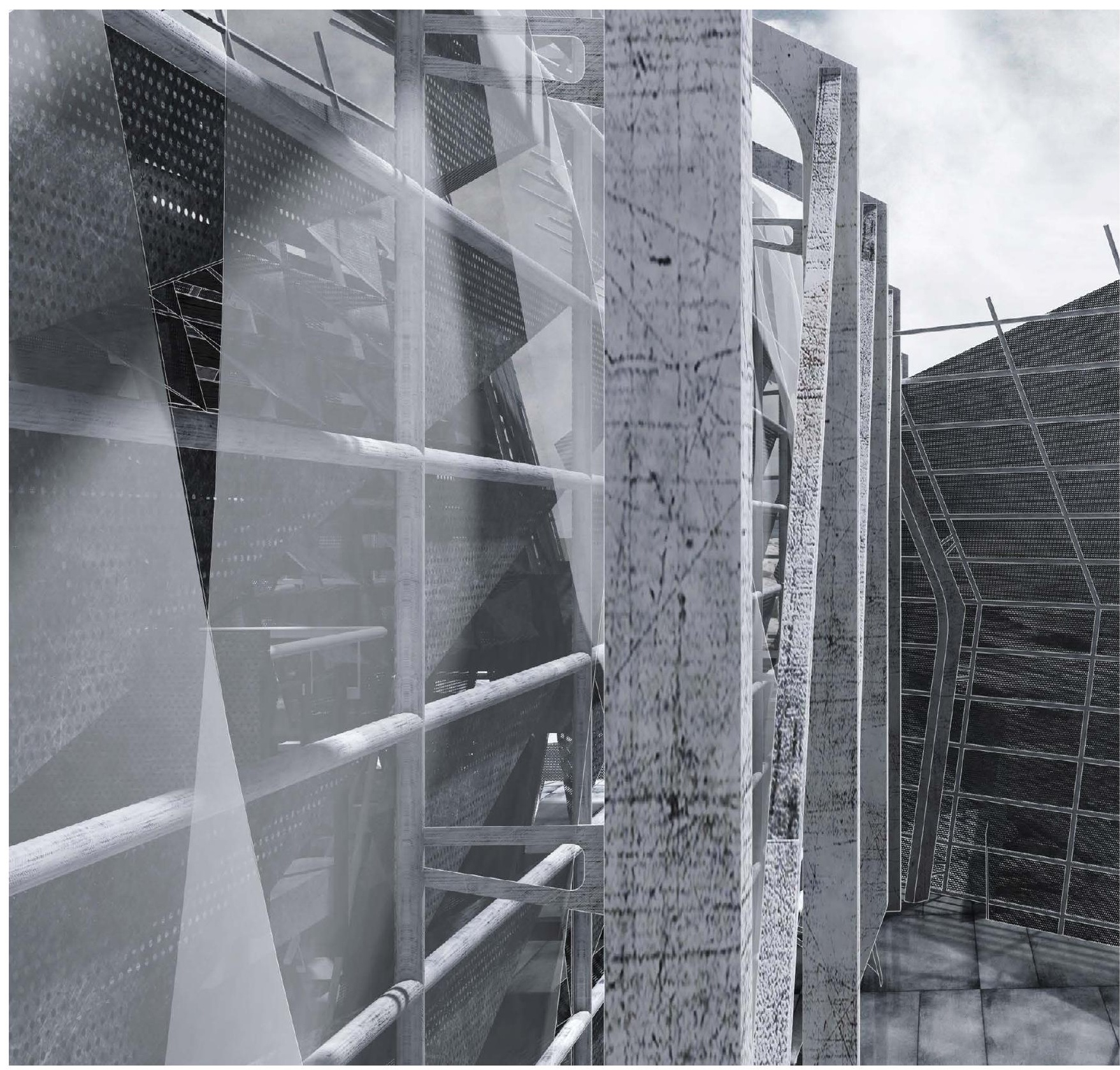




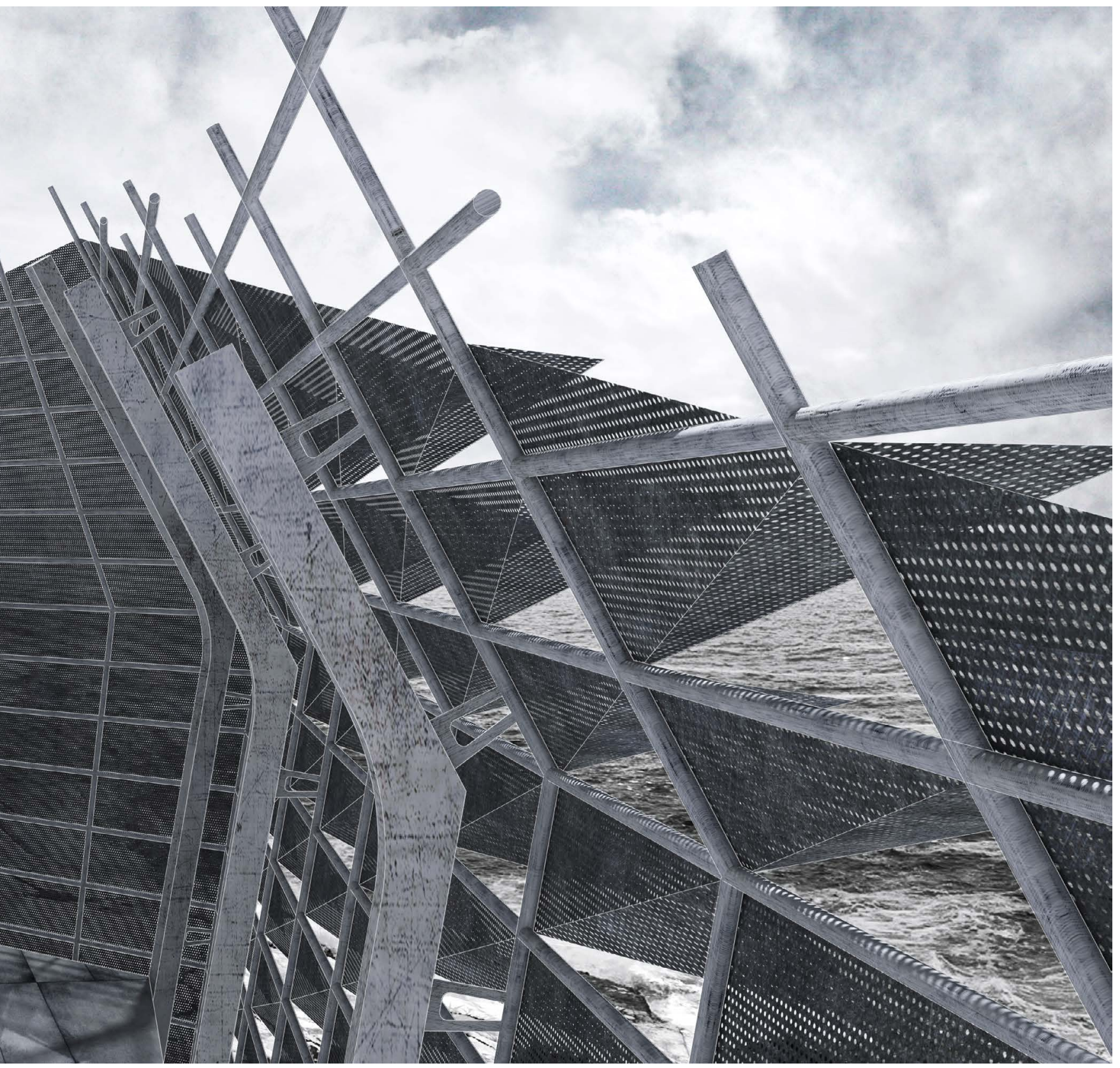

64 Cocooned 
Gravel-grey clouds which consumed the sky gradually pass, sun light increasingly begins to flood directly into this volume, projecting shadows of the structure onto the sheets of white fabric draped over the perforated metal shell to the left of the artist. The shadows choreograph a routine on the fabric as it flutters ever so delicately in the wind, providing glimpses of what lies beyond, revealing an opening which invites the artist in. Moving towards this opening, the presence of the persistent breeze, perceived distinctly thus far begins to subside, a consequence of the declining angle of the fold that defines the triangular openings across this exterior shell. 


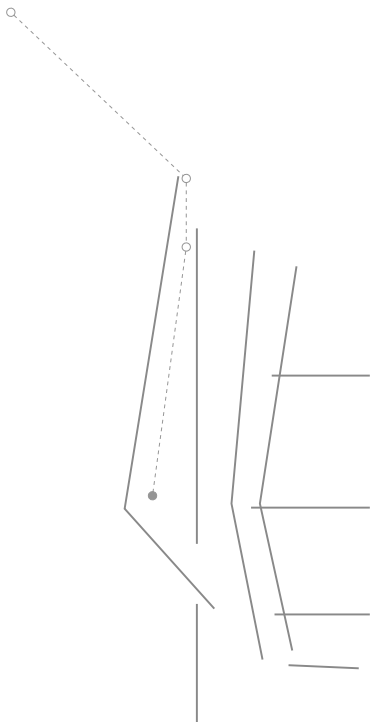




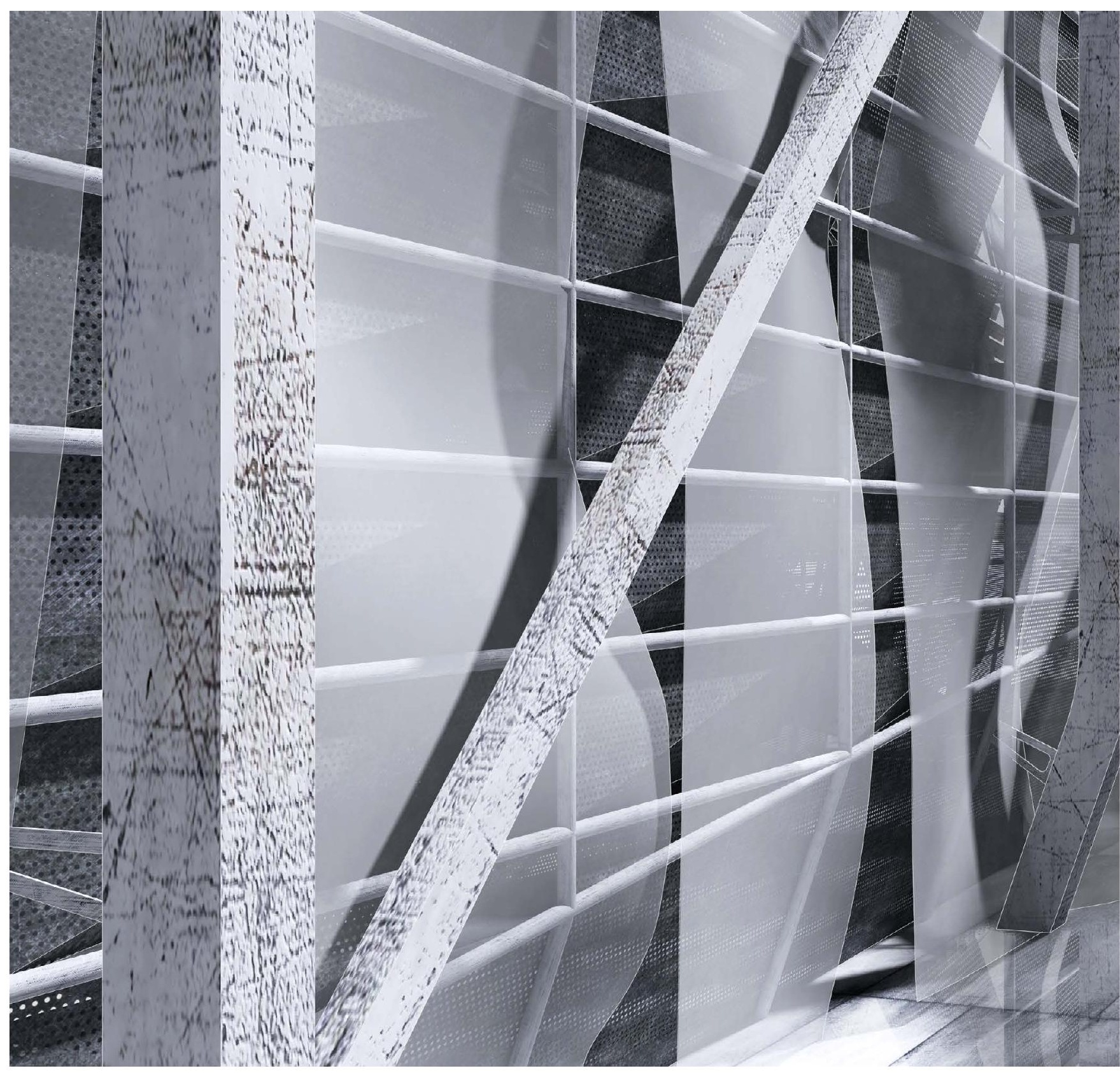




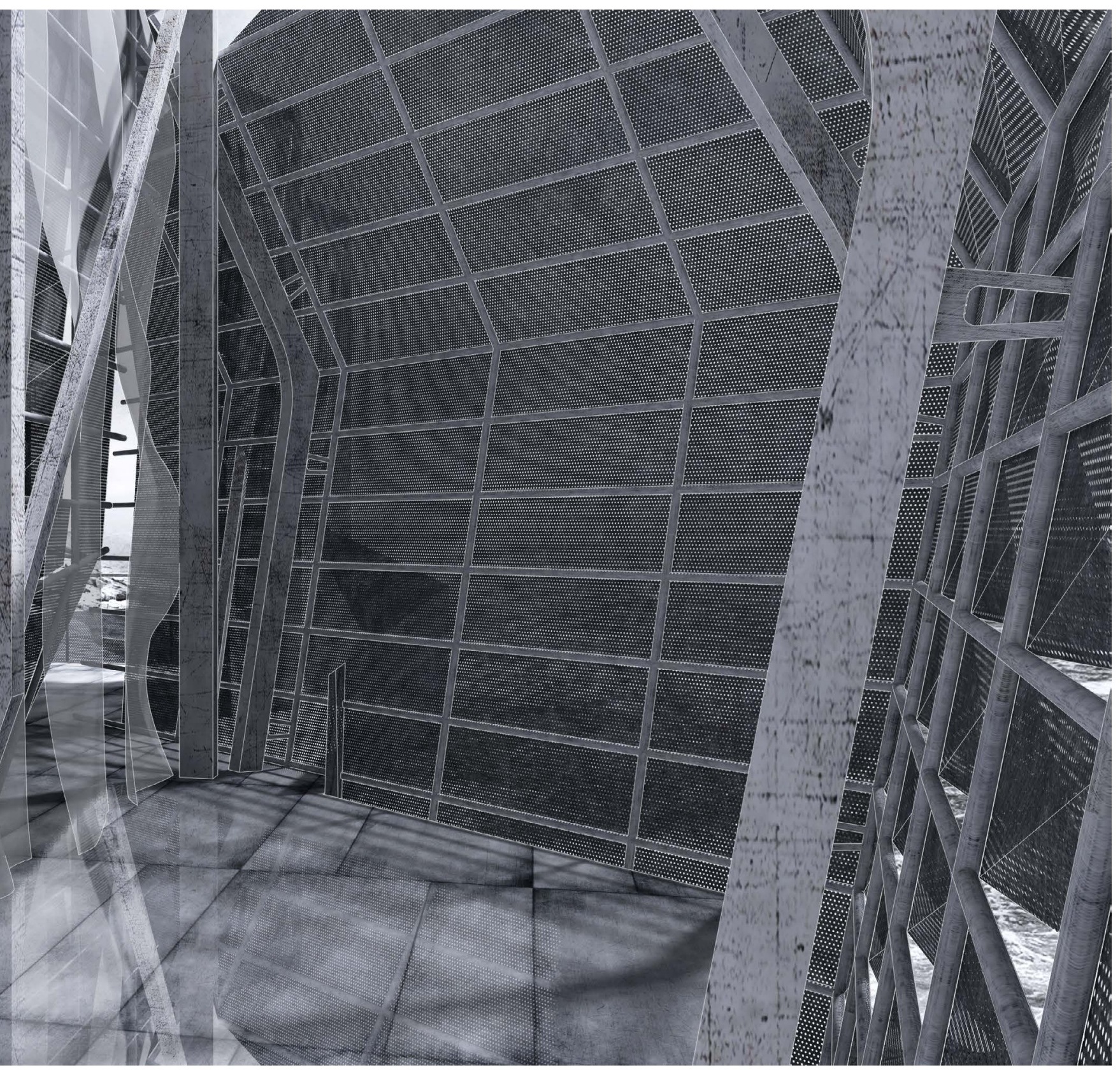

65 A choreographed routine 
Entering the second volume, the artist finds themselves nestled in a space that evokes the sensation of a thin but tall tunnel at a point where its two ends converge to a narrow. The air still so damp, one could almost taste it. The artist proceeds to the south, the tunnel gradually widening, towards the brightness that attempts to penetrate deep into the volume but falls short. 


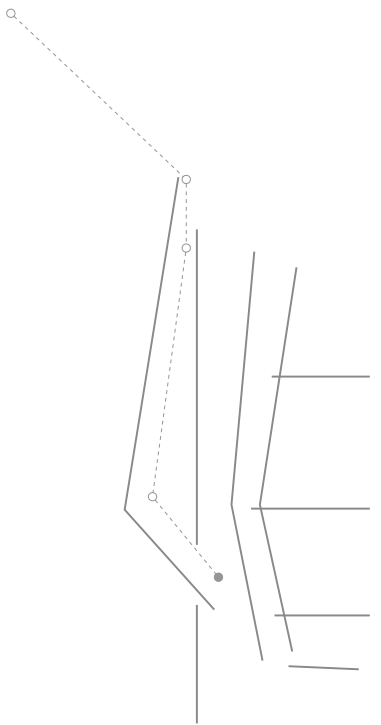




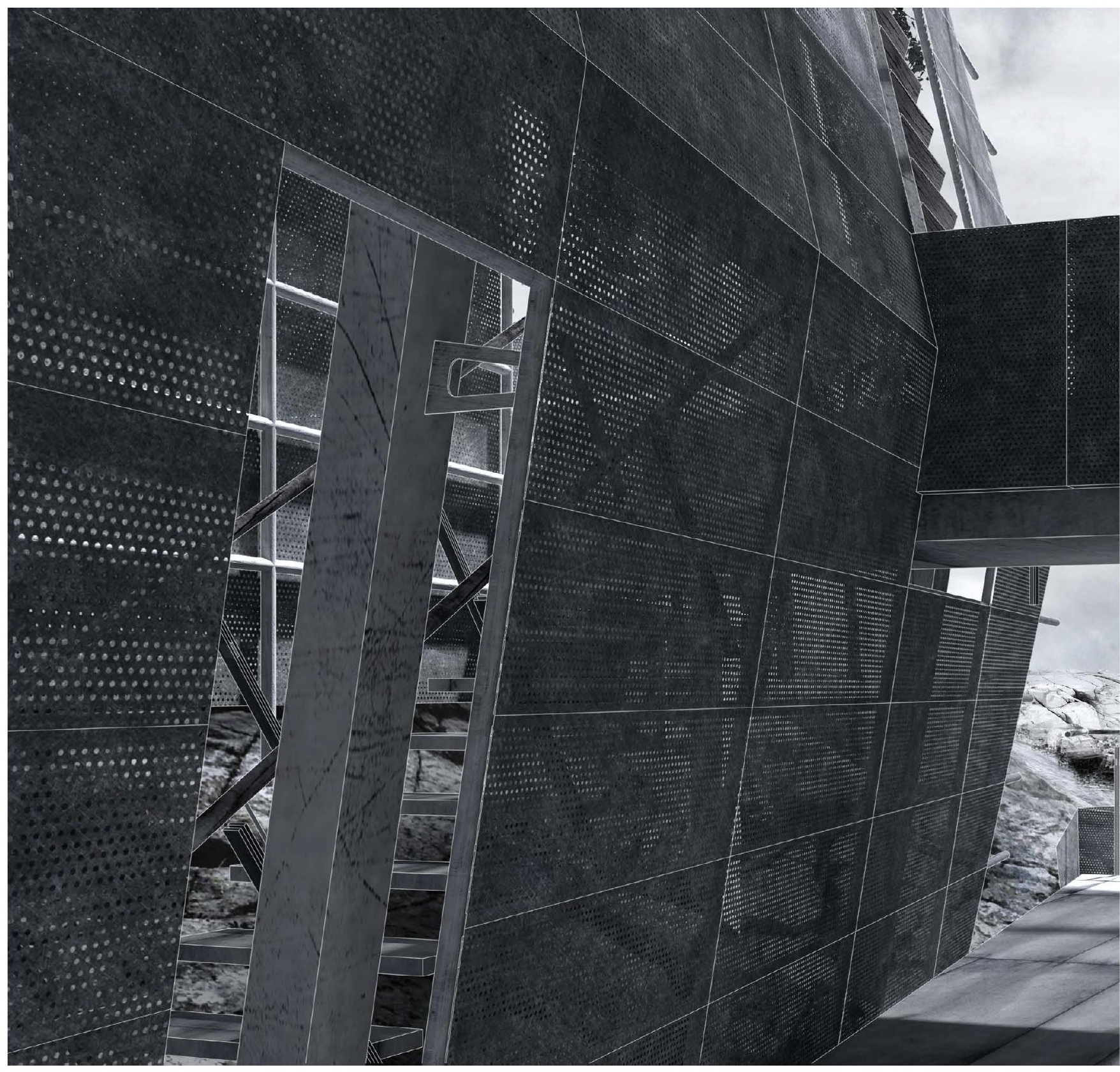




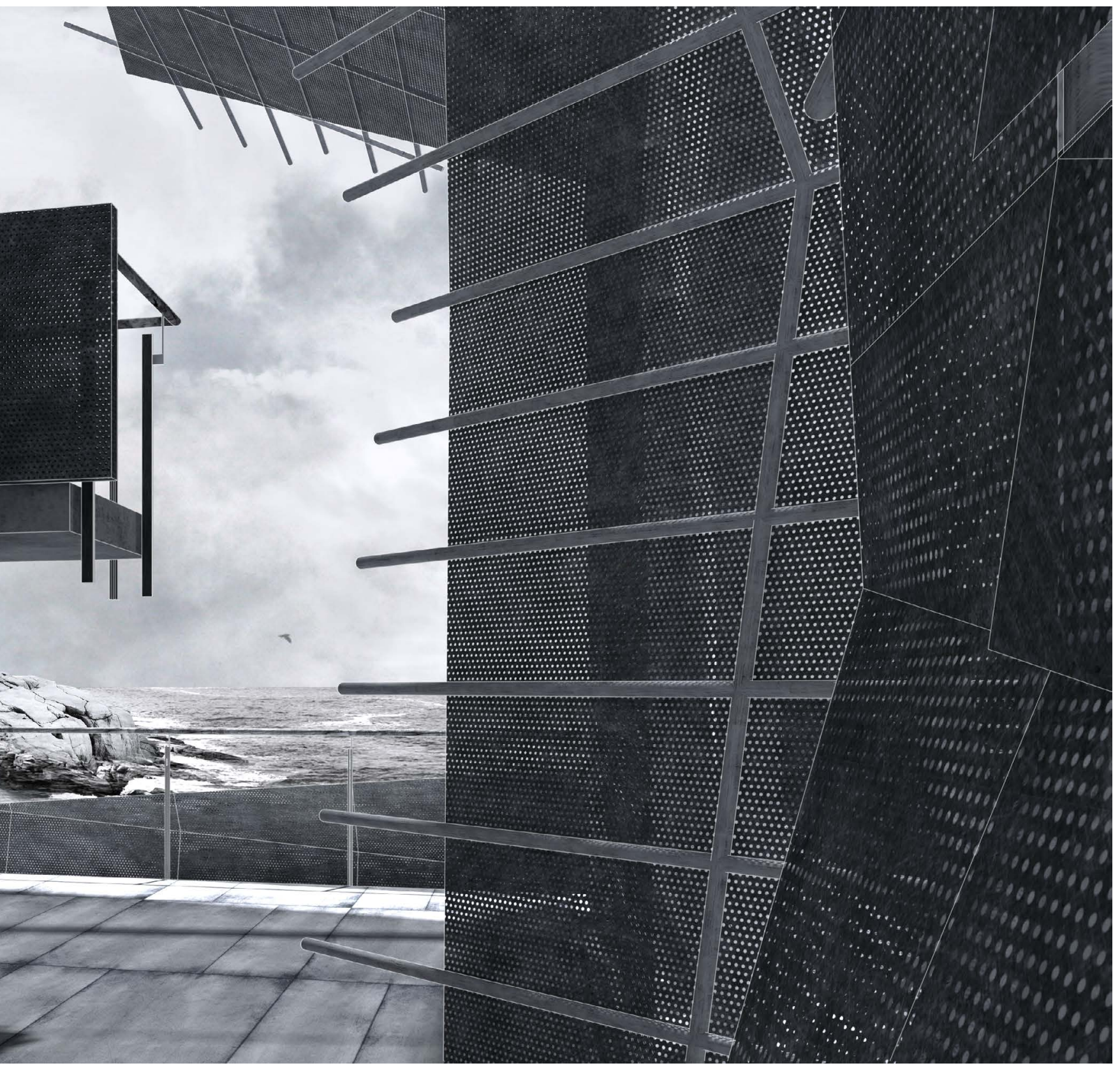

66 Tasting the air 
The eyes follow the contours of the site which disappears as it rounds the corner. In the distance, tiny islands sporadically emerge from the water. A fresh gust of southern wind brushes the face of artist. Its whistle gently fading as it races down the depth of the volume. 


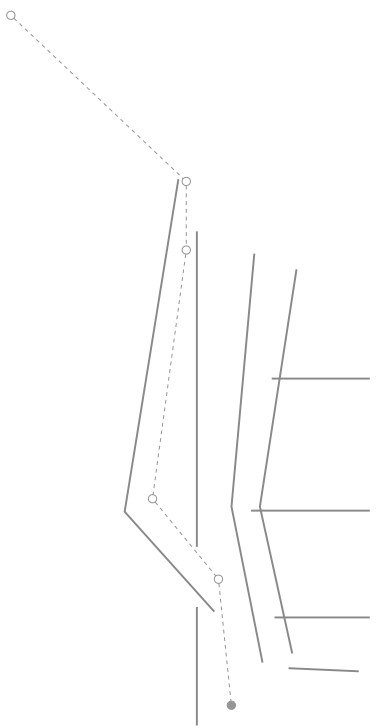




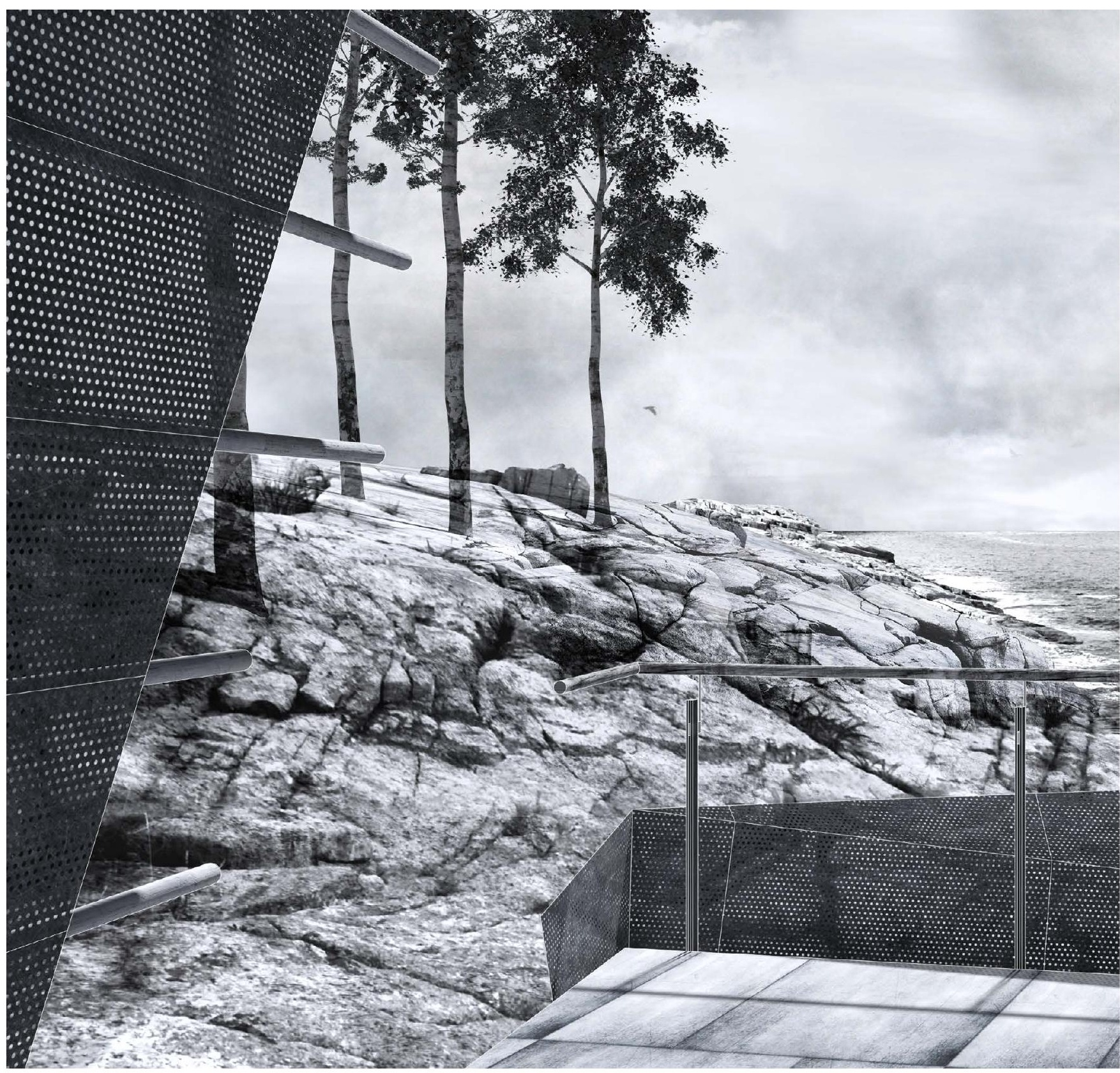


Now about face, the artist leisurely proceeds northwards where the retreat appears to collide with the rugged face of the depression. Here, unlike before, light punctures the surface of the shell in a much more diffused manner, a consequence of the perforations and draped fabric. A few openings above, towards the north, do for certain periods allow the high sun to permeate through directly. Passing the narrow, openings along the western surface once again invite the western winds in, though this time only to the degree the fabric permits. On the right, the artist will have passed three generous openings that provoke their interest. 


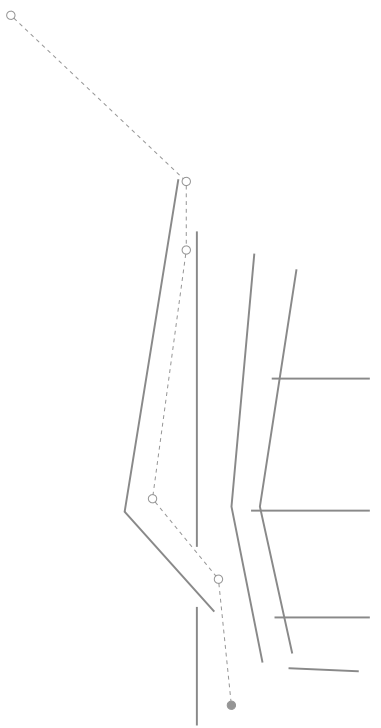




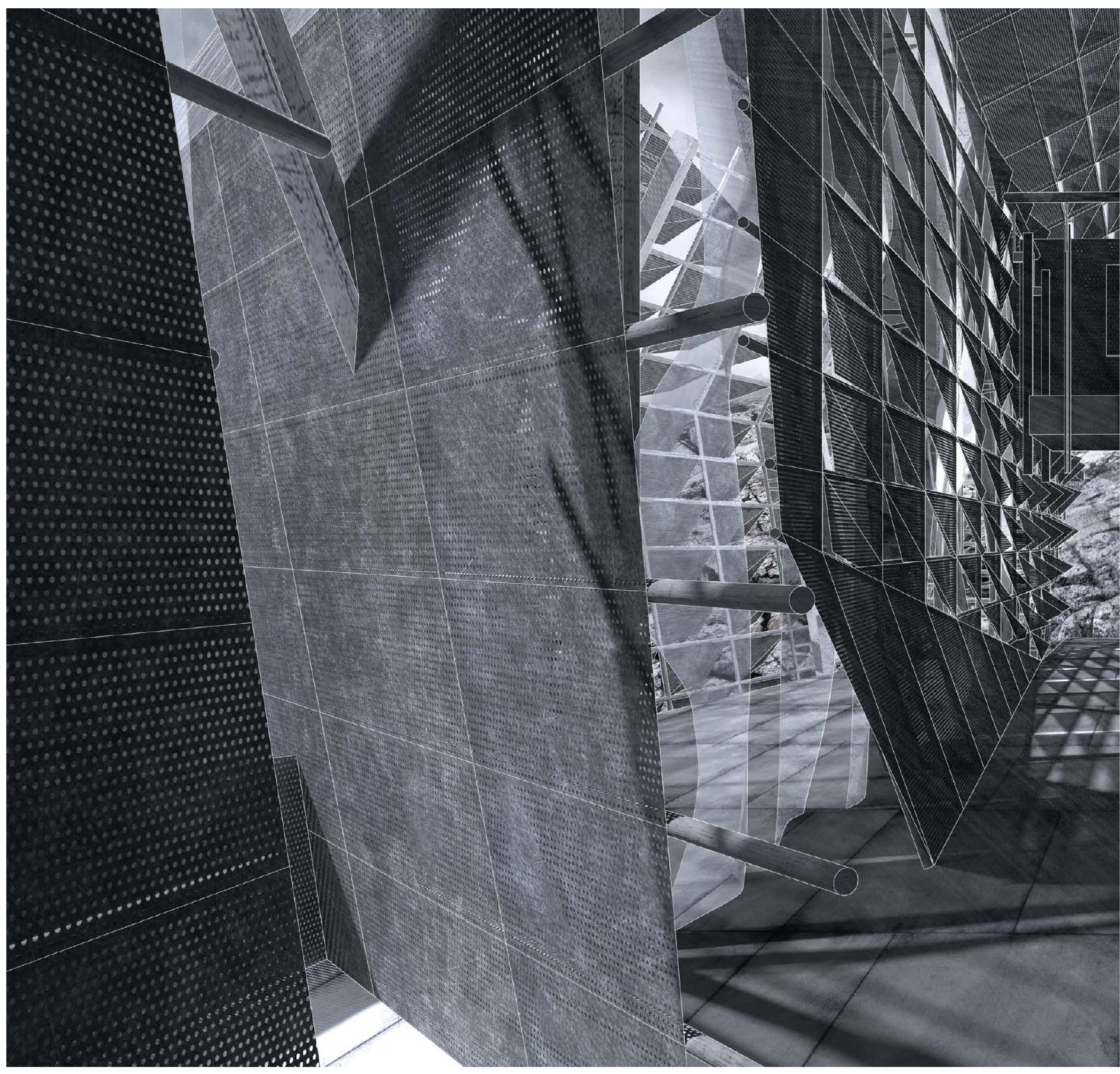




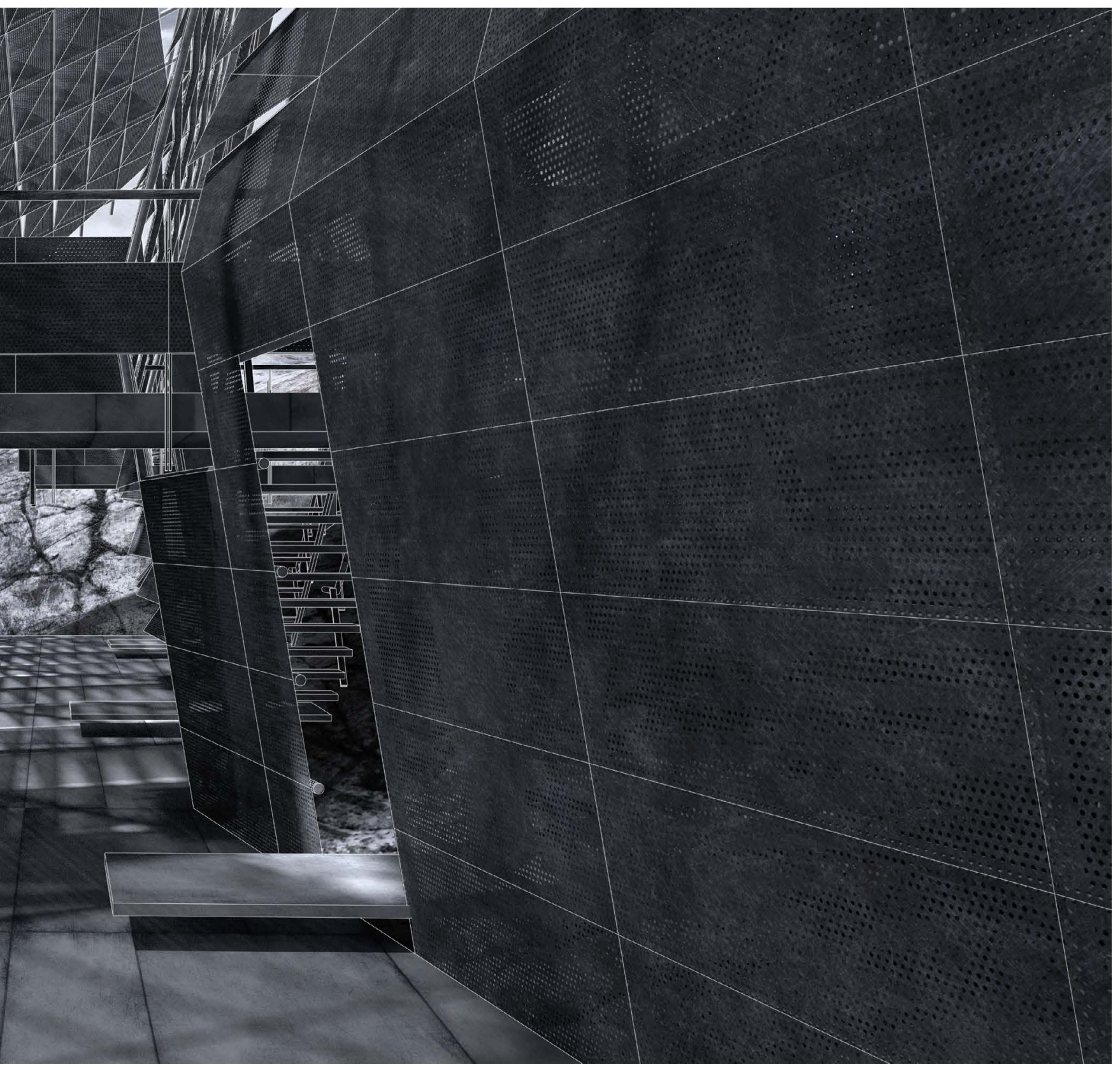

68 A rugged face 
Curiosity takes over as the artist steps into the last opening passed where they find themselves in a narrow, intimate, cavernous place of compression. Pressed up against the rock, all distractions fade away. Light can't enter in as easily the artist did, the timber louvres on the right ensure this. The sights and sounds of moments ago seem like distant memories now. Yet what has remained as constant as first encountered is that poignant aromatic essence of the site. 


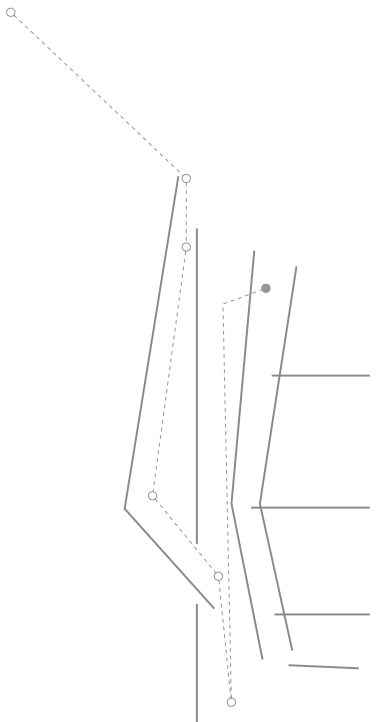




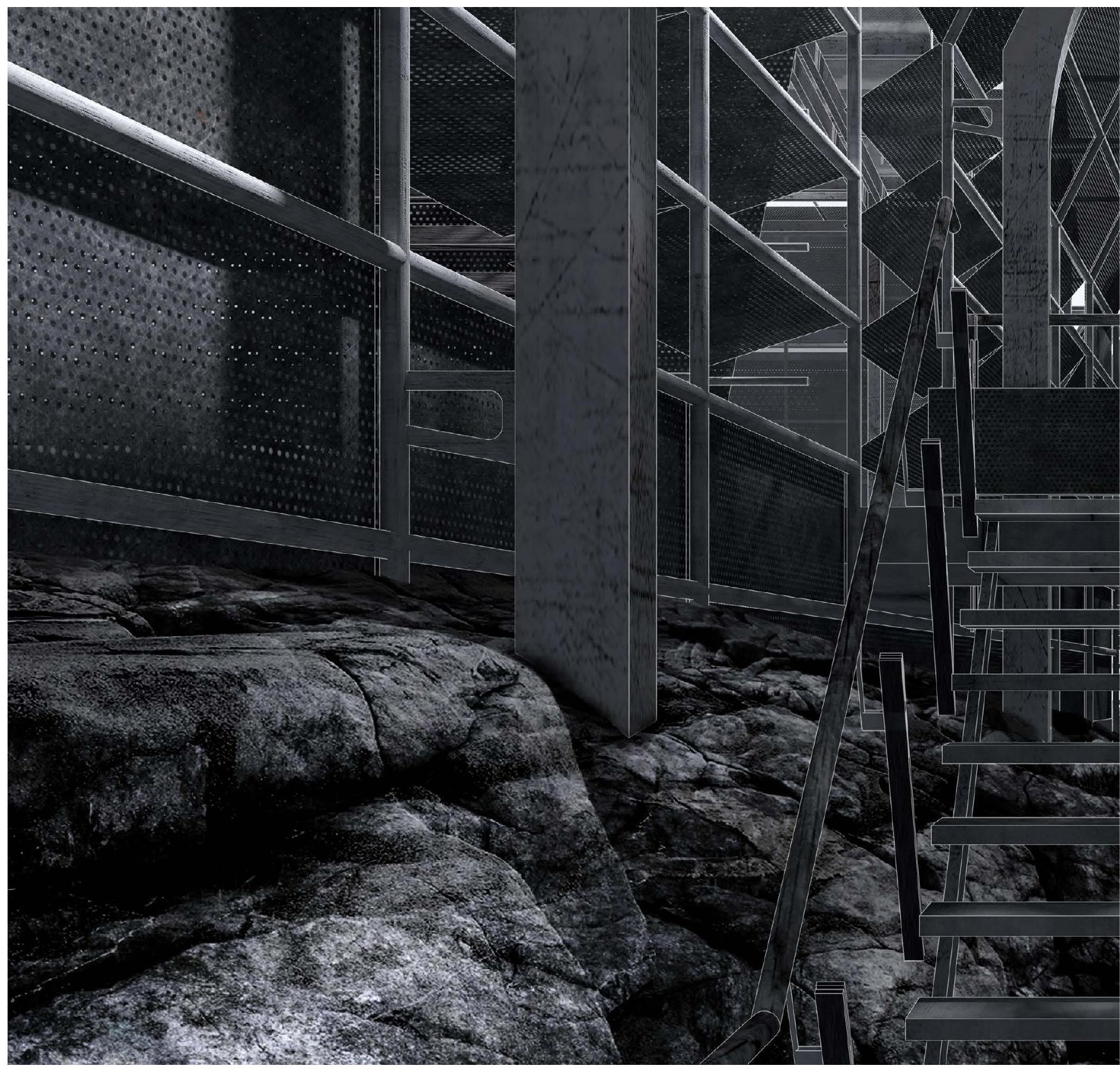




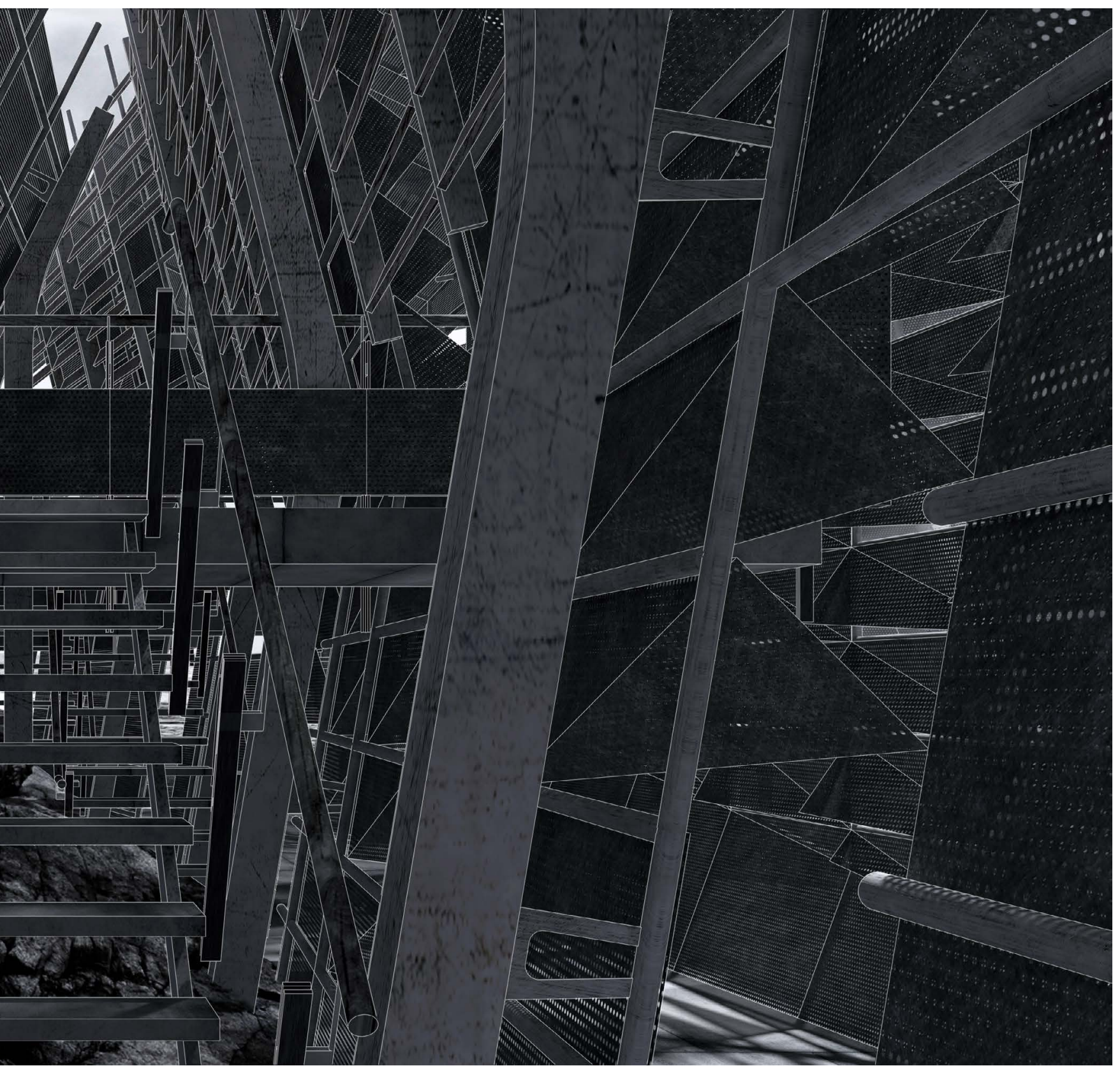

69 Cave of compression 
Ascending the stairs, the artist arrives at a junction. To the right, puncturing the shell of louvres and perforated metal is a lookout that bleeds into the adjacent volume. 


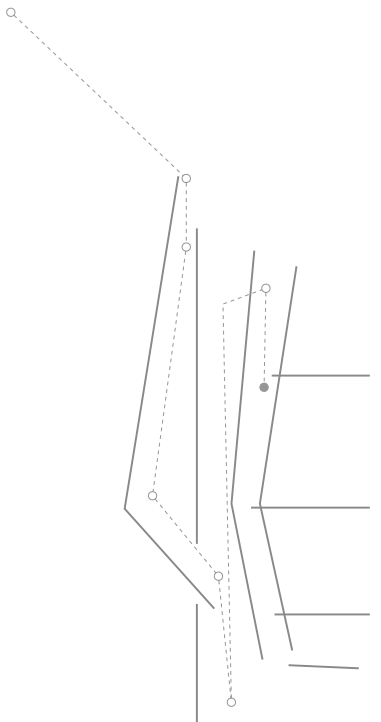




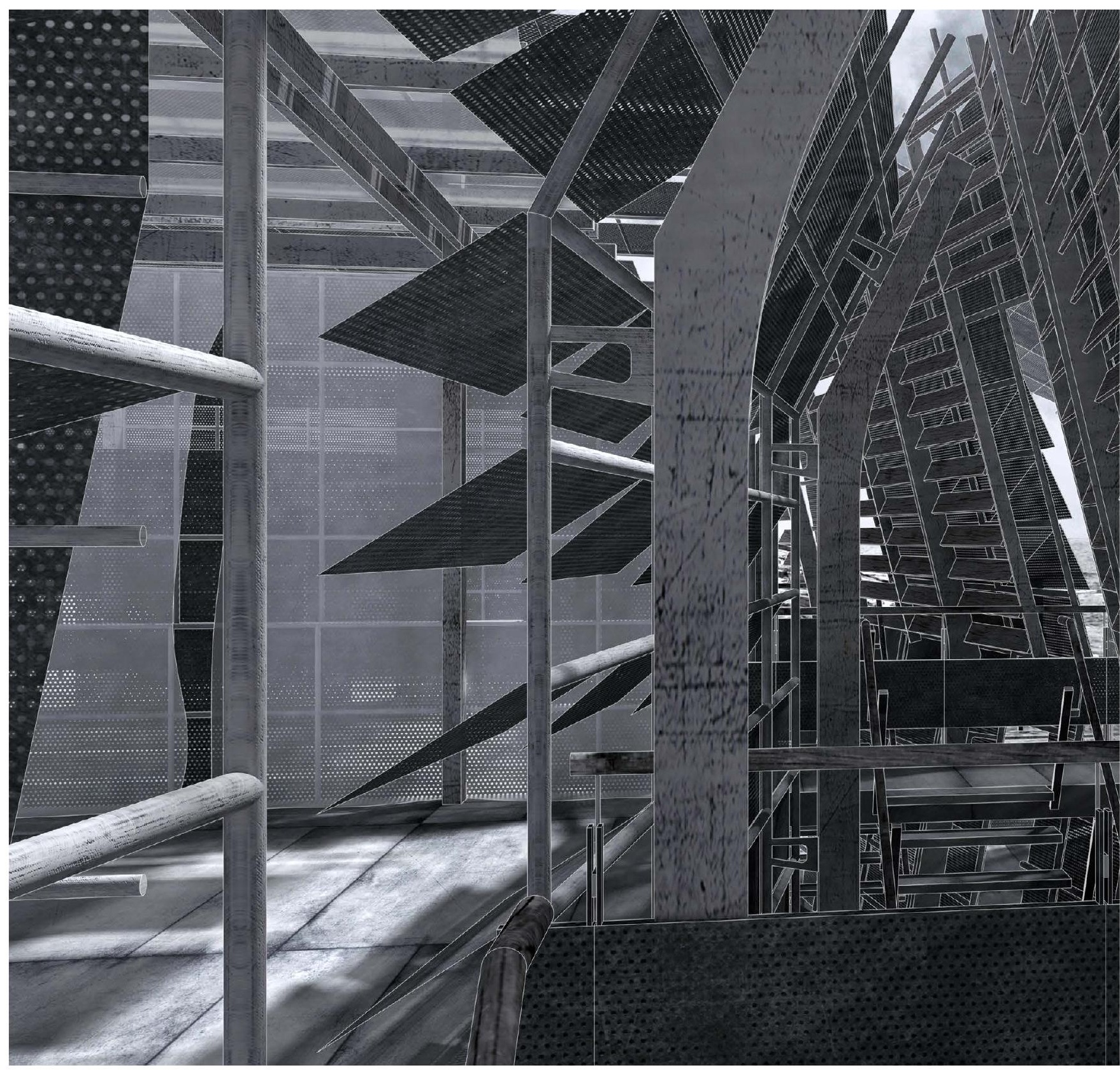




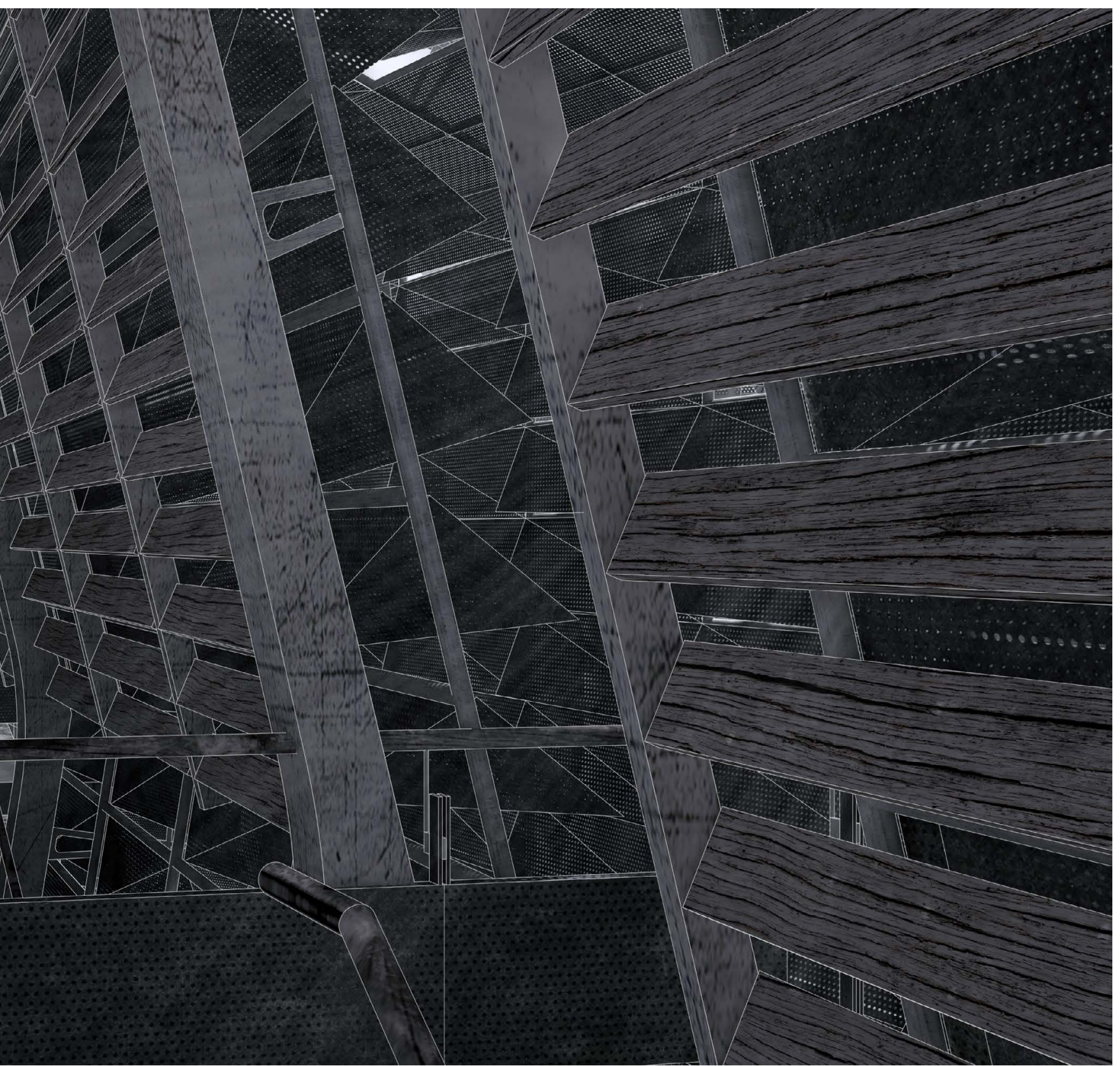

70 At a junction 
Choosing to go left, the artist enters what is the most temperate part of the retreat. Heat radiating from the fire place envelops the artist in a blanket of warmth as the intoxicating musky whiff of charred pine excites the nostrils. Taking advantage of the natural slope of the site, the rocky terrain defines the northern and eastern edges of this part of the retreat while layers of timber, fabric and perforated metal unravel in the remaining directions. Light, once again, is drawn in. 


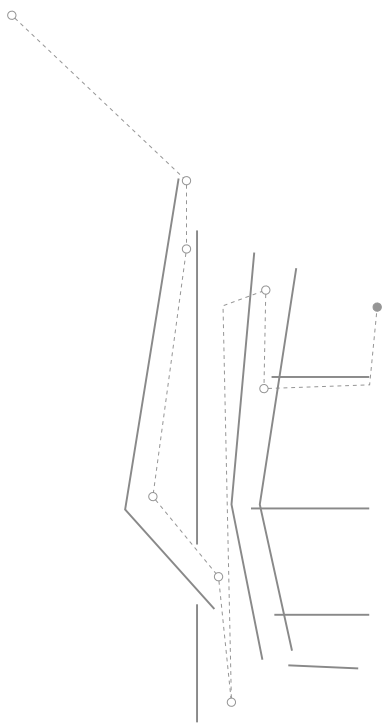




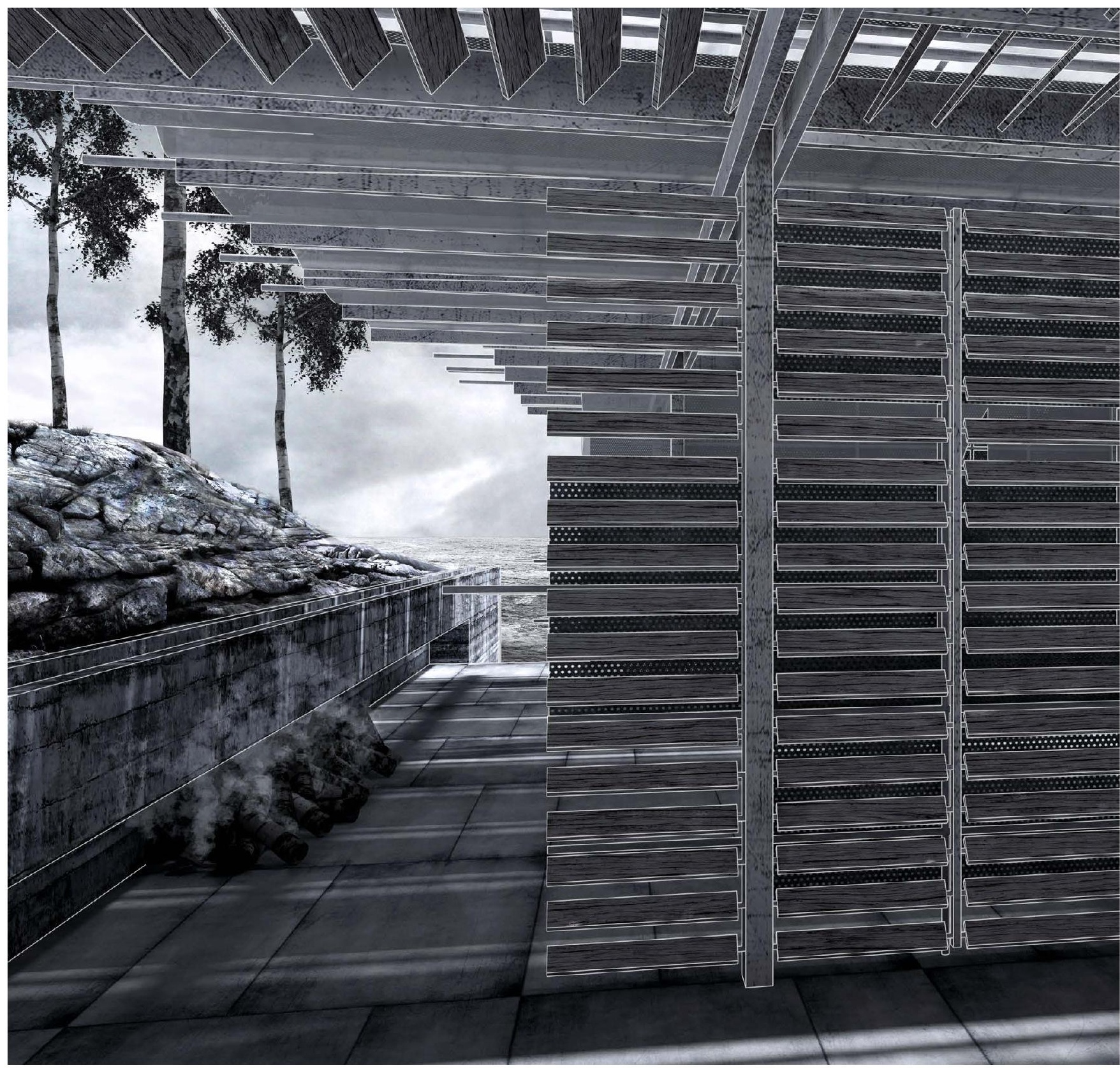




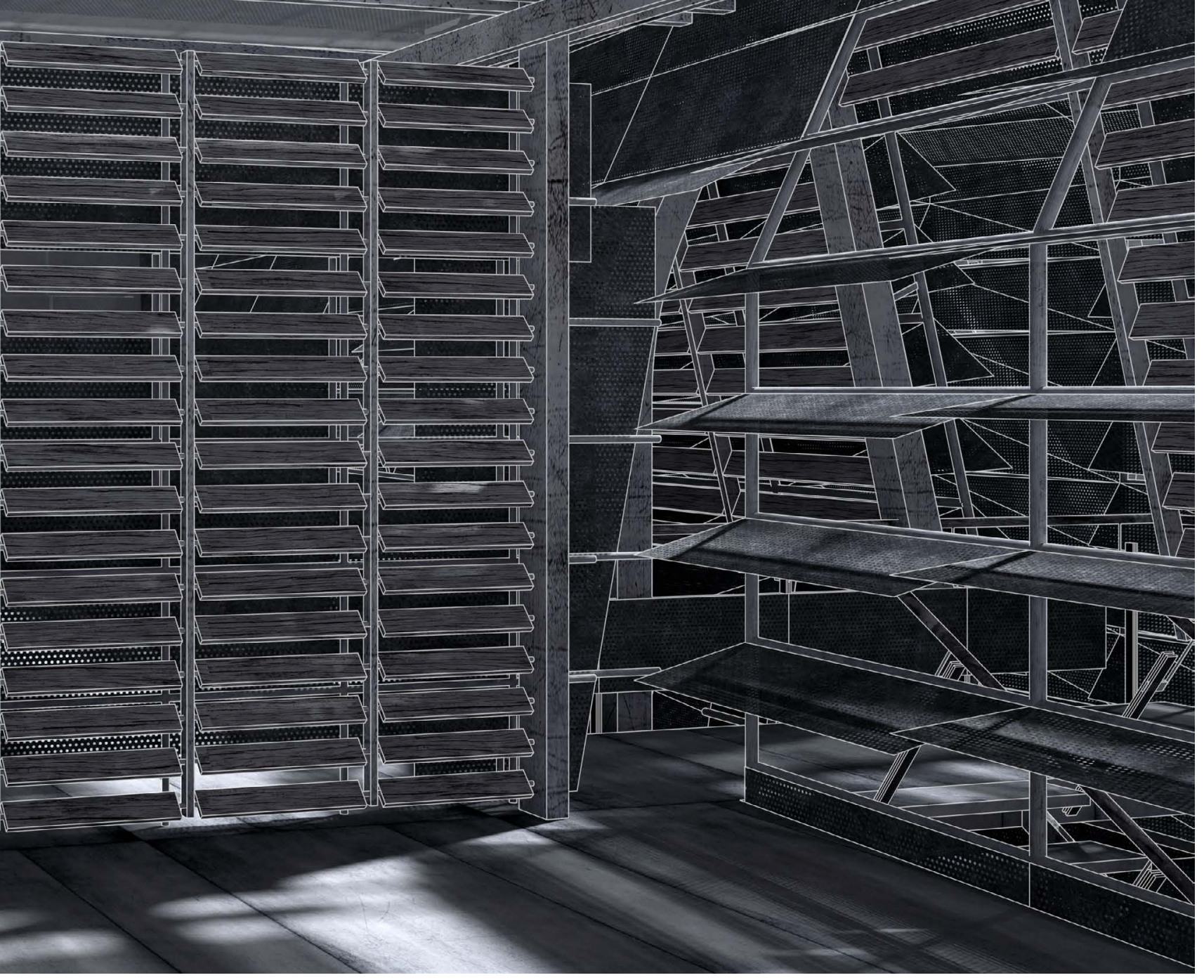

71 Blanket of warmth 
Each step forward sends a gentle shiver down the artist's spine. The presence of the wind is distinguishable again. This time the tranquil sound of the water pouring into the scupper along with the sporadic crackle of the kindling join the ensemble of foliage to compose a most harmonious symphony. Walking past the next surface, the frolic of the fabric reveals that the wind direction has changed, flowing this time from the south. 


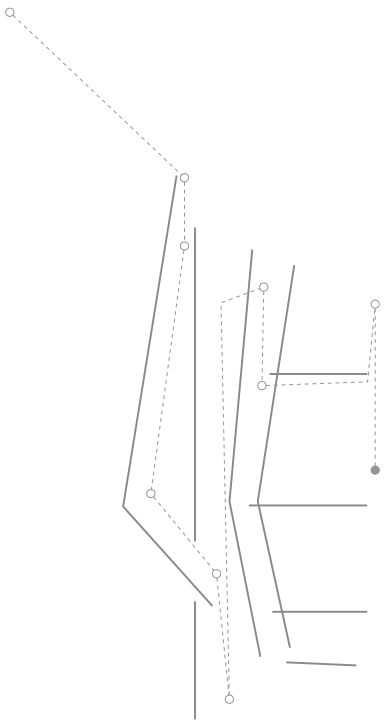




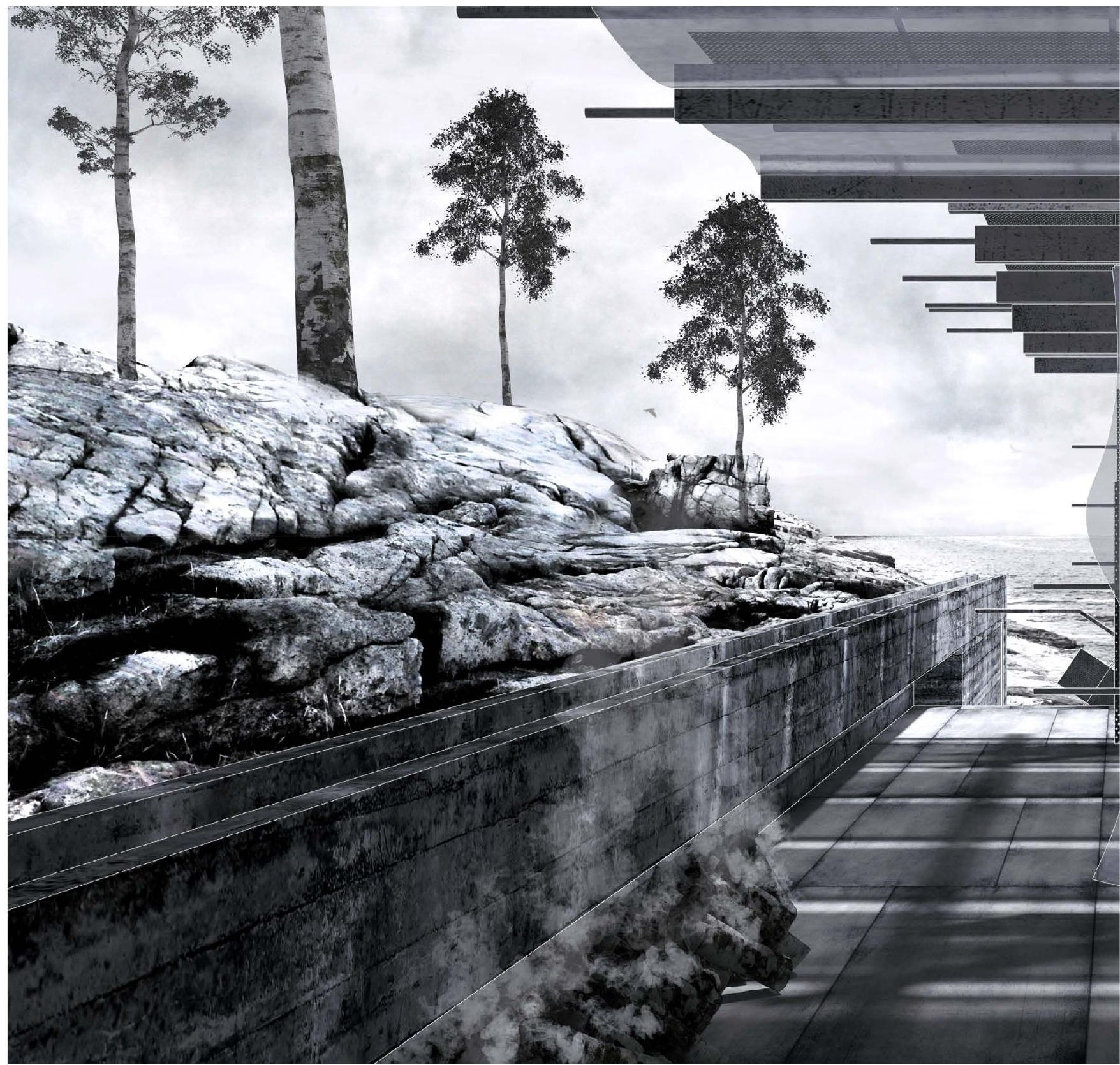




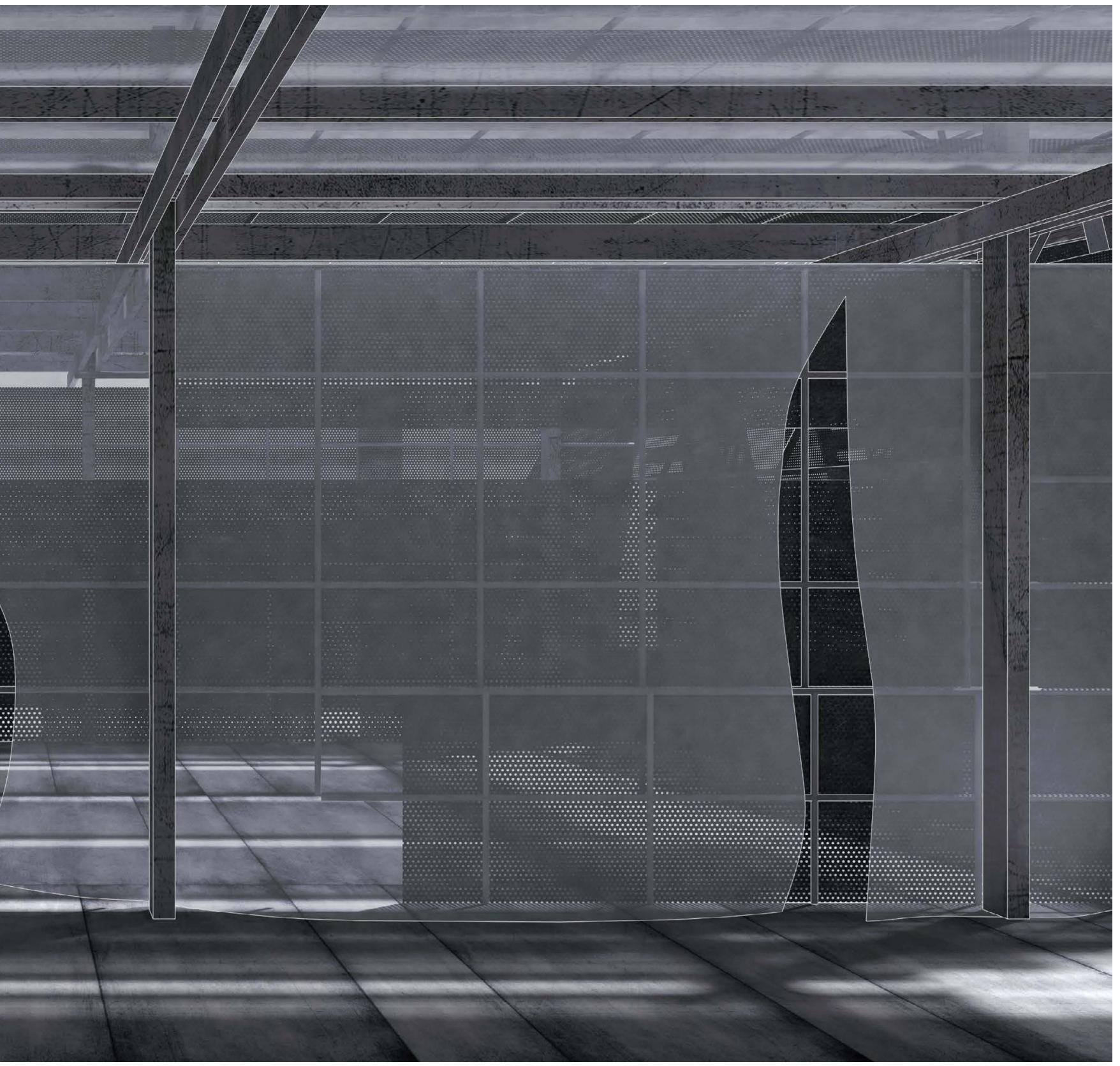

72 A harmonious symphony 
Arriving at a set of stairs that descend along the slope of the site, the artist finds themself in the same position as when they first stepped onto that bridge, only this time reflecting on their journey here as they once again look out onto the water of Six Mile Lake. 


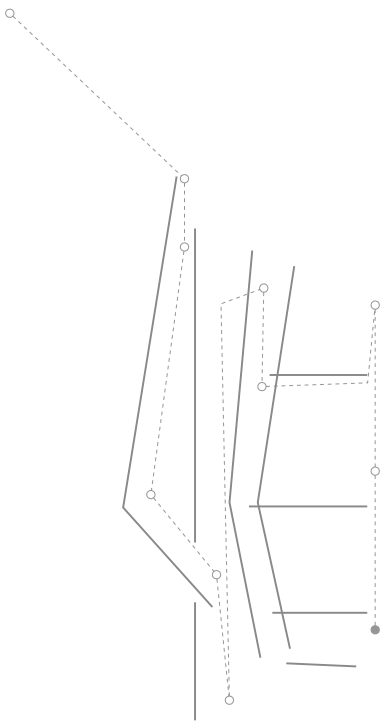




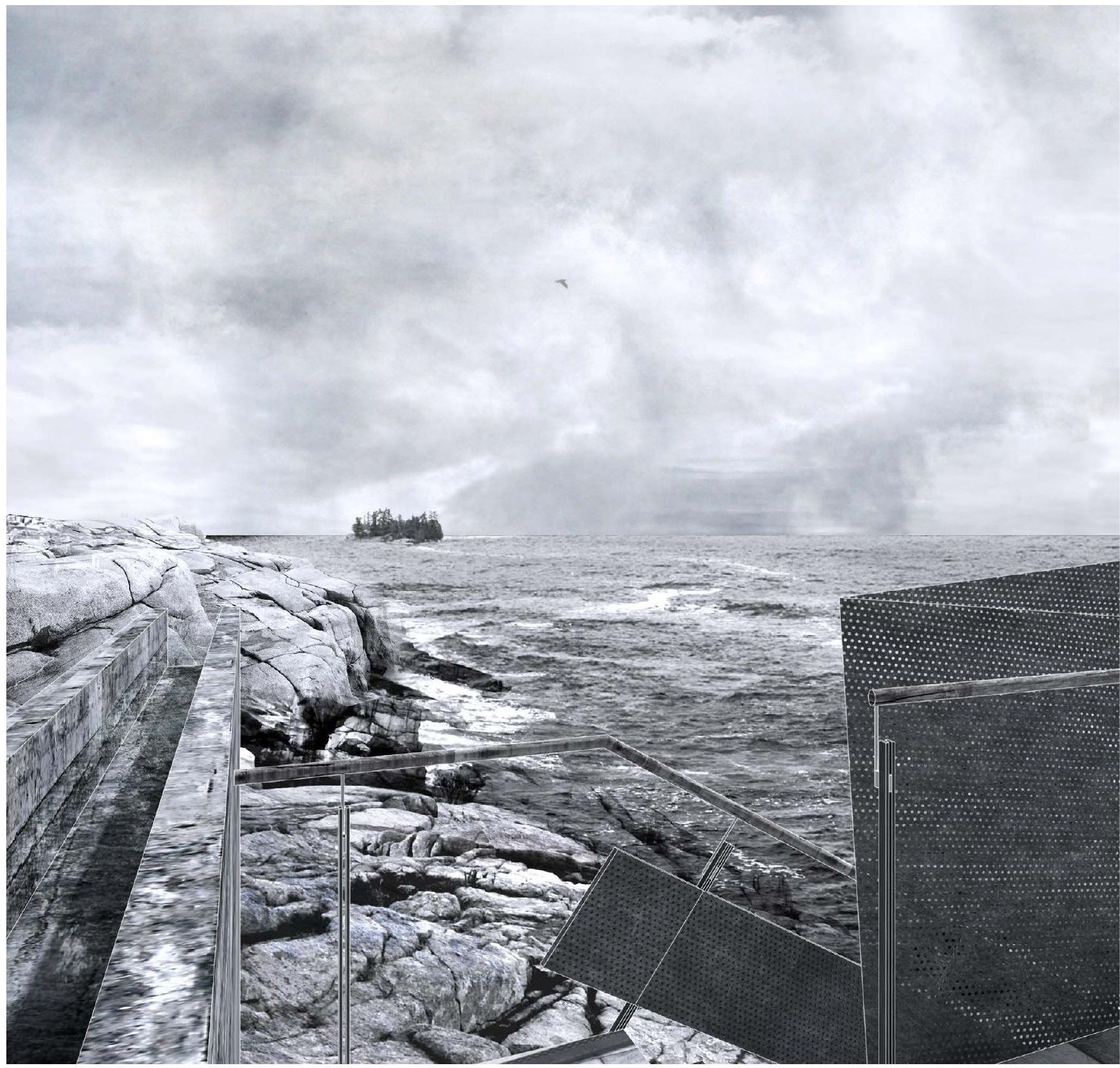




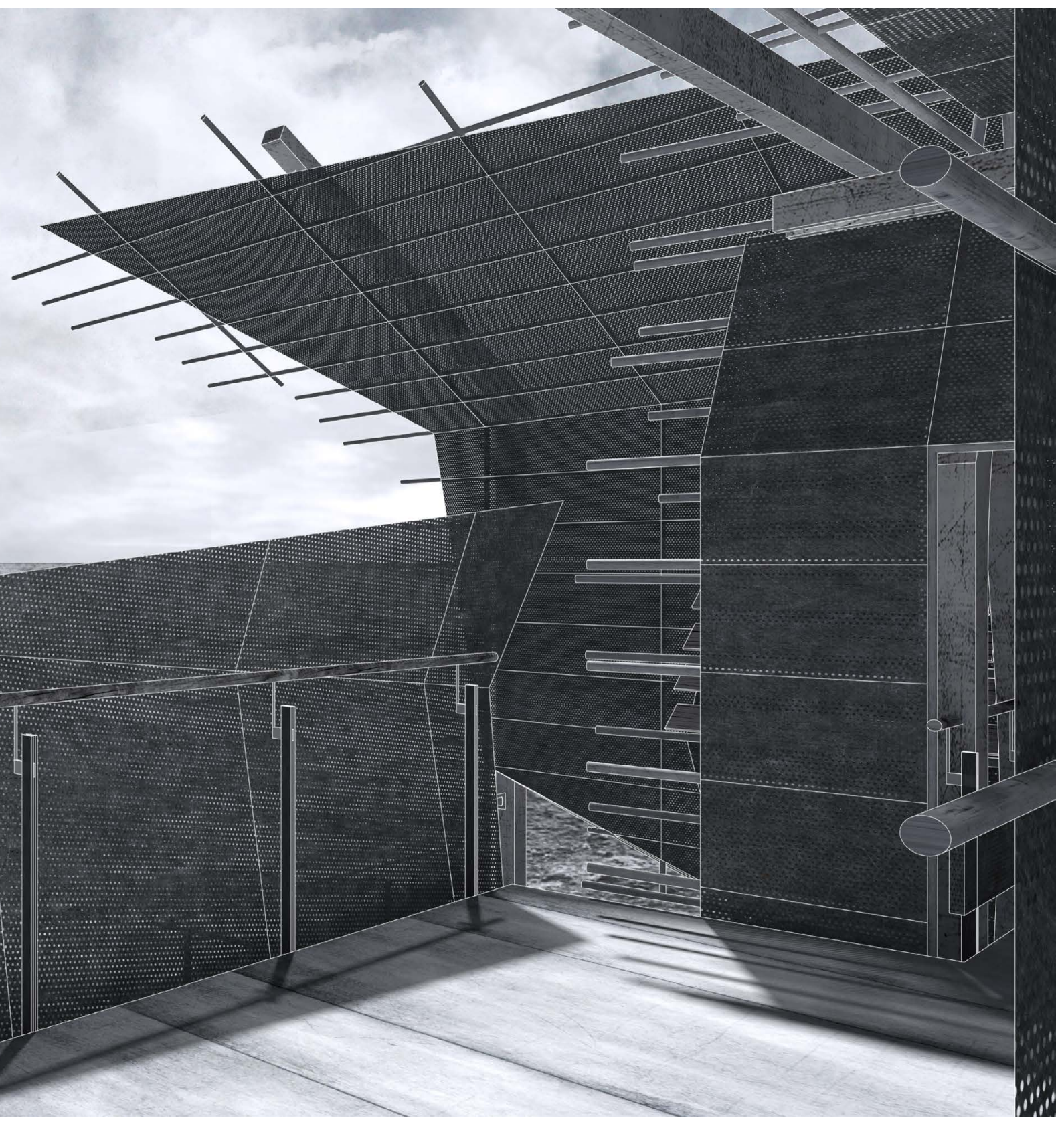

73 Moment of reflection 


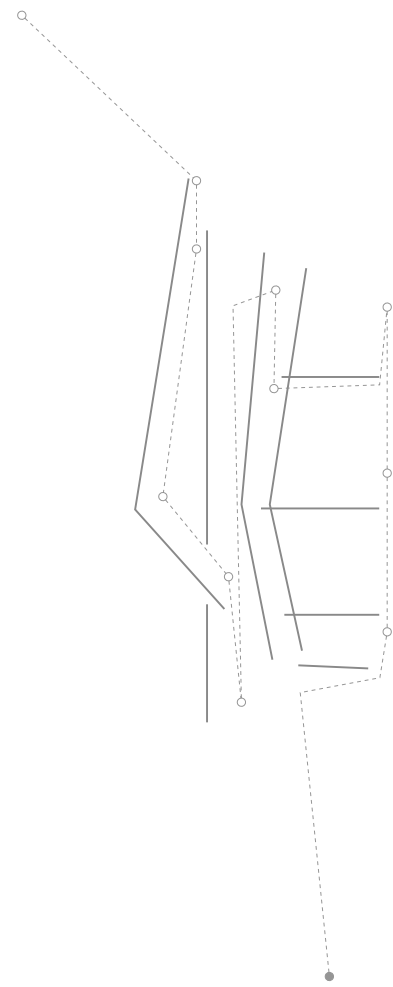




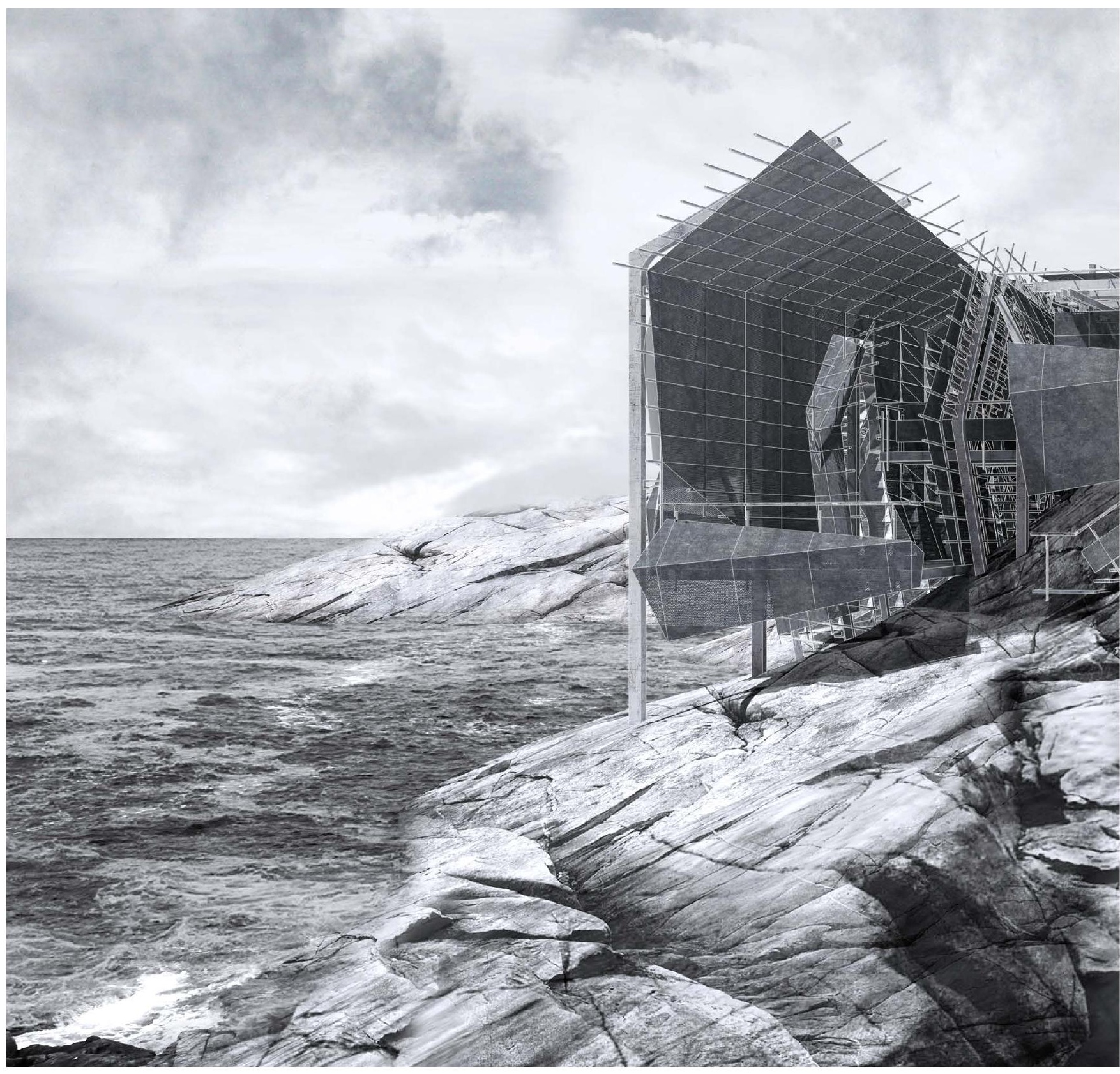




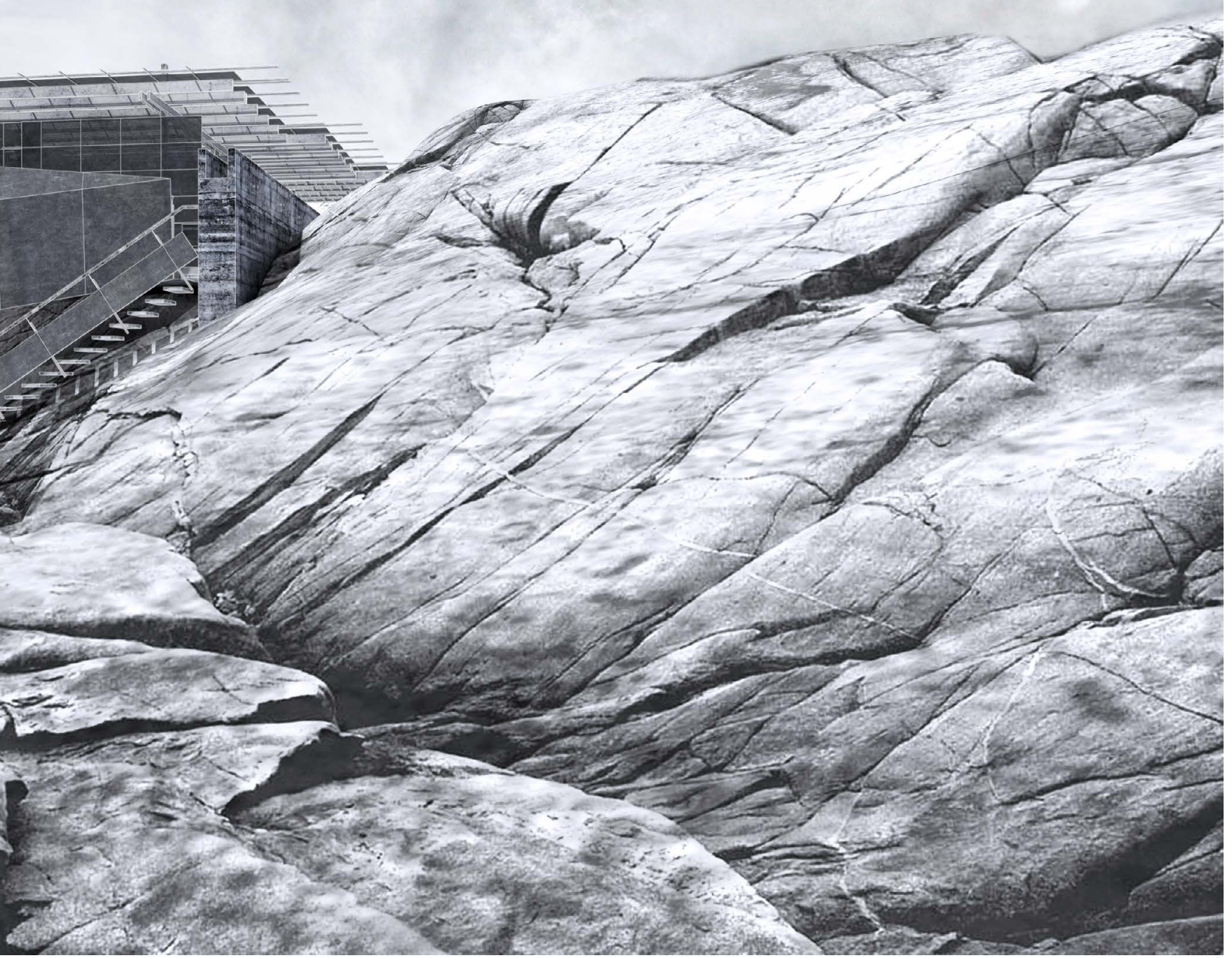

74 From the edge 


\section{0}

\section{SPECULATION}

Any attempt to conclude such a complex body of research into a few short paragraphs would be a futile endeavour. Instead, this brief final chapter serves to distill down to their core the arguments presented in this thesis. The potency of atmosphere as a relevant architectural concept is proven through the diverse range of perspectives offered on the matter within theoretical and philosophical realms. However, there exists a vast schism when it comes to translating those ideas into architectural design.

This specific thesis' interest in the concept of atmosphere was primarily borne out of a growing frustration with how architectural design is approached in contemporary practice. In addition to the long established culture of standardization, the ocularcentric bias so rampant in this "digital age" is fuelling an unhealthy infatuation with novel expressions of architecture in the form of striking visual imagery. The goal of architectural design has now been lamentably reduced to the production of image products, designed for instant gratification. "detached from any existential depth and sincerity." Consequently, this has all occurred at the expense of the very people who will eventually inhabit those places. 
It is instead suggested by this thesis that architects re-evaluate their priorities to ensure that the experience of the people they design for remains at the heart of their design proposals. By creating places for human activity, architects fundamentally craft the human experience. In its realized state, architecture is meant to be experienced sensually. Unfortunately, due to the path charted by the discourse over the last number of years, the experiences offered by architecture emerging under this current paradigm leave a lot to be desired.

How then can one begin to remedy this? Well, as asserted by this thesis; through the careful consideration of atmosphere in architecture, architects can begin to challenge the superficiality of experience today. After all, though architecture is grounded in the physical reality of built form, it is often the more intangible, ephemeral and perceptive qualities that make for a more enriching spatial experience.

The challenge that then emerges is one of integrating something as transient as atmosphere into the architect's repertoire. For atmosphere to be relevant to the design process, one must first recognize that atmosphere in fact precedes built form. Therefore, any discussion suggesting that architecture must manufacture an atmosphere is misguided. A space designed solely for 
atmospheric production cannot be defined as architecture. That, at its best, is spatial installation and at its worst, mere theatrics.

People are constantly immersed in the atmosphere of their context. The atmospheric peculiarities of one place are what distinguish it from another. It is the perception of this contextual atmosphere that roots people in time and place. Architects must thus attempt to cultivate an even deeper attachment between people and the atmosphere that surrounds them. Thus, in defining new and meaningful ways in which to manipulate how inhabitants experience the present atmosphere, the architecture doesn't artificially fabricate an atmosphere as much as it serves to evince atmospheres. 


\section{ENDNOTES}

1. Juhani Pallasmaa, The Eyes of the Skin: Architecture and the Senses (Chichester: Wiley, 2005), 33. 


\section{APPENDIX}

The manner in which the atmosphere of a place is articulated depends on how the boundaries of the enclosure, the built form within that place, are made. It is determined by the tectonic realization of those boundaries, the type of construction employed: whether that is massive and enclosed, open and transparent, skeletal, the type of joinery used, etc.

While the following details didn't find a place in the main body of research, they remained a critical part of the design process and thus contributed immensely to this thesis' understanding of atmosphere. These drawings focused purely on the tectonic articulation of the retreat. As such, the appendix is dedicated to documenting these details. 

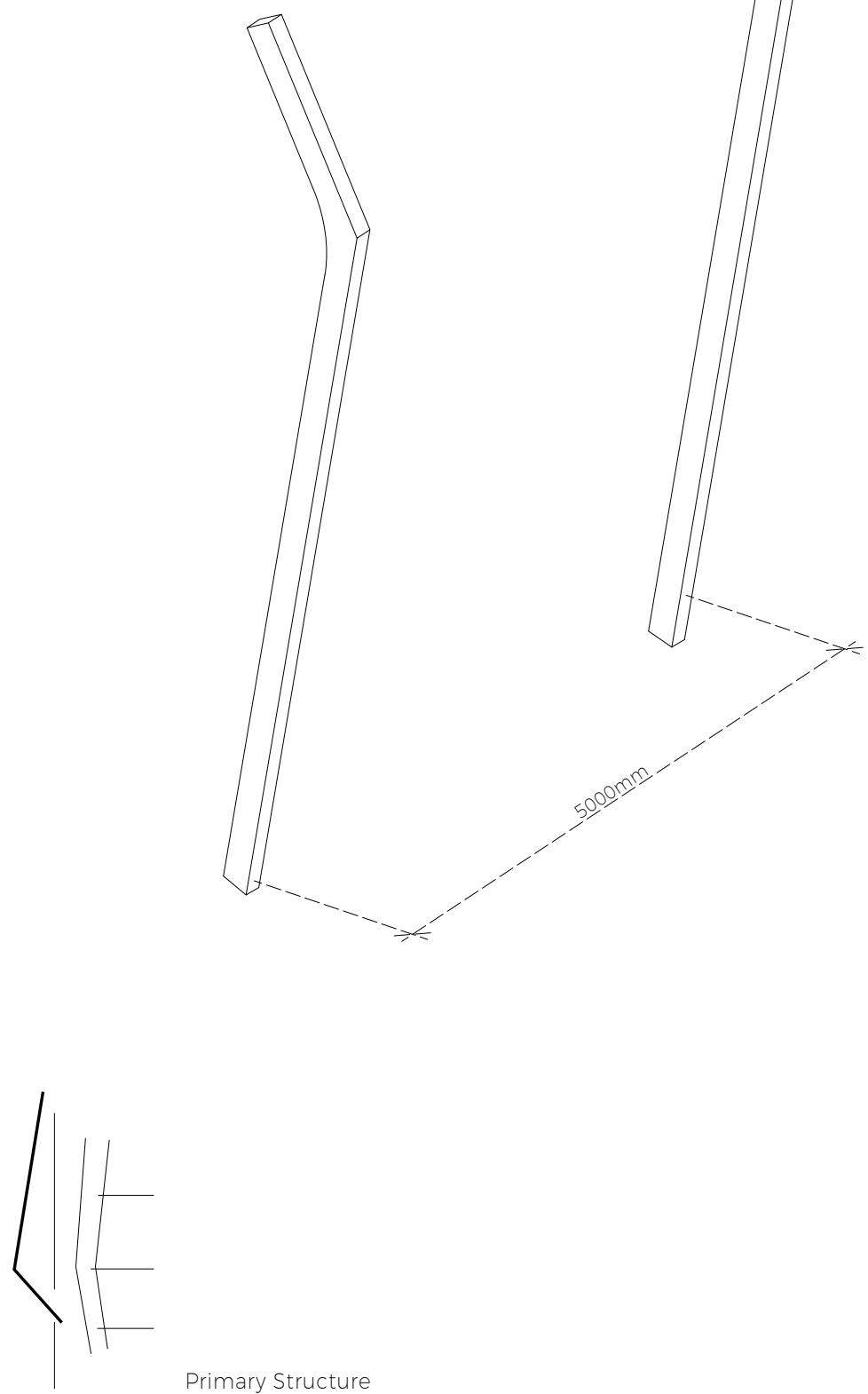

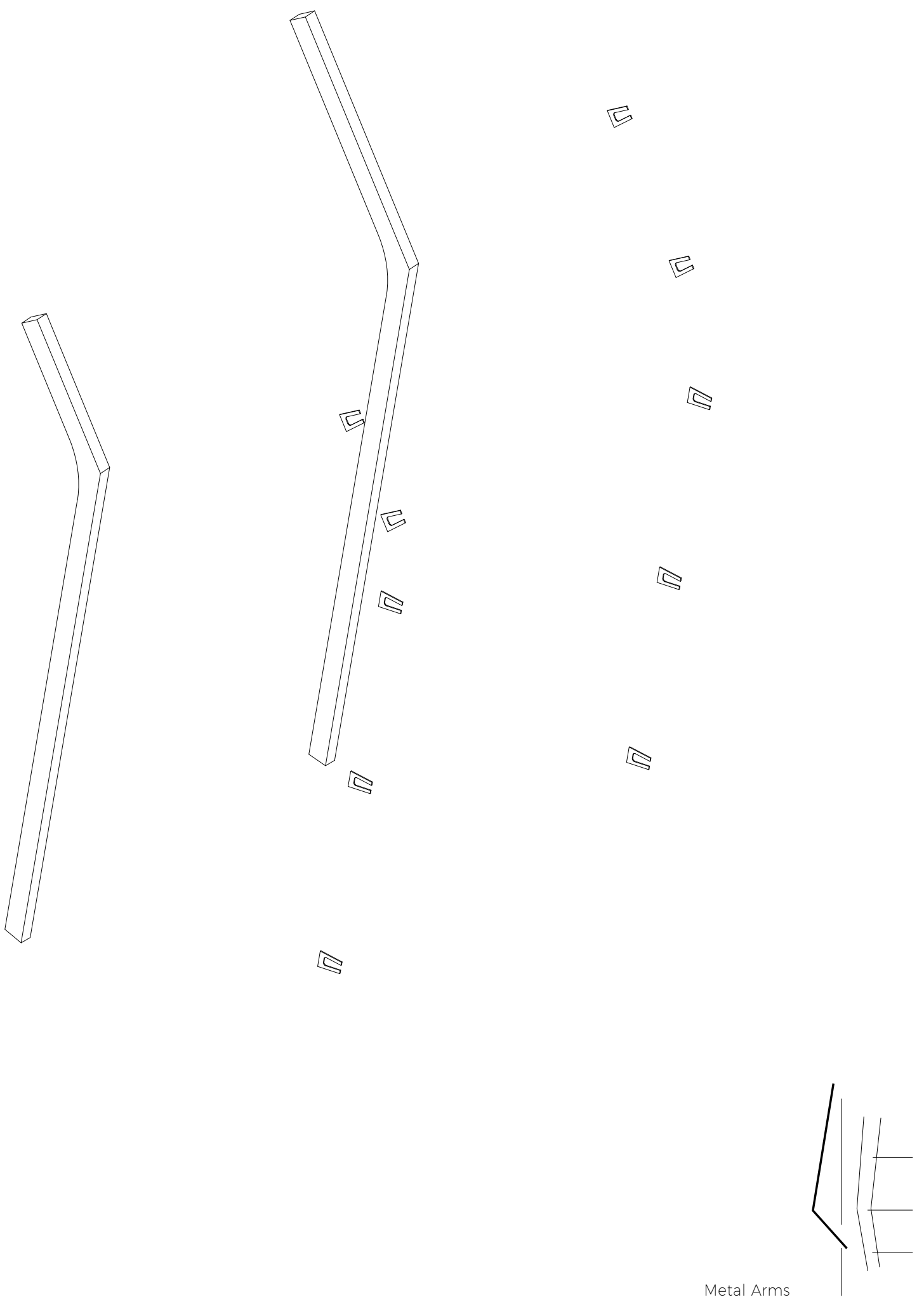

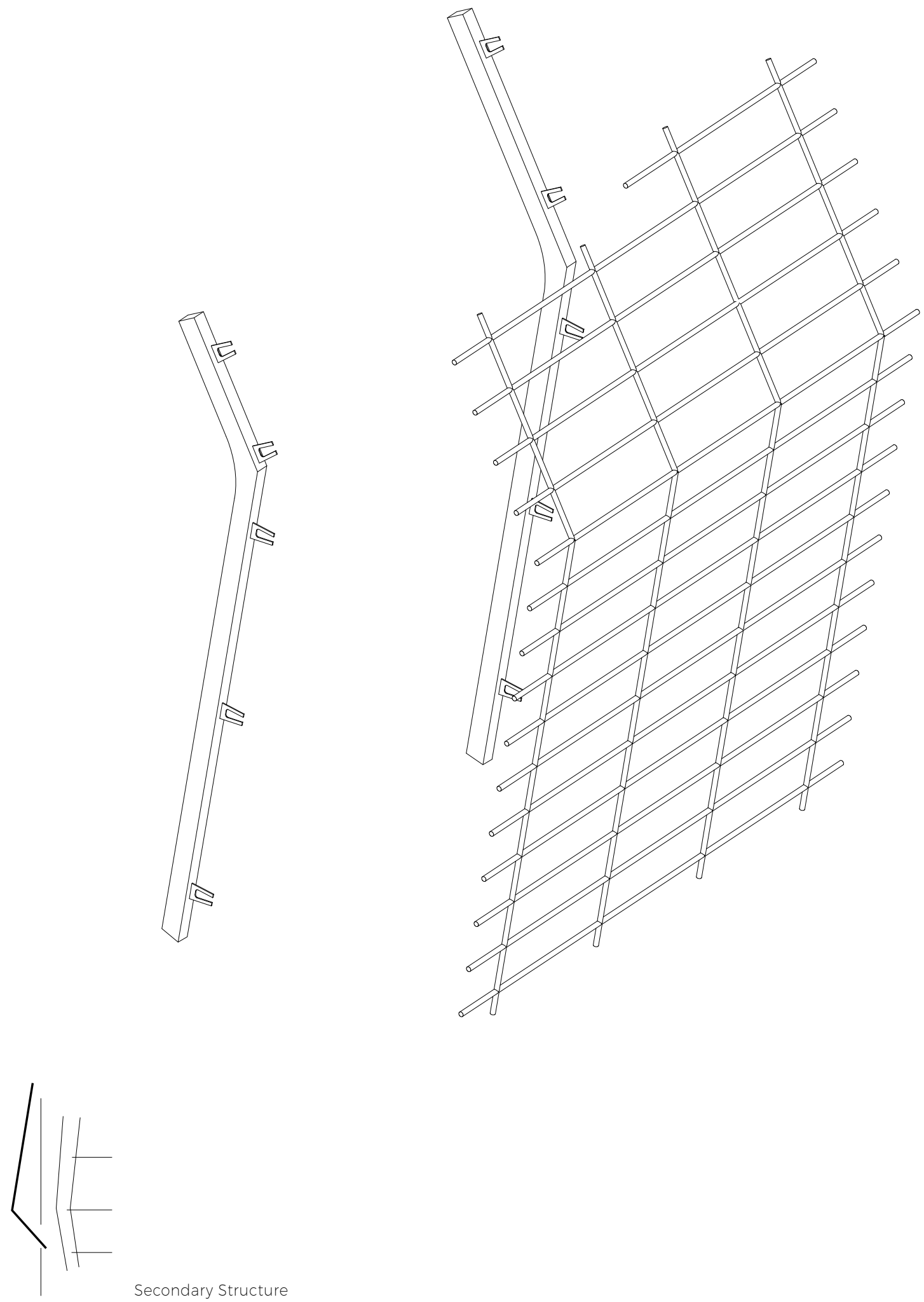

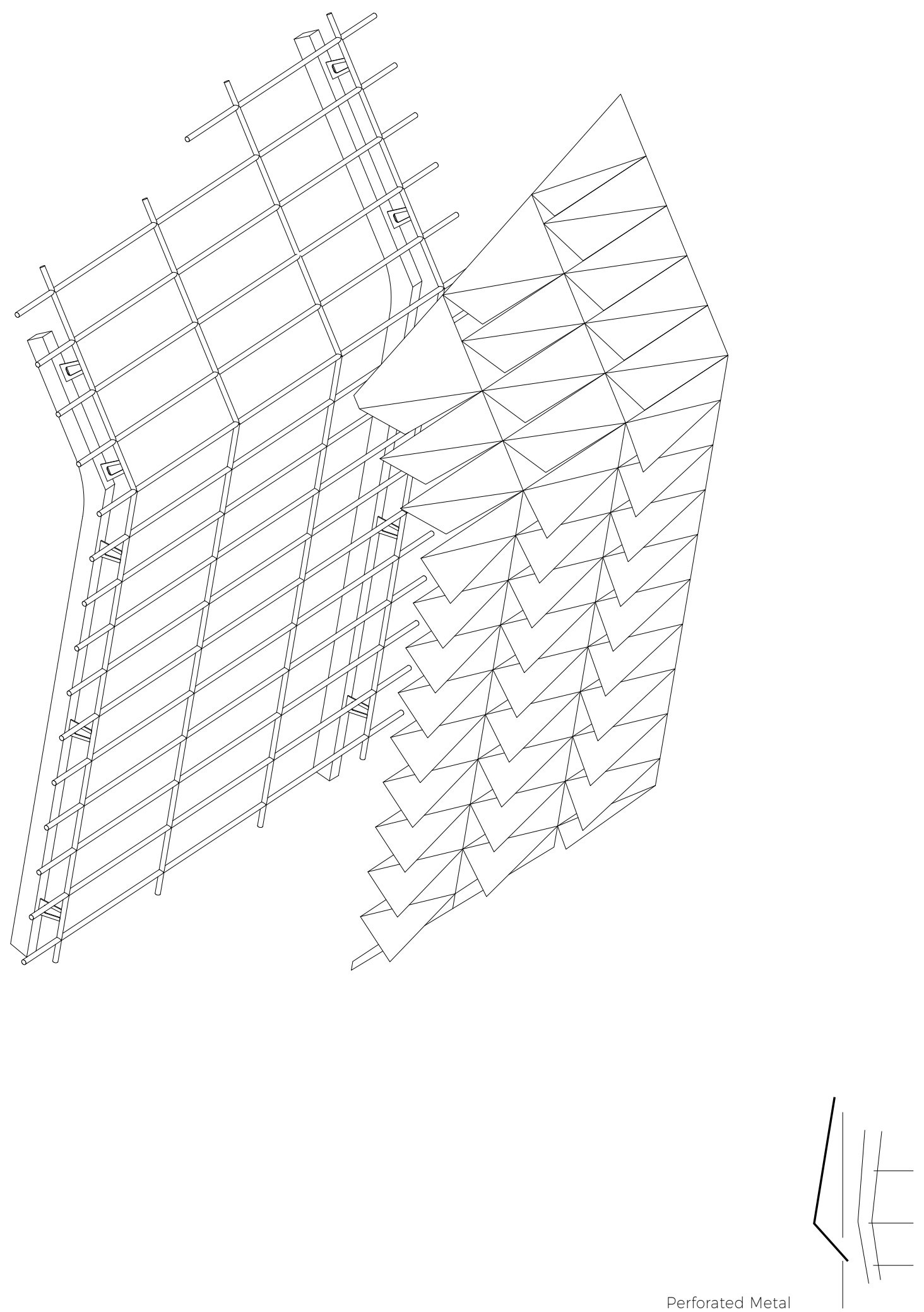

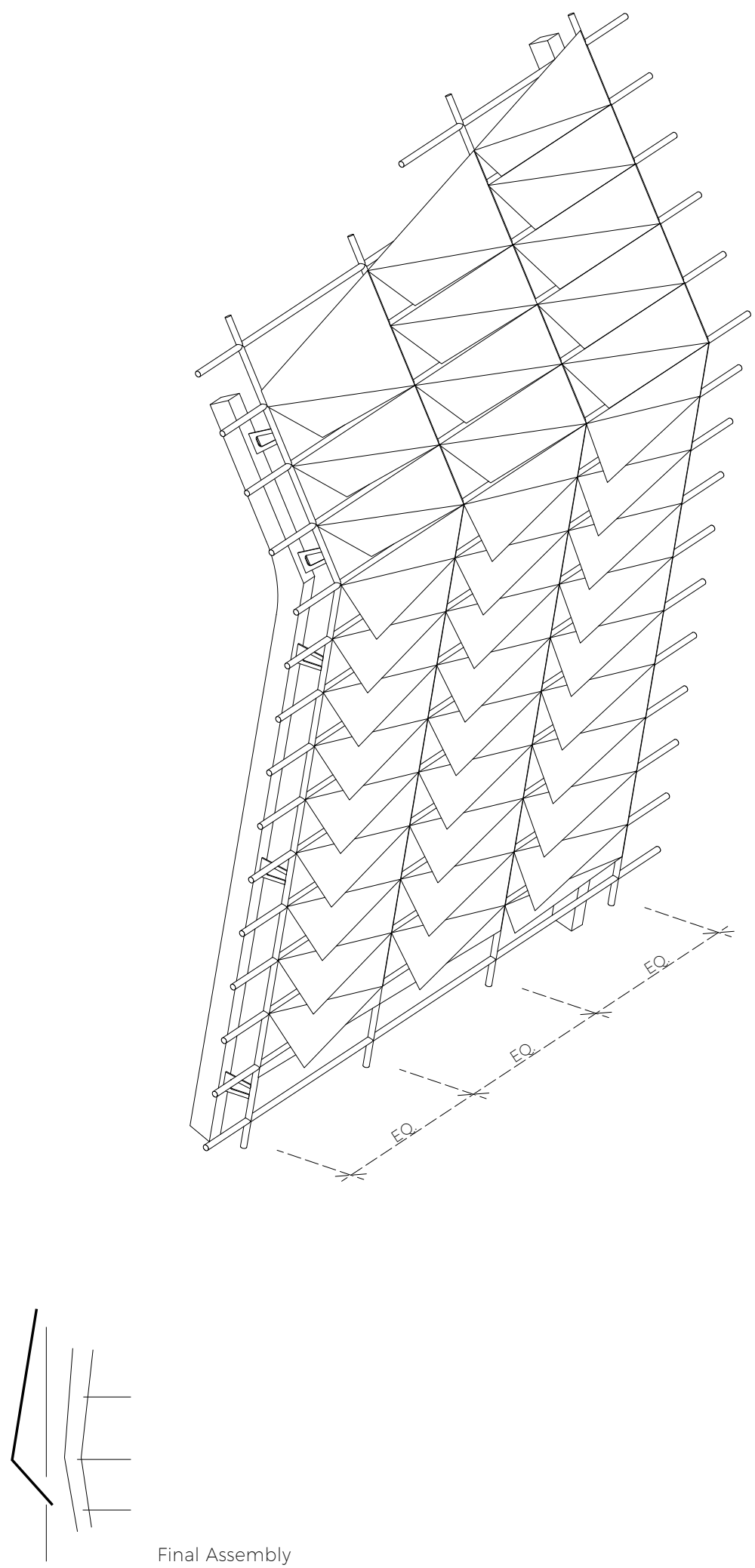

Final Assembly 

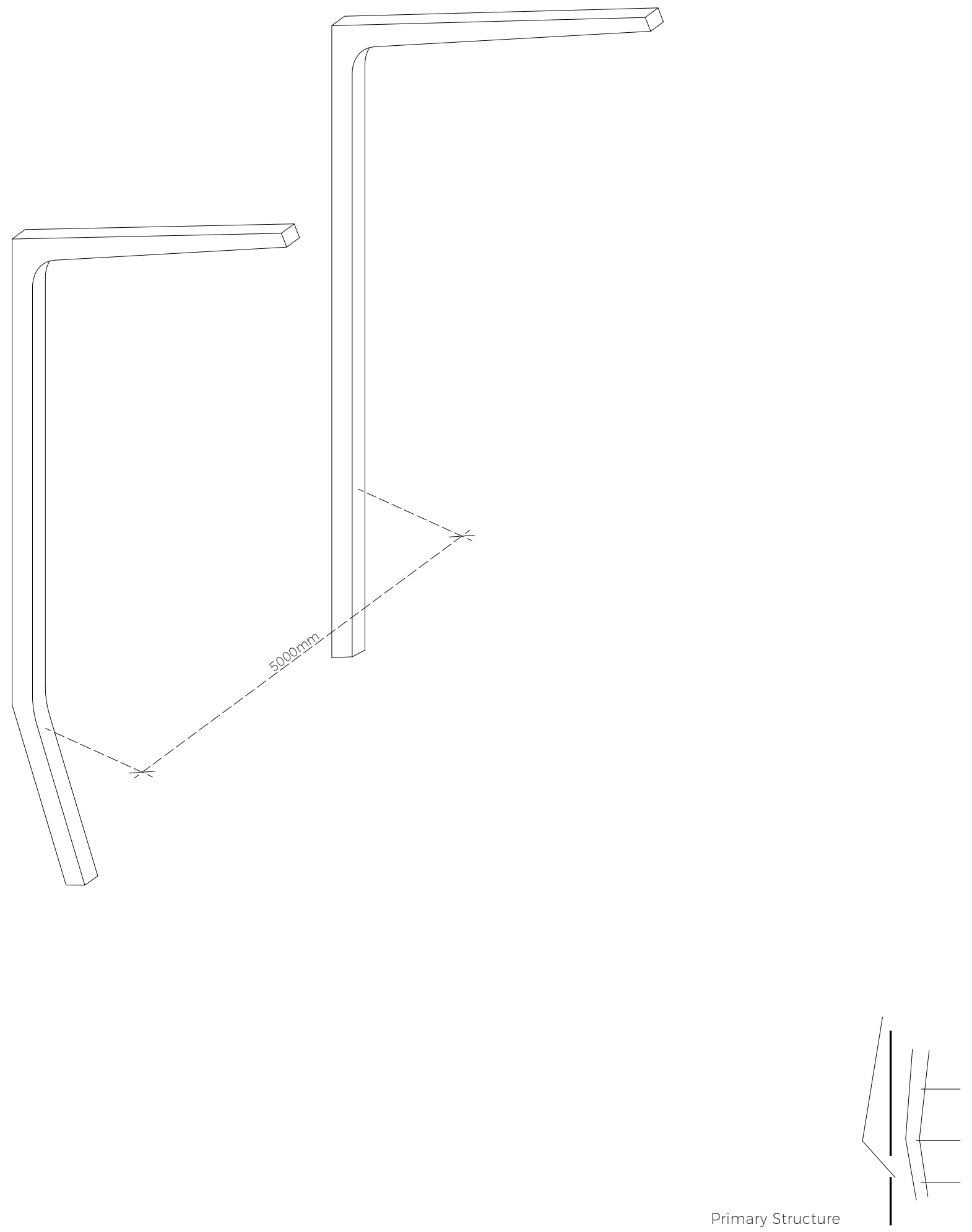


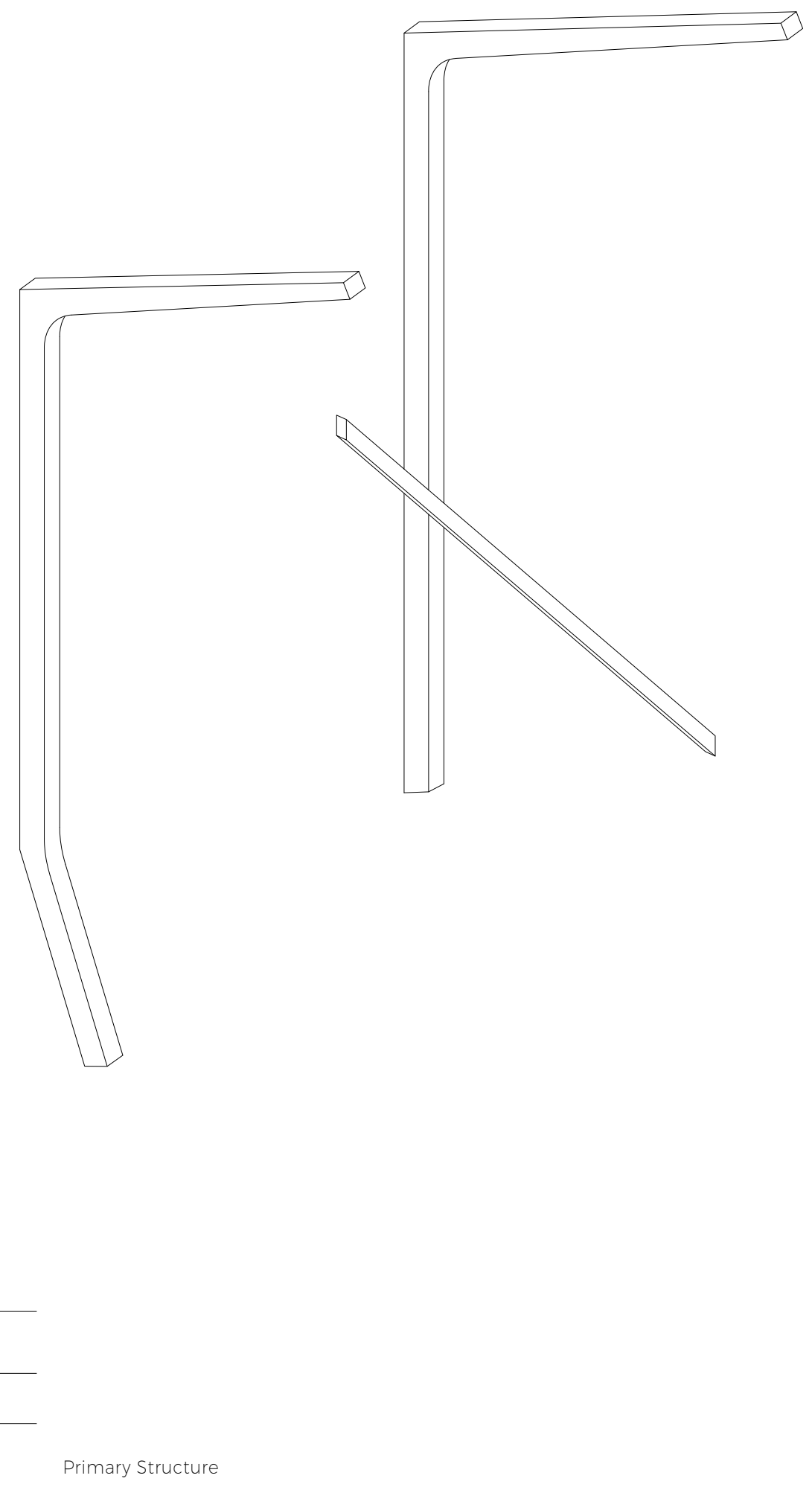


APPENDIX

172
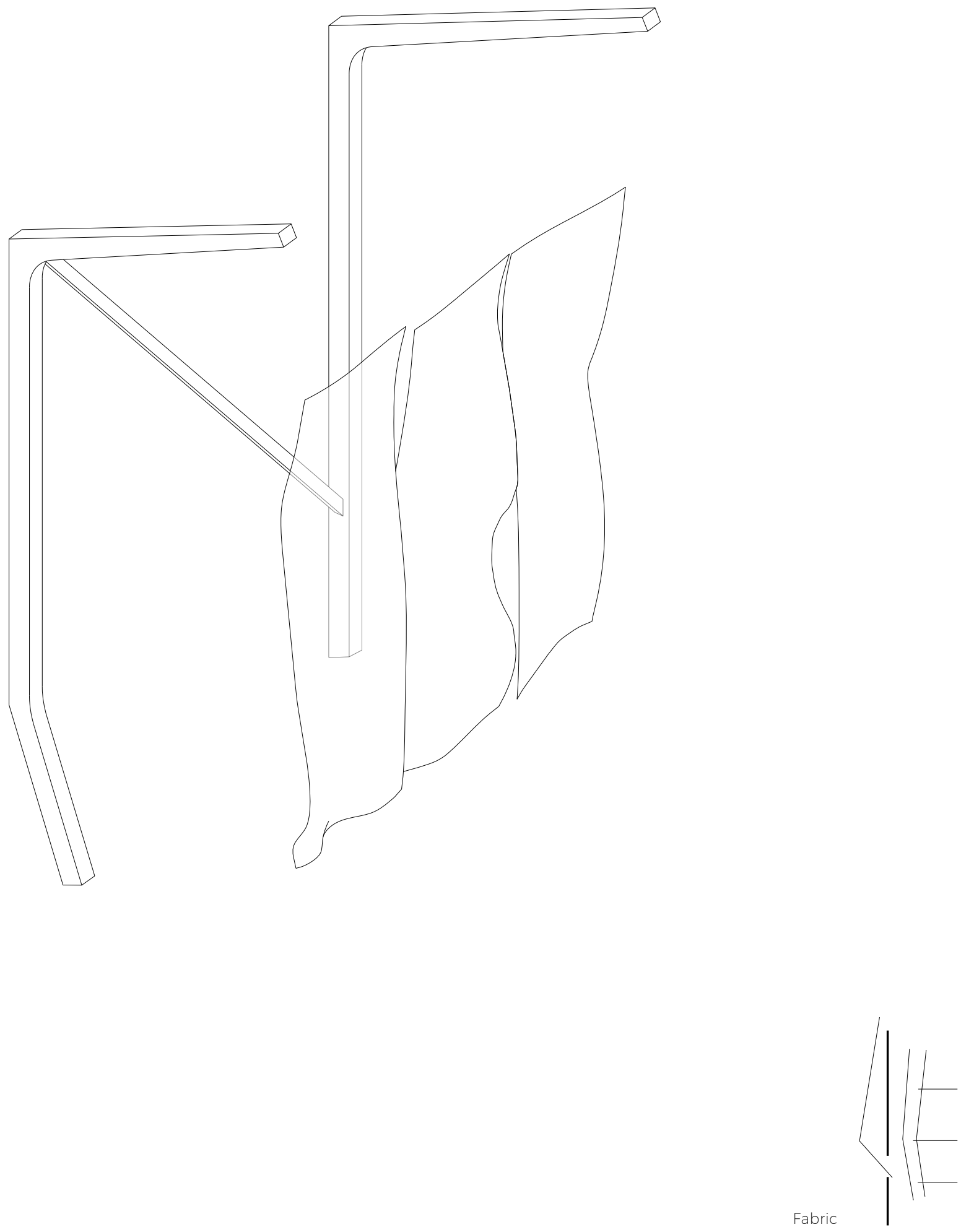


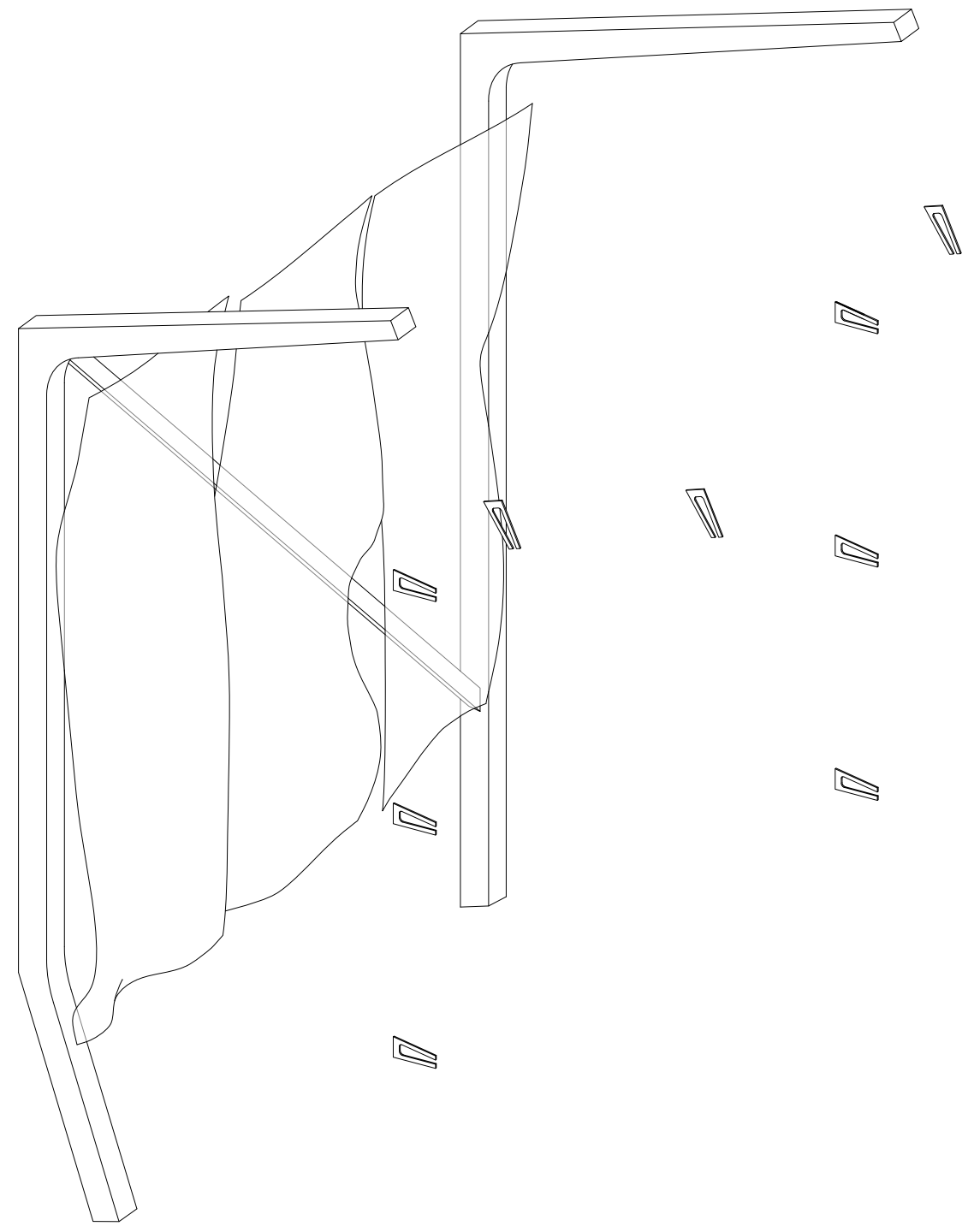



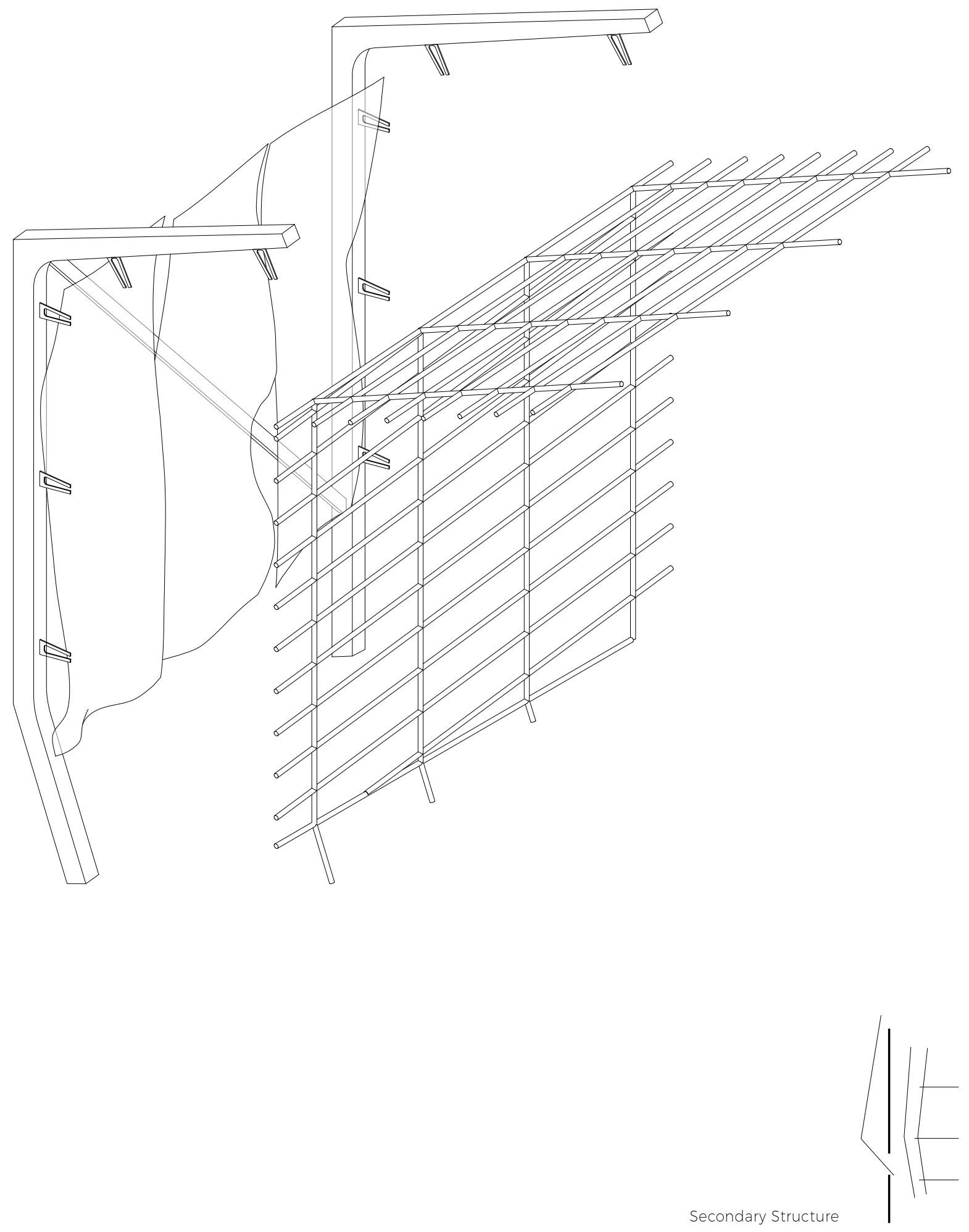


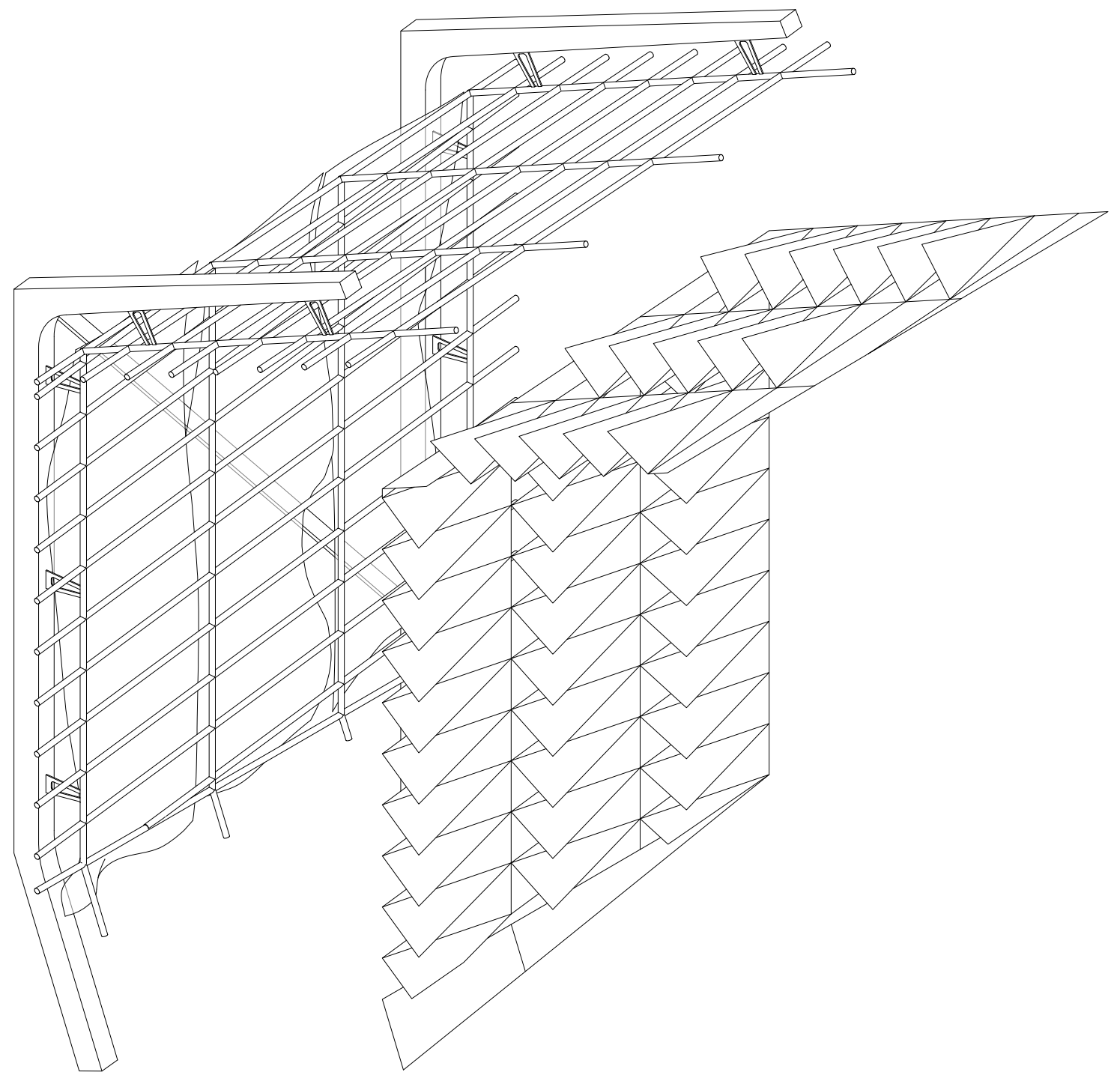



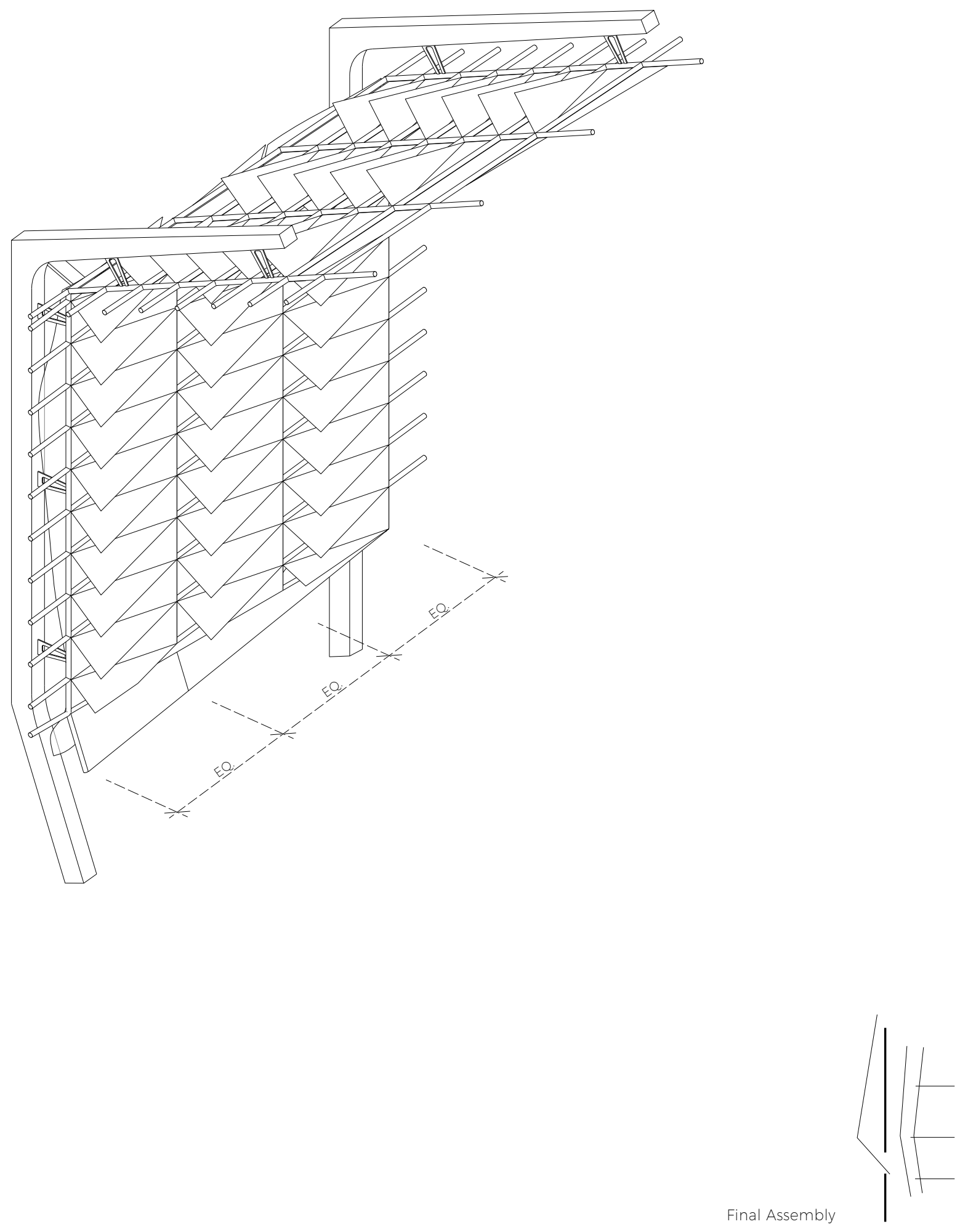

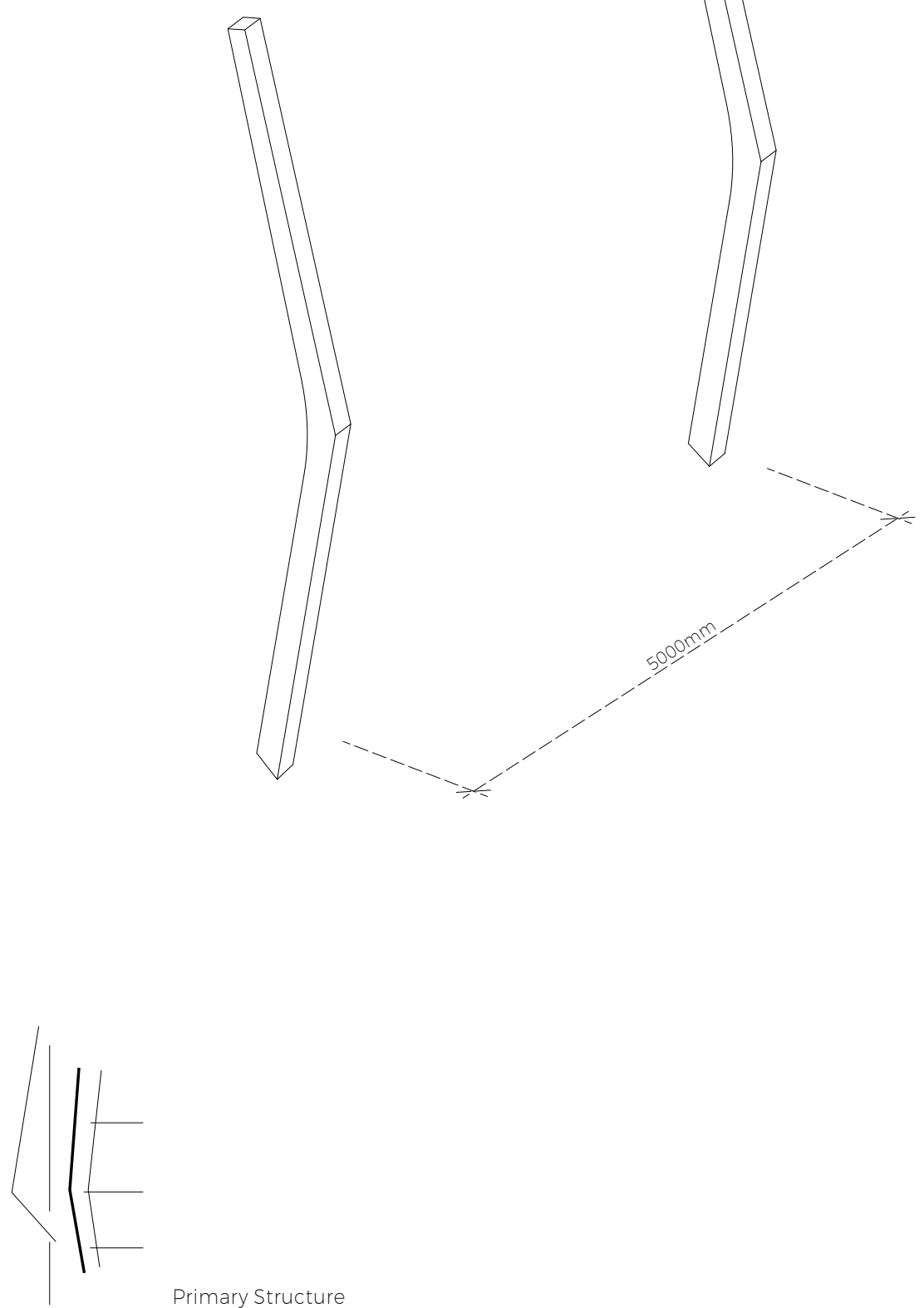

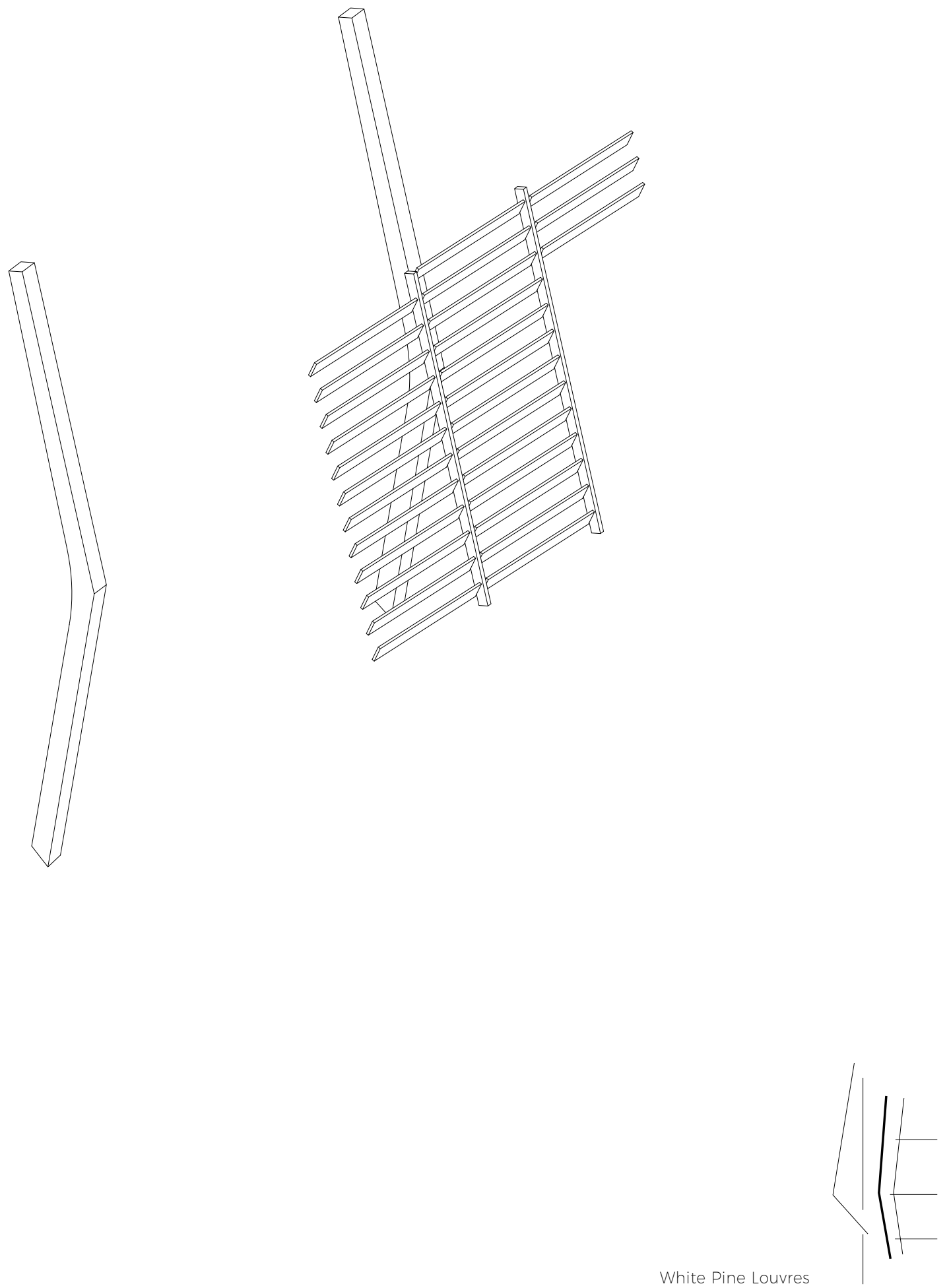


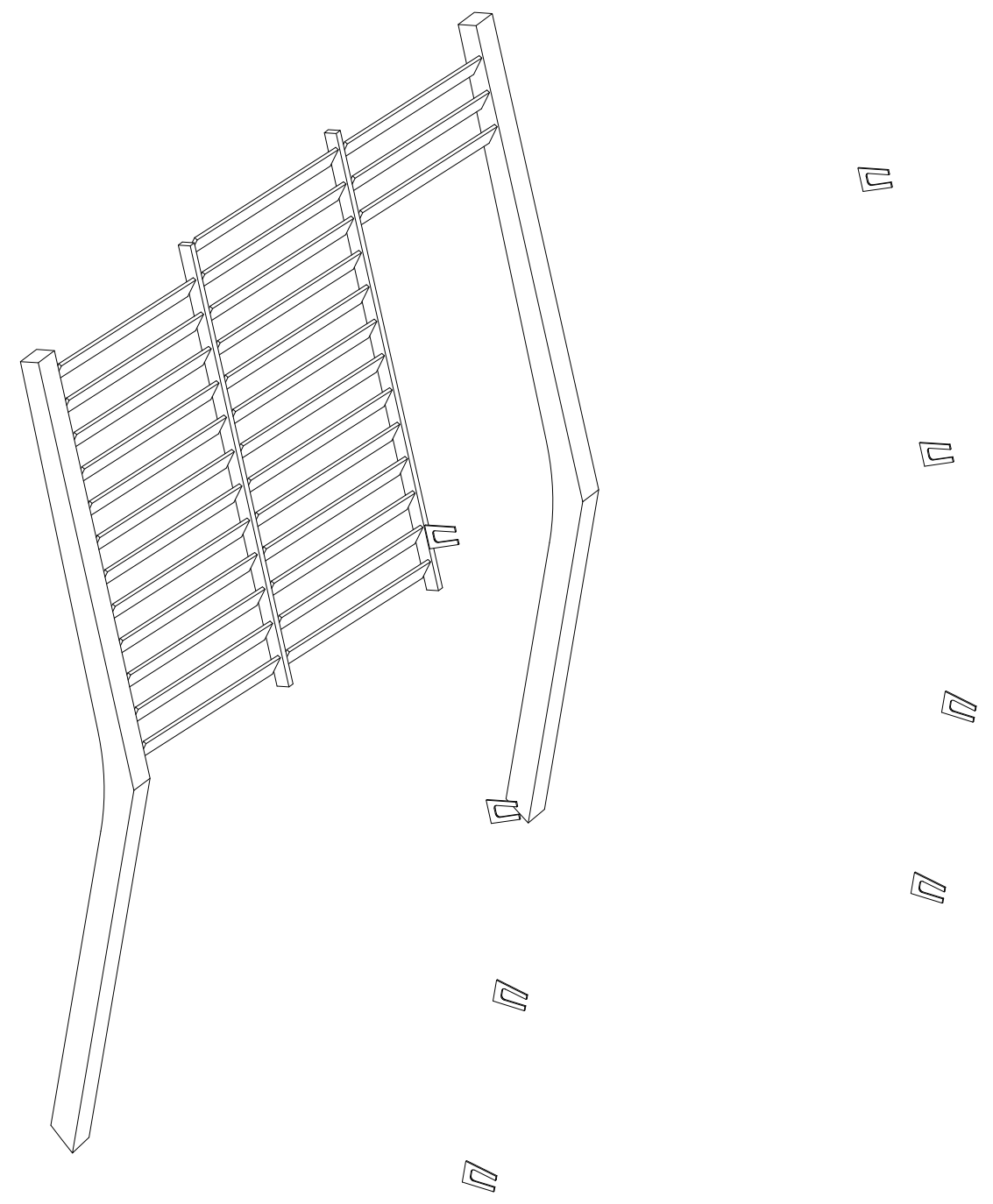



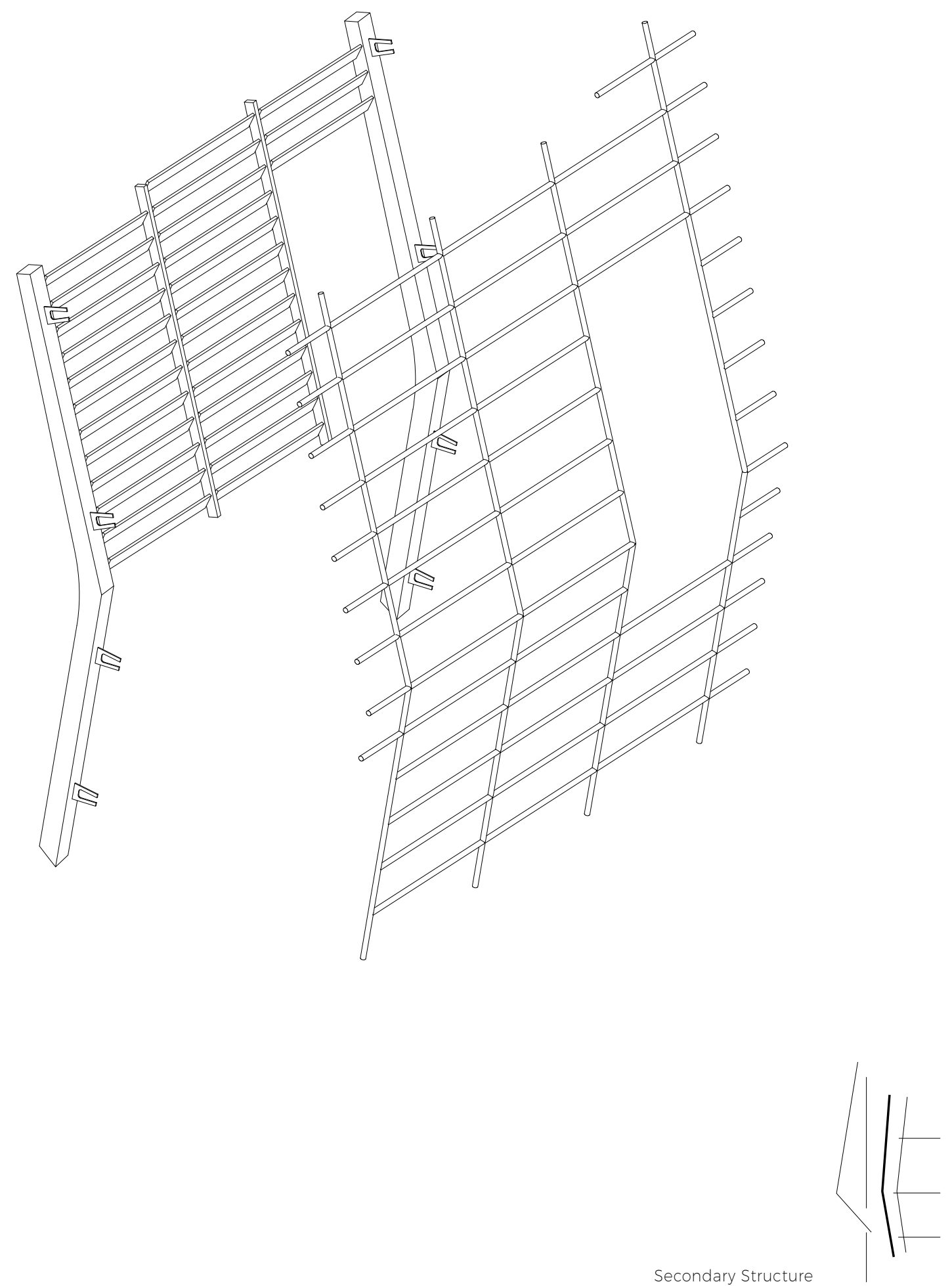


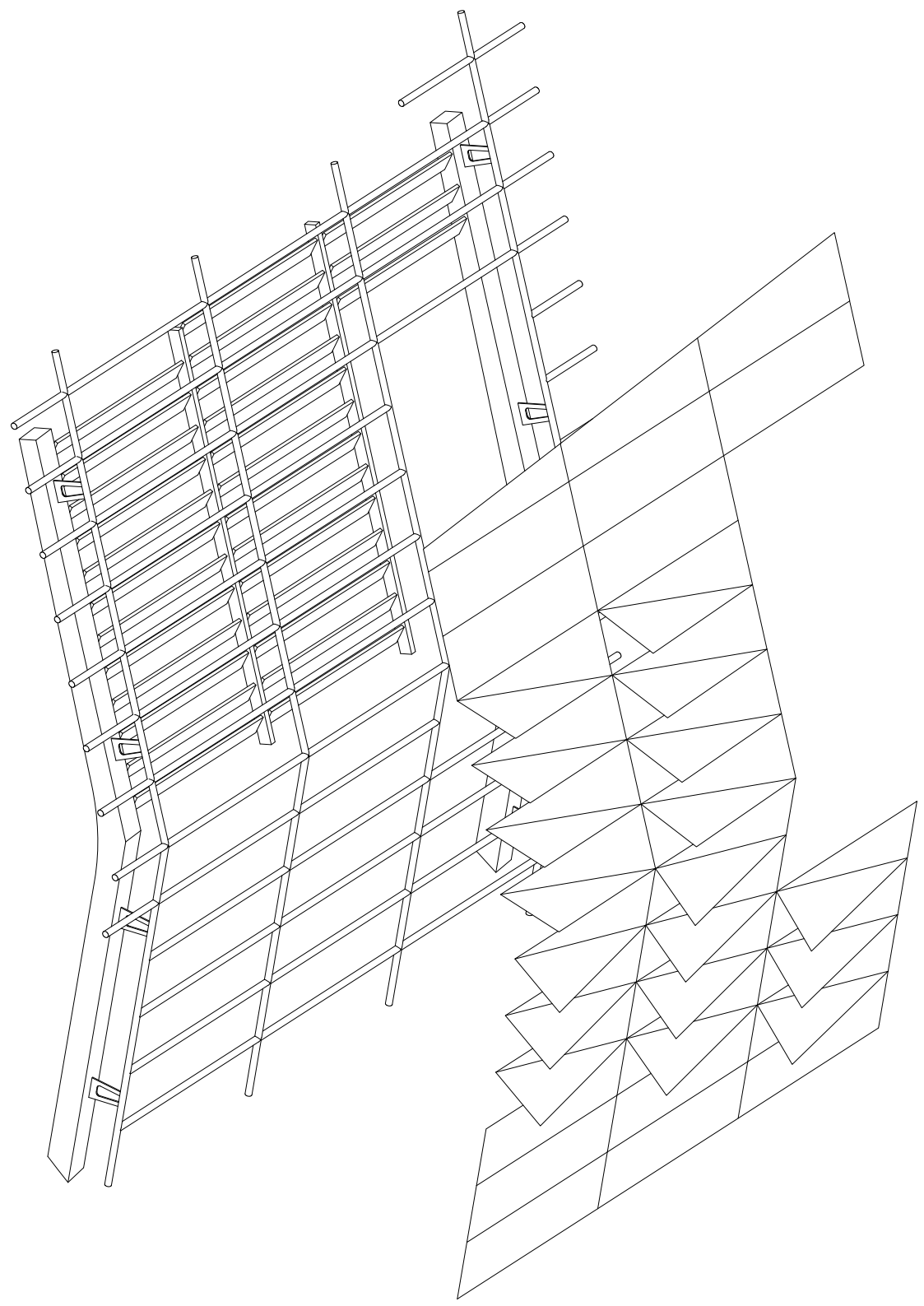




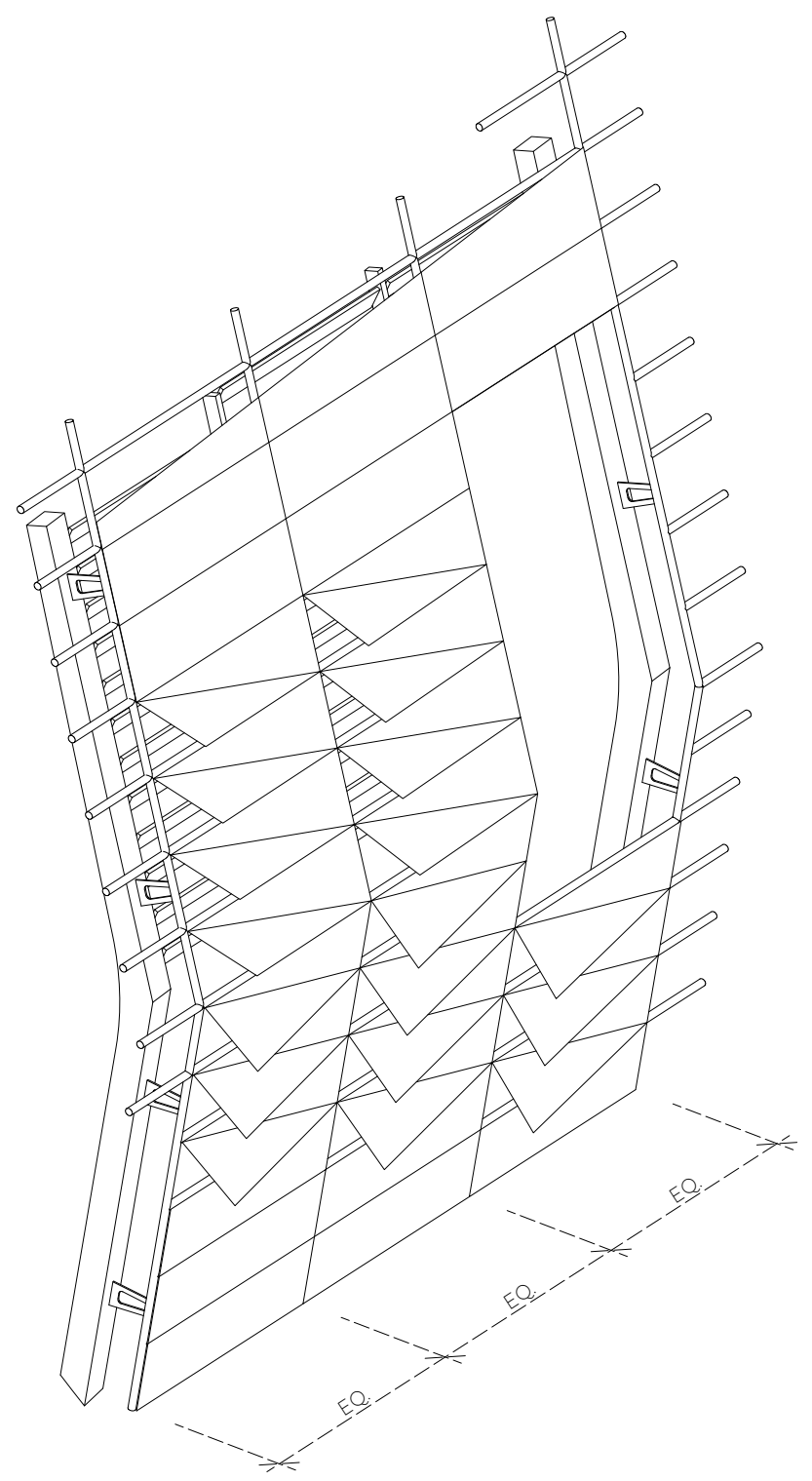




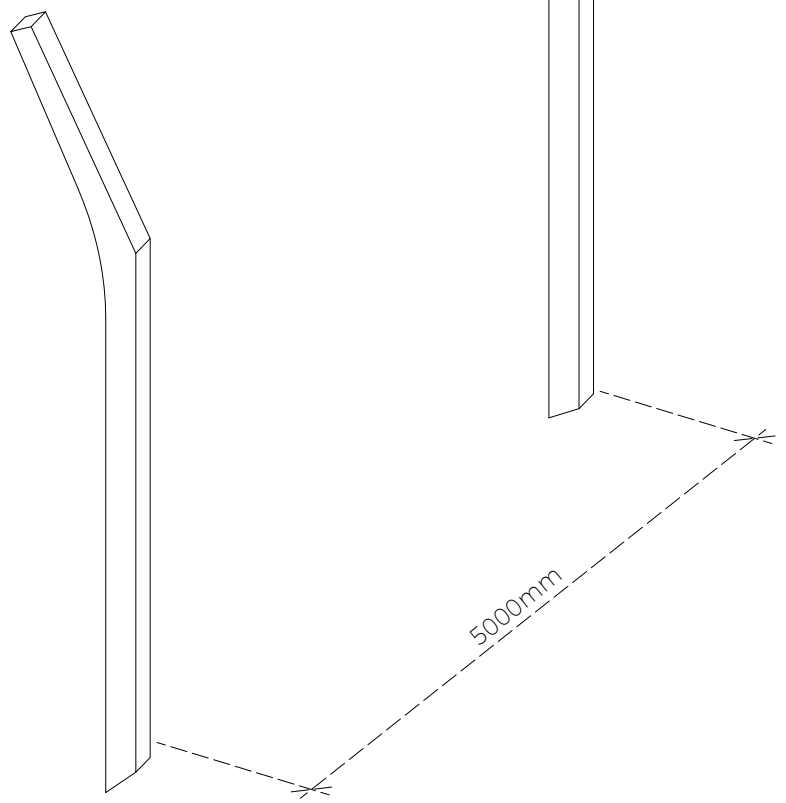



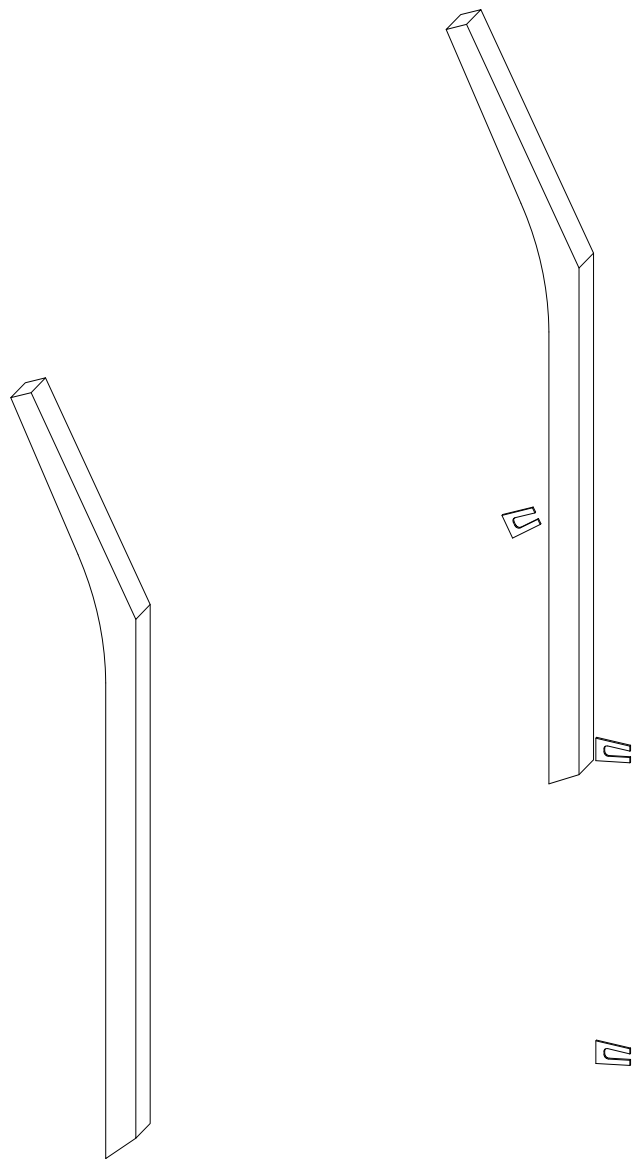

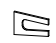

a

a

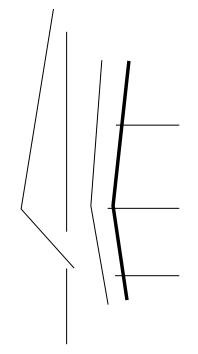


185

TO EVINCE ATMOSPHERES

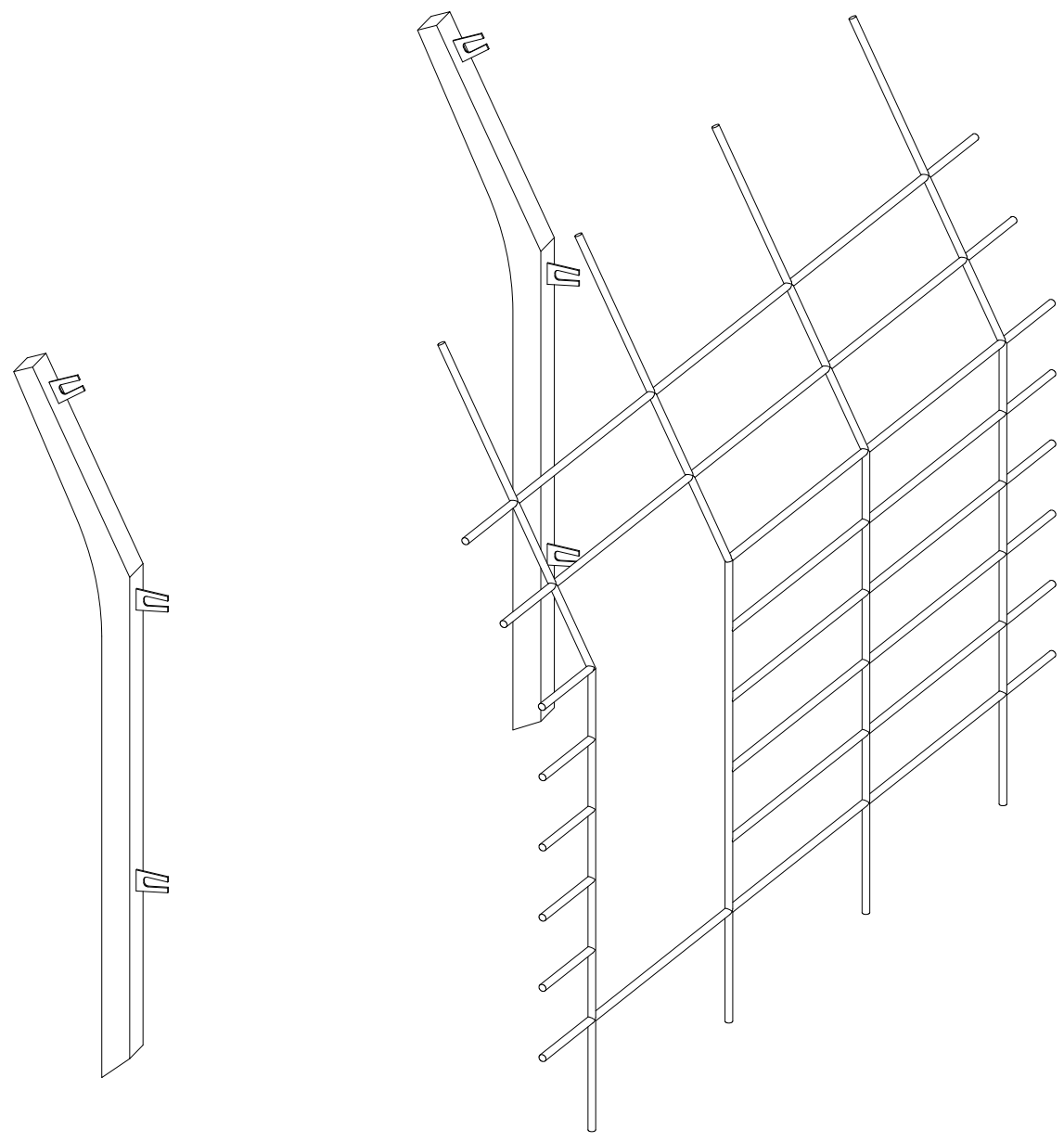

115

Secondary Structure 


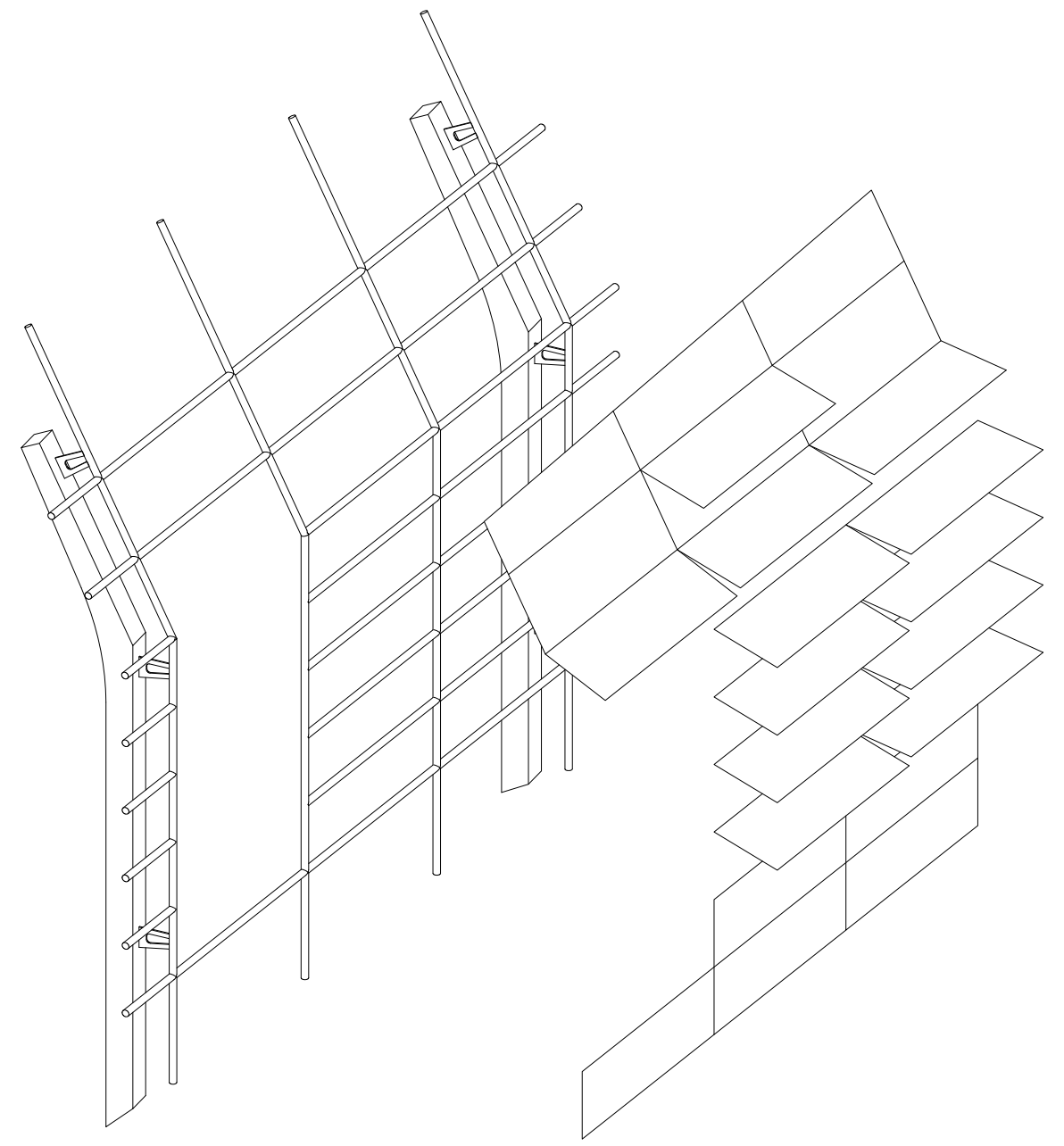




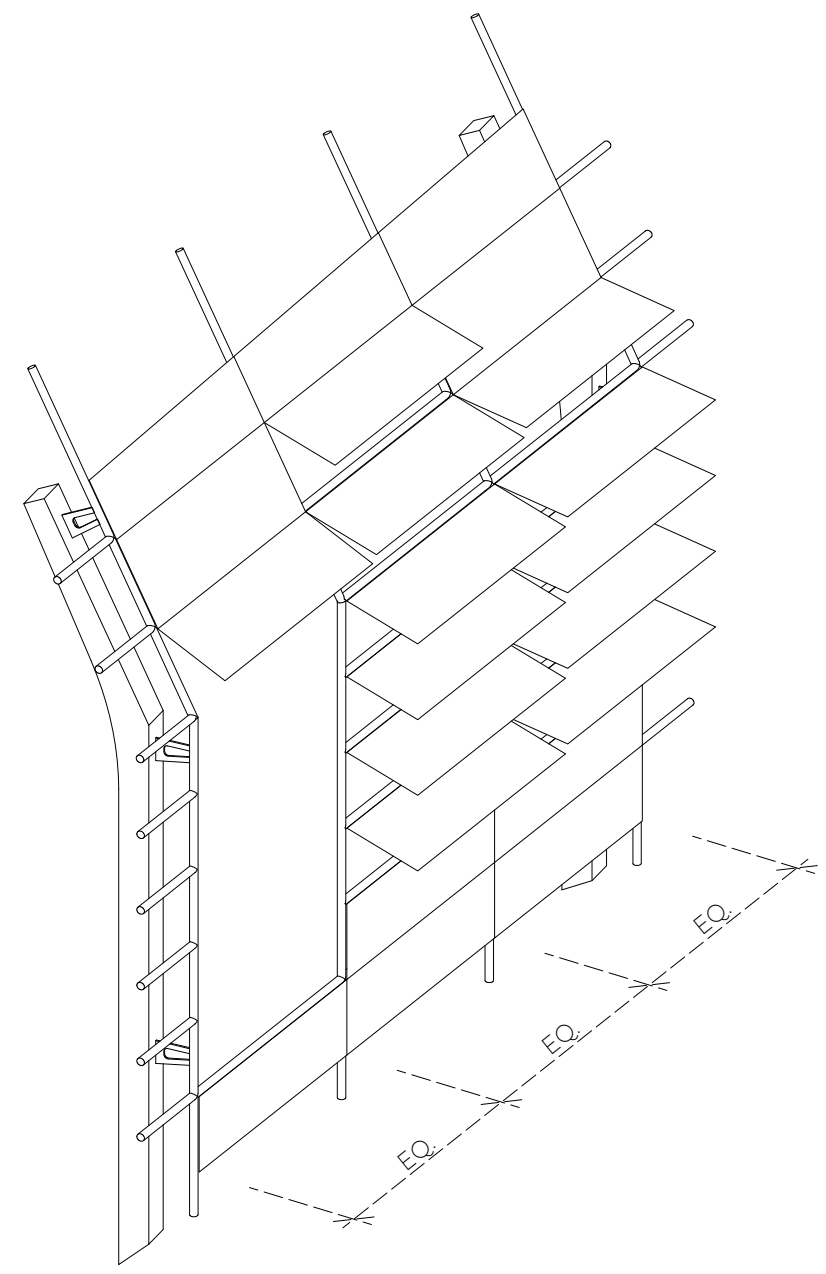



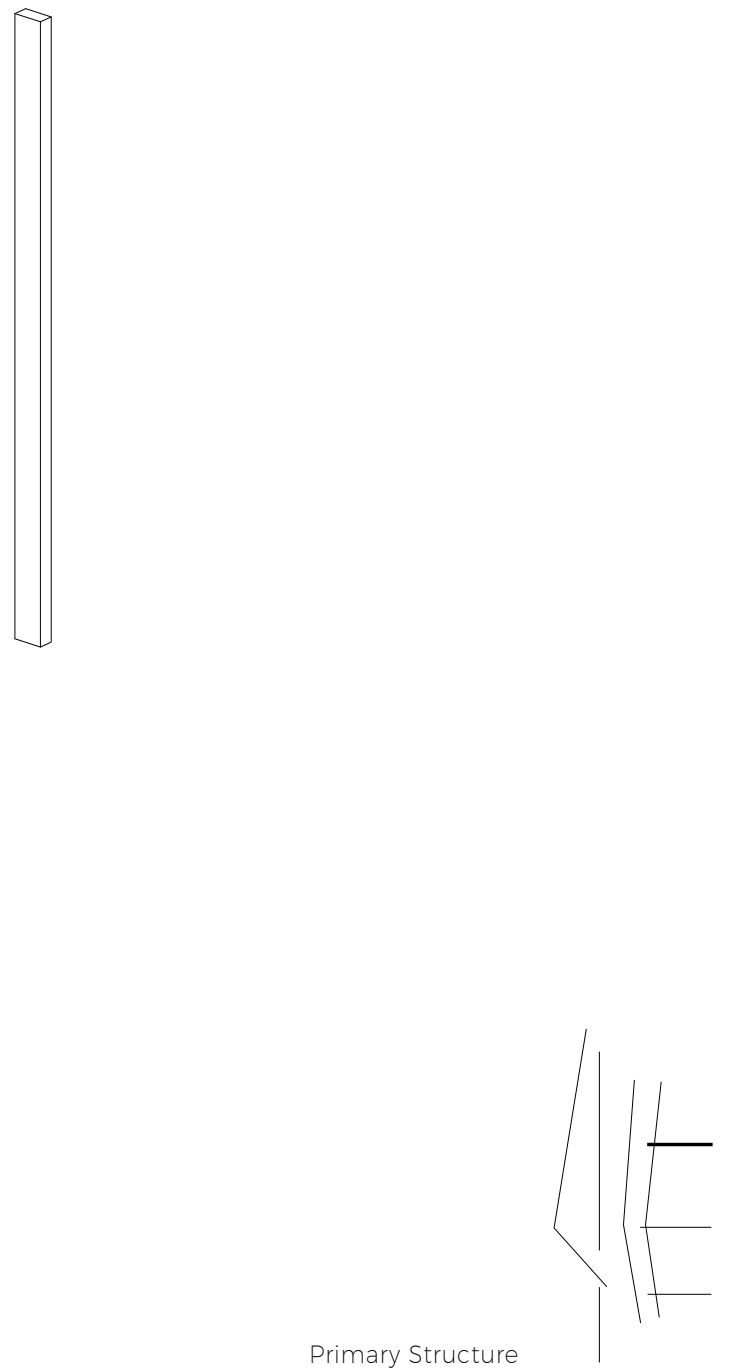


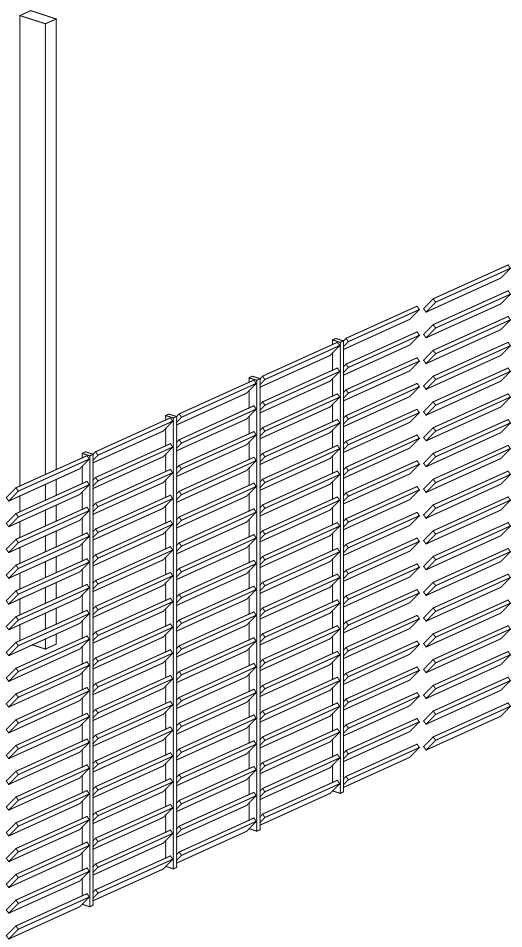



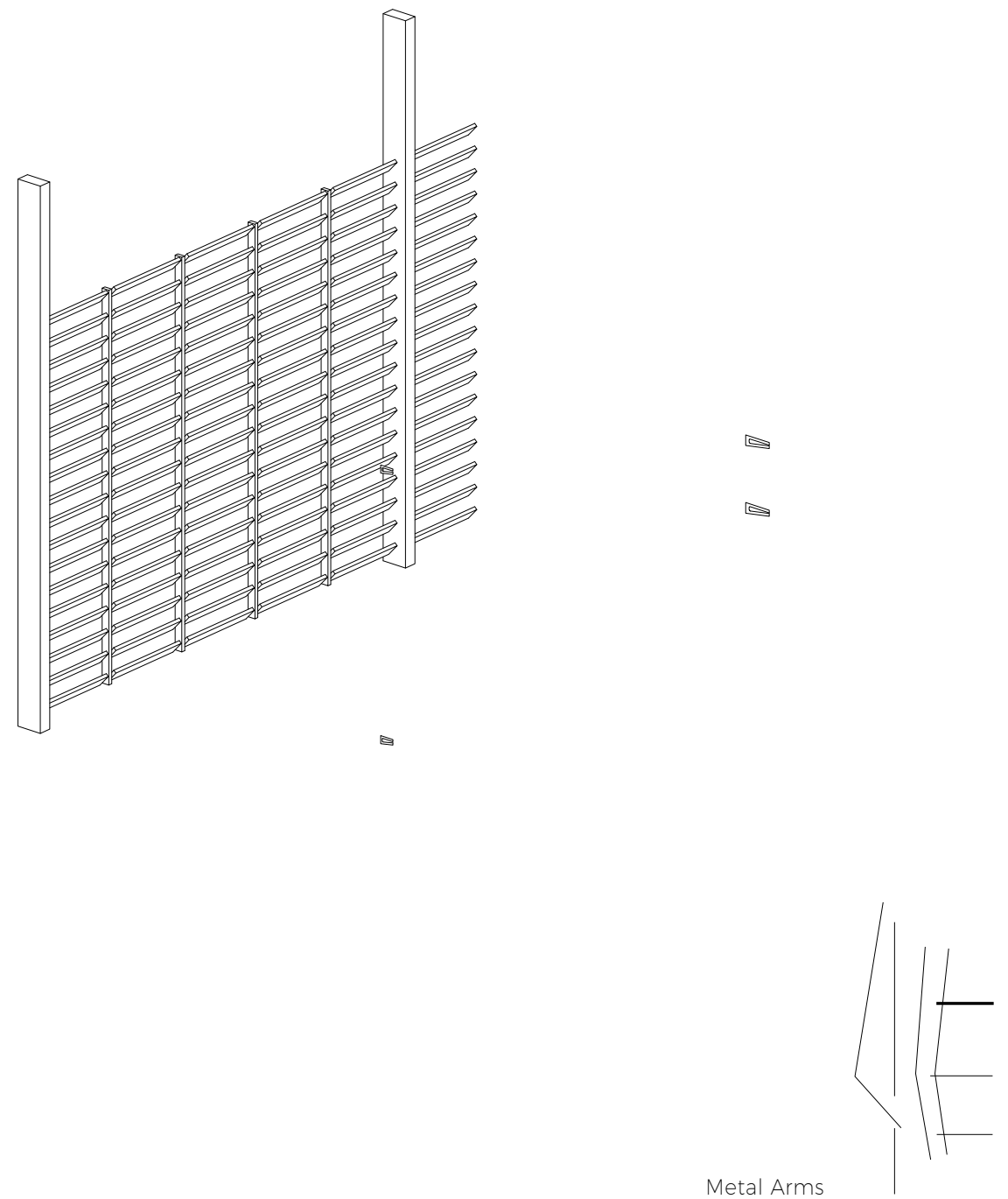


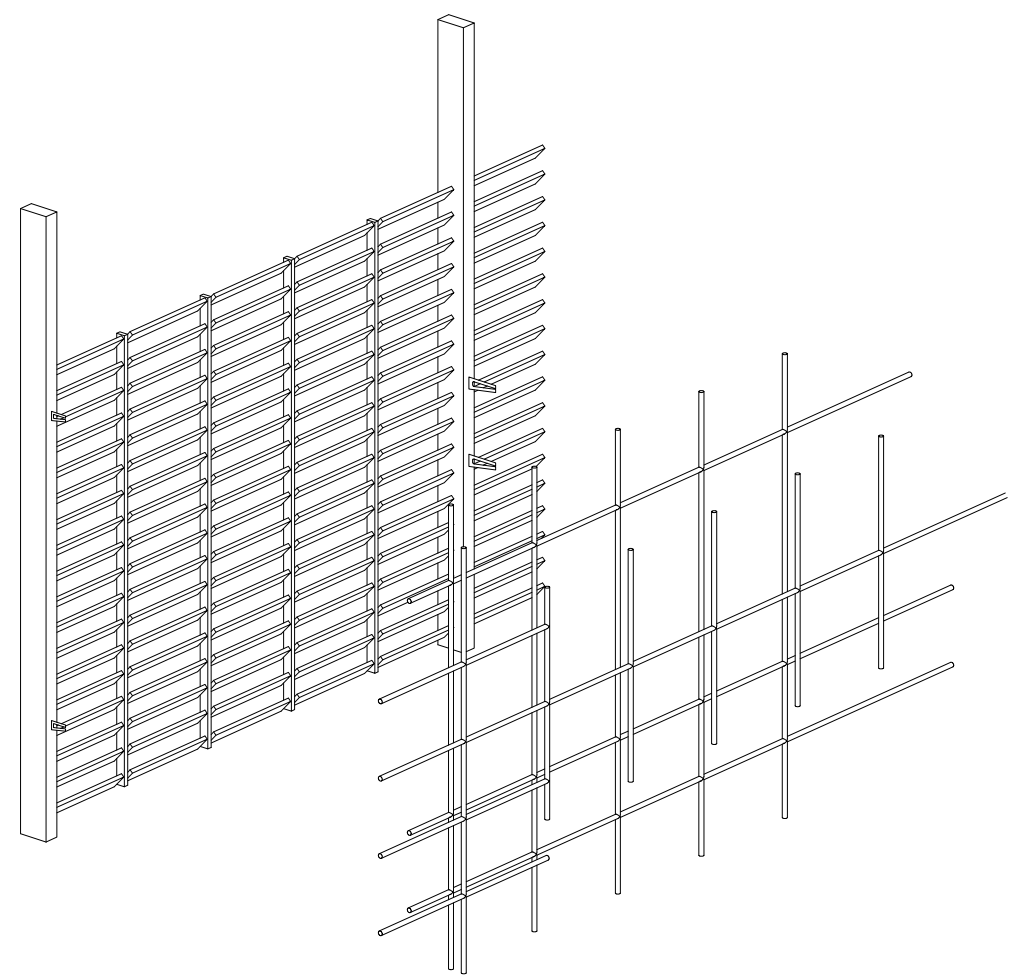



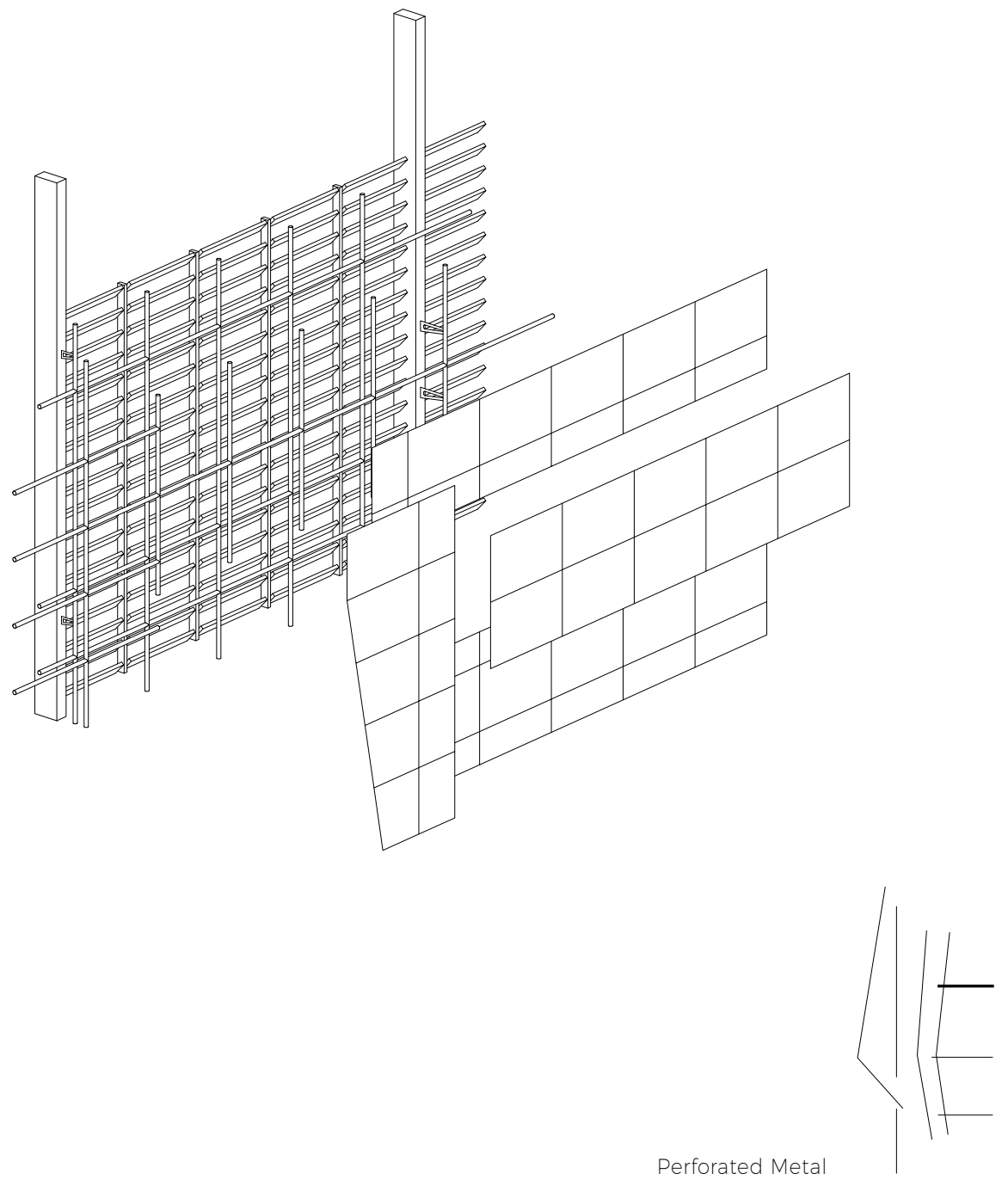


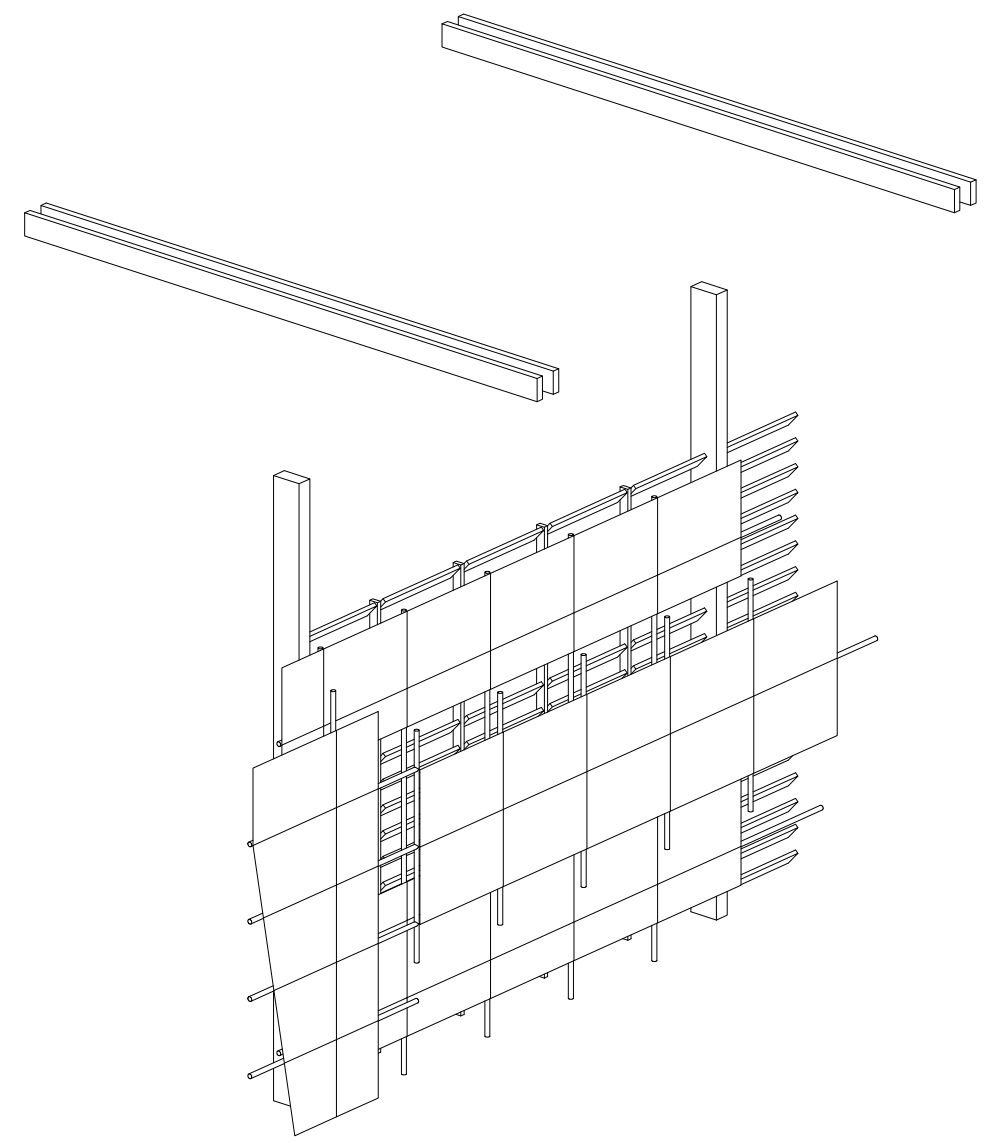



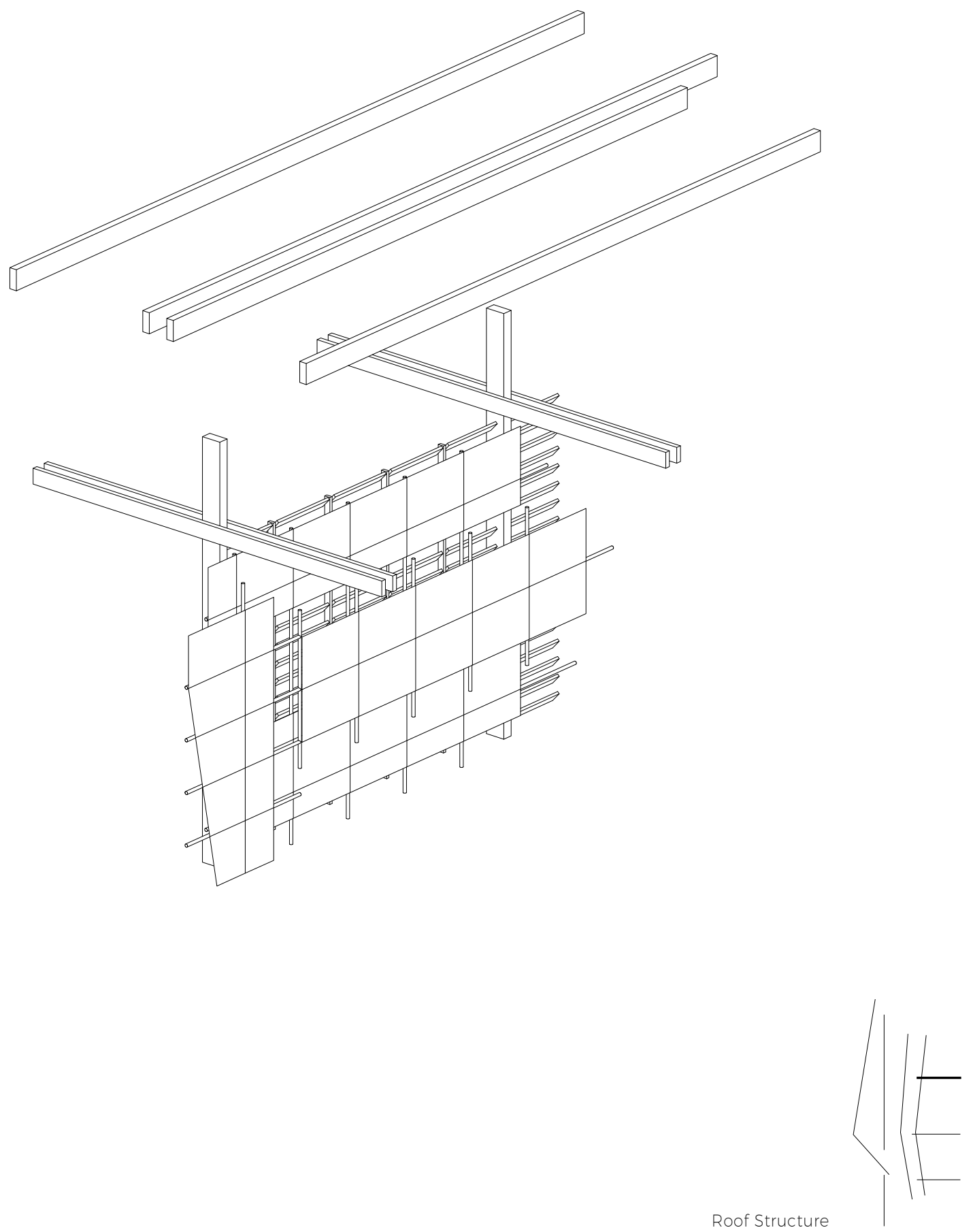


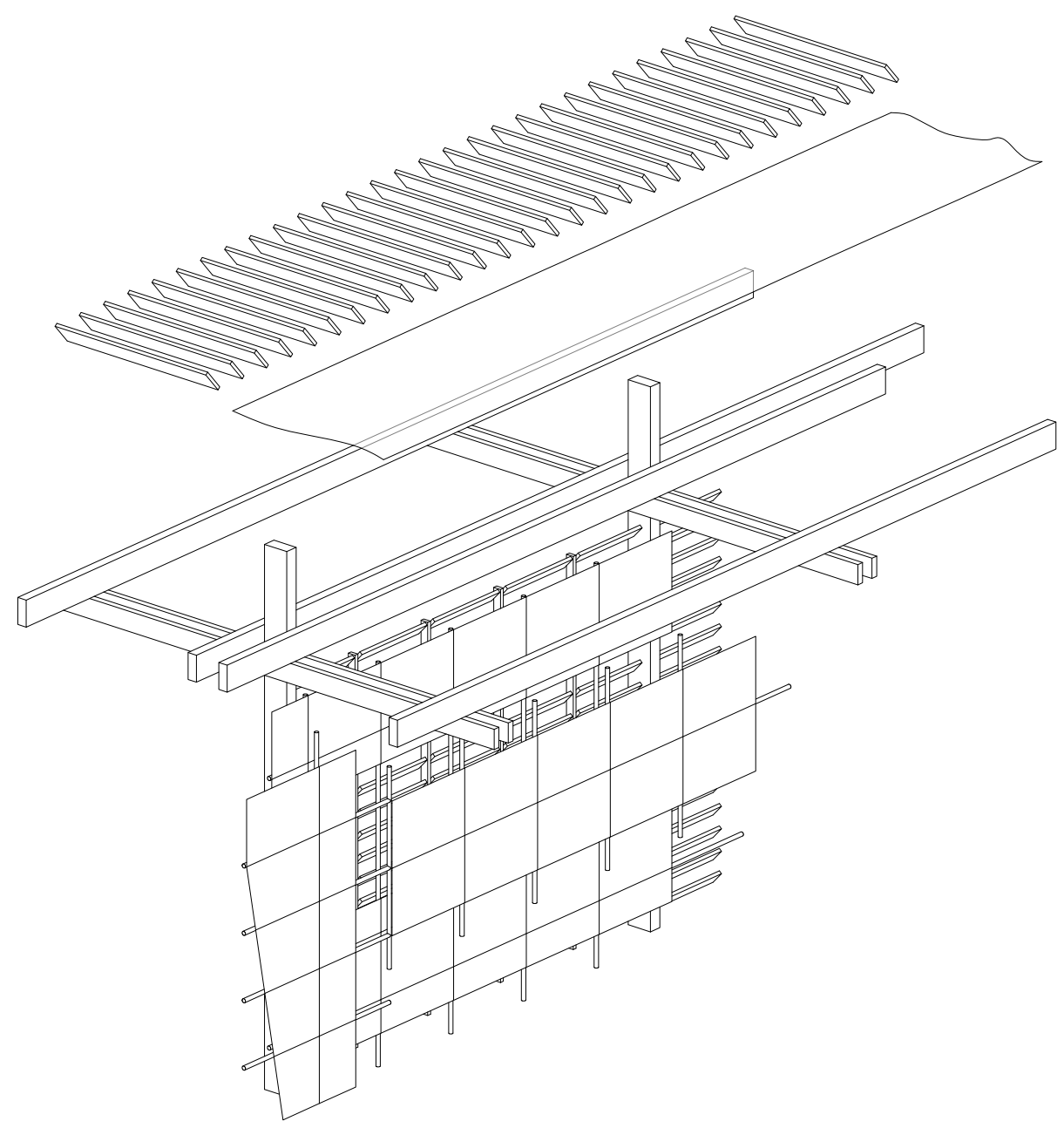



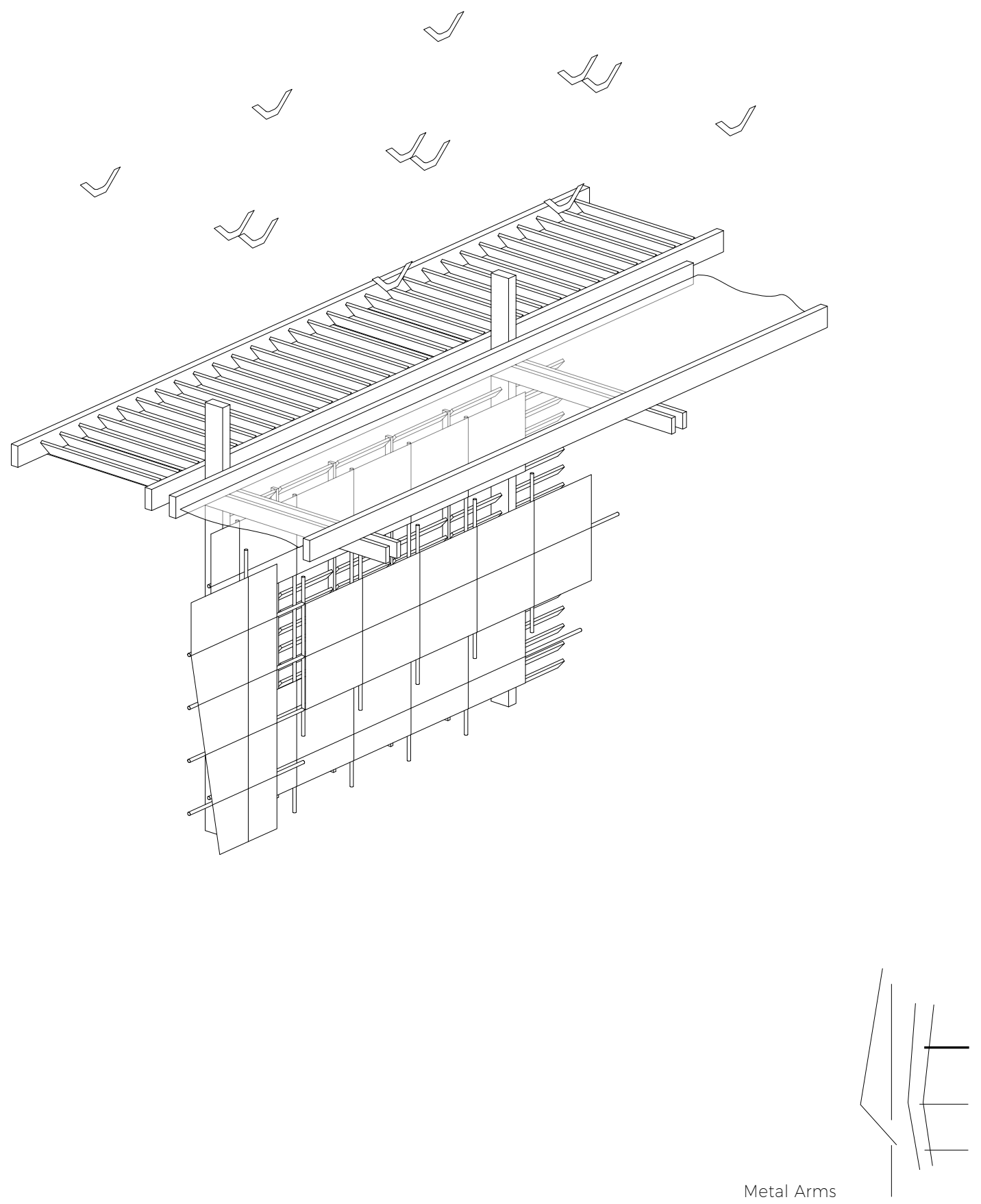


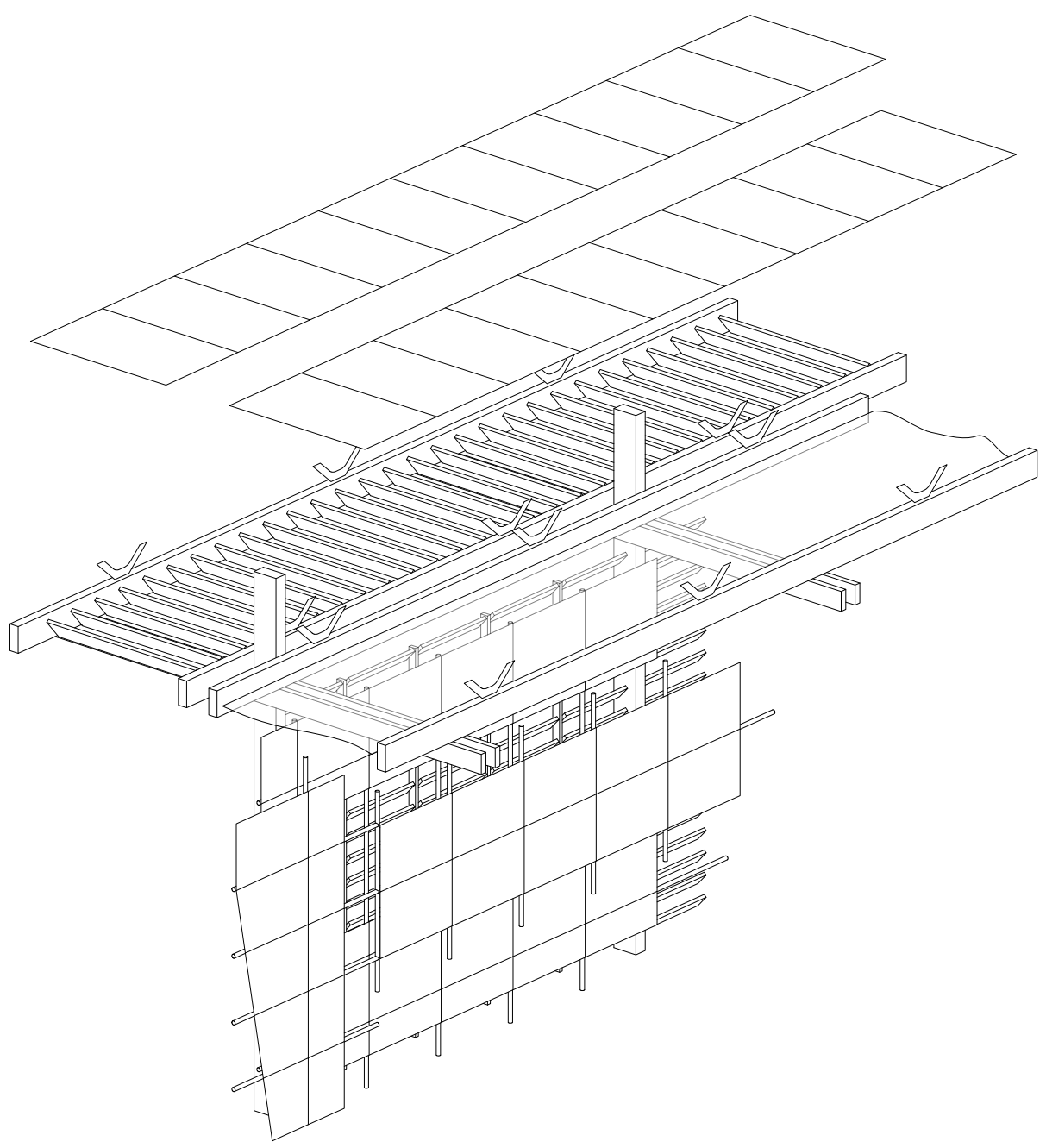




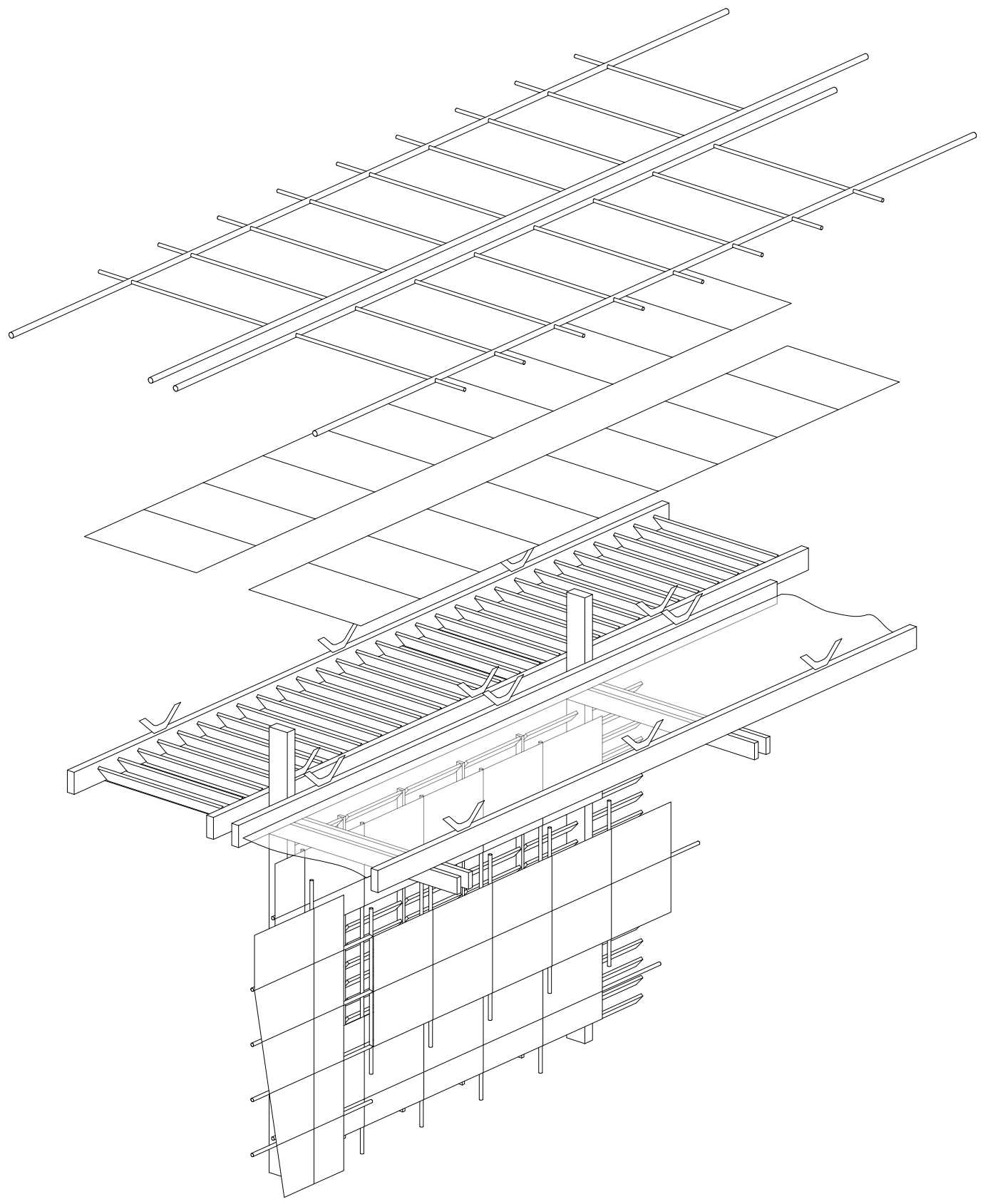




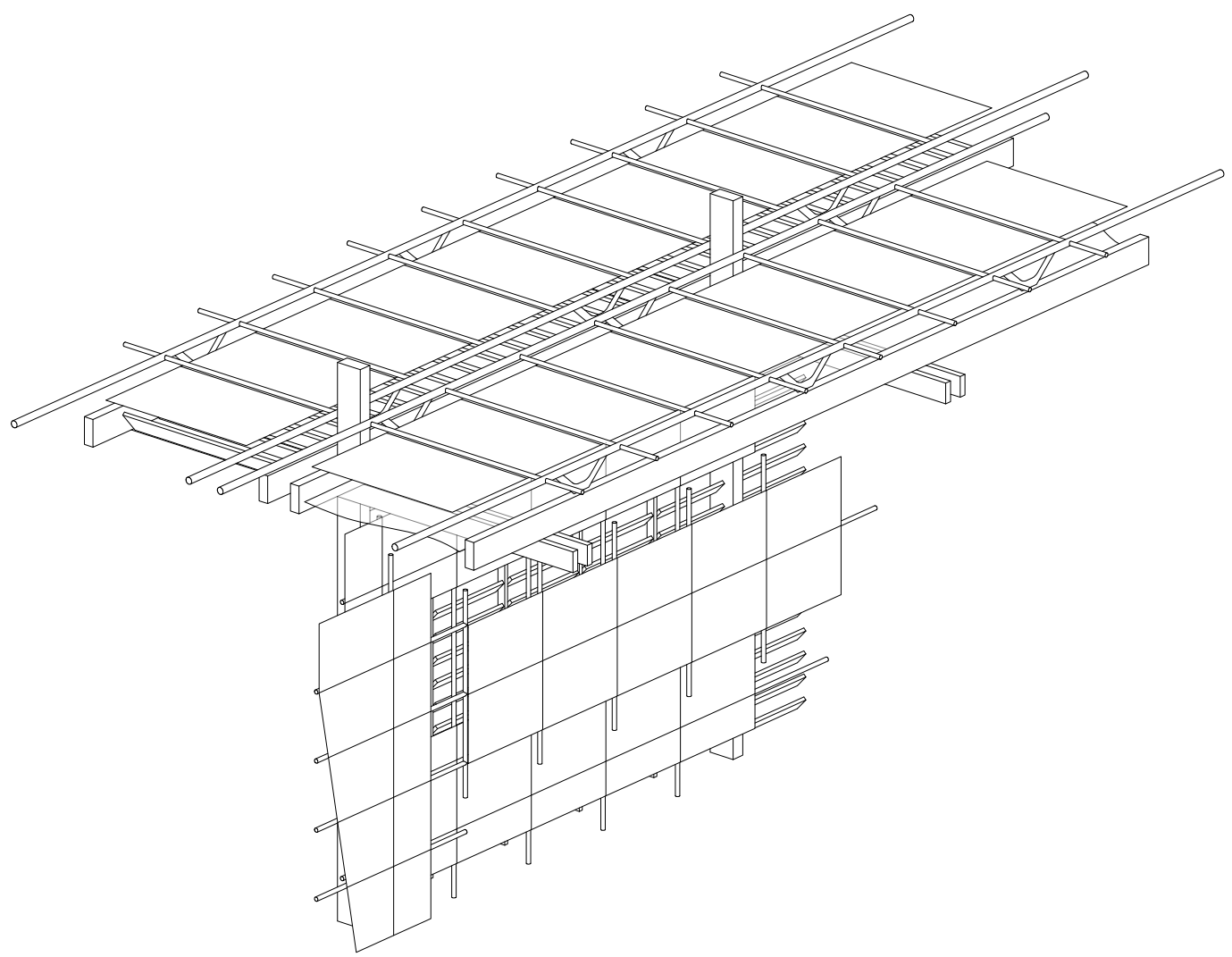



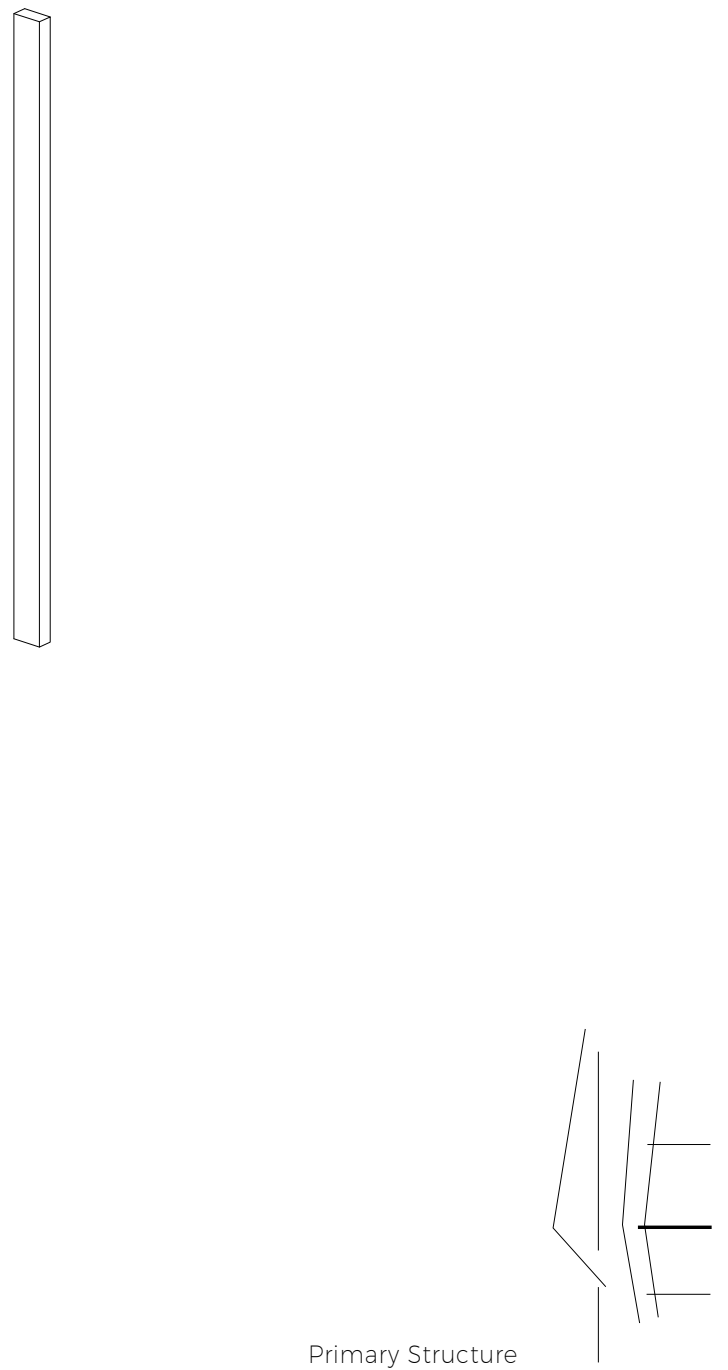


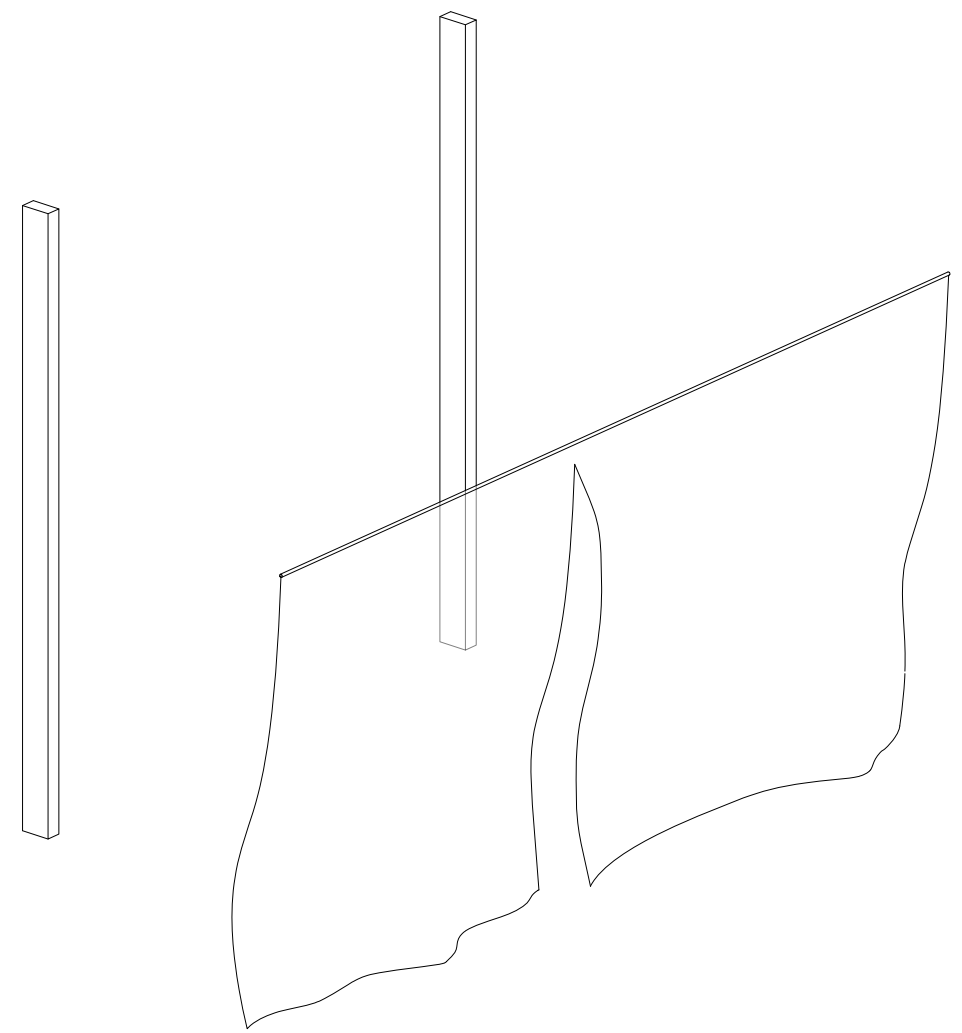




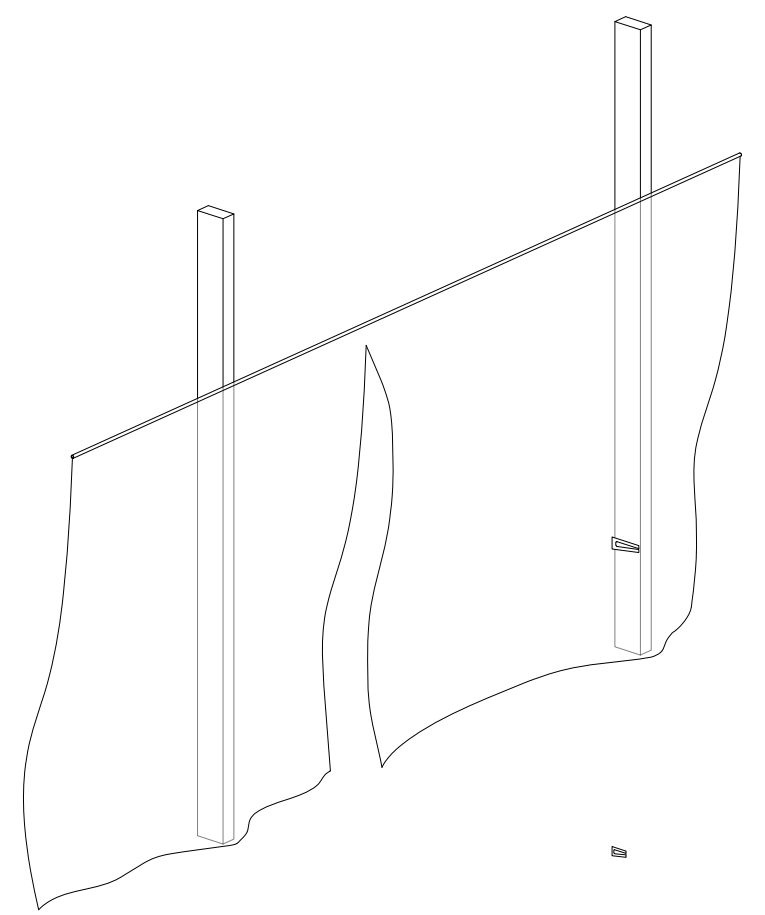

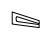

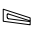

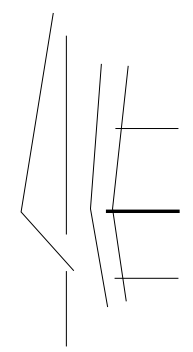




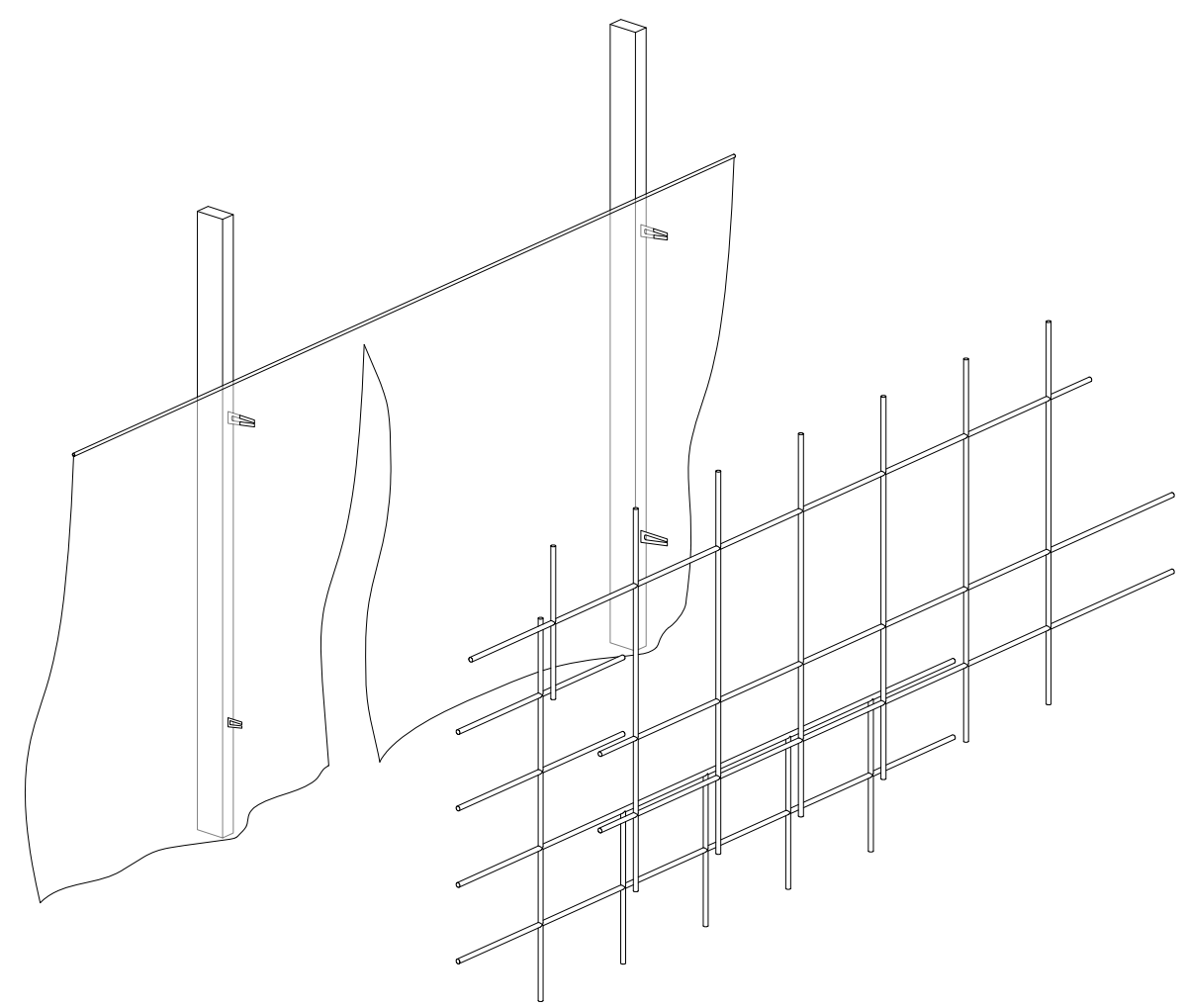



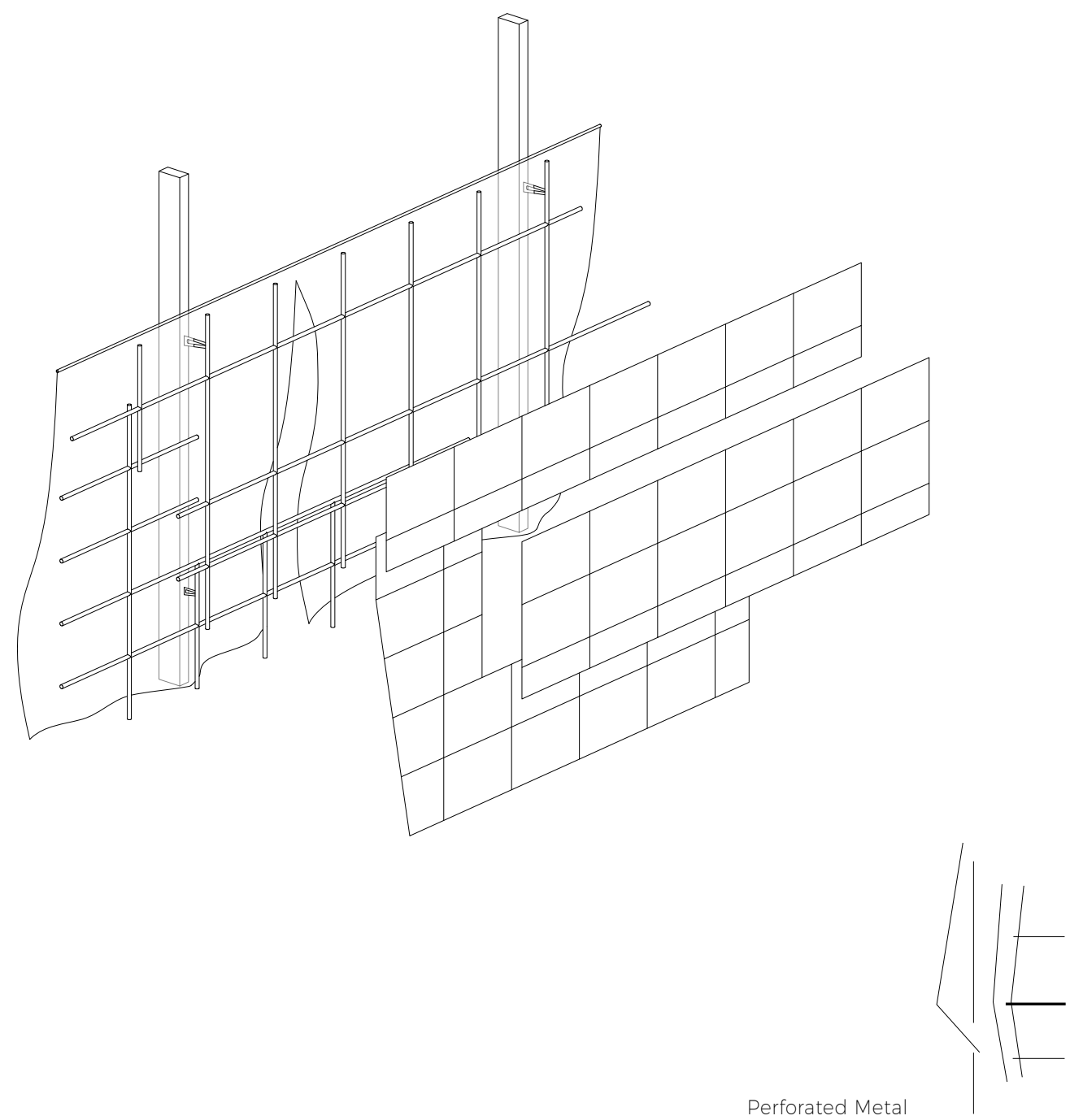


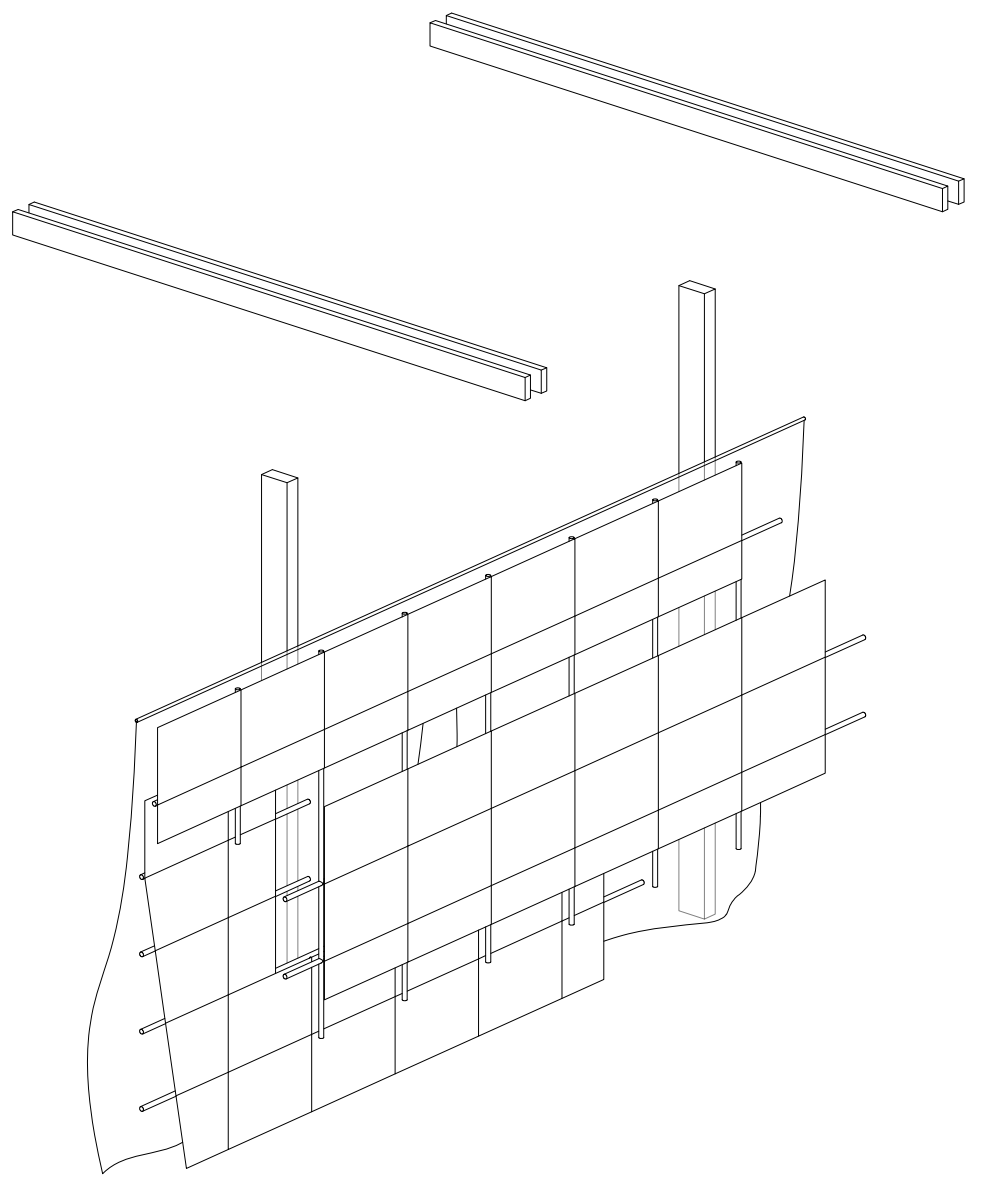




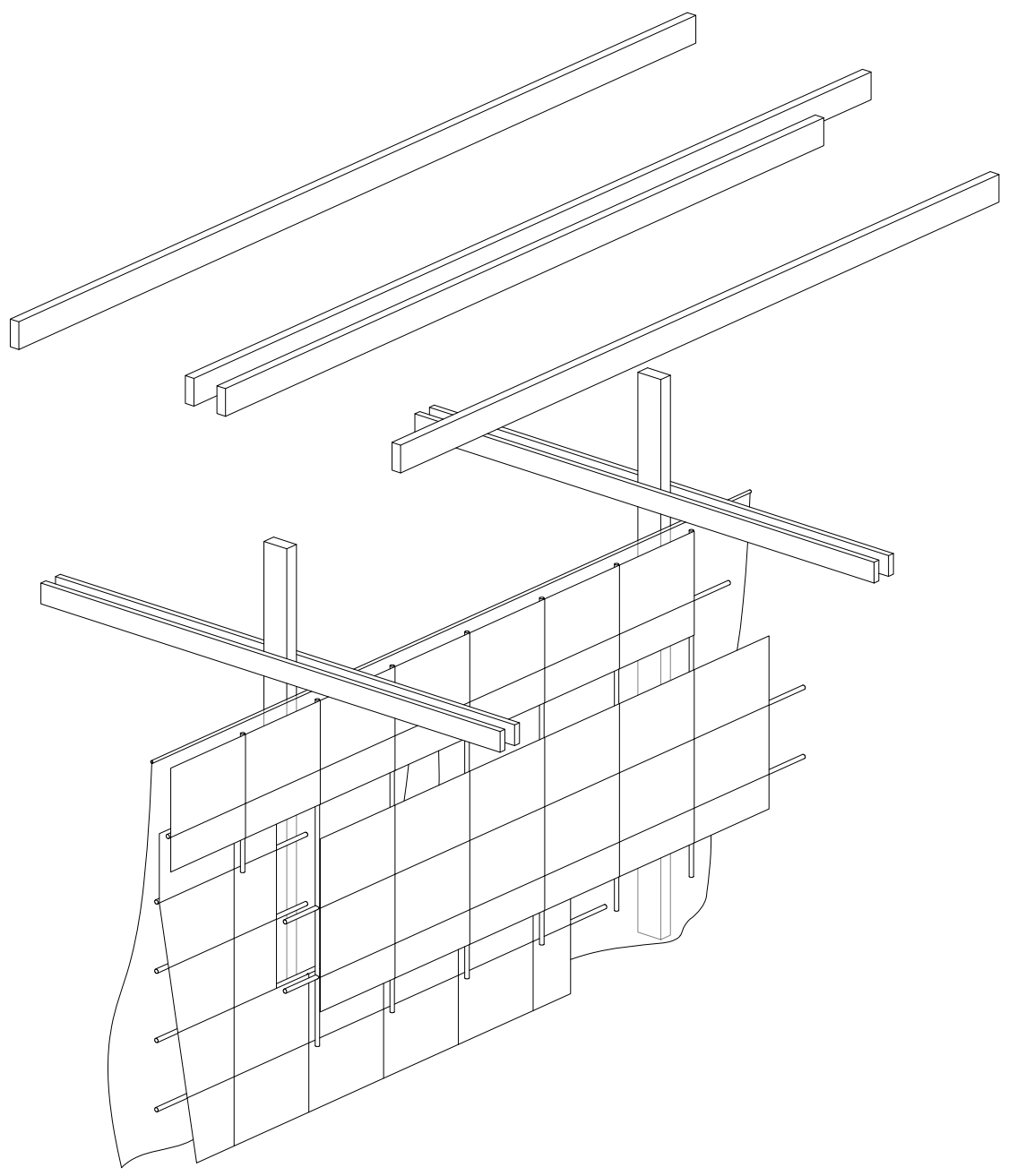




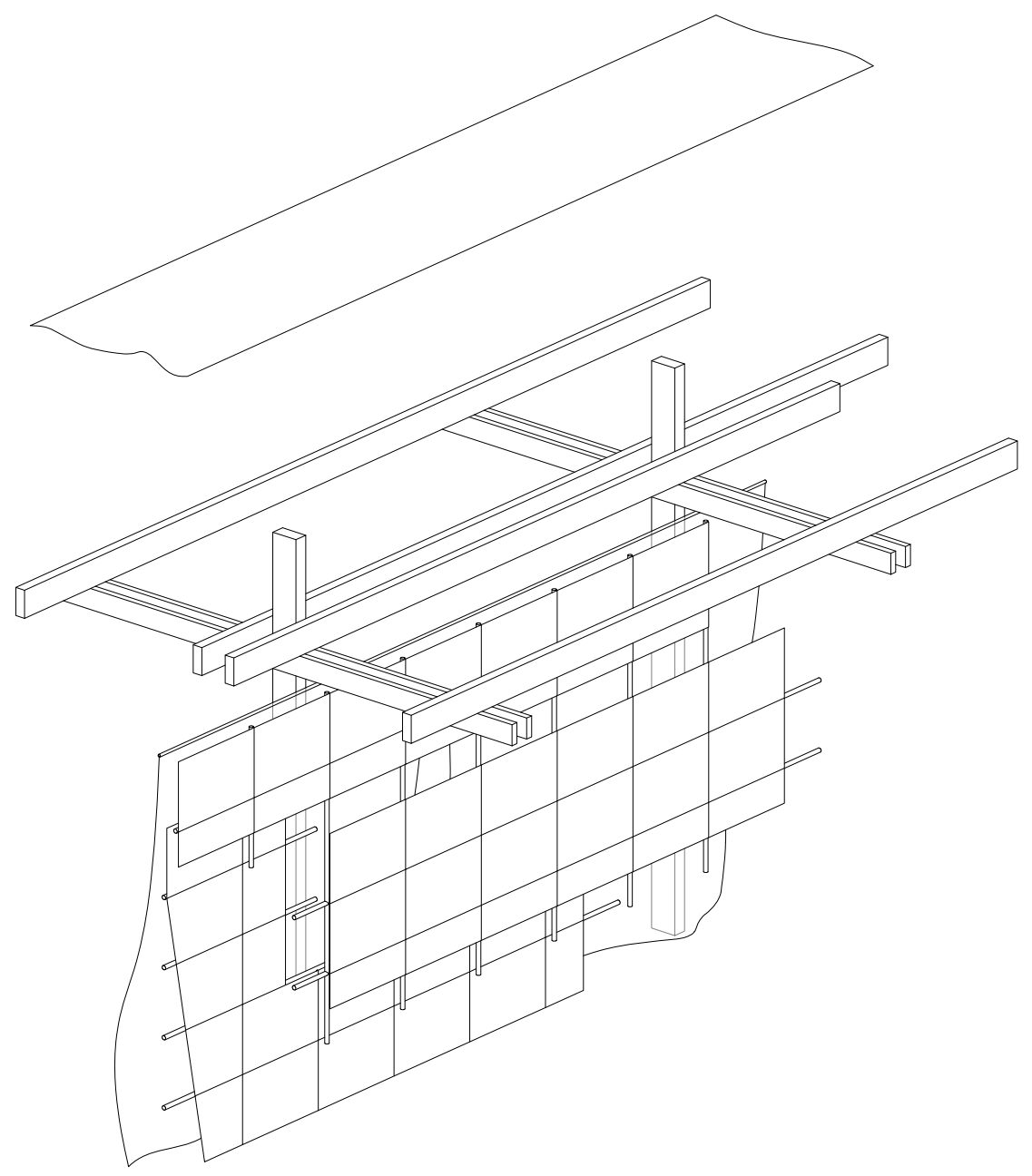




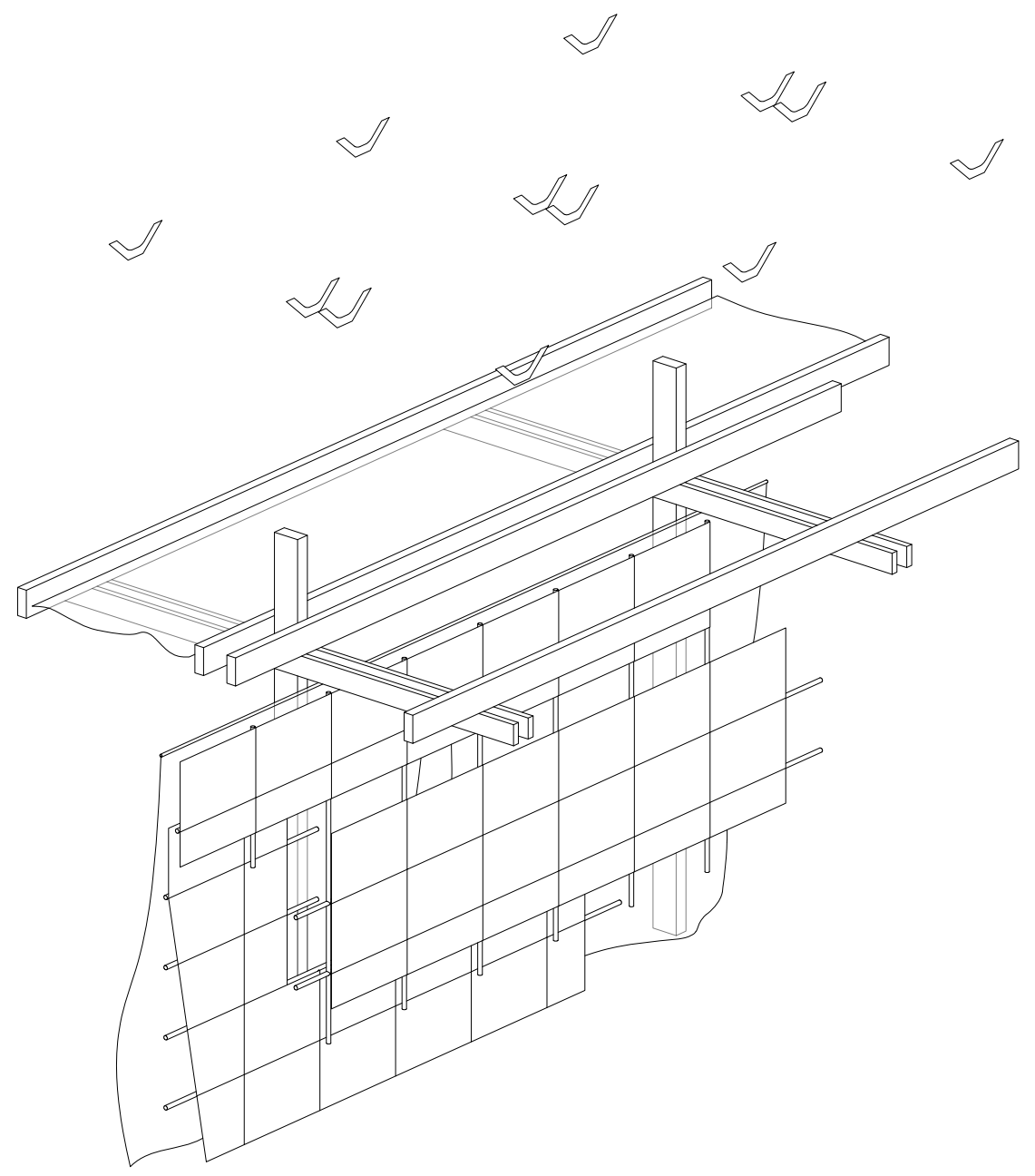




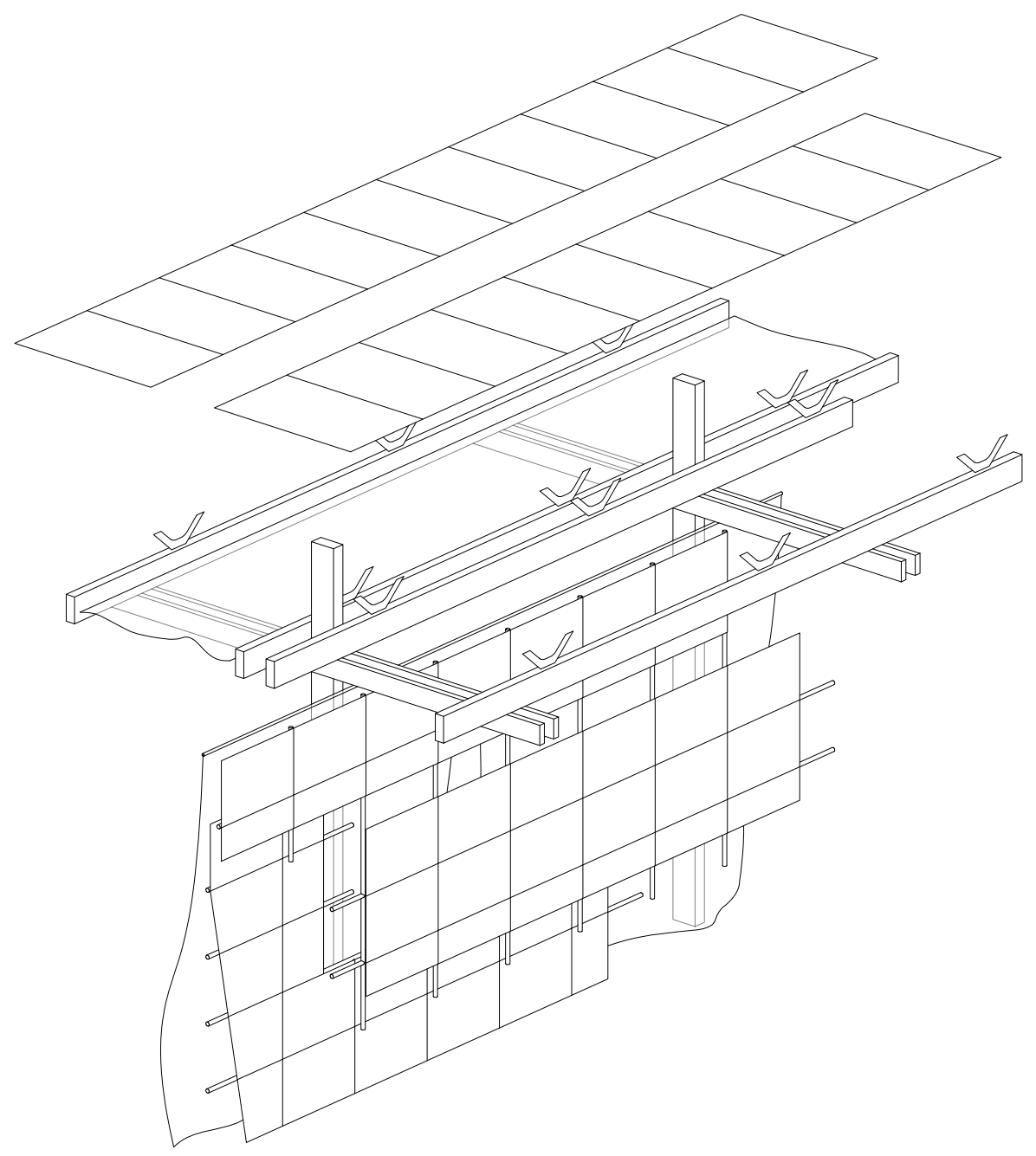




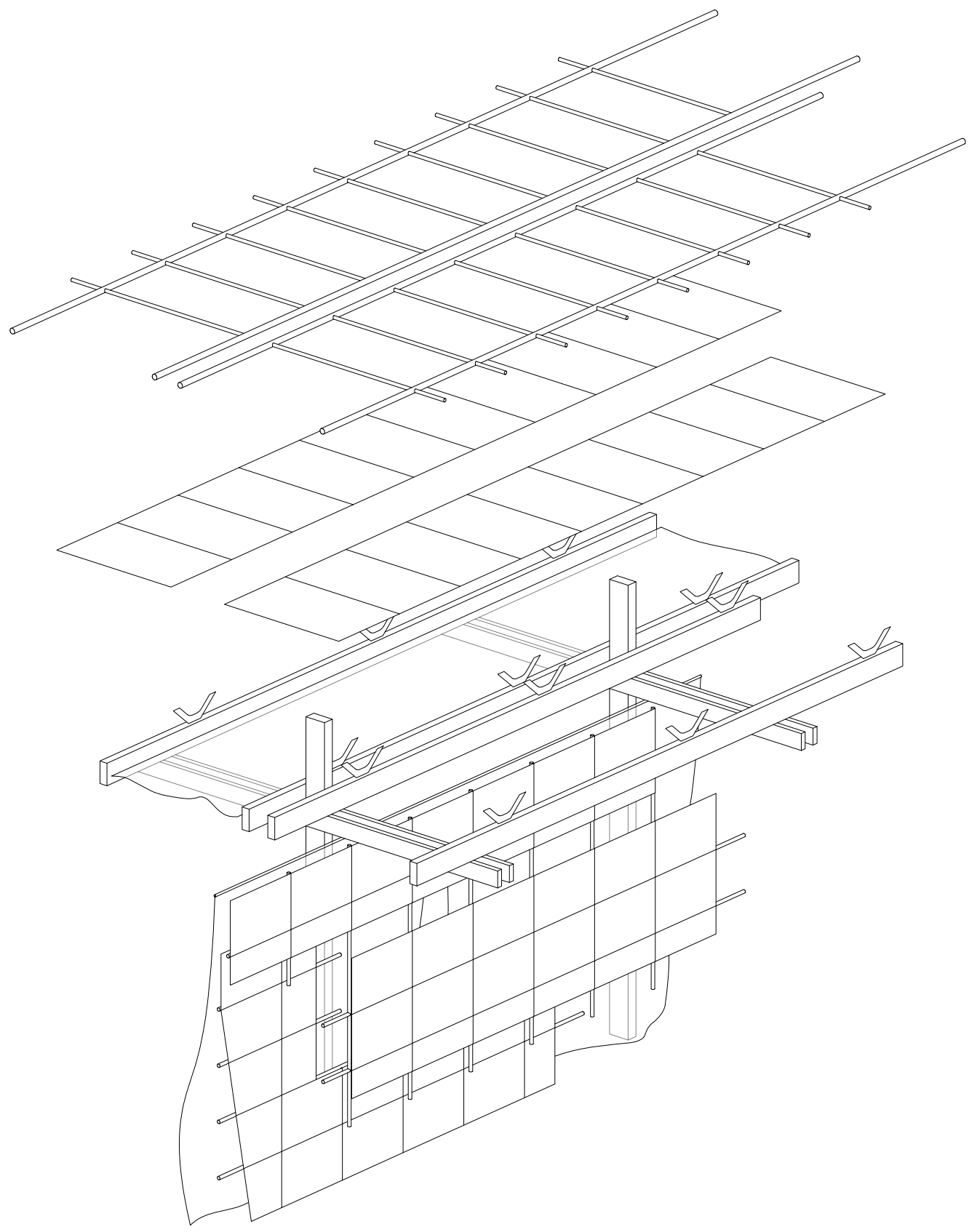




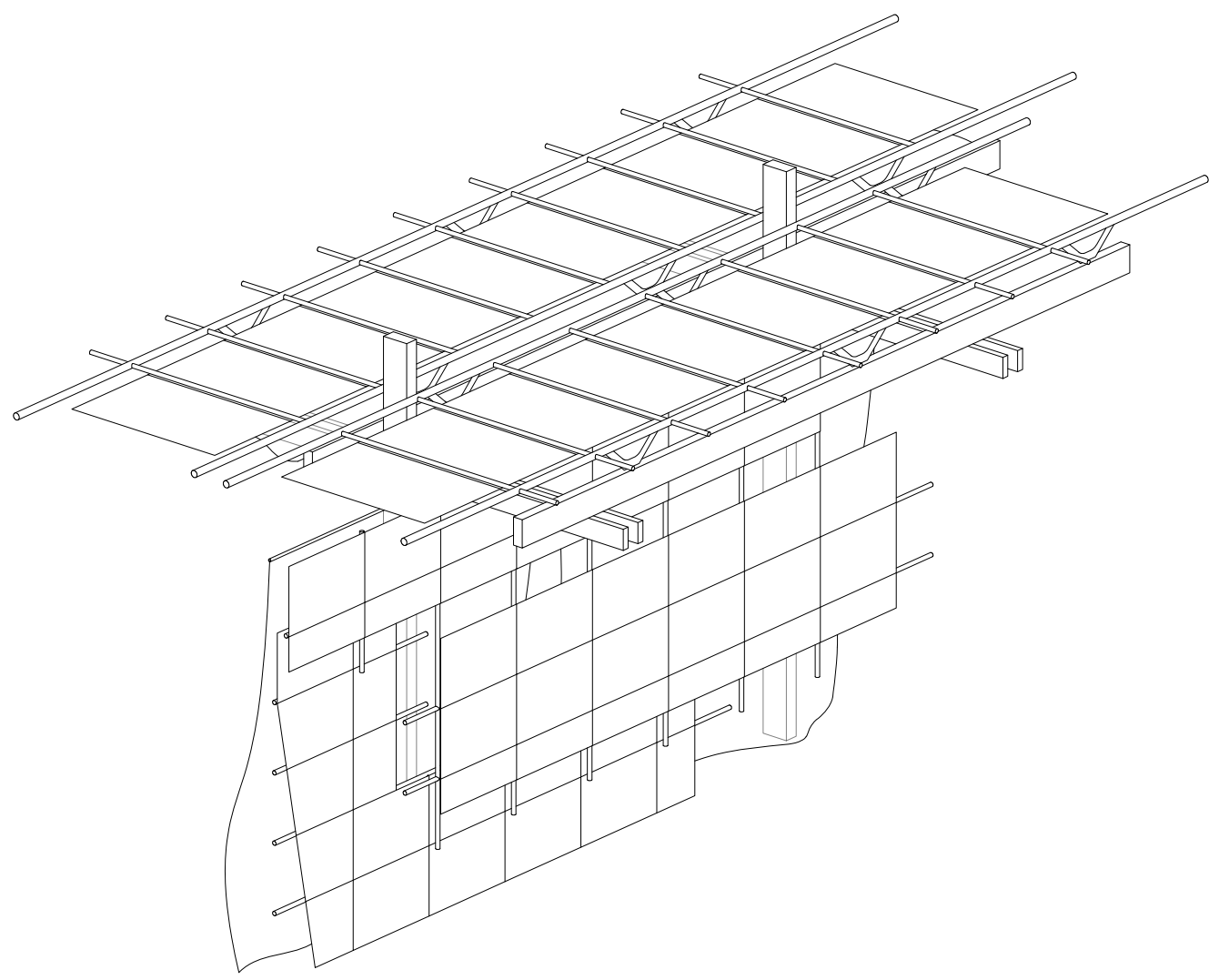



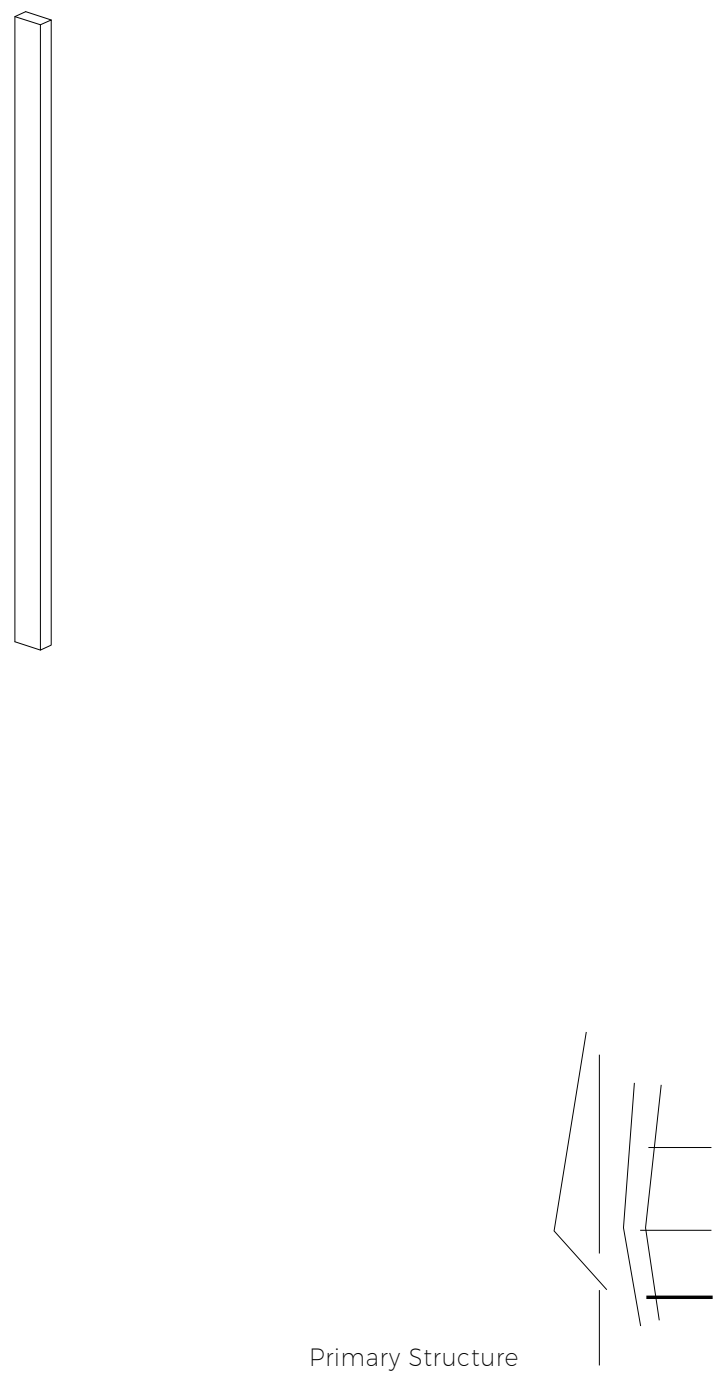


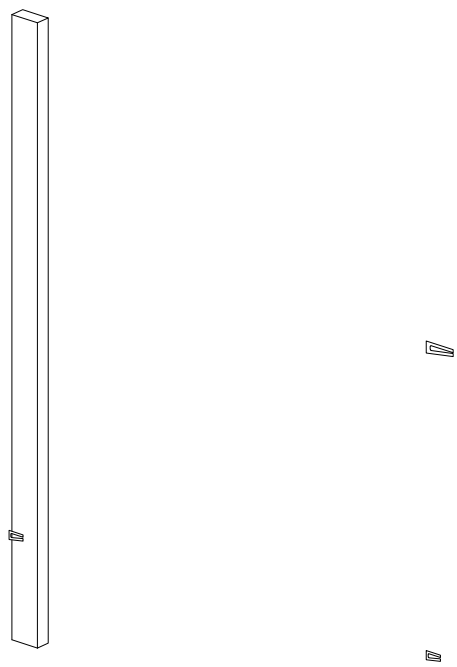



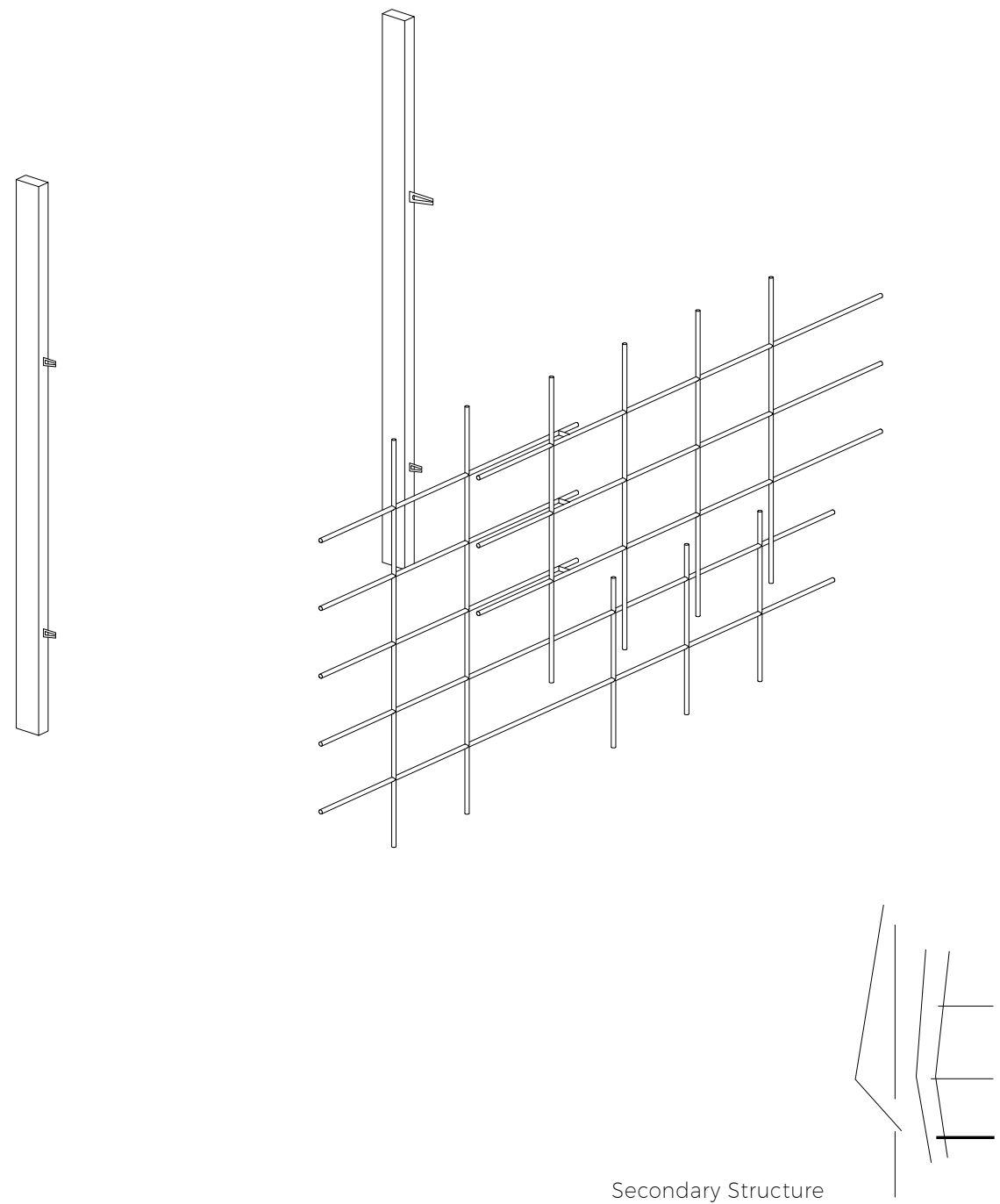


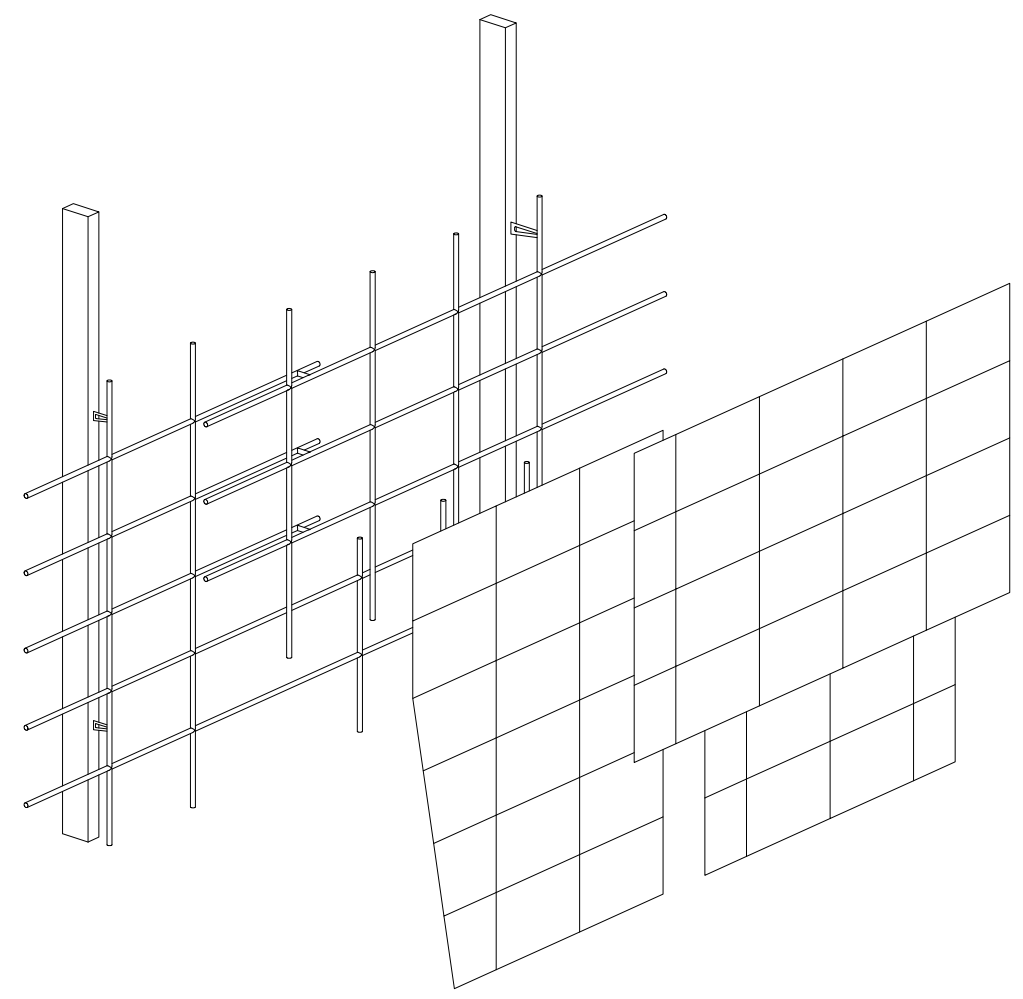




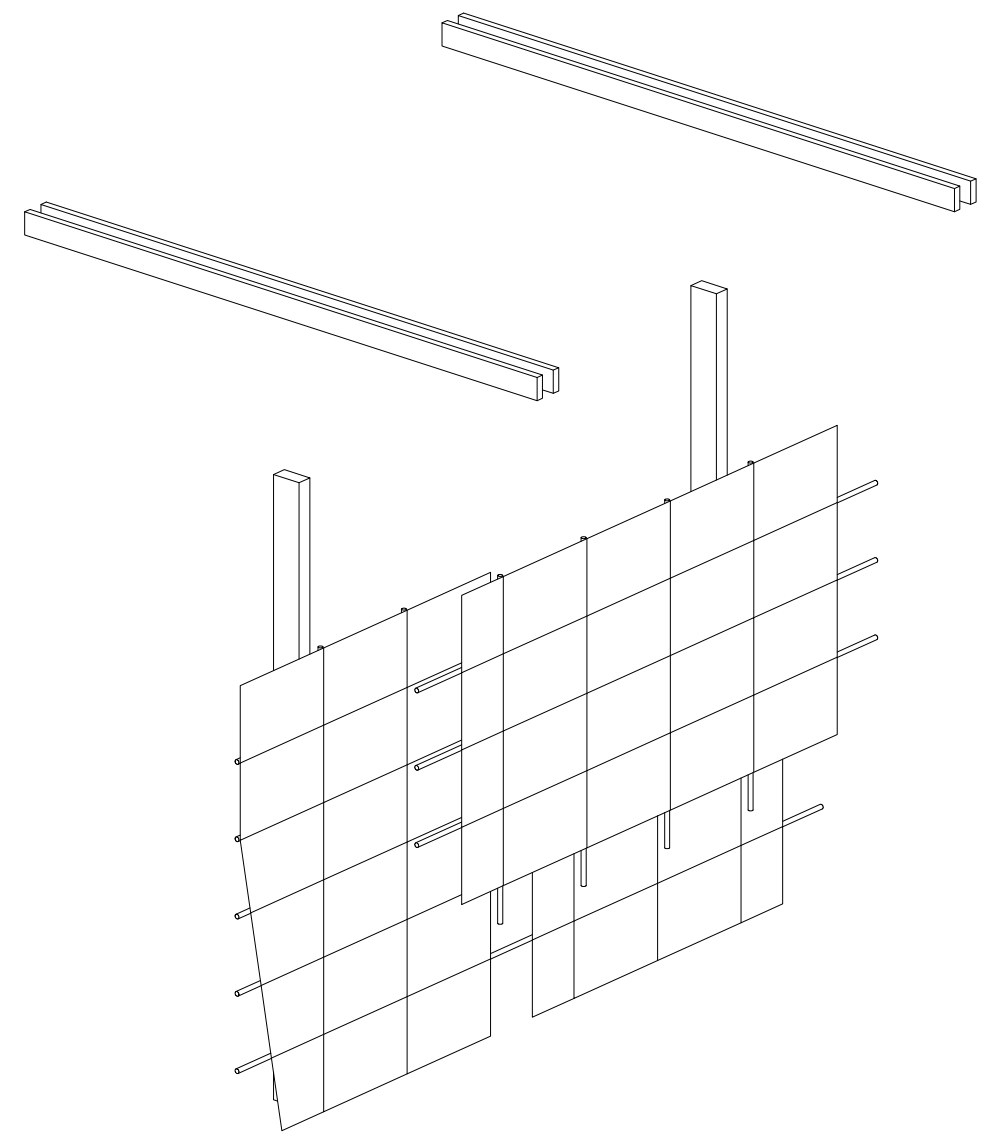




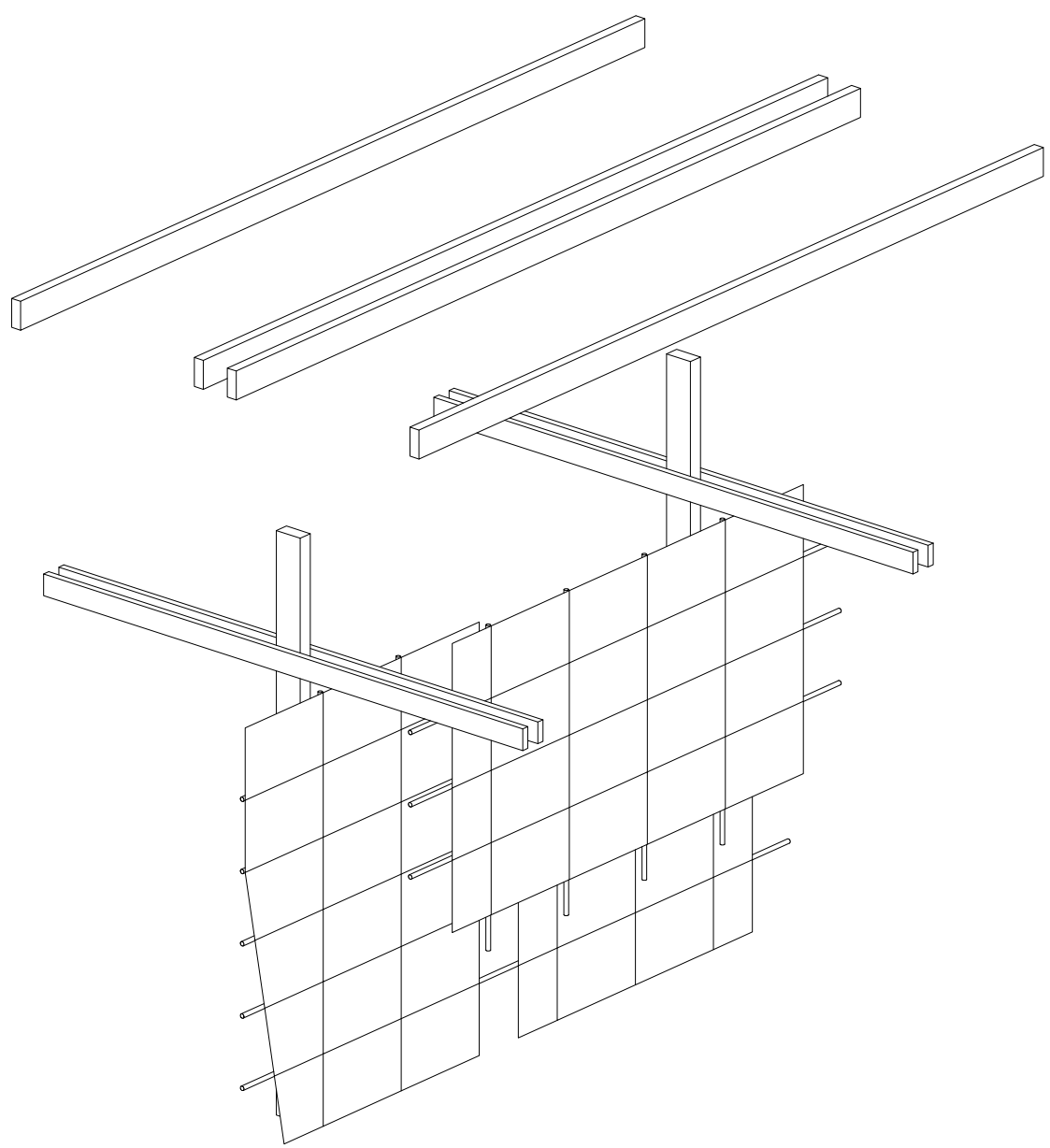




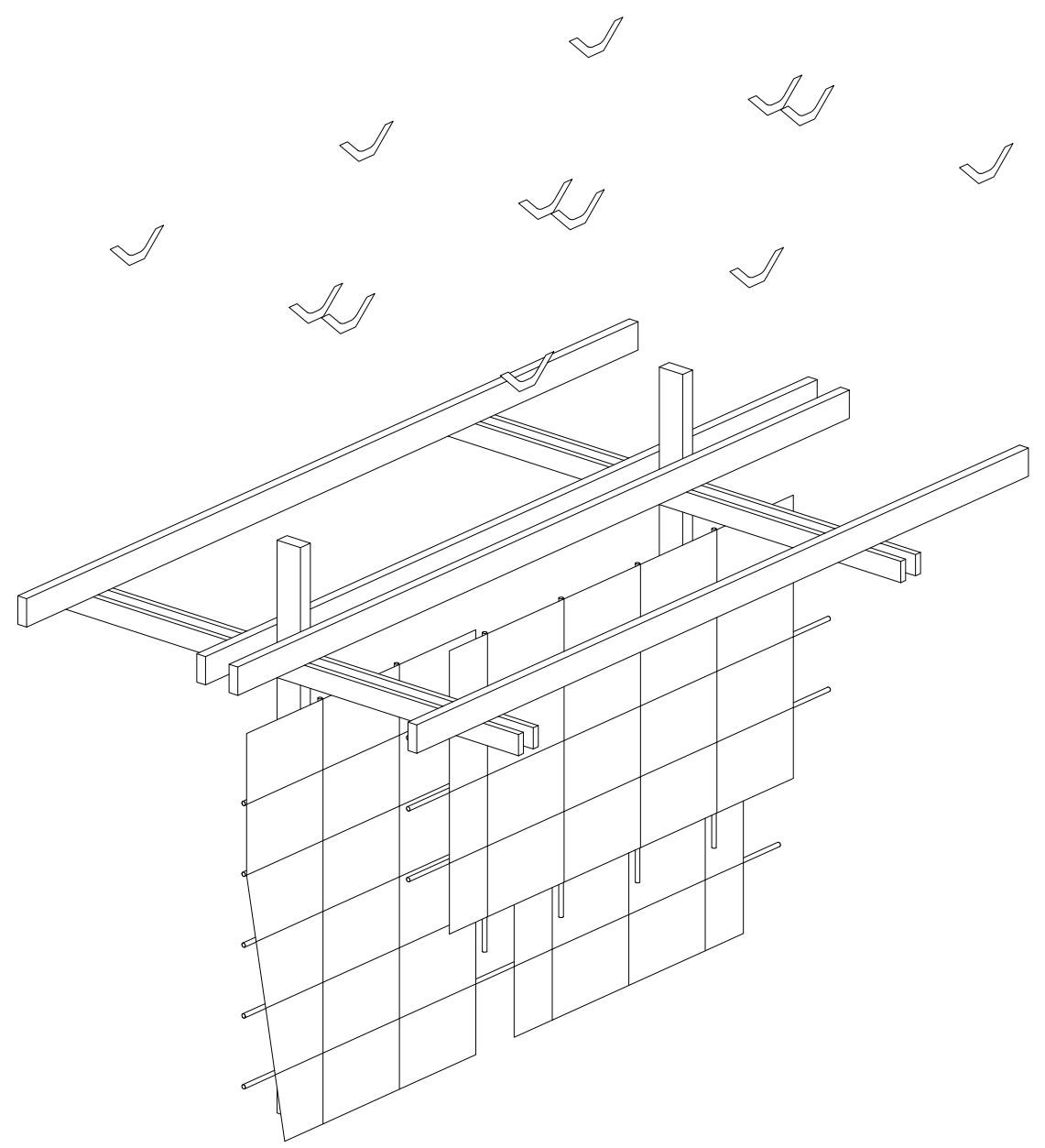




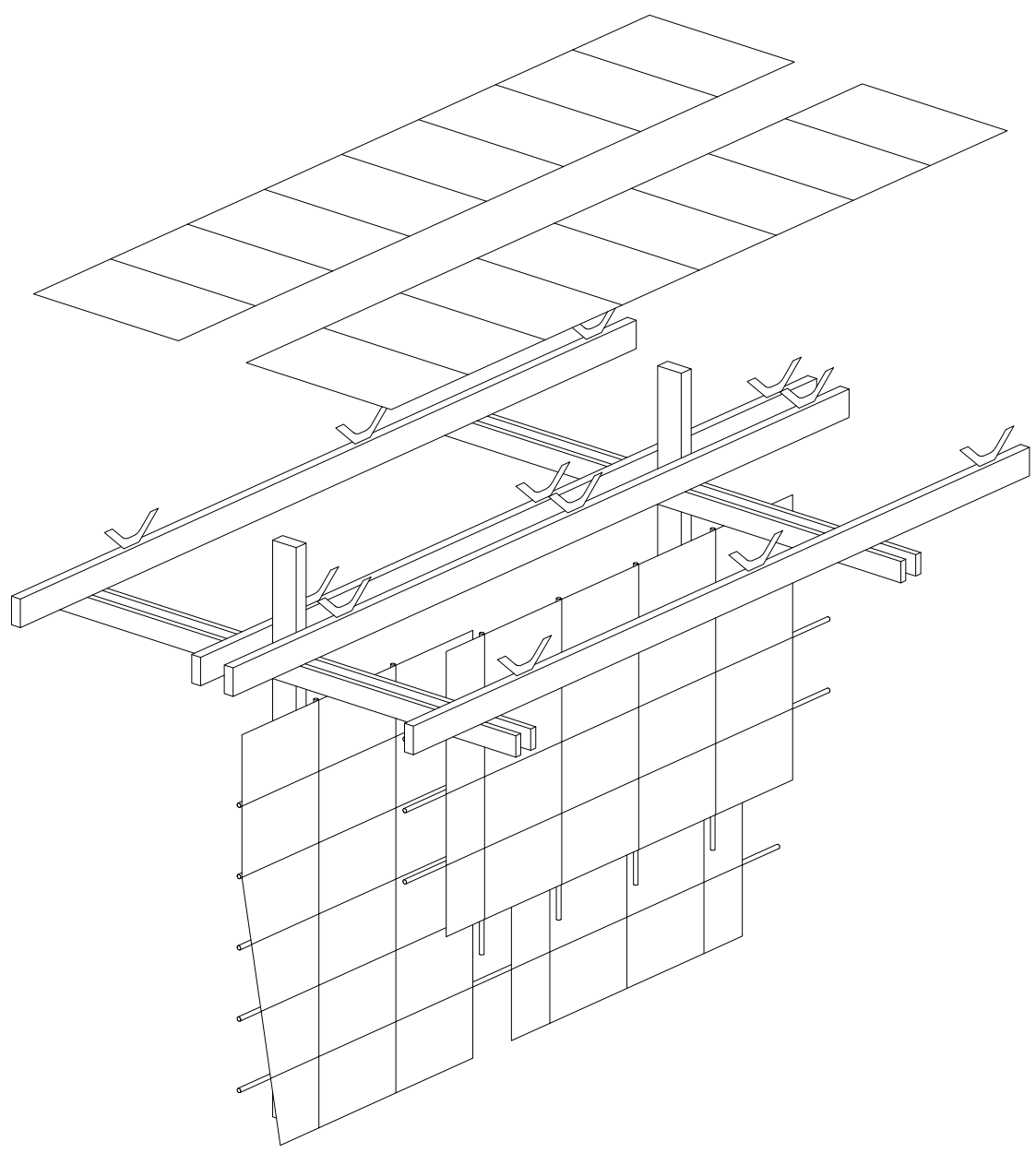




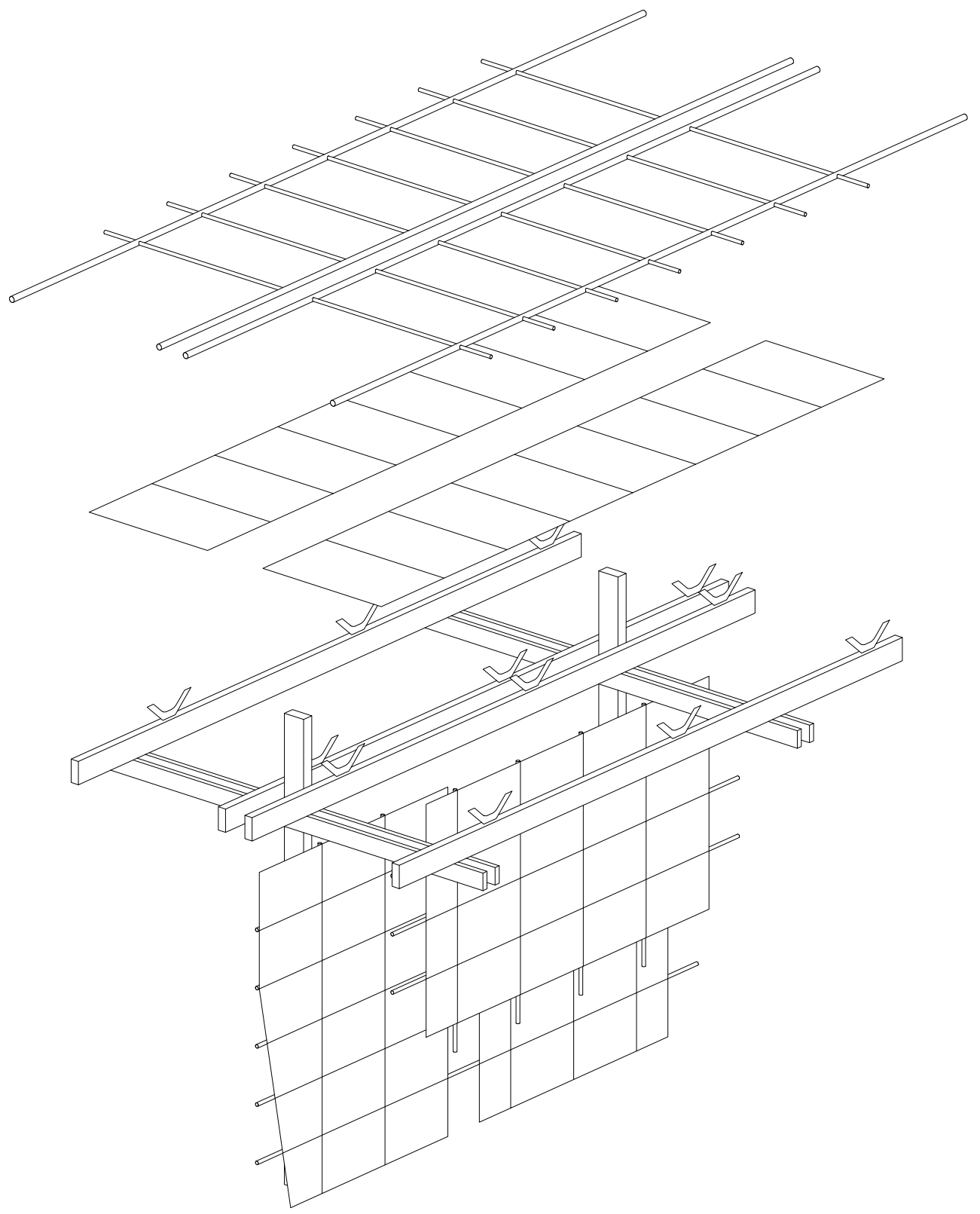




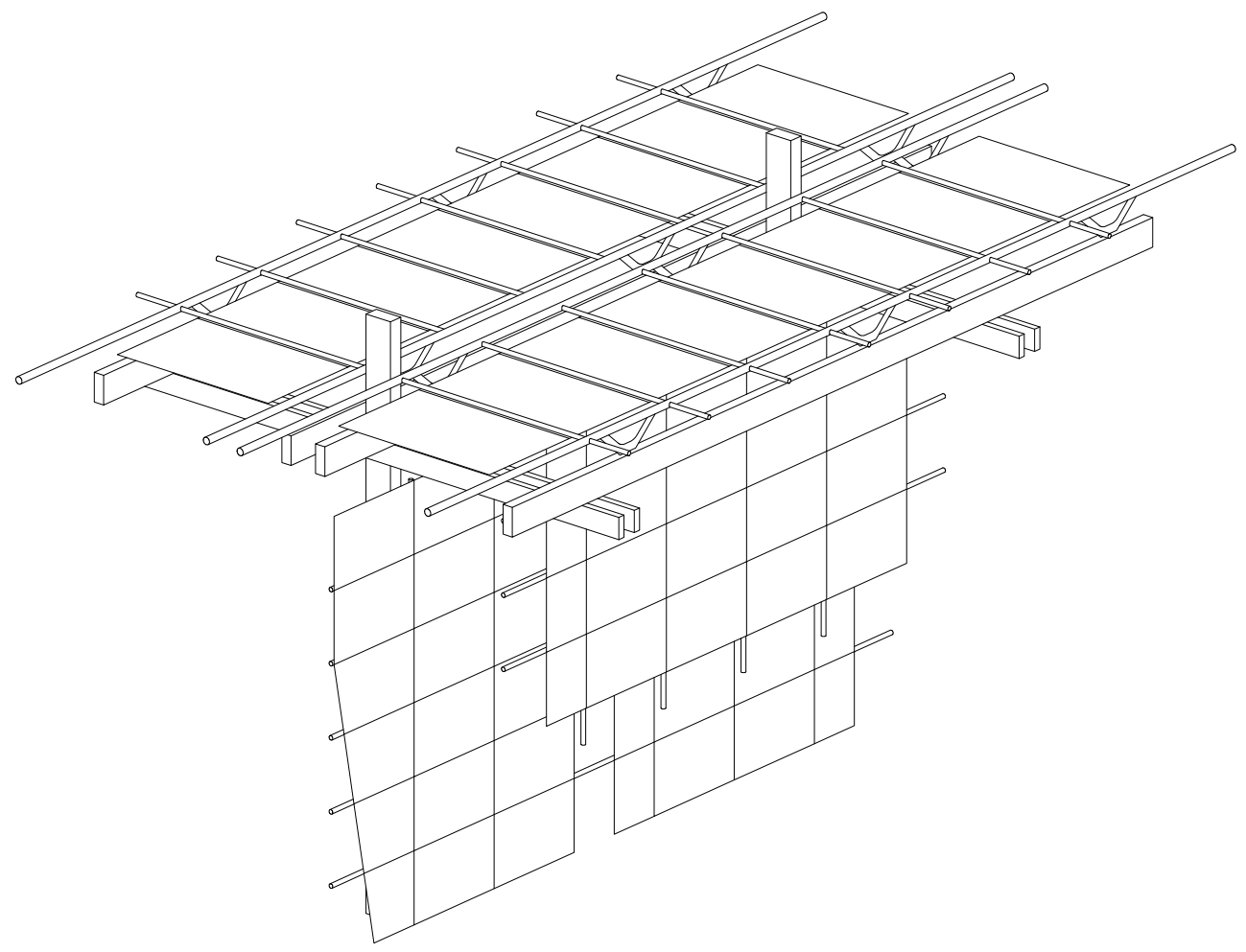




\section{BIBLIOGRAPHY}

Adam, Robert. The Globalisation of Modern Architecture: The Impact of Politics, Economics and Social Change on Architecture and Urban Design Since 1990. Newcastle Upon Tyne: Cambridge Scholars Publishing, 2013.

Addington, Michelle. "Contingent Behaviours." Architectural Design: Energies (Academy Press), 2009: 12-17.

Addington, Michelle. "The Phenomena of the Non-Visual." In Softspace: From a Representation of Form to a Simulation of Space, by Sean Lally, \& Jessica Young, 38-51. New York: Routledge, 2007.

Addington, Michelle, and Daniel Schodek. "Energy: behaviour, phenomena and environments." In Smart Materials and New Technologies for Architecture and Design Professions, by Michelle Addington, \& Daniel Schodek, 46-78. Burlington: Architectural Press, 2005.

Adler, Gerald, Timothy Brittain-Catlin, and Gordana FontanaGiusti. Scale: Imagination. Perception and Practice in 
Architecture. New York: Routledge, 2012.

Alberto Perez Gomes, Steven Holl, Juhani Pallasmaa. Questions of Perception: Phenomenology of Architecture. San Francisco: William Stout, 2006

Bachelard, Gaston. The Poetics of Space. Boston: Beacon Press, 1969.

Bell, Victoria Ballard, and Patrick Rand. Materials for Design. New York: Princeton Architectural Press, 2006.

Blaisse, Petra. "The Instinctive Sense of Space and Boundary." Architectural Design: Energies, 2009: 84-87.

Bockemühl, Michael. J.M.W. Turner, 1775-7857: The World of Light and Colour. Translated by Michael Claridge. Cologne: Taschen, 1991.

Böhme, Gernot. "Atmosphere as Mindful Physical Presence in Space." OASE, 2013: 21-32.

Böhme, Gernot. "Atmosphere as the Subject Matter of Architecture." In 
Herzog \& de Meuron: Natural History, by Philip Ursprung. Lars Muller Publishers, 2005.

Böhme, Gernot. “Encountering Atmospheres." OASE, 2013: 93-99.

Borch, Christian, Böhme Gernot, Ólafur Elíasson, and Pallasmaa Juhani. Architectural Atmospheres: On the Experience and Politics of Architecture. Basel: Birkhauser, 2014.

Chemero, Anthony, and Stephan Kaufer. "Maurice Merleau-Ponty: The Body and Perception." In Phenomenology, by Anthony Chemero, \& Stephan Kaufer. Cambridge: Wiley, 2015.

Erwine, Barbara. "Olfactory Space." In Creating Sensory Spaces, by Barbara Erwine. New York: Routledge, 2017.

Forbes, Karen. Site Specific. Novato: ORO Editions, 2015.

Frampton, Kenneth. "Place, Production and Architecture: Towards a Critical Theory of Building." In Modern Architecture: A Critical History, by Kenneth Frampton. New York: Oxford University Press, 1980.

Frampton, Kenneth. "Rappel à l'Ordre: The Case for the Tectonic." In Labour. Work and Architecture, by Kenneth Frampton. New York: Phiadon Press, 2002.

-. Studies in Tectonic Culture. Cambridge: The MIT Press, 1995. 
Frampton, Kenneth. "The International Style: Theme and Variation 1925 65." In Modern Architecture: A Critical History, by Kenneth Frampton. New York: Oxford University Press, 1980.

Frampton, Kenneth. "Towards a Critical Regionalism: Six Points for an Architecture of Resistance." In Labour. Work and Architecture, by Kenneth Frampton. New York: Phaidon Press, 2002.

Frascari, Marco. "The Tell The Tale Detail." In Semiotics 7987, by John N Deely. New York: Plenum Press, 1983.

Gibson, James J. The Senses Considered as Perceptual Systems. Boston: Houghton Mifflin Company, 1966.

Gramazio, Fabio, Matthias Kohler, and Jan Willmann. "Reality Matters." In The Robotic Touch: How Robots Change Architecture, by Fabio Gramazio, Matthias Kohler, \& Jan Willmann. Zurich: Park Books, 2014.

Grütter, Jörg Kurt. Architecture + Perception. Sulgen: Niggli, 2012.

Guzowski, Mary. "The New Architecture of Sun and Wind." AlA Cote Whitepaper, 2012

Havik, Klaske, and Gus Tielens. "Atmosphere, Compassion and Embodied Experience: A Conversation about Atmosphere with Juhani Pallasmaa." OASE, 2013: 33-52. 
Havik, Klaske, and Gus Tielens. "Concentrated Confidence: A Visit to Peter Zumthor." OASE, 2013: 59-82.

Havik, Klaske, Gus Teilens, and Hans Teerds. "Building Atmosphere." OASE, 2013: 3-11.

Heidegger, Martin. "Building, Dwelling, Thinking." In Basic Writings, by Martin Heidegger. New York: Harper Collins, 1977.

Hensel, Michael, and Achim Menges. "Nested Capacities, Gradient Thresholds and Modulated Environments." In Softspace: From a Representation of Form to a Simulation of Space, by Sean Lally, \& Jessica Young, 51-67. New York: Routledge, 2007.

Hight, Christopher. "Putting out the Fire with Gasoline." In Softspace: From a Representation of Form to a Simulation of Space, by Sean Lally, \& Jessica Young, 10-23. New York: Routledge, 2007.

Lally, Sean. "Introduction: Energies, Matter \& The Gradients of Space." In Softspace: From a Representation of Form to a Simulation of Space, by Sean Lally, \& Jessica Young, 1-9. New York: Routledge, 2007.

Lally, Sean. "Potential Energies." In Softspace: From a Representation of Form to a Simulation of Space, by Sean Lally, \& Jessica Young, 24-37. New York: Routledge, 2007.

-. The Air from Other Planets: A Brief History of Architecture to Come. 
Zürich: Lars Müller Publishers, 2014.

Lally, Sean. "Twelve Pieces for the Piano." Architectural Design: Energies, 2009: 6-11.

Lally, Sean. "When Cold Air Sleeps." Architectural Design: Energies, 2009: $54-63$.

Lally, Sean, and Jessica Young. "Preface: The Stuff Between, In and Around." In Softspace: From a Representation of Form to a Simulation of Space, by Sean Lally, \& Jessica Young, viii. New York: Routledge, 2007.

Malnar, Joy, and Frank Vodvarka. Sensory Design. Minneapolis: University of Minnesota Press, 2004.

Meagher, Robert. "Technê." Perspecta, 1988.

Moe, Kiel. "Matter is but Captured Energy." In Matter: Material Processes in Architectural Production, by Gail Borden, \& Michael Meredith, 313-327. New York: Routledge, 2013.

Mostafavi, Mohsen, and David Leatherbarrow. On Weathering: The Life of Buildings in Time. Cambridge: The MIT Press, 1997.

Mumford, Stephen. Metaphysics: A Very Short Introduction. London: Oxford University Press, 2013. 
Norberg-Schulz, Christian. Cenius Loci: Towards a Phenomenology of Architecture. New York: Rizzoli International Publications, 1980.

Pallasmaa, Juhani. "Hapticity and Time: Notes on Fragile Architecture." The Architectural Review, 2000: 78-84.

-. The Eyes of the Skin: Architecture and the Senses. Chichester: Wiley, 2005.

Payne, Jason, and Heather Roberge. "Matter and Sense." In Softspace: From a Representation of Form to a Simulation of Space, by Sean Lally, \& Jessica Young, 126-141. New York: Routledge, 2007.

Pérez-Gómez, Alberto. Attunement: Architectural Meaning after the Crisis of Modern Science. Cambridge: MIT Press, 2016.

Rahm, Philippe. "Meteorological Architecture." Architectural Design: Energies, 2009: 30-41.

Ramos, Elisa Valero. Light in Architecture: The Intangible Material. Newcastle Upon Tyne: RIBA Publishing, 2015.

Rasmussen, Steen Eiler. Experiencing Architecture. Cambridge: The MIT Press, 1959.

Seamon, David, and Jacob Sowers. "Places and Placelessness, Edward Relph." In Key Texts in Human Geography, by P Hubbard, R Kitchen, \& C 
Vallentine. London: Sage Publishers, 2008.

Semper, Gottfried. The Four Elements of Architecture. Cambridge: Cambridge University Press, 1989.

Shackelford, George. Monet and the Impressionists. Sydney: Art Gallery of New South Wales, 2008.

Sharr. Adam. Heidegger for Architects. New York: Routledge, 2007.

Sloterdijk, Peter. "Architecture as an Art of Immersion." Interstices - Journal of Architecture and Related Arts, 2011.

Venturi, Robert. Complexity and Contradiction in Architecture. New York: The Museum of Modern Art, 1992.

Weston, Richard. Materials, Form and Architecture. New Haven: Yale University Press, 2003.

Wigley, Mark. "The Architecture of Atmosphere." Daidalos, 1996: 18-27.

Zumthor. Peter. Atmospheres: Architectural Environments and Surrounding Objects. Basel: Birkhauser, 2006.

-. Thinking Architecture. Basel: Birkhauser, 2006. 